Andrew W. Lo

MIT Sloan School of Management AlphaSimplex Group, LLC

\title{
The Dynamics of the Hedge Fund Industry
}

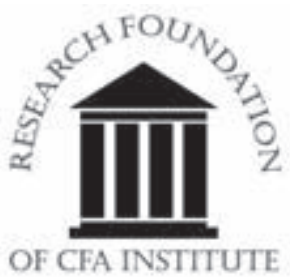


The Research Foundation of CFA Institute and the Research Foundation logo are trademarks owned by The Research Foundation of CFA Institute. CFA ${ }^{\oplus}$, Chartered Financial Analyst ${ }^{\oplus}$, AIMR-PPS ${ }^{\oplus}$, and GIPS ${ }^{\circledR}$ are just a few of the trademarks owned by CFA Institute. To view a list of CFA Institute trademarks and a Guide for the Use of CFA Institute Marks, please visit our website at www.cfainstitute.org.

(C) 2005 The Research Foundation of CFA Institute

All rights reserved. No part of this publication may be reproduced, stored in a retrieval system, or transmitted, in any form or by any means, electronic, mechanical, photocopying, recording, or otherwise, without the prior written permission of the copyright holder.

This publication is designed to provide accurate and authoritative information in regard to the subject matter covered. It is sold with the understanding that the publisher is not engaged in rendering legal, accounting, or other professional service. If legal advice or other expert assistance is required, the services of a competent professional should be sought.

ISBN 0-943205-72-7

Printed in the United States of America

19 August 2005

\section{Editorial Staff}

Maryann Dupes

Book Editor

$\begin{gathered}\text { Christine E. Kemper } \\ \text { Assistant Editor } \\ \text { Lara H. Morris } \\ \text { Lois Carrier } \\ \text { Composition and Production Manager }\end{gathered}$
Coduction




\section{Statement of Purpose}

The Research Foundation of CFA Institute is a not-for-profit organization established to promote the development and dissemination of relevant research for investment practitioners worldwide. 


\section{Biography}

Andrew W. Lo is Harris \& Harris Group Professor of Finance at the MIT Sloan School of Management and director of MIT's Laboratory for Financial Engineering. He is founder and chief scientific officer of AlphaSimplex Group, LLC, a quantitative investment management company based in Cambridge, Massachusetts. He previously taught at the University of Pennsylvania's Wharton School as W.P. Carey Assistant Professor of Finance and as W.P. Carey Associate Professor of Finance. He has published numerous articles in finance and economics journals and is a co-author of The Econometrics of Financial Markets and $A$ NonRandom Walk Down Wall Street. His awards include the Alfred P. Sloan Foundation Fellowship, the Paul A. Samuelson Award, the American Association for Individual Investors Award, the Financial Analysts Journal's Graham and Dodd Award, the 2001 IAFE-SunGard Financial Engineer of the Year award, a Guggenheim Fellowship, and awards for teaching excellence from both Wharton and MIT. He is a former governor of the Boston Stock Exchange and currently serves as a research associate of the National Bureau of Economic Research and as a member of the NASD's Economic Advisory Board. He holds a PhD in economics from Harvard University.

\section{Author's Note}

Parts of this monograph include ideas and exposition from several previously published papers and books of mine. Where appropriate, I have excerpted and, in some cases, modified the passages to suit the current context and composition without detailed citations and quotation marks so as to preserve continuity. However, several sections involve excerpts from co-authored articles, and I wish to acknowledge those sources explicitly: "Attrition Rates" in Chapter 4 is excerpted from Getmansky, Lo, and Mei (2004); parts of Chapter 5 are excerpted from Getmansky, Lo, and Makarov (2004); parts of Chapter 6 are excerpted from Lo, Petrov, and Wierzbicki (2003); and parts of "Hedge Funds and the Efficient Market Hypothesis" in Chapter 8 are excerpted from Lo (2004). 


\section{Contents}

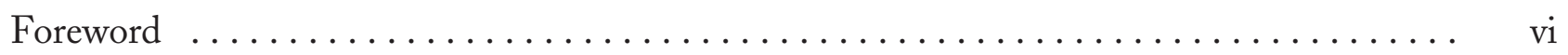

Chapter 1. Introduction................................... 1

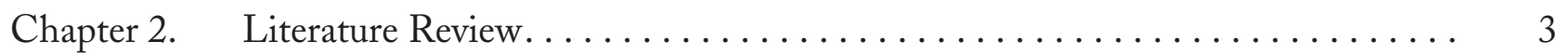

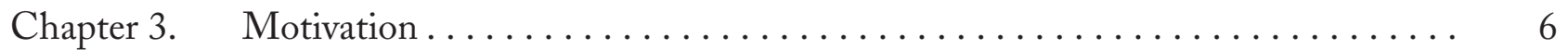

Chapter 4. Basic Properties of Hedge Fund Returns........................ 24

Chapter 5. Serial Correlation, Smoothed Returns, and Illiquidity............... 40

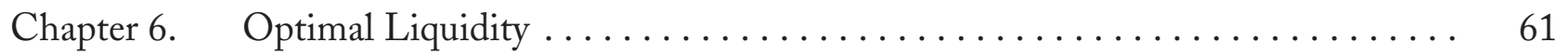

Chapter 7. An Integrated Hedge Fund Investment Process ...................... 84

Chapter 8. Practical Considerations............................. 97

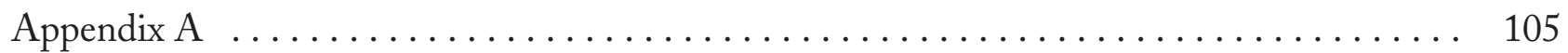

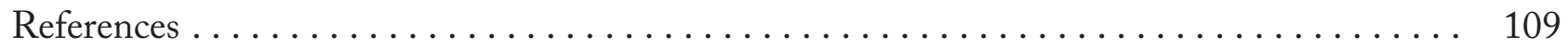




\section{Foreword}

The hedge fund industry has experienced enormous growth in recent years, and this trend seems destined to continue. A variety of seemingly compelling factors attract investors to hedge funds. For example, hedge funds are relatively market neutral. Therefore, they have a greater potential to generate profits whether the market rises or falls. They tend to have low correlations with traditional asset classes, which makes them strong diversifiers. They are less constrained by regulatory encumbrances and investment guidelines, which allows them to be eclectic and opportunistic in their quest for value. They typically require a lockup period; thus, they can bear more risk and focus on long-term results. They use leverage, which allows them to convert small overlooked return opportunities into large gains. And they tend not to disclose their positions, thereby allowing them to guard the profitability of their strategies.

Are hedge funds too good to be true, or could it be that hedge funds by their nature contain obscure risks yet to be discovered by investors? Thankfully, Andrew Lo addresses just this issue, and he shows that traditional approaches to performance and risk measurement are inadequate for evaluating hedge funds.

Lo begins by describing several hedge fund features that distinguish them from traditional investments, such as their propensity to experience more extreme returns than expected from a normal distribution and their exposure to nonlinear risk factors, which leads to skewed return distributions, nonrandom return patterns, and illiquidity. He then proposes a variety of new techniques for modeling these hedge fund features. For example, he shows how the variance ratio can be used to map high-frequency return and risk measures onto low-frequency measures, and he describes how to add a third dimension to mean-variance analysis to incorporate illiquidity.

Throughout the monograph, Lo takes care to explain the practices and other factors that give rise to the special properties of hedge funds, which helps the reader distinguish features that might reflect a random pass through history from those that we should expect to endure. He also illustrates his new techniques with applications based on actual hedge fund data. Many of his examples offer striking evidence of the superiority of his new metrics and analytical tools. And Lo presents his material in a style that is accessible and engaging without sacrificing rigor or attention to detail.

With a trillion dollars in assets in hedge funds, together with several high-profile blowups that threatened the stability of our financial system, there is no doubt of the need to develop more sophisticated methods for analyzing hedge fund dynamics. We are fortunate that one of our industry's most insightful and technically skilled members has devoted his time and energy to tackling this crucial challenge. The Research Foundation is especially pleased to present The Dynamics of the Hedge Fund Industry.

Mark Kritzman, CFA

Research Director

The Research Foundation of

CFA Institute 


\section{Introduction}

One of the fastest growing sectors of the financial services industry is the hedge fund or "alternative investments" sector, currently estimated at over $\$ 1$ trillion in assets worldwide. One of the main reasons for such interest is the performance characteristics of hedge funds — often known as "high-octane" investments, many hedge funds have yielded double-digit returns for their investors and, in many cases, in a fashion that seems uncorrelated with general market swings and with relatively low volatility. Most hedge funds accomplish this by maintaining both long and short positions in securities - hence the term "hedge" fund-which, in principle, gives investors an opportunity to profit from both positive and negative information while, at the same time, providing some degree of "market neutrality" because of the simultaneous long and short positions. Long the province of foundations, family offices, and high-net-worth investors, alternative investments are now attracting major institutional investors, such as large state and corporate pension funds, insurance companies, and university endowments, and efforts are under way to make hedge fund investments available to individual investors through more traditional mutual fund investment vehicles.

However, many institutional investors are not yet convinced that "alternative investments" is a distinct asset class (i.e., a collection of investments with a reasonably homogeneous set of characteristics that are stable over time). Unlike equities, fixed-income instruments, and real estate- asset classes each defined by a common set of legal, institutional, and statistical properties - "alternative investments" is a mongrel categorization that includes private equity, risk arbitrage, commodity futures, convertible bond arbitrage, emerging market equities, statistical arbitrage, foreign currency speculation, and many other strategies, securities, and styles. Therefore, the need for a set of portfolio analytics and risk management protocols specifically designed for alternative investments has never been more pressing.

Part of the gap between institutional investors and hedge fund managers is due to differences in investment mandate, regulatory oversight, and business culture between the groups, yielding very different perspectives on what a good investment process should look like. For example, the typical hedge fund manager's perspective can be characterized by the following statements:

- The manager is the best judge of the appropriate risk/reward trade-off of the portfolio and should be given broad discretion in making investment decisions.

- Trading strategies are highly proprietary and, therefore, must be jealously guarded lest they be reverseengineered and copied by others.

- Return is the ultimate and, in most cases, the only objective.

- Risk management is not central to the success of a hedge fund.

- Regulatory constraints and compliance issues are generally a drag on performance; the whole point of a hedge fund is to avoid these issues.

- There is little intellectual property involved in the fund; the general partner is the fund. ${ }^{1}$

Contrast these statements with the following characterization of a typical institutional investor:

- As fiduciaries, institutions need to understand the investment process before committing to it.

- Institutions must fully understand the risk exposures of each manager and, on occasion, may have to circumscribe the manager's strategies to be consistent with the institution's overall investment objectives and constraints.

- Performance is not measured solely by return but also includes other factors, such as risk adjustments, tracking error relative to a benchmark, and peer-group comparisons.

- Risk management and risk transparency are essential.

1 Of course, many experts in intellectual property law would certainly classify trading strategies, algorithms, and their software manifestations as intellectual property which, in some cases, is patentable. However, most hedge fund managers today (and, therefore, most investors) have not elected to protect such intellectual property through patents but have chosen instead to keep them as "trade secrets," purposely limiting access to these ideas even within their own organizations. As a result, the departure of key personnel from a hedge fund often causes the demise of the fund. 
- Institutions operate in a highly regulated environment and must comply with a number of federal and state laws governing the rights, responsibilities, and liabilities of pension plan sponsors and other fiduciaries.

- Institutions desire structure, stability, and consistency in a well-defined investment process that is institutionalized, not dependent on any single individual.

Now, of course, these are rather broad-brush caricatures of the two groups, made extreme for clarity, but they do capture the essence of the existing gulf between hedge fund managers and institutional investors. However, despite these differences, hedge fund managers and institutional investors clearly have much to gain from a better understanding of each other's perspectives, and they do share the common goal of generating superior investment performance for their clients. One of the purposes of this monograph is to help create more common ground between hedge fund managers and investors through new quantitative models and methods for gauging the risks and rewards of alternative investments.

This might seem to be more straightforward a task than it is because of the enormous body of literature in investments and quantitative portfolio management, of which a significant portion has appeared through CFA Institute publications like the Research Foundation's monograph series. However, several recent empirical studies have cast some doubt on the applicability of standard methods for assessing the risks and returns of hedge funds, concluding that they can often be quite misleading. For example, Asness, Krail, and Liew (2001) show that in some cases where hedge funds purport to be market neutral (i.e., funds with relatively small market betas), including both contemporaneous and lagged market returns as regressors and summing the coefficients yields significantly higher market exposure. Getmansky, Lo, and Makarov (2004) argue that this is due to significant serial correlation in the returns of certain hedge funds, which is likely the result of illiquidity and smoothed returns. Such correlation can yield substantial biases in the variances, betas, Sharpe ratios, and other performance statistics. For example, in deriving statistical estimators for Sharpe ratios of a sample of mutual and hedge funds, Lo (2002) shows that the correct method for computing annual Sharpe ratios based on monthly means and standard deviations can yield point estimates that differ from the naive Sharpe ratio estimator by as much as 70 percent.

These empirical facts suggest that hedge funds and other alternative investments have unique properties, requiring new tools to properly characterize their risks and expected returns. In this monograph, I describe some of these unique properties and propose several new quantitative measures for modeling them. I begin in Chapter 2 with a brief review of the burgeoning hedge fund literature, and in Chapter 3, I provide three examples that motivate the need for new hedge fund risk analytics: tail risk, nonlinear risk factors, and serial correlation and illiquidity. In Chapter 4, I summarize some of the basic empirical properties of hedge fund returns using the CSFB/Tremont hedge fund indexes and individual hedge fund returns from the TASS database. One of the most striking properties is the high degree of serial correlation in monthly returns of certain hedge funds, and I present Getmansky, Lo, and Makarov's (2004) econometric model of such correlation in Chapter 5, along with adjustments for performance statistics such as market betas, volatilities, and Sharpe ratios, and an empirical analysis of serial correlation and illiquidity in the TASS database. Given the increasing role that liquidity is playing in portfolio management, a natural extension of the standard portfolio optimization framework is to include liquidity as a third characteristic to be optimized along with mean and variance, and this is done in Chapter 6 along the lines of Lo, Petrov, and Wierzbicki (2003). In Chapter 7, I propose an integrated investment process for hedge funds that combines the insights of modern quantitative portfolio management with the traditional qualitative approach of managing alternative investments. I conclude in Chapter 8 by discussing some practical considerations for hedge fund managers and investors, including risk management for hedge funds, the risk preferences of hedge fund managers and investors, and the apparent conflict between the Efficient Markets Hypothesis and the existence of the hedge fund industry. 


\section{Literature Review}

The explosive growth in the hedge fund sector over the past several years has generated a rich literature both in academia and among practitioners, including a number of books, newsletters, and trade magazines, several hundred published articles, and an entire journal dedicated solely to this industry (Journal of Alternative Investments). Thanks to the availability of hedge fund return data from sources such as Altvest, the Center for International Securities and Derivatives Markets (CISDM), HedgeFund.net, Hedge Fund Research (HFR), and TASS, a number of empirical studies have highlighted the unique risk/reward profiles of hedge fund investments. For example, Ackermann, McEnally, and Ravenscraft (1999); Fung and Hsieh (1999, 2000, 2001); Liang (1999, 2000, 2001); Agarwal and Naik (2000b, 2000c); Edwards and Caglayan (2001); Kao (2002); and Amin and Kat (2003a) provide comprehensive empirical studies of historical hedge fund performance using various hedge fund databases. Brown, Goetzmann, and Park (1997, 2000, 2001); Fung and Hsieh (1997a, 1997b); Brown, Goetzmann, and Ibbotson (1999); Agarwal and Naik (2000a, 2000d); Brown and Goetzmann (2003); and Lochoff (2002) present more detailed performance attribution and "style" analysis for hedge funds.

Several recent empirical studies have challenged the uncorrelatedness of hedge fund returns with market indexes, arguing that the standard methods of assessing hedge funds' risks and rewards may be misleading. For example, Asness, Krail, and Liew (2001) show that in several cases where hedge funds purport to be market neutral (i.e., funds with relatively small market betas), including both contemporaneous and lagged market returns as regressors and summing the coefficients yields significantly higher market exposure. Moreover, in deriving statistical estimators for Sharpe ratios of a sample of mutual and hedge funds, Lo (2002) proposes a better method for computing annual Sharpe ratios based on monthly means and standard deviations, yielding point estimates that differ from the naive Sharpe ratio estimator by as much as 70 percent in the empirical application. Getmansky, Lo, and Makarov (2004) focus directly on the unusual degree of serial correlation in hedge fund returns and argue that illiquidity exposure and smoothed returns are the most common sources of such serial correlation. They also propose methods for estimating the degree of return-smoothing and adjusting performance statistics like the Sharpe ratio to account for serial correlation.

The persistence of hedge fund performance over various time intervals has also been studied by several authors. Such persistence may be indirectly linked to serial correlation (e.g., persistence in performance usually implies positively autocorrelated returns). Agarwal and Naik (2000c) examine the persistence of hedge fund performance over quarterly, half-yearly, and yearly intervals by examining the series of wins and losses for two, three, and more consecutive time periods. Using net-of-fee returns, they find that persistence is highest at the quarterly horizon and decreases when moving to the yearly horizon. The authors also find that performance persistence, whenever present, is unrelated to the type of hedge fund strategy. Brown, Goetzmann, Ibbotson, and Ross (1992); Ackermann, McEnally, and Ravenscraft (1999); and Baquero, ter Horst, and Verbeek (forthcoming 2005) show that survivorship bias — the fact that most hedge fund databases do not contain funds that were unsuccessful and went out of business — can affect the first and second moments and cross-moments of returns and generate spurious persistence in performance when there is dispersion of risk among the population of managers. However, using annual returns of both defunct and currently operating offshore hedge funds between 1989 and 1995, Brown, Goetzmann, and Ibbotson (1999) find virtually no evidence of performance persistence in raw returns or risk-adjusted returns, even after breaking funds down according to their returns-based style classifications.

Fund flows in the hedge fund industry have been considered by Agarwal, Daniel, and Naik (2004) and Getmansky (2004), with the expected conclusion that funds with higher returns tend to receive higher net inflows and funds with poor performance suffer withdrawals and, eventually, liquidation, much as is the case 
with mutual funds and private equity. ${ }^{2}$ Agarwal, Daniel, and Naik (2004); Goetzmann, Ingersoll, and Ross (2003); and Getmansky (2004) all find decreasing returns to scale among their samples of hedge funds, implying that an optimal amount of assets under management exists for each fund and mirroring similar findings for the mutual fund industry by Pérold and Salomon (1991) and for the private equity industry by Kaplan and Schoar (forthcoming 2005). Hedge fund survival rates have been studied by Brown, Goetzmann, and Ibbotson (1999); Fung and Hsieh (2000); Liang (2000, 2001); Bares, Gibson, and Gyger (2003); Brown, Goetzmann, and Park (2001); Gregoriou (2002); and Amin and Kat (2003b). Baquero, ter Horst, and Verbeek (forthcoming 2005) estimate liquidation probabilities of hedge funds and find that they are greatly dependent on past performance.

The survival rates of hedge funds have been estimated by Brown, Goetzmann, and Ibbotson (1999); Fung and Hsieh (2000); Liang (2000, 2001); Brown, Goetzmann, and Park (1997, 2001); Gregoriou (2002); Amin and Kat (2003b); Bares, Gibson, and Gyger (2003); and Getmansky, Lo, and Mei (2004). Brown, Goetzmann, and Park (2001) show that the probability of liquidation increases with increasing risk and that funds with negative returns for two consecutive years have a higher risk of shutting down. Liang (2000) finds that the annual hedge fund attrition rate is 8.3 percent for the 1994-98 sample period using TASS data, and Baquero, ter Horst, and Verbeek (forthcoming 2005) find a slightly higher rate of 8.6 percent for the 1994-2000 sample period. Baquero, ter Horst, and Verbeek (forthcoming) also find that surviving funds outperform nonsurviving funds by approximately 2.1 percent per year, which is similar to the findings of Fung and Hsieh (2000, 2002b) and Liang (2000), and that investment style, size, and past performance are significant factors in explaining survival rates. Many of these patterns are also documented by Liang (2000); Boyson (2002); and Getmansky, Lo, and Mei (2004). In particular, Getmansky, Lo, and Mei (2004) find that attrition rates in the TASS database from 1994 to 2004 differ significantly across investment styles, from a low of 5.2 percent per year on average for convertible arbitrage funds to a high of 14.4 percent per year on average for managed futures funds. They also relate a number of factors to these attrition rates, including past performance, volatility, and investment style, and document differences in illiquidity risk between active and liquidated funds. In analyzing the life cycle of hedge funds, Getmansky (2004) finds that the liquidation probabilities of individual hedge funds depend on fund-specific characteristics, such as past returns, asset flows, age, and assets under management, as well as category-specific variables, such as competition and favorable positioning within the industry.

Brown, Goetzmann, and Park (2001) find that the half-life of the TASS hedge funds is exactly 30 months, while Brooks and Kat (2002) estimate that approximately 30 percent of new hedge funds do not make it past 36 months due to poor performance, and in Amin and Kat's (2003b) study, 40 percent of their hedge funds do not make it to the fifth year. Howell (2001) observes that the probability of hedge funds failing in their first year was 7.4 percent, only to increase to 20.3 percent in their second year. Poorly performing younger funds drop out of databases at a faster rate than older funds (see Getmansky 2004; Jen, Heasman, and Boyatt 2001), presumably because younger funds are more likely to take additional risks to obtain good performance, which they can use to attract new investors, whereas older funds that have survived already have track records with which to attract and retain capital.

A number of case studies of hedge fund liquidations have been published recently, no doubt spurred by the most well-known liquidation in the hedge fund industry to date: Long-Term Capital Management (LTCM). The literature on LTCM is vast, spanning a number of books, journal articles, and news stories; a representative sample includes Greenspan (1998); McDonough (1998); Pérold (1999); the President's Working Group on Financial Markets (1999); and MacKenzie (2003). Ineichen (2001) has compiled a list of selected hedge funds and analyzed the reasons for their liquidations. Kramer (2001) focuses on fraud, providing detailed accounts of six of history's most egregious cases. Although it is virtually impossible to obtain hard data on the frequency of fraud among liquidated hedge funds, ${ }^{3}$ in a study of over 100 liquidated hedge funds during the past two decades, Feffer and Kundro (2003) conclude that "half of all failures could be attributed to operational

2 See, for example, Ippolito (1992); Chevalier and Ellison (1997); Goetzmann and Peles (1997); Gruber (1996); Sirri and Tufano (1998); Zheng (1999); and Berk and Green (2004) for studies of mutual fund flows, and Kaplan and Schoar (forthcoming 2005) for private equity fund flows.

${ }^{3}$ The lack of transparency and the unregulated status of most hedge funds are significant barriers to any systematic data collection effort; hence, it is difficult to draw inferences about industry norms. 
risk alone," of which fraud is one example. In fact, they observe that "The most common operational issues related to hedge fund losses have been misrepresentation of fund investments, misappropriation of investor funds, unauthorized trading, and inadequate resources" (p. 5). The last of these issues is, of course, not related to fraud, but Feffer and Kundro (2003, Figure 2) report that only 6 percent of their sample involved inadequate resources, whereas 41 percent involved misrepresentation of investments, 30 percent misappropriation of funds, and 14 percent unauthorized trading. These results suggest that operational issues are indeed an important factor in hedge fund liquidations and deserve considerable attention from investors and managers alike.

Collectively, these studies show that the dynamics of hedge funds are quite different from those of more traditional investments. In the next chapter, I provide several examples that illustrate some of the possible sources of such differences. 


\section{Motivation}

One of the justifications for the unusually rich fee structures that characterize hedge fund investments is the fact that hedge funds employ active strategies involving highly skilled portfolio managers. Moreover, it is common wisdom that the most talented managers are drawn first to the hedge fund industry because the absence of regulatory constraints enables them to make the most of their investment acumen. With the freedom to trade as much or as little as they like on any given day, to go long or short any number of securities and with varying degrees of leverage, and to change investment strategies at a moment's notice, hedge fund managers enjoy enormous flexibility and discretion in pursuing performance. But dynamic investment strategies imply dynamic risk exposures, and while modern financial economics has much to say about the risk of static investments - the market beta is sufficient in this case - there is currently no single measure of the risks of a dynamic investment strategy. 4

These challenges have important implications for both managers and investors, since both parties seek to manage the risk/reward trade-offs of their investments. Consider, for example, the now-standard approach to constructing an optimal portfolio in the mean-variance sense:

$$
\operatorname{Max}_{\left\{\omega_{i}\right\}} \mathrm{E}\left[U\left(W_{1}\right)\right]
$$

subject to

$$
\begin{aligned}
& W_{1}=W_{0}\left(1+R_{p}\right) \\
& R_{p} \equiv \sum_{i=1}^{n} \omega_{i} R_{i}, \quad 1=\sum_{i=1}^{n} \omega_{i},
\end{aligned}
$$

where $R_{i}$ is the return of security $i$ between this period and the next, $W_{1}$ is the individual's next period's wealth (which is determined by the product of the $\left\{R_{i}\right\}$ with the portfolio weights $\left\{\omega_{i}\right\}$ ), and $U(\cdot)$ is the individual's utility function. By assuming that $U(\cdot)$ is quadratic, or by assuming that individual security returns $R_{i}$ are normally distributed random variables, it can be shown that maximizing the individual's expected utility is tantamount to constructing a mean-variance optimal portfolio $\boldsymbol{\omega}^{*} .5$

It is one of the great lessons of modern finance that mean-variance optimization yields benefits through diversification, the ability to lower volatility for a given level of expected return by combining securities that are not perfectly correlated. But what if the securities are hedge funds, and what if their correlations change over time, as hedge funds tend to do (see "Nonlinear Risks," below)?6 Table 3.1 shows that for the two-asset case with fixed means of 5 percent and 30 percent, respectively, and fixed standard deviations of 20 percent and 30 percent, respectively, as the correlation $\rho$ between the two assets varies from -90 percent to 90 percent, the optimal portfolio weights - and the properties of the optimal portfolio-change dramatically. For example, with a -30 percent correlation between the two funds, the optimal portfolio holds 38.6 percent in the first fund and 61.4 percent in the second, yielding a Sharpe ratio of 1.01. But if the correlation changes to 10 percent, the optimal weights change to 5.2 percent in the first fund and 94.8 percent in the second, despite the fact that the Sharpe ratio of this new portfolio, 0.92 , is virtually identical to the previous portfolio's Sharpe ratio. The mean-variance-efficient frontiers are plotted in Figure 3.1 for various correlations between the two funds, and it is apparent that the optimal portfolio depends heavily on the correlation structure of the underlying assets.

\footnotetext{
${ }^{4}$ For this reason, hedge fund track records are often summarized with multiple statistics (e.g., mean, standard deviation, Sharpe ratio, market beta, Sortino ratio, maximum drawdown, worst month, etc.).

${ }^{5}$ See, for example, Ingersoll (1987).

6Several authors have considered mean-variance optimization techniques for determining hedge fund allocations, with varying degrees of success and skepticism. See, in particular, Amenc and Martinelli (2002); Amin and Kat (2003c); Terhaar, Staub, and Singer (2003); and Cremers, Kritzman, and Page (2004).
} 
Table 3.1. Mean-Variance Optimal Portfolios for Two-Asset Case

$\left(\mu_{1}, \sigma_{1}\right)=(5 \%, 20 \%)$,

$\left(\mu_{2}, \sigma_{2}\right)=(30 \%, 30 \%), R_{f}=2.5 \%$

\begin{tabular}{lrrrrr}
\hline$\rho$ & $\mathrm{E}\left(R^{*}\right)$ & $\mathrm{SD}\left(R^{*}\right)$ & Sharpe & \multicolumn{1}{c}{$\omega_{1}^{*}$} & \multicolumn{1}{c}{$\omega_{2}^{*}$} \\
\hline-90 & 15.5 & 5.5 & 2.36 & 58.1 & 41.9 \\
-80 & 16.0 & 8.0 & 1.70 & 55.9 & 44.1 \\
-70 & 16.7 & 10.0 & 1.41 & 53.4 & 46.6 \\
-60 & 17.4 & 11.9 & 1.25 & 50.5 & 49.5 \\
-50 & 18.2 & 13.8 & 1.14 & 47.2 & 52.8 \\
-40 & 19.2 & 15.7 & 1.06 & 43.3 & 56.7 \\
-30 & 20.3 & 17.7 & 1.01 & 38.6 & 61.4 \\
-20 & 21.8 & 19.9 & 0.97 & 32.9 & 67.1 \\
-10 & 23.5 & 22.3 & 0.94 & 25.9 & 74.1 \\
0 & 25.8 & 25.1 & 0.93 & 17.0 & 83.0 \\
10 & 28.7 & 28.6 & 0.92 & 5.2 & 94.8 \\
20 & 32.7 & 32.9 & 0.92 & -10.9 & 110.9 \\
30 & 38.6 & 38.8 & 0.93 & -34.4 & 134.4 \\
40 & 48.0 & 47.7 & 0.95 & -71.9 & 171.9 \\
50 & 65.3 & 63.2 & 0.99 & -141.2 & 241.2 \\
60 & 108.1 & 99.6 & 1.06 & -312.2 & 412.2 \\
70 & 387.7 & 329.9 & 1.17 & $-1,430.8$ & $1,530.8$ \\
$80^{\mathrm{a}}$ & -208.0 & -154.0 & 1.37 & 952.2 & -852.2 \\
$90^{\mathrm{a}}$ & -76.8 & -42.9 & 1.85 & 427.1 & -327.1 \\
\hline
\end{tabular}

Note: Mean-variance optimal portfolio weights for the two-asset case with fixed means and variances and correlations ranging from -90 percent to 90 percent.

${ }^{a}$ Correlations imply nonpositive definite covariance matrices for the two assets.

Figure 3.1. Mean-Variance-Efficient Frontiers for the Two-Asset Case

Expected Return (\%)

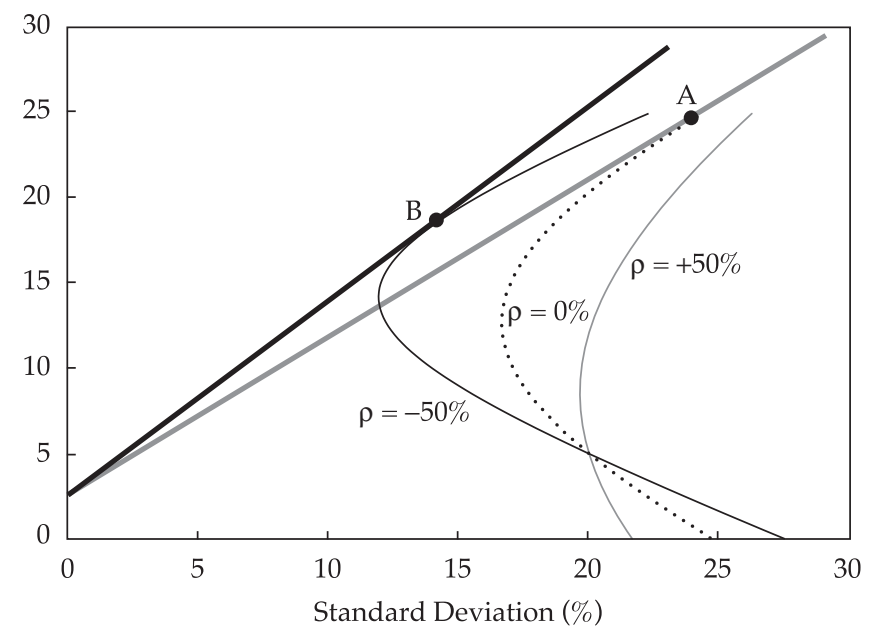

Note: Parameters $\left(\mu_{1}, \sigma_{1}\right)=(5$ percent, 20 percent $),\left(\mu_{2}, \sigma_{2}\right)=(30$ percent, 30 percent), and correlation $\rho=-50$ percent, 0 percent, and 50 percent. 
Because of the dynamic nature of hedge fund strategies, their correlations are particularly unstable over time and over varying market conditions, as will be shown later in this chapter, and swings from -30 percent to 30 percent are not unusual.

Table 3.1 shows that as the correlation between the two assets increases, the optimal weight for Asset 1 eventually becomes negative, which makes intuitive sense from a hedging perspective even if it is unrealistic for hedge fund investments and other assets that cannot be shorted. Note that for correlations of 80 percent and greater, the optimization approach does not yield a well-defined solution because a mean-variance-efficient tangency portfolio does not exist for the parameter values that were hypothesized for the two assets. However, numerical optimization procedures may still yield a specific portfolio for this case (e.g., a portfolio on the lower branch of the mean-variance parabola), even if it is not optimal. This example underscores the importance of modeling means, standard deviations, and correlations in a consistent manner when accounting for changes in market conditions and statistical regimes; otherwise, degenerate or nonsensical "solutions" may arise.

To illustrate the challenges and opportunities in modeling the risk exposures of hedge funds, I provide three extended examples in this chapter. In the section titled "Tail Risk," I present a hypothetical hedge fund strategy that yields remarkable returns with seemingly little risk, yet a closer examination will reveal a different story. In "Nonlinear Risks," I show that correlations and market beta are sometimes incomplete measures of risk exposures for hedge funds, and that such measures can change over time, in some cases quite rapidly and without warning. And in "Illiquidity and Serial Correlation," I describe one of the most prominent empirical features of the returns of many hedge funds - large positive serial correlation - and argue that serial correlation can be a very useful proxy for liquidity risk. These examples will provide an introduction to the more involved quantitative analysis in Chapters 5-7 and serve as motivation for an analytical approach to alternative investments.

\section{Tail Risk}

Consider the eight-year track record of a hypothetical hedge fund, Capital Decimation Partners, LP, summarized in Table 3.2. This track record was obtained by applying a specific investment strategy, to be revealed below, to actual market prices from January 1992 to December 1999. Before I discuss the particular strategy that generated these results, consider its overall performance: an average monthly return of 3.7 percent versus 1.4 percent for the S\&P 500 during the same period; a total return of 2,721.3 percent over the eight-year period versus 367.1 percent for the S\&P 500; a Sharpe ratio of 1.94 versus 0.98 for the S\&P 500; and only 6 negative monthly returns out of 96 versus 36 out of 96 for the S\&P 500. In fact, the monthly performance history-displayed in Table 3.3shows that, as with many other hedge funds, the worst months for this fund were August and September of 1998.

Table 3.2. Capital Decimation Partners, L.P., Performance Summary: January 1992 to December 1999

\begin{tabular}{lcc}
\hline Statistic & S\&P 500 & CDP \\
\hline Monthly mean & $1.4 \%$ & $3.7 \%$ \\
Monthly std. dev. & 3.6 & 5.8 \\
Min month & -8.9 & -18.3 \\
Max month & 14.0 & 27.0 \\
Annual Sharpe ratio & 0.98 & 1.94 \\
No. negative months & $36 / 96$ & $6 / 96$ \\
Correlation with S\&P 500 & 100.0 & 59.9 \\
Total return & $367.1 \%$ & $2,721.3 \%$ \\
\hline
\end{tabular}

Note: Summary of simulated performance of a particular dynamic trading strategy using monthly historical market prices from January 1992 to December 1999. 


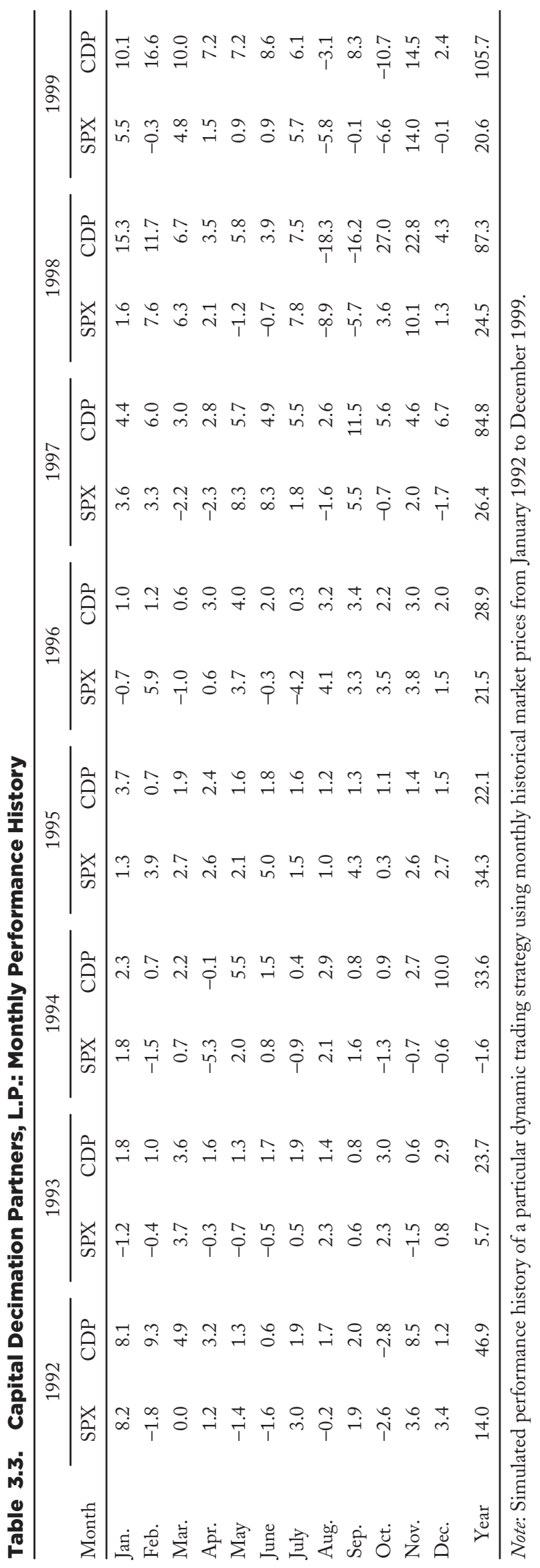


Yet October and November 1998 were the fund's two best months, and for 1998 as a whole the fund was up 87.3 percent versus 24.5 percent for the S\&P 500! By all accounts, this is an enormously successful hedge fund with a track record that would be the envy of most managers. ${ }^{7}$ What is its secret?

The investment strategy summarized in Tables 3.2 and 3.3 consists of shorting out-of-the-money S\&P 500 (SPX) put options on each monthly expiration date for maturities less than or equal to three months and with strikes approximately 7 percent out of the money. The number of contracts sold each month is determined by the combination of (1) Chicago Board Options Exchange margin requirements, ${ }^{8}$ (2) an assumption that the fund is required to post 66 percent of the margin as collateral, ${ }^{9}$ and (3) \$10 million of initial risk capital. For concreteness, Table 3.4 reports the positions and profit/loss statement for this strategy for 1992.

The track record in Tables 3.2 and 3.3 seems much less impressive in light of the simple strategy on which it is based, and few investors would pay hedge fund-type fees for such a fund. However, given the secrecy surrounding most hedge fund strategies and the broad discretion that managers are given by the typical hedge fund offering memorandum, it is difficult for investors to detect this type of behavior without resorting to more sophisticated risk analytics - analytics that can capture dynamic risk exposures.

Some might argue that this example illustrates the need for position transparency-after all, it would be apparent from the positions in Table 3.4 that the manager of Capital Decimation Partners is providing little or no value-added. However, there are many ways of implementing this strategy that are not nearly so transparent, even when positions are fully disclosed. For example, Table 3.5 reports the weekly positions over a six-month period in 1 of 500 securities contained in a second hypothetical fund, Capital Decimation Partners II. Casual inspection of the positions of this one security seems to suggest a contrarian trading strategy: When the price declines, the position in $\mathrm{XYZ}$ is increased, and when the price advances, the position is reduced. A more careful analysis of the stock and cash positions and the varying degree of leverage in Table 3.5 reveals that these trades constitute a so-called "delta-hedging" strategy, designed to synthetically replicate a short position in a two-year European put option on 10,000,000 shares of XYZ with a strike price of $\$ 25$ (recall that XYZ's initial stock price is $\$ 40$; hence, this is a deep out-of-the-money put).

Shorting deep out-of-the-money puts is a well-known artifice employed by unscrupulous hedge fund managers to build an impressive track record quickly, and most sophisticated investors are able to avoid such chicanery. However, imagine an investor presented with position reports such as Table 3.5, but for 500 securities, not just 1 , as well as a corresponding track record that is likely to be even more impressive than that of Capital Decimation Partners, LP. 10 Without additional analysis that explicitly accounts for the dynamic aspects of the trading strategy described in Table 3.5, it is difficult for an investor to fully appreciate the risks inherent in such a fund.

In particular, static methods such as traditional mean-variance analysis cannot capture the risks of dynamic trading strategies such as those of Capital Decimation Partners (note the impressive Sharpe ratio in Table 3.2). In the case of the strategy of shorting out-of-the-money put options on the S\&P 500, returns are positive most of the time and losses are infrequent, but when losses occur, they are extreme. This is a very specific type of risk signature that is not well summarized by static measures such as standard deviation. In fact, the estimated standard deviations of such strategies tend to be rather low; hence, a naive application of mean-variance analysis such as risk-budgeting - an increasingly popular method used by institutions to make allocations based on risk units - can lead to unusually large allocations to funds like Capital Decimation Partners. The fact that total position transparency does not imply risk transparency is further cause for concern.

7In fact, as a mental exercise to check your own risk preferences, take a hard look at the monthly returns in Table 3.3 and ask yourself whether you would invest in such a fund.

8The margin required per contract is assumed to be: $100 \times\{15 \% \times($ current level of the SPX) - (put premium) - (amount out of the money)\}, where the amount out of the money is equal to the current level of the SPX minus the strike price of the put.

${ }^{9}$ This figure varies from broker to broker and is meant to be a rather conservative estimate that might apply to a $\$ 10$ million startup hedge fund with no prior track record.

${ }^{10} \mathrm{~A}$ portfolio of options is worth more than an option on the portfolio; hence, shorting 500 puts on the individual stocks that constitute the S\&P 500 Index will yield substantially higher premiums than shorting puts on the index. 


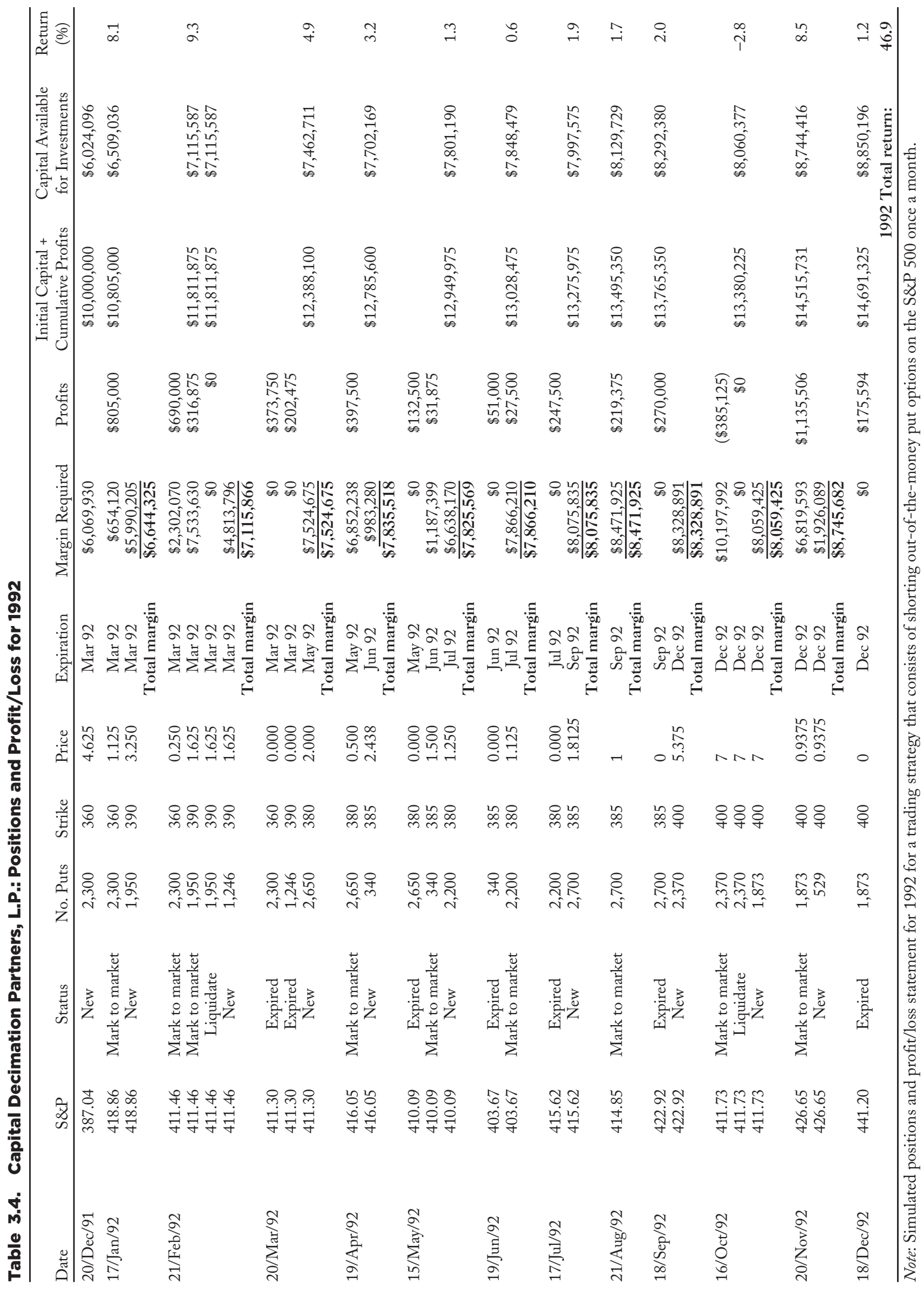


Table 3.5. Capital Decimation Partners II, L.P.:

Weekly Positions in XYZ

\begin{tabular}{|c|c|c|c|c|}
\hline Week $t$ & $\begin{array}{l}P_{t} \\
(\$)\end{array}$ & $\begin{array}{c}\text { Position } \\
\text { (shares) }\end{array}$ & $\begin{array}{l}\text { Value } \\
(\$)\end{array}$ & $\begin{array}{c}\text { Financing } \\
(\$)\end{array}$ \\
\hline 0 & 40.000 & 7,057 & 282,281 & $-296,974$ \\
\hline 1 & 39.875 & 7,240 & 288,712 & $-304,585$ \\
\hline 2 & 40.250 & 5,850 & 235,456 & $-248,918$ \\
\hline 3 & 36.500 & 33,013 & $1,204,981$ & $-1,240,629$ \\
\hline 4 & 36.875 & 27,128 & $1,000,356$ & $-1,024,865$ \\
\hline 5 & 36.500 & 31,510 & $1,150,101$ & $-1,185,809$ \\
\hline 6 & 37.000 & 24,320 & 899,841 & $-920,981$ \\
\hline 7 & 39.875 & 5,843 & 232,970 & $-185,111$ \\
\hline 8 & 39.875 & 5,621 & 224,153 & $-176,479$ \\
\hline 9 & 40.125 & 4,762 & 191,062 & $-142,159$ \\
\hline 10 & 39.500 & 6,280 & 248,065 & $-202,280$ \\
\hline 11 & 41.250 & 2,441 & 100,711 & $-44,138$ \\
\hline 12 & 40.625 & 3,230 & 131,205 & $-76,202$ \\
\hline 13 & 39.875 & 4,572 & 182,300 & $-129,796$ \\
\hline 14 & 39.375 & 5,690 & 224,035 & $-173,947$ \\
\hline 15 & 39.625 & 4,774 & 189,170 & $-137,834$ \\
\hline 16 & 39.750 & 4,267 & 169,609 & $-117,814$ \\
\hline 17 & 39.250 & 5,333 & 209,312 & $-159,768$ \\
\hline 18 & 39.500 & 4,447 & 175,657 & $-124,940$ \\
\hline 19 & 39.750 & 3,692 & 146,777 & $-95,073$ \\
\hline 20 & 39.750 & 3,510 & 139,526 & $-87,917$ \\
\hline 21 & 39.875 & 3,106 & 123,832 & $-71,872$ \\
\hline 22 & 39.625 & 3,392 & 134,408 & $-83,296$ \\
\hline 23 & 39.875 & 2,783 & 110,986 & $-59,109$ \\
\hline 24 & 40.000 & 2,445 & 97,782 & $-45,617$ \\
\hline 25 & 40.125 & 2,140 & 85,870 & $-33,445$ \\
\hline
\end{tabular}

Note: Simulated weekly positions in XYZ for a particular trading strategy over a six-month period.

This is not to say that the risks of shorting out-of-the-money puts are inappropriate for all investorsindeed, the thriving catastrophe reinsurance industry makes a market in precisely this type of risk, often called "tail risk." However, such insurers do so with full knowledge of the loss profile and probabilities for each type of catastrophe, and they set their capital reserves and risk budgets accordingly. The same should hold true for institutional investors of hedge funds, but the standard tools and lexicon of the industry currently provide only an incomplete characterization of such risks. The need for a new set of dynamic risk analytics specifically targeted for hedge fund investments is clear.

\section{Nonlinear Risks}

One of the most compelling reasons for investing in hedge funds is the fact that their returns seem relatively uncorrelated with market indexes such as the S\&P 500, and modern portfolio theory has convinced even the most hardened skeptic of the benefits of diversification. For example, Table $\mathbf{3 . 6}$ reports the correlation matrix for the returns of the $\mathrm{CSFB} /$ Tremont hedge fund indexes, where each index represents a particular hedge fund "style," such as currencies, emerging markets, relative value, etc. The last four rows report the correlations of all these hedge fund indexes with the returns of more traditional investments - the S\&P 500 Index and indexes for small-cap equities, long-term corporate bonds, and long-term government bonds. These correlations show that many hedge fund styles have low or, in some cases, negative correlations with broad-based market indexes, and they also exhibit a great deal of heterogeneity, ranging from -71.8 percent (between Long/Short Equity and Dedicated Shortsellers) to 93.6 percent (between Event Driven and Distressed). 


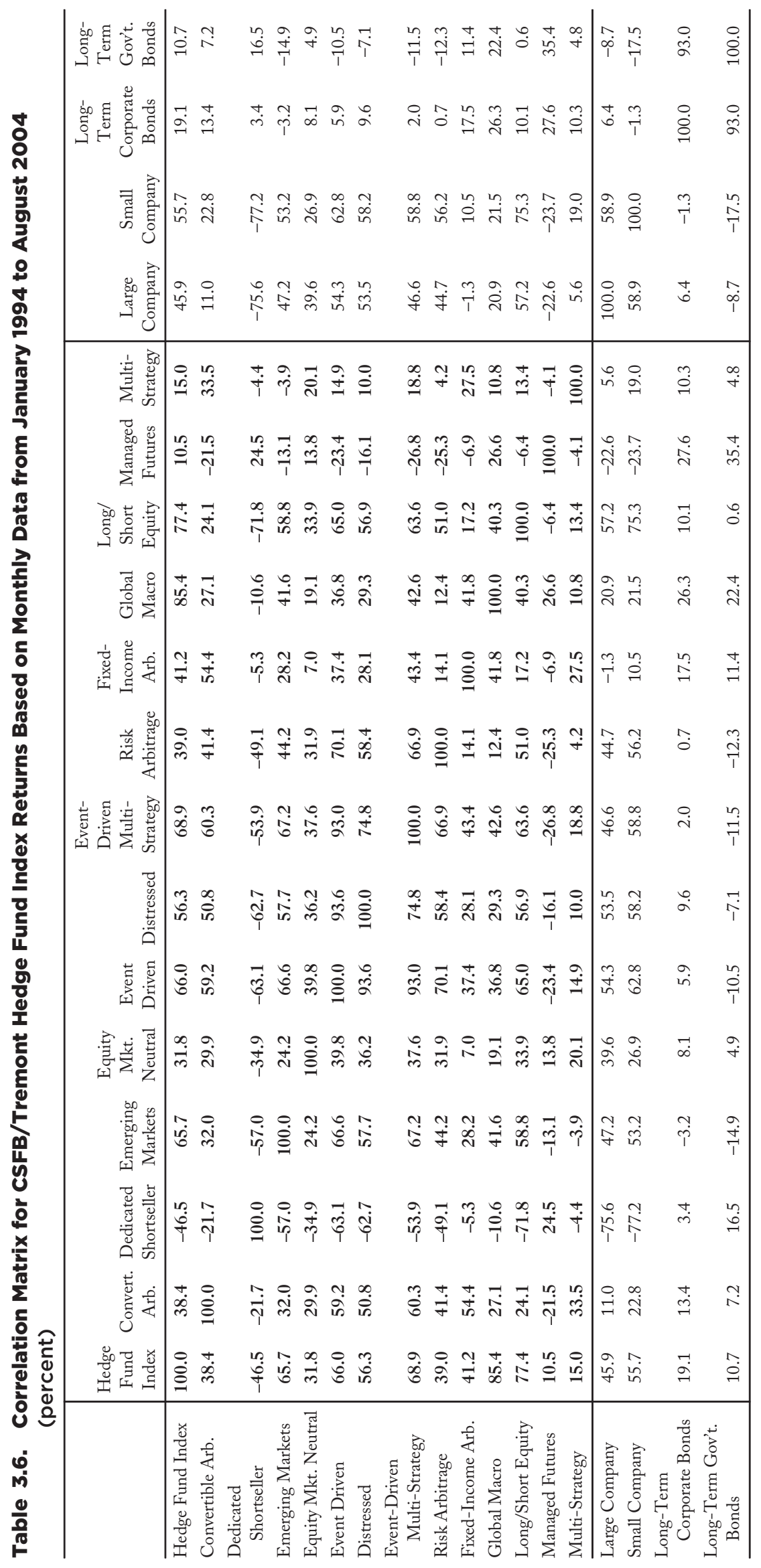


However, correlations can change over time. For example, consider a rolling 60-month correlation between the CSFB/Tremont Multi-Strategy Index and the S\&P 500 from January 1999 to December 2003, plotted in Figure 3.2. The correlation is -13.4 percent at the start of the sample in January 1999, drops to -21.7 percent a year later, and increases to 31.0 percent by January 2004. Although such changes in rolling correlation estimates are partly attributable to estimation errors, in this case, another possible explanation for the positive trend in correlation is the enormous inflow of capital into multi-strategy funds and funds of funds over the past five years. As assets under management increase, it becomes progressively more difficult for fund managers to implement strategies that are truly uncorrelated with broad-based market indexes like the S\&P 500. Moreover, Figure 3.2 shows that the correlation between the Multi-Strategy Index return and the lagged S\&P 500 return has also increased in the past year, indicating an increase in the illiquidity exposure of this investment style (see Getmansky, Lo, and Makarov 2004 and Chapter 5, below). This is also consistent with large inflows of capital into the hedge fund sector.

Correlations between hedge fund style categories can also shift over time, as Table 3.7 illustrates. Over the sample period, from April 1994 to December 2003, the correlation between the Convertible Arbitrage and Emerging Market Indexes is 32.0 percent, but Table 3.7 shows that during the first half of the sample (April 1994 to December 1999) this correlation is 45.7 percent and during the second half (January 2000 to December 2003 ) it is -6.9 percent. The third panel of Table 3.7, which reports the difference of the correlation matrices from the two subperiods, suggests that hedge fund index correlations are not very stable over time.

A graph of the 60-month rolling correlation between the Convertible Arbitrage and Emerging Market Indexes from January 1999 to December 2003 provides a clue as to the source of this nonstationarity: Figure 3.3 shows a sharp drop in the correlation during the month of September 2003. This is the first month for which the August 1998 data point - the start of the LTCM event - is not included in the 60-month rolling window. During this period, the default in Russian government debt triggered a global flight to quality that apparently changed many correlations from zero to one over the course of just a few days, and Table 3.8 shows that in August 1998, the returns for the Convertible Arbitrage and Emerging Market Indexes were -4.64 percent and

Figure 3.2. Sixty-Month Rolling Correlations between CSFB/Tremont Multi-Strategy Index Returns and Contemporaneous and Lagged Returns of the S\&P 500, January 1999 to December 2003

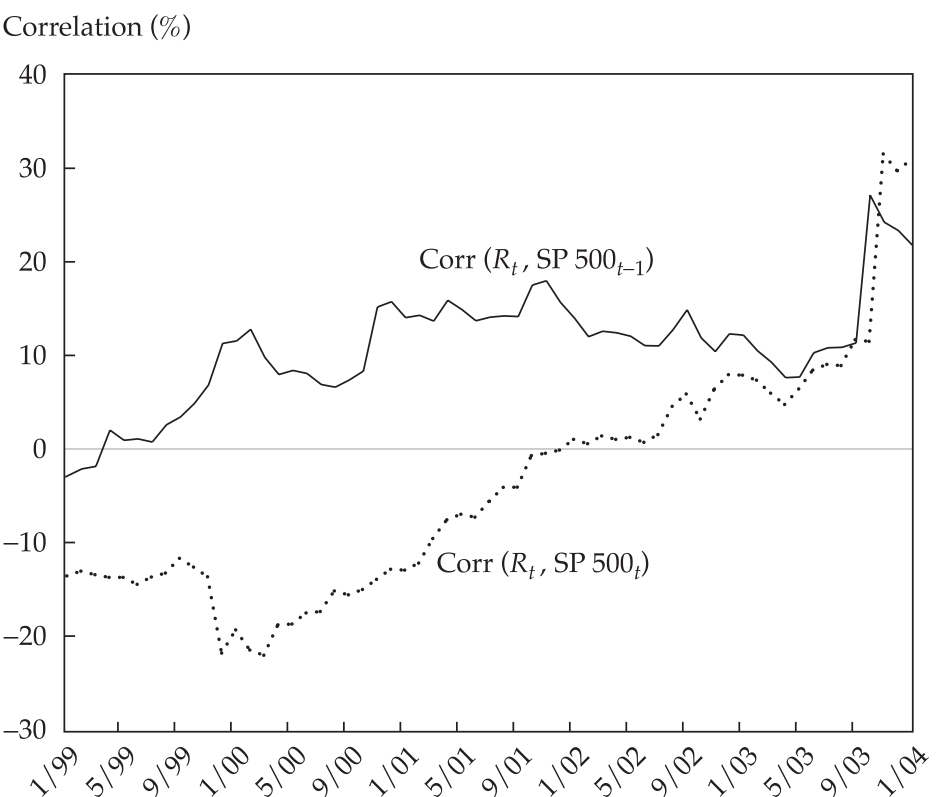

Note: Under the null hypothesis of no correlation, the approximate standard error of the correlation coefficient is $1 / \sqrt{60}=13$ percent; hence, the differences between the beginning-of-sample and end-ofsample correlations are statistically significant at the 1 percent level. 
Table 3.7. Correlation Matrix for Seven CSFB/Tremont Hedge Fund Index Returns Based on Monthly Data from April 1994 to December 2003

(percent)

\begin{tabular}{|c|c|c|c|c|c|c|c|}
\hline & $\begin{array}{l}\text { Hedge Fund } \\
\text { Index }\end{array}$ & $\begin{array}{l}\text { Convert. } \\
\text { Arbitrage }\end{array}$ & $\begin{array}{l}\text { Emerging } \\
\text { Markets }\end{array}$ & $\begin{array}{c}\text { Equity Mkt. } \\
\text { Neutral }\end{array}$ & Distressed & $\begin{array}{c}\text { Long/Short } \\
\text { Equity }\end{array}$ & $\begin{array}{l}\text { Multi- } \\
\text { Strategy }\end{array}$ \\
\hline \multicolumn{8}{|c|}{ April 1994 to December 1999} \\
\hline Hedge Fund Index & 100.0 & 52.8 & 65.5 & 38.3 & 58.1 & 70.9 & 8.4 \\
\hline Convertible Arbitrage & 52.8 & 100.0 & 45.7 & 31.2 & 62.1 & 37.9 & 29.7 \\
\hline Emerging Markets & 65.5 & 45.7 & 100.0 & 26.8 & 60.1 & 59.2 & -12.0 \\
\hline Equity Mkt. Neutral & 38.3 & 31.2 & 26.8 & 100.0 & 48.0 & 44.9 & 16.8 \\
\hline Distressed & 58.1 & 62.1 & 60.1 & 48.0 & 100.0 & 64.3 & 1.1 \\
\hline Long/Short Equity & 70.9 & 37.9 & 59.2 & 44.9 & 64.3 & 100.0 & 4.1 \\
\hline Multi-Strategy & 8.4 & 29.7 & -12.0 & 16.8 & 1.1 & 4.1 & 100.0 \\
\hline \multicolumn{8}{|c|}{ January 2000 to December 2003} \\
\hline Hedge Fund Index & 100.0 & 12.6 & 71.8 & -0.6 & 48.8 & 97.3 & 43.8 \\
\hline Convertible Arbitrage & 12.6 & 100.0 & -6.9 & 35.7 & 31.6 & 8.6 & 50.9 \\
\hline Emerging Markets & 71.8 & -6.9 & 100.0 & 12.7 & 51.8 & 69.3 & 37.4 \\
\hline Equity Mkt. Neutral & -0.6 & 35.7 & 12.7 & 100.0 & -7.8 & -1.6 & 34.8 \\
\hline Distressed & 48.8 & 31.6 & 51.8 & -7.8 & 100.0 & 38.4 & 43.7 \\
\hline Long/Short Equity & 97.3 & 8.6 & 69.3 & -1.6 & 38.4 & 100.0 & 43.5 \\
\hline Multi-Strategy & 43.8 & 50.9 & 37.4 & 34.8 & 43.7 & 43.5 & 100.0 \\
\hline \multicolumn{8}{|c|}{ Difference between two correlation matrices } \\
\hline Hedge Fund Index & 0.0 & 40.2 & -6.2 & 38.9 & 9.3 & -26.4 & -35.3 \\
\hline Convertible Arbitrage & 40.2 & 0.0 & 52.7 & -4.4 & 30.5 & 29.2 & -21.2 \\
\hline Emerging Markets & -6.2 & 52.7 & 0.0 & 14.1 & 8.3 & -10.2 & -49.3 \\
\hline Equity Mkt. Neutral & 38.9 & -4.4 & 14.1 & 0.0 & 55.7 & 46.5 & -18.0 \\
\hline Distressed & 9.3 & 30.5 & 8.3 & 55.7 & 0.0 & 26.0 & -42.6 \\
\hline Long/Short Equity & -26.4 & 29.2 & -10.2 & 46.5 & 26.0 & 0.0 & -39.4 \\
\hline Multi-Strategy & -35.3 & -21.2 & -49.3 & -18.0 & -42.6 & -39.4 & 0.0 \\
\hline
\end{tabular}

Source: AlphaSimplex Group.

-23.03 percent, respectively. In fact, 10 out of the 13 style-category indexes yielded negative returns in August 1998, many of which were extreme outliers relative to the entire sample period; hence, rolling windows containing this month can yield dramatically different correlations than those without it.

In the physical and natural sciences, sudden changes from low correlation to high correlation are examples of "phase-locking" behavior, situations in which otherwise uncorrelated actions suddenly become synchronized. ${ }^{11}$ The fact that market conditions can create phase-locking behavior is certainly not new-market crashes have been with us since the beginning of organized financial markets - but prior to 1998, few hedge fund investors and managers incorporated this possibility into their investment processes in any systematic fashion.

From a financial-engineering perspective, the most reliable way to capture phase-locking effects is to estimate a risk model for returns in which such events are explicitly allowed. For example, suppose returns are generated by the following two-factor model:

$$
R_{i t}=\alpha_{i}+\beta_{i} \Lambda_{t}+I_{t} Z_{t}+\varepsilon_{i t}
$$

11 One of the most striking examples of phase-locking behavior is the automatic synchronization of the flickering of Southeast Asian fireflies. See Strogatz (1994) for a description of this remarkable phenomenon as well as an excellent review of phase-locking behavior in biological systems. 
Figure 3.3. Sixty-Month Rolling Correlations between CSFB/Tremont Convertible Arbitrage and Emerging Market Index Returns, January 1999 to December 2003

Correlation $(\%)$

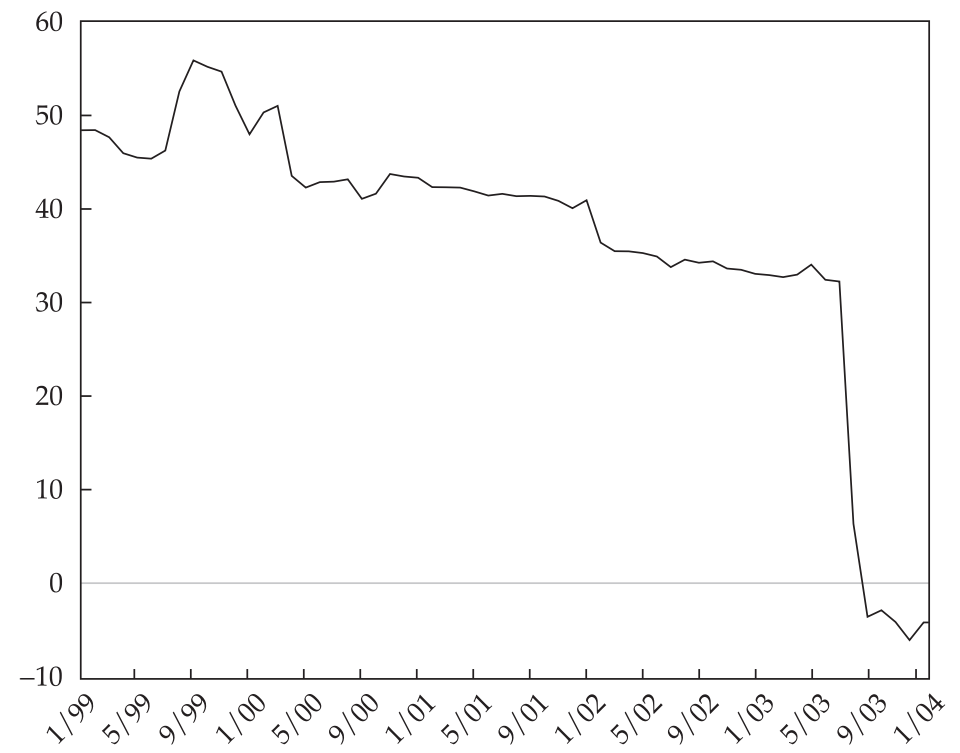

Note: The sharp decline in September 2003 is due to the fact that this is the first month in which the August 1998 observation is dropped from the 60-month rolling window.

Table 3.8. CSFB/Tremont Hedge Fund Index and Market Index Returns, August to October 1998

\begin{tabular}{lrcr}
\hline Index & August & September & October \\
\hline Aggregate Index & -7.55 & -2.31 & -4.57 \\
Convert. Arb. & -4.64 & -3.23 & -4.68 \\
Dedicated Shortseller & 22.71 & -4.98 & -8.69 \\
Emerging Markets & -23.03 & -7.40 & 1.68 \\
Equity Market Neutral & -0.85 & 0.95 & 2.48 \\
Event Driven & -11.77 & -2.96 & 0.66 \\
Distressed & -12.45 & -1.43 & 0.89 \\
ED Multi-Strategy & -11.52 & -4.74 & 0.26 \\
Risk Arbitrage & -6.15 & -0.65 & 2.41 \\
Fixed-Income Arb. & -1.46 & -3.74 & -6.96 \\
Global Macro & -4.84 & -5.12 & -11.55 \\
Long/Short Equity & -11.43 & 3.47 & 1.74 \\
Managed Futures & 9.95 & 6.87 & 1.21 \\
Multi-Strategy & 1.15 & 0.57 & -4.76 \\
Ibbotson S\&P 500 & -14.46 & 6.41 & 8.13 \\
Ibbotson Small Cap & -20.10 & 3.69 & 3.56 \\
Ibbotson LT Corp. Bonds & 0.89 & 4.13 & -1.90 \\
Ibbotson LT Gov't. Bonds & 4.65 & 3.95 & -2.18 \\
\hline
\end{tabular}

Note: Monthly returns of CSFB/Tremont hedge fund indexes and Ibbotson stock and bond indexes during August, September, and October 1998 (in percent). ED = event-driven.

Source: AlphaSimplex Group. 
and assume that $\Lambda_{t}, I_{t}, Z_{t}$, and $\varepsilon_{i t}$ are mutually independently and identically distributed (IID) with the following moments:

$$
\begin{array}{ll}
\mathrm{E}\left[\Lambda_{t}\right]=\mu_{\lambda}, & \operatorname{Var}\left[\Lambda_{t}\right]=\sigma_{\lambda}^{2} \\
\mathrm{E}\left[Z_{t}\right]=0, & \operatorname{Var}\left[Z_{t}\right]=\sigma_{z}^{2} \\
\mathrm{E}\left[\varepsilon_{i t}\right]=0, & \operatorname{Var}\left[\varepsilon_{i t}\right]=\sigma_{\varepsilon_{i}}^{2}
\end{array}
$$

and let the phase-locking event indicator $I_{t}$ be defined by

$$
I_{t}=\left\{\begin{array}{l}
1 \text { with probability } p \\
0 \text { with probability } p_{0}=1-p
\end{array} .\right.
$$

According to Equation 3.3, expected returns are the sum of three components: the fund's alpha, $\alpha_{i}$; a "market" component, $\Lambda_{t}$, to which each fund has its own individual sensitivity, $\beta_{i}$; and a phase-locking component that is identical across all funds at all times, taking only one of two possible values, either 0 (with probability $p$ ) or $Z_{t}$ (with probability $1-p$ ). If $p$ is assumed to be small, say 0.001 , then most of the time, the expected returns of fund $i$ are determined by $\alpha_{i}+\beta_{i} \Lambda_{t}$, but every once in a while an additional term $Z_{t}$ appears. If the volatility $\sigma_{z}$ of $Z_{t}$ is much larger than the volatilities of the market factor, $\Lambda_{t}$, and the idiosyncratic risk, $\varepsilon_{i t}$, then the common factor $Z_{t}$ will dominate the expected returns of all stocks when $I_{t}=1$ (i.e., phase-locking behavior).

More formally, consider the conditional correlation coefficient of two funds $i$ and $j$, defined as the ratio of the conditional covariance divided by the square root of the product of the conditional variances, conditioned on $I_{t}=0$ :

$$
\begin{aligned}
\operatorname{Corr}\left[R_{i t}, R_{j t} \mid I_{t}=0\right] & =\frac{\beta_{i} \beta_{j} \sigma_{\lambda}^{2}}{\sqrt{\beta_{i}^{2} \sigma_{\lambda}^{2}+\sigma_{\varepsilon_{i}}^{2}} \sqrt{\beta_{j}^{2} \sigma_{\lambda}^{2}+\sigma_{\varepsilon_{j}}^{2}}} \\
& \approx 0 \text { for } \beta_{i} \approx \beta_{j} \approx 0,
\end{aligned}
$$

where I assume $\beta_{i} \approx \beta_{j} \approx 0$ to capture the market-neutral characteristic that many hedge fund investors desire. Now consider the conditional correlation conditioned on $I_{t}=1$ :

$$
\begin{aligned}
\operatorname{Corr}\left[R_{i t}, R_{j t} \mid I_{t}=1\right] & =\frac{\beta_{i} \beta_{j} \sigma_{\lambda}^{2}+\sigma_{z}^{2}}{\sqrt{\beta_{i}^{2} \sigma_{\lambda}^{2}+\sigma_{z}^{2}+\sigma_{\varepsilon_{i}}^{2}} \sqrt{\beta_{j}^{2} \sigma_{\lambda}^{2}+\sigma_{z}^{2}+\sigma_{\varepsilon_{j}}^{2}}} \\
& \approx \frac{1}{\sqrt{1+\sigma_{\varepsilon_{i}}^{2} / \sigma_{z}^{2}} \sqrt{1+\sigma_{\varepsilon_{j}}^{2} / \sigma_{z}^{2}}} \text { for } \beta_{i} \approx \beta_{j} \approx 0 .
\end{aligned}
$$

If $\sigma_{z}^{2}$ is large relative to $\sigma_{\varepsilon_{i}}^{2}$ and $\sigma_{\varepsilon_{j}}^{2}$ (i.e., if the variability of the catastrophe component dominates the variability of the residuals of both funds - a plausible condition that follows from the very definition of a catastrophe), then Equation 3.9 will be approximately equal to 1 ! When phase-locking occurs, the correlation between two funds $i$ and $j$-close to zero during normal times—can become arbitrarily close to 1 .

An insidious feature of Equation 3.3 is the fact that it implies a very small value for the unconditional correlation, which is the quantity most readily estimated and the most commonly used in risk reports, Valueat-Risk calculations, and portfolio decisions. To see why, recall that the unconditional correlation coefficient is simply the unconditional covariance divided by the product of the square roots of the unconditional variances:

$$
\operatorname{Corr}\left[R_{i t}, R_{j t}\right] \equiv \frac{\operatorname{Cov}\left[R_{i t}, R_{j t}\right]}{\sqrt{\operatorname{Var}\left[R_{i t}\right] \operatorname{Var}\left[R_{j t}\right]}},
$$




$$
\begin{aligned}
& \operatorname{Cov}\left[R_{i t}, R_{j t}\right]=\beta_{i} \beta_{j} \sigma_{\lambda}^{2}+\operatorname{Var}\left[I_{t} Z_{t}\right]=\beta_{i} \beta_{j} \sigma_{\lambda}^{2}+p \sigma_{z}^{2} \\
& \operatorname{Var}\left[R_{i t}\right]=\beta_{i}^{2} \sigma_{\lambda}^{2}+\operatorname{Var}\left[I_{t} Z_{t}\right]+\sigma_{\varepsilon_{i}}^{2}=\beta_{i}^{2} \sigma_{\lambda}^{2}+p \sigma_{z}^{2}+\sigma_{\varepsilon_{i}}^{2} .
\end{aligned}
$$

Combining these expressions yields the unconditional correlation coefficient under Equation 3.3:

$$
\begin{aligned}
\operatorname{Corr}\left[R_{i t}, R_{j t}\right] & =\frac{\beta_{i} \beta_{j} \sigma_{\lambda}^{2}+p \sigma_{z}^{2}}{\sqrt{\beta_{i}^{2} \sigma_{\lambda}^{2}+p \sigma_{z}^{2}+\sigma_{\varepsilon_{i}}^{2}} \sqrt{\beta_{j}^{2} \sigma_{\lambda}^{2}+p \sigma_{z}^{2}+\sigma_{\varepsilon_{j}}^{2}}} \\
& \approx \frac{p}{\sqrt{p+\sigma_{\varepsilon_{i}}^{2} / \sigma_{z}^{2}} \sqrt{p+\sigma_{\varepsilon_{j}}^{2} / \sigma_{z}^{2}}} \text { for } \beta_{i} \approx \beta_{j} \approx 0 .
\end{aligned}
$$

If I let $p=0.001$ and assume that the variability of the phase-locking component is 10 times the variability of the residuals $\varepsilon_{i}$ and $\varepsilon_{j}$, this implies an unconditional correlation of

$$
\operatorname{Corr}\left[R_{i t}, R_{j t}\right] \approx \frac{p}{\sqrt{p+0.1} \sqrt{p+0.1}}=0.001 / 0.101=0.0099
$$

or less than 1 percent. As the variance $\sigma_{z}^{2}$ of the phase-locking component increases, the unconditional correlation (Equation 3.14) also increases, so that eventually, the existence of $Z_{t}$ will have an impact. However, to achieve an unconditional correlation coefficient of, say, 10 percent, $\sigma_{z}^{2}$ would have to be about 100 times larger than $\sigma_{\varepsilon}^{2}$. Without the benefit of an explicit risk model such as Equation 3.3, it is virtually impossible to detect the existence of a phase-locking component from standard correlation coefficients.

Hedge fund returns exhibit other nonlinearities that are not captured by linear methods such as correlation coefficients and linear factor models. An example of a simple nonlinearity is an asymmetric sensitivity to the S\&P 500 (i.e., different beta coefficients for down markets versus up markets). Specifically, consider the following regression:

$$
R_{i t}=\alpha_{i}+\beta_{i}^{+} \Lambda_{t}^{+}+\beta_{i}^{-} \Lambda_{t}^{-}+\varepsilon_{i t}
$$

where

$$
\Lambda_{t}^{+}=\left\{\begin{array}{l}
\Lambda_{t} \text { if } \Lambda_{t}>0 \\
0 \text { otherwise }
\end{array}, \Lambda_{t}^{-}=\left\{\begin{array}{l}
\Lambda_{t} \text { if } \Lambda_{t} \leq 0 \\
0 \text { otherwise }
\end{array},\right.\right.
$$

and $\Lambda_{t}$ is the return on the S\&P 500 Index. Since $\Lambda_{t}=\Lambda_{t}^{+}+\Lambda_{t}^{-}$, the standard linear model in which fund $i$ 's market betas are identical in up and down markets is a special case of the more general specification (Equation 3.15), the case where $\beta_{i}^{+}=\beta_{i}^{-}$. However, the estimates reported in Table 3.9 for the hedge fund index returns of Table 3.6 show that beta asymmetries can be quite pronounced for certain hedge fund styles. For example, the Distressed index has an up-market beta of 0.04-seemingly market neutral; however, its down-market beta is 0.43 ! For the Managed Futures index, the asymmetries are even more pronounced: The coefficients are of opposite sign, with a beta of 0.05 in up markets and a beta of -0.41 in down markets. These asymmetries are to be expected for certain nonlinear investment strategies, particularly those that have optionlike characteristics, such as the short-put strategy of Capital Decimation Partners (see "Tail Risk," above). Such nonlinearities can yield even greater diversification benefits than more traditional asset classes - for example, Managed Futures seems to provide S\&P 500 downside protection with little exposure on the upside - but investors must first be aware of the specific nonlinearities to take advantage of them.

These empirical results suggest the need for a more sophisticated analysis of hedge fund returns - one that accounts for asymmetries in factor exposures, phase-locking behavior, jump risk, nonstationarities, and other nonlinearities that are endemic to high-performance active investment strategies. In particular, nonlinear risk 
Table 3.9. Regressions of Monthly CSFB/Tremont Hedge Fund Index Returns on the S\&P 500 Index Return and on Positive and Negative S\&P 500 Index Returns, January 1994-August 1994

\begin{tabular}{|c|c|c|c|c|c|c|c|c|c|c|c|c|c|c|}
\hline Category & $\alpha$ & $t(\alpha)$ & $\beta$ & $t(\beta)$ & $\begin{array}{l}R^{2} \\
(\%)\end{array}$ & $\begin{array}{c}p-\text { Value } \\
(\%)\end{array}$ & $\alpha$ & $t(\alpha)$ & $\beta^{+}$ & $t\left(\beta^{+}\right)$ & $\beta^{-}$ & $t\left(\beta^{-}\right)$ & $\begin{array}{l}R^{2} \\
(\%)\end{array}$ & $\begin{array}{c}p \text {-Value } \\
(\%)\end{array}$ \\
\hline Hedge Funds & 0.74 & 3.60 & 0.24 & 5.48 & 21.0 & 0.0 & 1.14 & 3.22 & 0.14 & 1.58 & 0.34 & 3.95 & 22.4 & 0.0 \\
\hline Convertible Arb. & 0.83 & 6.31 & 0.03 & 1.17 & 1.2 & 23.8 & 1.00 & 4.37 & -0.01 & -0.18 & 0.08 & 1.36 & 1.9 & 33.2 \\
\hline Dedicated Shortseller & 0.70 & 2.12 & -0.86 & -12.26 & 57.2 & 0.0 & 0.23 & 0.41 & -0.74 & -5.33 & -0.98 & -7.01 & 57.6 & 0.0 \\
\hline Emerging Markets & 0.13 & 0.31 & 0.52 & 5.68 & 22.3 & 0.0 & 1.06 & 1.43 & 0.28 & 1.57 & 0.76 & 4.18 & 23.9 & 0.0 \\
\hline Equity Mkt. Neutral & 0.80 & 10.23 & 0.08 & 4.57 & 15.6 & 0.0 & 0.67 & 4.95 & 0.11 & 3.34 & 0.04 & 1.26 & 16.7 & 0.0 \\
\hline Event Driven & 0.71 & 5.06 & 0.20 & 6.86 & 29.5 & 0.0 & 1.35 & 5.84 & 0.04 & 0.68 & 0.37 & 6.54 & 36.1 & 0.0 \\
\hline Distressed & 0.84 & 5.16 & 0.23 & 6.72 & 28.6 & 0.0 & 1.58 & 5.86 & 0.04 & 0.65 & 0.43 & 6.42 & 35.2 & 0.0 \\
\hline ED Multi-Strategy & 0.64 & 4.09 & 0.19 & 5.59 & 21.7 & 0.0 & 1.25 & 4.76 & 0.03 & 0.46 & 0.34 & 5.34 & 27.0 & 0.0 \\
\hline Risk Arbitrage & 0.55 & 4.96 & 0.13 & 5.30 & 20.0 & 0.0 & 0.87 & 4.56 & 0.04 & 0.96 & 0.21 & 4.46 & 22.9 & 0.0 \\
\hline Fixed-Income Arb. & 0.59 & 5.57 & 0.00 & -0.13 & 0.0 & 89.3 & 0.95 & 5.26 & -0.10 & -2.15 & 0.09 & 2.02 & 5.0 & 5.4 \\
\hline Global Macro & 1.14 & 3.53 & 0.16 & 2.27 & 4.4 & 2.4 & 1.48 & 2.64 & 0.07 & 0.50 & 0.25 & 1.78 & 4.8 & 5.9 \\
\hline Long/Short Equity & 0.67 & 2.66 & 0.39 & 7.40 & 32.7 & 0.0 & 0.92 & 2.12 & 0.33 & 3.11 & 0.46 & 4.32 & 33.0 & 0.0 \\
\hline Managed Futures & 0.80 & 2.40 & -0.17 & -2.47 & 5.1 & 1.4 & -0.09 & -0.15 & 0.05 & 0.38 & -0.41 & -2.90 & 8.1 & 0.8 \\
\hline Multi-Strategy & 0.77 & 6.11 & 0.02 & 0.60 & 0.3 & 54.7 & 0.86 & 3.91 & -0.01 & -0.11 & 0.04 & 0.71 & 0.5 & 74.2 \\
\hline
\end{tabular}

Note: $\mathrm{ED}=$ event-driven.

models must be developed for the various types of securities that hedge funds trade (e.g., equities, fixed-income instruments, foreign exchange, commodities, and derivatives), and for each type of security, the risk model should include the following general groups of factors:

- $\quad$ Price factors

- Sectors

- Investment style

- Volatilities

- Credit

- Liquidity

- Macroeconomic factors

- Sentiment

- Nonlinear interactions

The last category involves dependencies between the previous groups of factors, some of which are nonlinear in nature. For example, credit factors may be more highly correlated with market factors during economic downturns and virtually uncorrelated at other times. Often difficult to detect empirically, these types of dependencies are more readily captured through economic intuition and practical experience and should not be overlooked when constructing a risk model.

Finally, although common factors listed above may serve as a useful starting point for developing a quantitative model of hedge fund risk exposures, it should be emphasized that a certain degree of customization will be required. To see why, consider the following list of key components of a typical long/short equity hedge fund:

- Investment style (value, growth, etc.)

- Fundamental analysis (earnings, analyst forecasts, accounting data)

- Factor exposures (S\&P 500, industries, sectors, characteristics)

- Portfolio optimization (mean-variance analysis, market neutrality)

- Stock loan considerations (hard-to-borrow securities, short "squeezes")

- Execution costs (price impact, commissions, borrowing rate, short rebate)

- Benchmarks and tracking error (T-bill rate versus S\&P 500)

Compare them with a similar list for a typical fixed-income hedge fund:

- Yield-curve models (equilibrium versus arbitrage models) 
- Prepayment models (for mortgage-backed securities)

- Optionality (call, convertible, and put features)

- Credit risk (defaults, rating changes, etc.)

- Inflationary pressures, central bank activity

- Other macroeconomic factors and events

The degree of overlap is astonishingly small. While these differences are also present among traditional institutional asset managers, they do not have nearly the latitude that hedge fund managers do in their investment activities; hence, the differences are not as consequential for traditional managers. Therefore, the number of unique hedge fund risk models may have to match the number of hedge fund styles that exist in practice.

\section{Illiquidity and Serial Correlation}

In addition to the dynamic and nonlinear risk exposures described in the two previous sections, many hedge funds exhibit a third characteristic that differentiates them from more traditional investments: credit and liquidity risk. Although liquidity and credit are separate sources of risk exposures for hedge funds and their investors-one type of risk can exist without the other-nevertheless, they have been inextricably intertwined in the minds of most investors because of the problems encountered by Long-Term Capital Management and many other fixed-income relative-value hedge funds in August and September of 1998. Because many hedge funds rely on leverage, the sizes of the positions are often considerably larger than the amounts of collateral posted to support those positions. Leverage has the effect of a magnifying glass, expanding small profit opportunities into larger ones but also expanding small losses into larger losses. And when adverse changes in market prices reduce the market value of collateral, credit is withdrawn quickly, and the subsequent forced liquidation of large positions over short periods of time can lead to widespread financial panic, as in the aftermath of the default of Russian government debt in August 1998.12 Along with the many benefits of an integrated global financial system comes the associated cost that a financial crisis in one country can be more easily transmitted to several others.

The basic mechanisms driving liquidity and credit are familiar to most hedge fund managers and investors, and there has been much progress in the recent literature in modeling both credit and liquidity risk. 13 However, the complex network of creditor/obligor relationships, revolving credit agreements, and other financial interconnections is largely unmapped. Perhaps some of the newly developed techniques in the mathematical theory of networks will allow the construction of systemic measures for liquidity and credit exposures and the robustness of the global financial system to idiosyncratic shocks. The "small world" networks considered by Watts and Strogatz (1998) and Watts (1999) seem to be particularly promising starting points.

A more immediate method for gauging the liquidity risk exposure of a given hedge fund is to examine the autocorrelation coefficients $\rho_{k}$ of the fund's monthly returns, where $\rho_{k} \equiv \operatorname{Cov}\left[R_{t}, R_{t-k}\right] / \operatorname{Var}\left[R_{t}\right]$ is the $k$ th-order autocorrelation of $\left\{R_{t}\right\}, 14$ which measures the degree of correlation between month $t^{\prime}$ s return and month $t+k$ 's return. To see why autocorrelations may be useful indicators of liquidity exposure, recall that one of the earliest financial asset pricing models is the martingale model, in which asset returns are serially uncorrelated $\left(\rho_{k}=0\right.$ for all $k \neq 0$ ). Indeed, the title of Samuelson's (1965) seminal paper-"Proof That Properly Anticipated Prices Fluctuate Randomly"-provides a succinct summary for the motivation of the martingale property: In an informationally efficient market, price changes must be unforecastable if they are properly anticipated (i.e., if they fully incorporate the expectations and information of all market participants).

\footnotetext{
12 Note that in the case of Capital Decimation Partners (see "Tail Risk," above), the fund's consecutive returns of -18.3 percent and -16.2 percent in August and September 1998 would have made it virtually impossible for the fund to continue without a massive injection of capital. In all likelihood, it would have closed down along with many other hedge funds during those fateful months, never to realize the extraordinary returns that it would have earned had it been able to withstand the losses in August and September (see Table 3.3).

13 See, for example, Bookstaber $(1999,2000)$ and Kao (2000) and their citations.

14The $k$ th-order autocorrelation of a time series $\left\{R_{t}\right\}$ is defined as the correlation coefficient between $R_{t}$ and $R_{t-k}$, which is simply the covariance between $R_{t}$ and $\mathrm{R}_{t-k}$ divided by the square root of the product of the variances of $R_{t}$ and $R_{t-k}$. But since the variances of $R_{t}$ and $R_{t-k}$ are the same under the assumption of stationarity, the denominator of the autocorrelation is simply the variance of $R_{t}$.
} 
This extreme version of market efficiency is now recognized as an idealization that is unlikely to hold in practice. 15 In particular, market frictions, such as transaction costs, borrowing constraints, costs of gathering and processing information, and institutional restrictions on short sales and other trading practices, do exist, and they all contribute to the possibility of serial correlation in asset returns which cannot easily be "arbitraged" away precisely because of the presence of these frictions. From this perspective, the degree of serial correlation in an asset's returns can be viewed as a proxy for the magnitude of the frictions, and illiquidity is one of most common forms of such frictions. For example, it is well known that the historical returns to residential real estate investments are considerably more highly autocorrelated than, say, the returns to the S\&P 500 Index during the same sample period. Similarly, the returns to the S\&P 500 futures exhibit less serial correlation than those of the index itself. In both examples, the more liquid instrument exhibits less serial correlation, and the economic rationale is a modified version of Samuelson's (1965) argument — predictability in asset returns will be exploited and eliminated only to the extent allowed by market frictions. Despite the fact that the returns to residential real estate are highly predictable, it is impossible to take full advantage of such predictability because of the high transaction costs associated with real estate transactions, the inability to short sell properties, and other frictions. ${ }^{16}$

There is another, more mundane reason for using autocorrelations to proxy for liquidity. For portfolios of illiquid securities (i.e., securities that are not frequently traded and for which there may not be well-established market prices), a hedge fund manager has considerable discretion in marking the portfolio's value at the end of each month to arrive at the fund's net asset value. Given the nature of hedge fund compensation contracts and performance statistics, managers have an incentive to "smooth" their returns by marking their portfolios to less than their actual value in months with large positive returns so as to create a "cushion" for those months with lower returns. Such return-smoothing behavior yields a more consistent set of returns over time, with lower volatility and, therefore, a higher Sharpe ratio, but it also produces serial correlation as a side effect. Of course, if the securities in the manager's portfolio are actively traded, the manager has little discretion in marking the portfolio; it is "marked to market." The more illiquid the portfolio, the more discretion the manager has in marking its value and smoothing returns, creating serial correlation in the process. ${ }^{17}$

To obtain a summary measure of the overall statistical significance of the autocorrelations, Ljung and Box (1978) propose the following statistic:

$$
Q=T(T+2) \sum_{k=1}^{p} \hat{\rho}_{k}^{2} /(T-k),
$$

which is asymptotically $\chi_{p}^{2}$ under the null hypothesis of no autocorrelation. 18 By forming the sum of squared autocorrelations, the statistic $Q$ reflects the absolute magnitudes of the $\hat{\rho}_{k}$ 's, irrespective of their signs; hence, funds with large positive or negative autocorrelation coefficients will exhibit large $Q$-statistics.

To illustrate the potential value of autocorrelations and the $Q$-statistic for measuring liquidity risk, I estimate these quantities with monthly historical total returns of the 10 largest (as of 11 February 2001) mutual funds, from various start dates through June 2000, and 12 hedge funds from various inception dates to January 2001. Monthly total returns for the mutual funds were obtained from the University of Chicago's Center for Research in Security Prices. The 12 hedge funds were selected from the Altvest database to yield a diverse range of annual Sharpe ratios (from 1 to 5 ) computed in the standard way $(\sqrt{12} \widehat{\mathrm{SR}}$, where $\widehat{\mathrm{SR}}$ is the Sharpe ratio estimator applied to monthly returns), with the additional requirement that the funds have a minimum fiveyear history of returns. The names of the hedge funds have been omitted to maintain their privacy, and I will refer to them only by their stated investment styles (e.g., Relative Value Fund, Risk Arbitrage Fund, etc.).

Table 3.10 reports the means, standard deviations, $\hat{\rho}_{1}$ to $\hat{\rho}_{6}$, and the $p$-values of the $Q$-statistic using the first six autocorrelations for the sample of mutual and hedge funds. The first subpanel shows that the 10 mutual funds have very little serial correlation in returns, with first-order autocorrelations ranging from -3.99 percent

15See, for example, Farmer and Lo (1999), Lo (2004), and the discussion in Chapter 8 under "Hedge Funds and the Efficient Market Hypothesis."

16These frictions have led to the creation of real estate investment trusts (REITs), and the returns to these securities-which are considerably more liquid than the underlying assets on which they are based-exhibit much less serial correlation.

17There are, of course, other considerations in interpreting the serial correlation of any portfolio's returns, of which return-smoothing is only one. Others include nonsynchronous trading, time-varying expected returns, and market inefficiencies.

18 See Kendall, Stuart, and Ord (1983, Section 50.13) for details. 
Table 3.10. Autocorrelations of Mutual Fund and Hedge Fund Returns (monthly data, various sample periods)

\begin{tabular}{|c|c|c|c|c|c|c|c|c|c|c|c|}
\hline Fund & $\begin{array}{l}\text { Start } \\
\text { Date }\end{array}$ & $T$ & $\begin{array}{c}\hat{\mu} \\
(\%)\end{array}$ & $\begin{array}{c}\hat{\sigma} \\
(\%)\end{array}$ & $\begin{array}{l}\hat{\rho}_{1} \\
(\%)\end{array}$ & $\begin{array}{c}\hat{\rho}_{2} \\
(\%) \\
\end{array}$ & $\begin{array}{c}\hat{\rho}_{3} \\
(\%) \\
\end{array}$ & $\begin{array}{l}\hat{\rho}_{4} \\
(\%)\end{array}$ & $\begin{array}{l}\hat{\rho}_{5} \\
(\%)\end{array}$ & $\begin{array}{c}\hat{\rho}_{6} \\
(\%)\end{array}$ & $\begin{array}{c}p \text {-Value of } \\
Q_{6}(\%) \\
\end{array}$ \\
\hline \multicolumn{12}{|l|}{ Mutual funds } \\
\hline Vanguard 500 Index & 76.10 & 286 & 1.30 & 4.27 & -3.99 & -6.60 & -4.94 & -6.38 & 10.14 & -3.63 & 31.85 \\
\hline Fidelity Magellan & 67.01 & 402 & 1.73 & 6.23 & 12.37 & -2.31 & -0.35 & 0.65 & 7.13 & 3.14 & 17.81 \\
\hline \multicolumn{12}{|l|}{ Investment Co. of } \\
\hline Janus & 70.03 & 364 & 1.52 & 4.75 & 10.49 & -0.04 & -3.74 & -8.16 & 2.12 & -0.60 & 30.32 \\
\hline Fidelity Contrafund & 67.05 & 397 & 1.29 & 4.97 & 7.37 & -2.46 & -6.81 & -3.88 & 2.73 & -4.47 & 42.32 \\
\hline \multicolumn{12}{|l|}{ Washington Mutual } \\
\hline Investors & 63.01 & 450 & 1.13 & 4.09 & -0.10 & -7.22 & -2.64 & 0.65 & 11.55 & -2.61 & 16.73 \\
\hline Janus Worldwide & 92.01 & 102 & 1.81 & 4.36 & 11.37 & 3.43 & -3.82 & -15.42 & -21.36 & -10.33 & 10.95 \\
\hline \multicolumn{12}{|l|}{ Fidelity Growth \& } \\
\hline Income & 86.01 & 174 & 1.54 & 4.13 & 5.09 & -1.60 & -8.20 & -15.58 & 2.10 & -7.29 & 30.91 \\
\hline American Century Ultra & 81.12 & 223 & 1.72 & 7.11 & 2.32 & 3.35 & 1.36 & -3.65 & -7.92 & -5.98 & 80.96 \\
\hline Growth Fund of America & 64.07 & 431 & 1.18 & 5.35 & 8.52 & -2.65 & -4.11 & -3.17 & 3.43 & 0.34 & 52.45 \\
\hline \multicolumn{12}{|l|}{ Hedge funds } \\
\hline Convertible/Option Arb. & 92.05 & 104 & 1.63 & 0.97 & 42.59 & 28.97 & 21.35 & 2.91 & -5.89 & -9.72 & 0.00 \\
\hline Relative Value & 92.12 & 97 & 0.66 & 0.21 & 25.90 & 19.23 & -2.13 & -16.39 & -6.24 & 1.36 & 3.32 \\
\hline \multicolumn{12}{|l|}{ Mortgage-Backed } \\
\hline Securities & 93.01 & 96 & 1.33 & 0.79 & 42.04 & 22.11 & 16.73 & 22.58 & 6.58 & -1.96 & 0.00 \\
\hline High-Yield Debt & 94.06 & 79 & 1.30 & 0.87 & 33.73 & 21.84 & 13.13 & -0.84 & 13.84 & 4.00 & 1.11 \\
\hline Risk Arb. A & 93.07 & 90 & 1.06 & 0.69 & -4.85 & -10.80 & 6.92 & -8.52 & 9.92 & 3.06 & 74.10 \\
\hline Long/Short Equities & 89.07 & 138 & 1.18 & 0.83 & -20.17 & 24.62 & 8.74 & 11.23 & 13.53 & 16.94 & 0.05 \\
\hline Multi-Strategy A & 95.01 & 72 & 1.08 & 0.75 & 48.88 & 23.38 & 3.35 & 0.79 & -2.31 & -12.82 & 0.06 \\
\hline Risk Arb. B & 94.11 & 74 & 0.90 & 0.77 & -4.87 & 2.45 & -8.29 & -5.70 & 0.60 & 9.81 & 93.42 \\
\hline Convertible Arb. A & 92.09 & 100 & 1.38 & 1.60 & 33.75 & 30.76 & 7.88 & -9.40 & 3.64 & -4.36 & 0.06 \\
\hline Convertible Arb. B & 94.07 & 78 & 0.78 & 0.62 & 32.36 & 9.73 & -4.46 & 6.50 & -6.33 & -10.55 & 8.56 \\
\hline Multi-Strategy B & 89.06 & 139 & 1.34 & 1.63 & 49.01 & 24.60 & 10.60 & 8.85 & 7.81 & 7.45 & 0.00 \\
\hline Fund of Funds & 94.10 & 75 & 1.68 & 2.29 & 29.67 & 21.15 & 0.89 & -0.90 & -12.38 & 3.01 & 6.75 \\
\hline
\end{tabular}

Notes: Means, standard deviations, and autocorrelation coefficients for monthly total returns of mutual funds and hedge funds from various start dates through June 2000 for the mutual fund sample and various start dates through December 2000 for the hedge fund sample; " $\hat{\rho}_{k}$ " denotes the $k$ th autocorrelation coefficient, and " $p$-value of $Q_{6}$ " denotes the significance level of the Ljung-Box (1978) $Q_{-}$ statistic $T(T+2) \sum_{k=1}^{6} \rho_{k}^{2} /(T-k)$, which is asymptotically $\chi_{6}^{2}$ under the null hypothesis of no serial correlation.

Source: AlphaSimplex Group.

to 12.37 percent and with $p$-values of the corresponding $Q$-statistics ranging from 10.95 percent to 80.96 percent, implying that none of the $Q$-statistics is significant at the 5 percent level. ${ }^{19}$ The lack of serial correlation in these 10 mutual fund returns is not surprising. Because of their sheer size, these funds consist primarily of highly liquid securities, and as a result, there is little discretion in valuing such portfolios. Moreover, many of the U.S. SEC regulations that govern the mutual fund industry (e.g., detailed prospectuses, daily net asset value calculations, and quarterly filings) were enacted specifically to guard against arbitrary marks, price manipulation, and other unsavory investment practices.

${ }^{19}$ The $p$-value of a statistic is defined as the smallest level of significance for which the null hypothesis can be rejected based on the statistic's value. For example, a $p$-value of 16.73 percent for the $Q$-statistic of Washington Mutual Investors implies that the null hypothesis of no serial correlation can be rejected only at the 16.73 percent significance level - at any smaller level of significance, say 5 percent, the null hypothesis cannot be rejected. Therefore, smaller $p$-values indicate stronger evidence against the null hypothesis, and larger $p$-values indicate stronger evidence in favor of the null. Because they are easier to interpret, $p$-values are often reported instead of test statistics (to interpret a test statistic, one must compare it to the critical values of the appropriate distribution; this comparison is performed in computing the $p$-value). See, for example, Bickel and Doksum (1977, Section 5.2.B) for further discussion of $p$-values and their interpretation. 
The results for the 12 hedge funds are considerably different. In sharp contrast to the mutual fund sample, the hedge fund sample displays substantial serial correlation, with first-order autocorrelation coefficients that range from -20.17 percent to 49.01 percent, with 8 out of 12 funds that have $Q$-statistics with $p$-values less than 5 percent, and 10 out of 12 funds with $p$-values less than 10 percent. The only two funds with $p$-values that are not significant at the 5 percent or 10 percent level are the Risk Arbitrage A and Risk Arbitrage B funds, which have $p$-values of 74.10 percent and 93.42 percent, respectively. This is consistent with the notion of serial correlation as a proxy for liquidity risk because among the various types of funds in this sample, risk arbitrage is likely to be the most liquid, since, by definition, such funds invest in securities that are exchange traded and where trading volume is typically heavier than usual because of the impending merger events on which risk arbitrage is based.

Of course, there are several other aspects of liquidity that are not captured by serial correlation, and certain types of trading strategies can generate serial correlation even though they invest in highly liquid instruments. In particular, conditioning variables such as investment style, the types of securities traded, and other aspects of the market environment should be taken into account, perhaps through the kind of risk model proposed in the previous section. However, as a first cut for measuring and comparing the liquidity exposures of various hedge fund investments, autocorrelation coefficients and $Q$-statistics provide a great deal of insight and information in a convenient manner. A more detailed analysis of serial correlation in hedge fund returns is provided by Getmansky, Lo, and Makarov (2004) and summarized below in Chapter 5. 


\section{Basic Properties of Hedge Fund Returns}

It is clear from Chapter 3 that hedge funds exhibit unique and dynamic characteristics that bear further study. Fortunately, the returns of many individual hedge funds are now available through a number of commercial databases such as Altvest, the Center for International Securities and Derivatives Markets (CISDM), HedgeFund.net, Hedge Fund Research (HFR), and TASS Research. For the empirical analysis in Chapters 4 and 5, I use two main sources: (1) a set of aggregate hedge fund index returns from CSFB/Tremont and (2) the TASS database of hedge funds, which consists of monthly returns, assets under management, and other fund-specific information for 4,781 individual hedge funds (as of August 2004) from February 1977 to August 2004.20

The CSFB/Tremont indexes are asset-weighted indexes of funds with a minimum of $\$ 10$ million of assets under management, a minimum one-year track record, and current audited financial statements. An aggregate index is computed from this universe, and 10 subindexes based on investment style are also computed using a similar method. Indexes are computed and rebalanced on a monthly basis, and the universe of funds is redefined on a quarterly basis.

The TASS database is divided into two parts: "Live" and "Graveyard" funds. Hedge funds that are in the "Live" database are considered to be active as of 31 August 2004.21 As of August 2004, the combined database of both live and dead hedge funds contained 4,781 funds with at least one monthly return observation. Out of these 4,781 funds, 2,920 funds are in the Live database and 1,861 in the Graveyard database. The earliest data available for a fund in either database is February 1977. TASS started tracking dead funds in 1994; hence, it is only since 1994 that TASS transferred funds from the Live database to the Graveyard database. Funds that were dropped from the Live database prior to 1994 are not included in the Graveyard database, which may yield a certain degree of survivorship bias. 22

The majority of the 4,781 funds reported returns net of management and incentive fees on a monthly basis, ${ }^{23}$ and I eliminated 50 funds that reported only gross returns, leaving 4,731 funds in the "Combined" database (2,893 in the Live and 1,838 in the Graveyard database). I also eliminated funds that reported returns on a quarterly — not a monthly — basis, leaving 4,705 funds in the Combined database (2,884 in the Live and 1,821 in the Graveyard database). Finally, I dropped funds that did not report assets under management, or reported only partial assets under management, leaving a final sample of 4,536 hedge funds in the Combined database, which consists of 2,771 funds in the Live database and 1,765 funds in the Graveyard database. For the "Empirical Analysis of Smoothing and Illiquidity" section of Chapter 5, I impose an additional filter which requires funds to have at least five years of nonmissing returns, leaving 1,226 funds in the Live database and

${ }^{20}$ For further information about these data, see www.hedgeindex.com (CSFB/Tremont indexes) and www.tassresearch.com (TASS). I also use data from Altvest, the University of Chicago's Center for Research in Security Prices (CRSP), and Yahoo! Finance.

21 Once a hedge fund decides not to report its performance or is liquidated, closed to new investment, restructured, or merged with other hedge funds, the fund is transferred into the "Graveyard" database. A hedge fund can be listed in the "Graveyard" database only after being listed in the "Live" database. Because the TASS database fully represents returns and asset information for live and dead funds, the effects of survivorship bias are minimized. However, the database is subject to backfill bias—when a fund decides to be included in the database, TASS adds the fund to the "Live" database and includes all available prior performance of the fund. Hedge funds do not need to meet any specific requirements to be included in the TASS database. Due to reporting delays and time lags in contacting hedge funds, some Graveyard funds can be incorrectly listed in the Live database for a period of time. However, TASS has adopted a policy of transferring funds from the Live database to the Graveyard database if they do not report over an 8- to 10-month period.

22 For studies attempting to quantify the degree and impact of survivorship bias, see Baquero, ter Horst, and Verbeek (forthcoming); Brown, Goetzmann, Ibbotson, and Ross (1992); Brown, Goetzmann, and Ibbotson (1999); Brown, Goetzmann, and Park (1997); Carpenter and Lynch (1999); Fung and Hsieh (1997b, 2000); ter Horst, Nijman, and Verbeek (2001); Hendricks, Patel, and Zeckhauser (1997); and Schneeweis, Spurgin, and McCarthy (1996).

23TASS defines returns as the change in net asset value during the month (assuming the reinvestment of any distributions on the reinvestment date used by the fund) divided by the net asset value at the beginning of the month, net of management fees, incentive fees, and other fund expenses. Therefore, these reported returns should approximate the returns realized by investors. TASS also converts all returns denominated in a foreign currency to U.S. dollar returns using the appropriate exchange rates. 
611 in the Graveyard database for a combined total of 1,837 funds. This approach obviously creates additional survivorship bias in the remaining sample of funds, but since the main objective is to estimate measures of illiquidity exposure, not to make inferences about overall performance, this filter may not be so problematic. ${ }^{24}$

TASS also classifies funds into 11 different investment styles, listed in Table 4.1 and described in the Appendix, of which 10 correspond exactly to the CSFB/Tremont subindex definitions. ${ }^{25}$ Table 4.1 also reports the number of funds in each category for the Live, Graveyard, and Combined databases, and it is apparent from these figures that the representation of investment styles is not evenly distributed but is concentrated among four categories: Long/Short Equity (1,415), Fund of Funds (952), Managed Futures (511), and Event Driven (384). Together, these four categories account for 71.9 percent of the funds in the Combined database. Figure 4.1 shows that the relative proportions in the Live and Graveyard databases are roughly comparable, with the exception of two categories: Funds of Funds (24 percent in the Live and 15 percent in the Graveyard database) and Managed Futures (7 percent in the Live and 18 percent in the Graveyard database). This reflects the current trend in the industry toward funds of funds and the somewhat slower growth of managed futures funds.

Table 4.1. Number of Funds in the TASS Hedge Fund Live, Graveyard, and Combined Databases, February 1977-August 2004

\begin{tabular}{llrcc}
\hline & & \multicolumn{3}{c}{ Number of Funds } \\
\cline { 3 - 5 } Category & \multicolumn{1}{c}{ Definition } & Live & Graveyard & Combined \\
\hline 1 & Convertible Arbitrage & 127 & 49 & 176 \\
2 & Dedicated Shortseller & 14 & 15 & 29 \\
3 & Emerging Markets & 130 & 133 & 263 \\
4 & Equity Market Neutral & 173 & 87 & 260 \\
5 & Event Driven & 250 & 134 & 384 \\
6 & Fixed-Income Arbitrage & 104 & 71 & 175 \\
7 & Global Macro & 118 & 114 & 232 \\
8 & Long/Short Equity & 883 & 532 & 1,415 \\
9 & Managed Futures & 195 & 316 & 511 \\
10 & Multi-Strategy & 98 & 41 & 139 \\
11 & Fund of Funds & 679 & 273 & 952 \\
\multicolumn{1}{c}{ Total } & & 2,771 & 1,765 & 4,536 \\
\hline
\end{tabular}

Figure 4.1. Breakdown of TASS Live and Graveyard Funds by Category

A. Live Funds

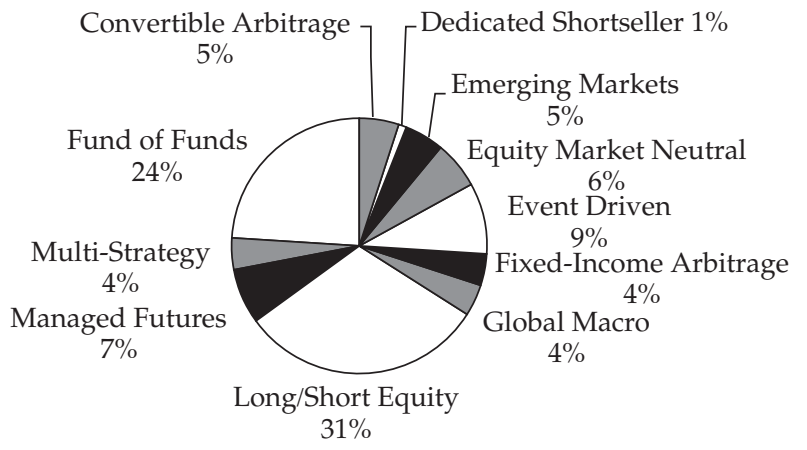

B. Graveyard Funds

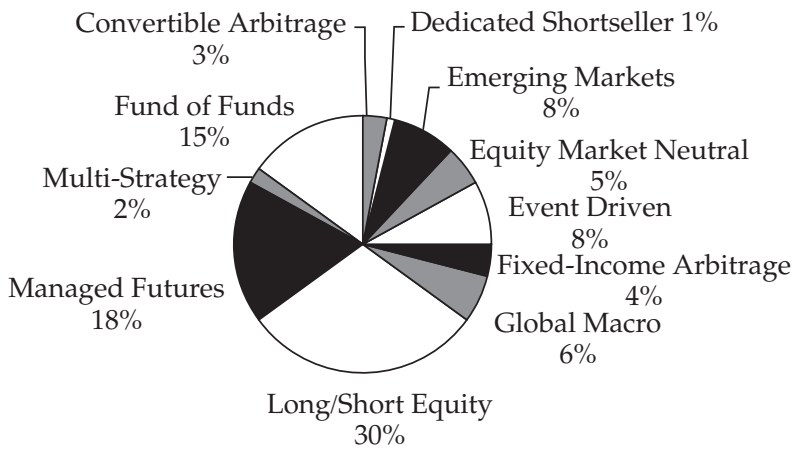

${ }^{24}$ See the references in Note 22.

${ }^{25}$ This is no coincidence; until March 2005, TASS was owned by Tremont Capital Management, which created the CSFB/Tremont indexes in partnership with Credit Suisse First Boston. 
In the next two sections, I present some summary statistics for the CSFB/Tremont indexes and similar statistics for the TASS database. Using the TASS Graveyard database, I then report a variety of attrition rates for TASS hedge funds, stratified by investment style, by assets under management, and over time.

\section{CSFB/Tremont Indexes}

In Chapter 3, I considered the correlation properties of the CSFB/Tremont hedge fund indexes. Table 4.2 reports summary statistics for the monthly returns of the CSFB/Tremont indexes from January 1994 to August 2004. Also included for purposes of comparison are summary statistics for a number of aggregate measures of market conditions, and their definitions are given in Table 4.3.

Table 4.2 shows that there is considerable heterogeneity in the historical risk and return characteristics of the various categories of hedge fund investment styles. For example, the annualized mean return ranges from -0.69 percent for Dedicated Shortsellers to 13.85 percent for Global Macro, and the annualized volatility ranges from 3.05 percent for Equity Market Neutral to 17.28 percent for Emerging Markets. The correlations of the hedge fund indexes with the S\&P 500 are generally low, with the largest correlation at 57.2 percent for Long/Short Equity and the lowest correlation at -75.6 percent for Dedicated Shortsellers—as investors have discovered, hedge funds offer greater diversification benefits than many traditional asset classes. However, these correlations can vary over time, as I illustrated in Chapter 3.

Despite their heterogeneity, several indexes do share a common characteristic: negative skewness. Convertible Arbitrage, Emerging Markets, Event Driven, Distressed, Event-Driven Multi-Strategy, Risk Arbitrage, Fixed-Income Arbitrage, and Fund of Funds all have skewness coefficients less than zero, in some cases substantially so. This property is an indication of tail risk exposure, as in the case of Capital Decimation Partners (see Chapter 3), and is consistent with the nature of the investment strategies employed by funds in those categories. For example, Fixed-Income Arbitrage strategies are known to generate fairly consistent profits, with occasional losses that may be extreme; hence, a skewness coefficient of -3.27 is not surprising. A more direct measure of tail risk or "fat tails" is kurtosis- the normal distribution has a kurtosis of 3.00, so values greater than this represent fatter tails than the normal. Not surprisingly, the two categories with the most negative skewness-Event Driven (-3.49) and Fixed-Income Arbitrage (-3.27)—also have the largest kurtosis: 23.95 and 17.05 , respectively.

Several indexes also exhibit a high degree of positive serial correlation, as measured by the first three autocorrelation coefficients $\hat{\rho}_{1}, \hat{\rho}_{2}$, and $\hat{\rho}_{3}$ and the Ljung-Box $Q$-statistic. In comparison to the S\&P 500, which has a first-order autocorrelation coefficient of -1.0 percent, the hedge fund indexes have very high autocorrelations, with values of 55.8 percent for Convertible Arbitrage, 39.2 percent for Fixed-Income Arbitrage, and 35.0 percent for Event Driven, all of which are significant at the 1 percent level according to the corresponding $p$-values. As discussed in Chapter 3, serial correlation can be a symptom of illiquidity risk exposure, and I shall focus on this issue in more detail in Chapter 5.

Table 4.4 illustrates an important characteristic of hedge fund returns-their remarkably diverse correlation patterns. Although certain indexes are quite highly correlated (e.g., Event Driven and Distressed), others exhibit strong negative correlation (e.g., Event Driven and Dedicated Shortseller), implying potentially significant diversification benefits.

\section{TASS Data}

To develop a sense of the dynamics of the TASS database, in Table 4.5 I report annual frequency counts of the funds in the database at the start of each year, funds entering during the year, funds exiting during the year, and funds entering and exiting within the year. The table shows that despite the start date of February 1977, the database is relatively sparsely populated until the 1990s, with the largest increase in new funds in 2001 and the largest number of funds exiting the database in the most recent year, 2003. The attrition rates reported in Table 4.5 are defined as the ratio of funds exiting in a given year to the number of existing funds at the start of the year. TASS began tracking fund exits starting only in 1994; hence, attrition rates cannot be computed for prior years. For the unfiltered sample of all funds, the average attrition rate from 1994 to 1999 is 7.51 percent, which is very similar to the 8.54 percent attrition rate obtained by Liang (2001) for the same period. 


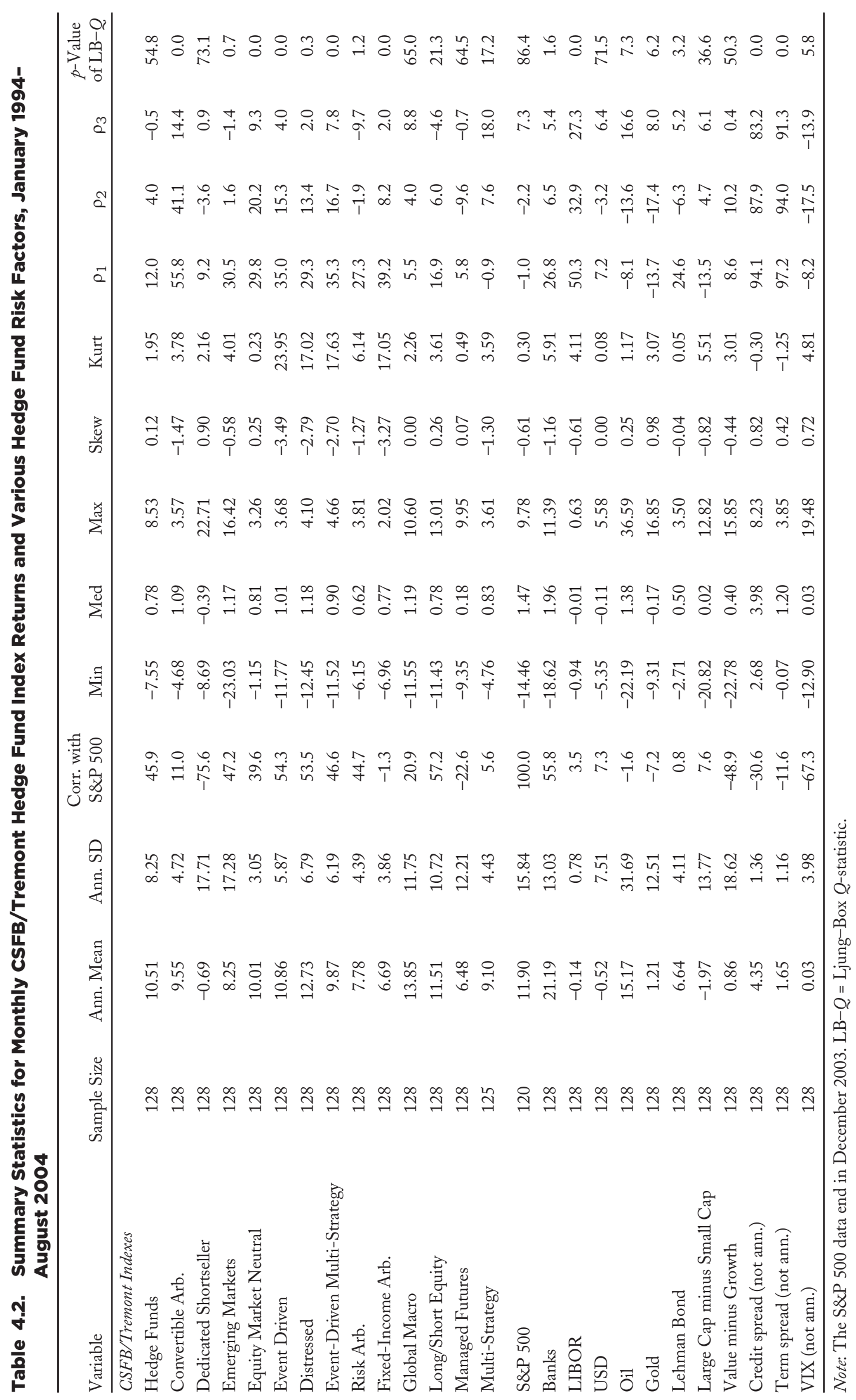


Table 4.3. Definitions of Aggregate Measures of Market Conditions and Risk Factors

\begin{tabular}{|c|c|}
\hline Variable & Definition \\
\hline S\&P 500 & Monthly return of the S\&P 500 Index including dividends. \\
\hline Banks & $\begin{array}{l}\text { Monthly return of equal-weighted portfolio of bank stocks in CRSP } \\
\text { (SIC codes 6000-6199 and 6710). }\end{array}$ \\
\hline LIBOR & $\begin{array}{l}\text { Monthly first difference in U.S. dollar six-month London interbank } \\
\text { offer rate. }\end{array}$ \\
\hline USD & Monthly return on U.S. dollar spot index. \\
\hline Oil & Monthly return on NYMEX crude oil front-month futures contract. \\
\hline Gold & Monthly return on gold spot price index. \\
\hline Lehman Bond & Monthly return on Dow Jones/Lehman Bond Index. \\
\hline Large Cap minus Small Cap & $\begin{array}{l}\text { Monthly return difference between Dow Jones large-cap and } \\
\text { small-cap indexes. }\end{array}$ \\
\hline Value minus Growth & $\begin{array}{l}\text { Monthly return difference between Dow Jones value and growth } \\
\text { indexes. }\end{array}$ \\
\hline Credit spread & $\begin{array}{l}\text { Beginning-of-month difference between KDP high-yield daily } \\
\text { index and U.S. 10-year yield. }\end{array}$ \\
\hline Term spread & $\begin{array}{l}\text { Beginning-of-month } 10 \text {-year U.S. dollar swap rate minus six-month } \\
\text { U.S. dollar LIBOR. }\end{array}$ \\
\hline VIX & Monthly first difference in the VIX implied volatility index. \\
\hline
\end{tabular}

Table 4.6 contains basic summary statistics for the funds in the TASS Live, Graveyard, and Combined databases. Not surprisingly, there is a great deal of variation in mean returns and volatilities both across and within categories and databases. For example, the 127 Convertible Arbitrage funds in the Live database have an average mean return of 9.92 percent and an average standard deviation of 5.51 percent, but in the Graveyard database, the 49 Convertible Arbitrage funds have an average mean return of 10.02 percent and a much higher average standard deviation of 8.14 percent. Not surprisingly, average volatilities in the Graveyard database are uniformly higher than those in the Live database because the higher-volatility funds are more likely to be eliminated. ${ }^{26}$

Average serial correlations also vary considerably across categories in the Combined database, but six categories stand out: Convertible Arbitrage (31.4 percent), Fund of Funds (19.6 percent), Event Driven (18.4 percent), Emerging Markets (16.5 percent), Fixed-Income Arbitrage (16.2 percent), and Multi-Strategy (14.7 percent). Given the descriptions of these categories provided by TASS (see Appendix A) and common wisdom about the nature of the strategies involved-these categories include some of the most illiquid securities traded-serial correlation seems to be a reasonable proxy for illiquidity and smoothed returns (see Lo 2001; Getmansky, Lo, and Makarov 2004; and Chapter 5, below). Alternatively, equities and futures are among the most liquid securities in which hedge funds invest, and not surprisingly, the average first-order serial correlations for Equity Market Neutral, Long/Short Equity, and Managed Futures are 5.1 percent, 9.5 percent, and -0.6 percent, respectively. Dedicated Shortseller funds also have a low average first-order autocorrelation, 5.9 percent, which is consistent with the high degree of liquidity that often characterizes shortsellers (by definition, the ability to short a security implies a certain degree of liquidity).

These summary statistics suggest that illiquidity and smoothed returns may be important attributes for hedge fund returns which can be captured to some degree by serial correlation and the time-series model of smoothing in Chapter 5.

26This effect works at both ends of the return distribution — funds that are wildly successful are also more likely to leave the database, since they have less of a need to advertise their performance. That the Graveyard database also contains successful funds is supported by the fact that in some categories, the average mean return in the Graveyard database is the same as or higher than that in the Live database (e.g., Convertible Arbitrage, Equity Market Neutral, and Dedicated Shortseller). 


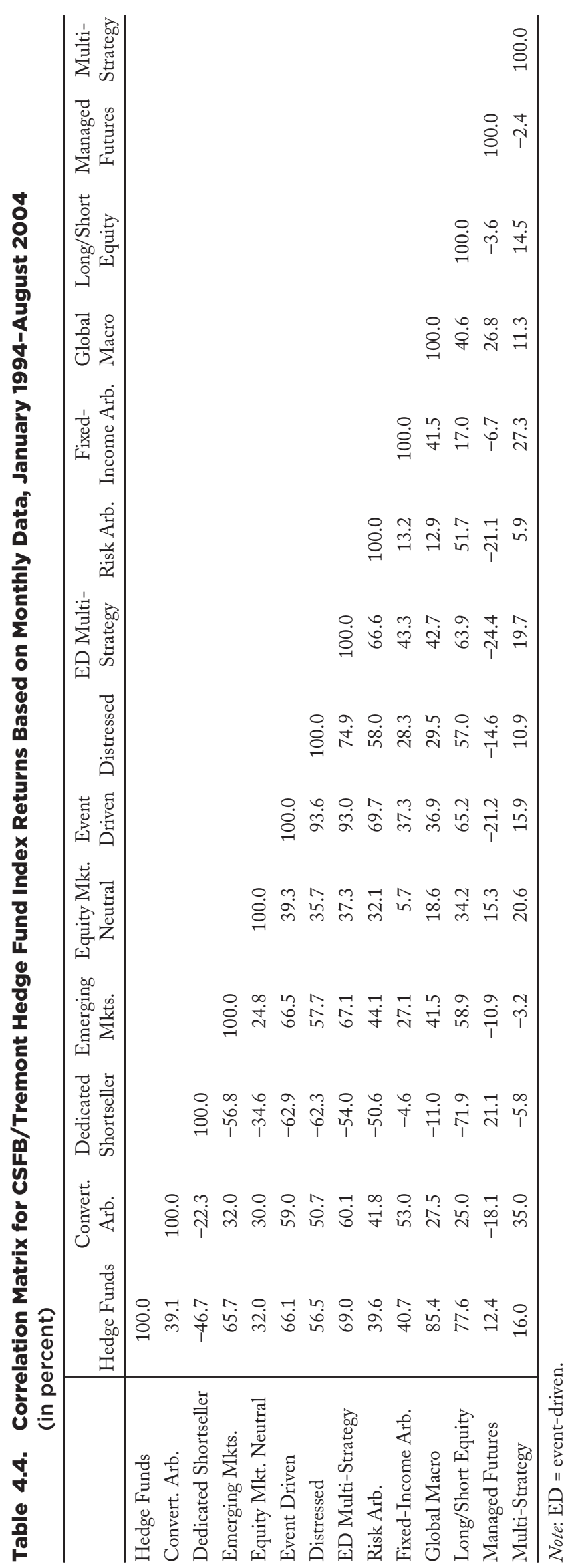


Table 4.5. Annual Frequency Counts of Entries into and Exits out of the TASS Hedge Fund Combined Database, February 1977-August 2004

\begin{tabular}{|c|c|c|c|c|c|c|}
\hline Year & Existing Funds & New Entries & New Exits & $\begin{array}{c}\text { Intra-Year } \\
\text { Entry and Exit }\end{array}$ & Total Funds & $\begin{array}{c}\text { Attrition Rate } \\
(\%)\end{array}$ \\
\hline 1977 & 0 & 4 & 0 & 0 & 4 & - \\
\hline 1978 & 4 & 2 & 0 & 0 & 6 & - \\
\hline 1979 & 6 & 2 & 0 & 0 & 8 & - \\
\hline 1980 & 8 & 4 & 0 & 0 & 12 & - \\
\hline 1981 & 12 & 3 & 0 & 0 & 15 & - \\
\hline 1982 & 15 & 6 & 0 & 0 & 21 & - \\
\hline 1983 & 21 & 9 & 0 & 0 & 30 & - \\
\hline 1984 & 30 & 15 & 0 & 0 & 45 & - \\
\hline 1985 & 45 & 9 & 0 & 0 & 54 & - \\
\hline 1986 & 54 & 23 & 0 & 0 & 77 & - \\
\hline 1987 & 77 & 29 & 0 & 0 & 106 & - \\
\hline 1988 & 106 & 35 & 0 & 0 & 141 & - \\
\hline 1989 & 141 & 45 & 0 & 0 & 186 & - \\
\hline 1990 & 186 & 107 & 0 & 0 & 293 & - \\
\hline 1991 & 293 & 94 & 0 & 0 & 387 & - \\
\hline 1992 & 387 & 155 & 0 & 0 & 542 & - \\
\hline 1993 & 542 & 247 & 0 & 0 & 789 & - \\
\hline 1994 & 789 & 252 & 24 & 2 & 1,017 & 3.0 \\
\hline 1995 & 1,017 & 300 & 62 & 1 & 1,255 & 6.1 \\
\hline 1996 & 1,255 & 332 & 122 & 9 & 1,465 & 9.7 \\
\hline 1997 & 1,465 & 357 & 101 & 6 & 1,721 & 6.9 \\
\hline 1998 & 1,721 & 347 & 164 & 9 & 1,904 & 9.5 \\
\hline 1999 & 1,904 & 403 & 186 & 7 & 2,121 & 9.8 \\
\hline 2000 & 2,121 & 391 & 237 & 9 & 2,275 & 11.2 \\
\hline 2001 & 2,275 & 460 & 257 & 6 & 2,478 & 11.3 \\
\hline 2002 & 2,478 & 432 & 249 & 9 & 2,661 & 10.0 \\
\hline 2003 & 2,661 & 325 & 287 & 12 & 2,699 & 10.8 \\
\hline
\end{tabular}

Note: The TASS Graveyard database did not exist prior to 1994; hence, attrition rates are available only from 1994 to 2003.

Finally, Table 4.7 reports the year-end assets under management for funds in each of the 11 TASS categories for the Combined database from 1977 to 2003, and the relative proportions are plotted in Figure 4.2. Table 4.7 shows that the total assets in the TASS Combined database are approximately $\$ 391$ billion, which is a significant percentage - though not nearly exhaustive — of the estimated $\$ 1$ trillion in the hedge fund industry today. ${ }^{27}$ The two dominant categories in the most recent year are Long/Short Equity (\$101.5 billion) and Fund of Funds ( $\$ 76.8$ billion), but Figure 4.2 shows that the relative proportions can change significantly over time (see Getmansky 2004 for a more detailed analysis of fund flows in the hedge fund industry).

\section{Attrition Rates}

Since the collapse of LTCM in 1998, it has become clear that hedge fund liquidations can have major consequences for the global financial system. This section provides a brief review of the hedge fund attrition rates documented in Getmansky, Lo, and Mei (2004).

Because of the voluntary nature of inclusion in the TASS database, Graveyard funds do not consist solely of liquidations. For each fund that is assigned to the Graveyard, TASS gives one of seven distinct reasons, summarized in Table 4.8. It may seem reasonable to confine our attention to those Graveyard funds categorized

27 Of course, part of the $\$ 391$ billion is Graveyard funds; hence, the proportion of current hedge fund assets represented by the TASS database is smaller. 


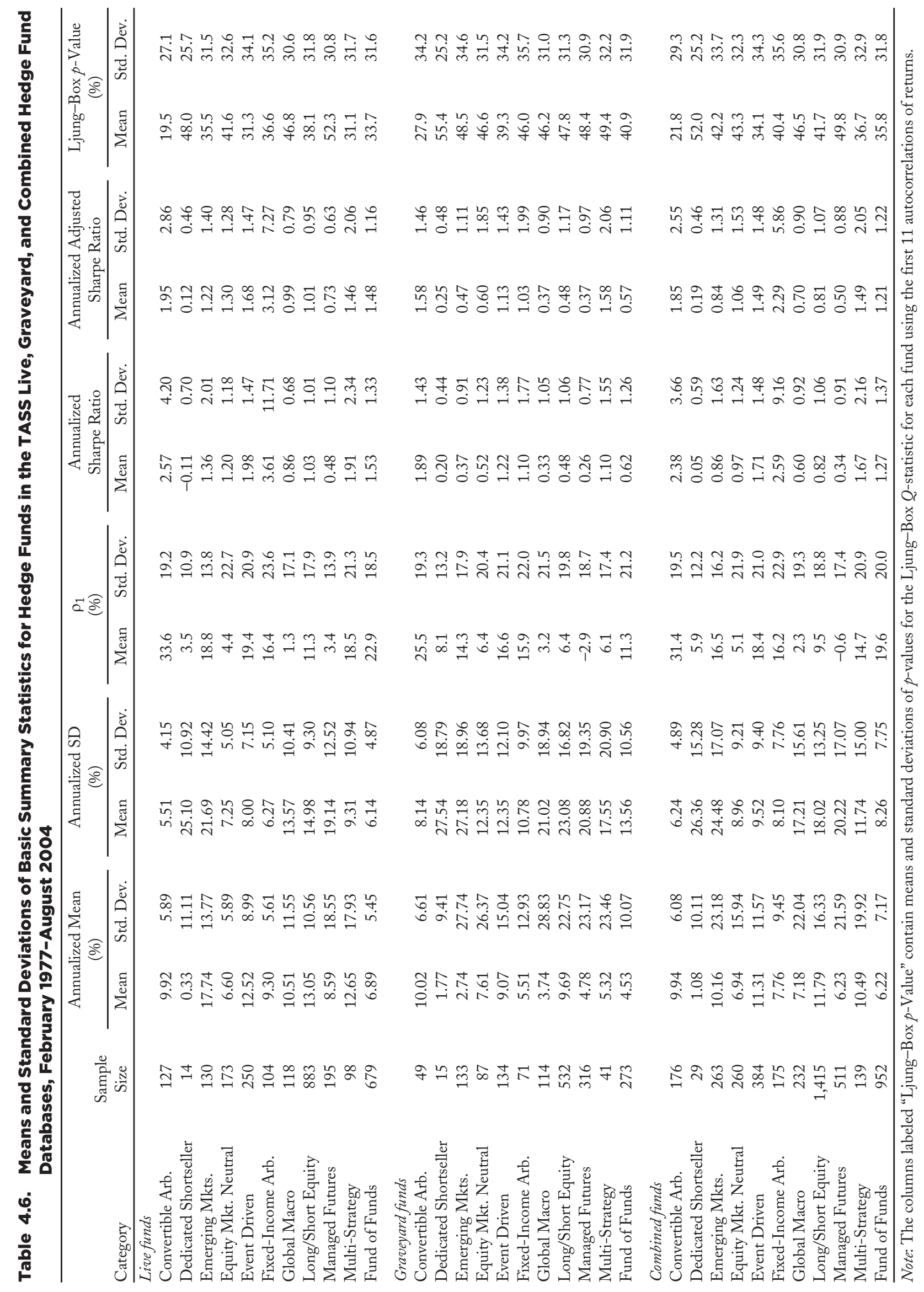


Table 4.7. Assets under Management at Year-End for Funds in Each of the 11 Categories in the TASS Combined Hedge Fund Database, 1977-2003 (US\$ millions)

\begin{tabular}{|c|c|c|c|c|c|c|c|c|c|c|c|c|}
\hline Year & $\begin{array}{c}\text { Convert. } \\
\text { Arb. }\end{array}$ & $\begin{array}{l}\text { Dedicated } \\
\text { Shortseller }\end{array}$ & $\begin{array}{c}\text { Emerging } \\
\text { Mkts. }\end{array}$ & $\begin{array}{l}\text { Equity } \\
\text { Mkt. } \\
\text { Neutral }\end{array}$ & $\begin{array}{l}\text { Event } \\
\text { Driven }\end{array}$ & $\begin{array}{c}\text { Fixed- } \\
\text { Income } \\
\text { Arb. }\end{array}$ & $\begin{array}{l}\text { Global } \\
\text { Macro }\end{array}$ & $\begin{array}{l}\text { Long/ } \\
\text { Short } \\
\text { Equity }\end{array}$ & $\begin{array}{c}\text { Managed } \\
\text { Futures }\end{array}$ & $\begin{array}{l}\text { Multi- } \\
\text { Strategy }\end{array}$ & $\begin{array}{c}\text { Fund of } \\
\text { Funds }\end{array}$ & Total \\
\hline 1977 & & & & & 16.2 & & & 42.9 & 5.4 & & & 64.4 \\
\hline 1978 & & & & & 22.1 & & & 53.2 & 18.0 & & 32.2 & 125.5 \\
\hline 1979 & & & & & 34.5 & & 0.0 & 77.6 & 44.3 & & 46.9 & 203.4 \\
\hline 1980 & & & & & 52.7 & & 0.1 & 110.6 & 55.1 & & 76.9 & 295.4 \\
\hline 1981 & & & & & 55.5 & & 0.2 & 125.6 & 62.4 & & 80.0 & 323.7 \\
\hline 1982 & 3.5 & & & & 76.9 & 13.5 & 0.3 & 174.3 & 72.2 & & 172.0 & 512.8 \\
\hline 1983 & 4.1 & & & & 114.9 & 20.4 & 5.8 & 249.7 & 68.9 & & 233.0 & 696.9 \\
\hline 1984 & 3.7 & & & & 168.7 & 23.0 & 6.2 & 345.0 & 68.8 & & 245.6 & 860.9 \\
\hline 1985 & 4.4 & 44.2 & & & 274.0 & 18.0 & 4.8 & 510.8 & 114.7 & & 386.3 & $1,357.3$ \\
\hline 1986 & 5.2 & 63.4 & & & 387.5 & 64.9 & 132.6 & 737.3 & 180.7 & & 641.9 & $2,213.4$ \\
\hline 1987 & 5.7 & 72.6 & & & 452.0 & & & 925.2 & 484.7 & $1,830.0$ & & $5,013.6$ \\
\hline 1988 & 27.5 & 108.5 & 17.9 & & $1,012.1$ & 95.1 & 265.2 & $1,324.8$ & 775.4 & $1,821.6$ & $1,318.7$ & $6,766.9$ \\
\hline 1989 & 82.4 & 133.8 & 169.3 & 134.6 & $1,216.5$ & 152.0 & 501.6 & $2,025.5$ & 770.5 & $2,131.2$ & $1,825.5$ & $9,143.0$ \\
\hline 1990 & 188.2 & 260.4 & 330.3 & 156.5 & $1,383.4$ & 289.0 & $1,964.9$ & $2,609.8$ & $1,006.6$ & $2,597.8$ & $2,426.2$ & $13,213.2$ \\
\hline 1991 & 286.9 & 221.7 & 696.4 & 191.0 & $2,114.7$ & 605.6 & $4,096.2$ & $3,952.2$ & $1,183.3$ & $3,175.6$ & $3,480.4$ & $20,004.0$ \\
\hline 1992 & $1,450.7$ & 237.0 & $1,235.4$ & 316.2 & $2,755.3$ & 928.2 & $7,197.0$ & $5,925.5$ & $1,466.8$ & $3,778.0$ & $4,941.8$ & $30,231.9$ \\
\hline 1993 & $2,334.9$ & 260.2 & $3,509.6$ & 532.1 & $4,392.4$ & $1,801.7$ & $14,275.5$ & $11,160.6$ & $2,323.2$ & $5,276.0$ & $10,224.3$ & $56,090.6$ \\
\hline 1994 & $2,182.4$ & 388.2 & $5,739.4$ & 577.2 & $5,527.6$ & $2,237.5$ & $11,822.6$ & $12,809.7$ & $2,965.4$ & $4,349.9$ & $10,420.2$ & $59,020.2$ \\
\hline 1995 & $2,711.1$ & 342.8 & $5,868.8$ & 888.3 & $7,025.5$ & $3,279.6$ & $12,835.3$ & $17,257.1$ & $2,768.8$ & $6,404.2$ & $11,816.1$ & $71,197.5$ \\
\hline 1996 & $3,913.3$ & 397.4 & $8,439.8$ & $2,168.7$ & $9,493.3$ & $5,428.4$ & $16,543.2$ & $23,165.7$ & $2,941.0$ & $7,170.1$ & $14,894.0$ & $94,554.9$ \\
\hline 1997 & $6,488.7$ & 581.5 & $12,780.2$ & $3,747.4$ & $14,508.8$ & $9,290.5$ & $25,917.6$ & $31,807.0$ & $3,665.0$ & $10,272.4$ & $21,056.9$ & $140,116.1$ \\
\hline 1998 & $7,802.7$ & 868.2 & $5,743.9$ & $6,212.5$ & $17,875.4$ & $8,195.3$ & $23,960.9$ & $36,432.9$ & $4,778.5$ & $9,761.3$ & $22,778.5$ & $144,410.3$ \\
\hline 1999 & $9,228.6$ & $1,061.2$ & $7,991.5$ & $9,165.5$ & $20,722.1$ & $8,052.1$ & $15,928.3$ & $62,817.2$ & $4,949.3$ & $11,520.2$ & $26,373.3$ & $177,809.3$ \\
\hline 2000 & $13,365.2$ & $1,312.7$ & $6,178.7$ & $13,507.5$ & $26,569.6$ & $8,245.0$ & $4,654.9$ & $78,059.0$ & $4,734.8$ & $10,745.2$ & $31,378.5$ & $198,751.0$ \\
\hline 2001 & $19,982.4$ & 802.8 & $6,940.1$ & $18,377.9$ & $34,511.9$ & $11,716.3$ & $5,744.1$ & $88,109.3$ & $7,286.4$ & $13,684.2$ & $40,848.5$ & $248,003.9$ \\
\hline 2002 & $23,649.4$ & 812.8 & $8,664.8$ & $20,008.2$ & $36,299.0$ & $17,256.8$ & $8,512.8$ & $84,813.5$ & $10,825.4$ & $16,812.1$ & $51,062.7$ & $278,717.4$ \\
\hline 2003 & $34,195.7$ & 503.8 & $16,874.0$ & $23,408.4$ & $50,631.1$ & $24,350.1$ & $21,002.2$ & $101,461.0$ & $19,449.1$ & $22,602.6$ & $76,792.4$ & $391,270.5$ \\
\hline
\end{tabular}

as "liquidated" (status code 1) or perhaps to drop those funds that are closed to new investment (status code 4) from the sample. However, because our purpose is to develop a broader perspective on the dynamics of the hedge fund industry, using the entire Graveyard database may be more informative. For example, eliminating Graveyard funds that are closed to new investors would create a downward bias in the performance statistics of the remaining funds. Because detailed information about each of these funds is not available, it cannot easily be determined how any particular selection criterion will affect the statistical properties of the remainder. Therefore, the entire set of Graveyard funds was included in the analysis, but readers are cautioned to keep in mind the composition of this sample when interpreting the empirical results.

For concreteness, Table 4.9 reports frequency counts for Graveyard funds in each status code and style category, as well as assets under management at the time of transfer to the Graveyard. ${ }^{28}$ These counts show that 1,571 of the 1,765 Graveyard funds, or 89 percent, fall into the first three categories - categories that can plausibly be considered liquidations - and within each of these three categories, the relative frequencies across style categories are roughly comparable, with Long/Short Equity being the most numerous and Dedicated Shortseller being the least numerous. Of the remaining 194 funds with status codes 4-9, only status code 4-funds that are closed to new investors - is distinctly different in character from the other status codes. There are only seven funds in this category, and these funds are all likely to be "success stories," providing some counterbalance to the

28 Of the 1,765 funds in the Graveyard database, 4 funds did not have status codes assigned; hence, I coded them as 9's ("Unknown"). The reference numbers for these funds are 3882 (Fund of Funds), 34053 (Managed Futures), 34054 (Managed Futures), 34904 (Long/ Short Equity). 


\section{Figure 4.2. Relative Proportions of Assets under Management at Year-End in the 11 Categories of the TASS Hedge Fund Combined Database, 1977 to 2003}

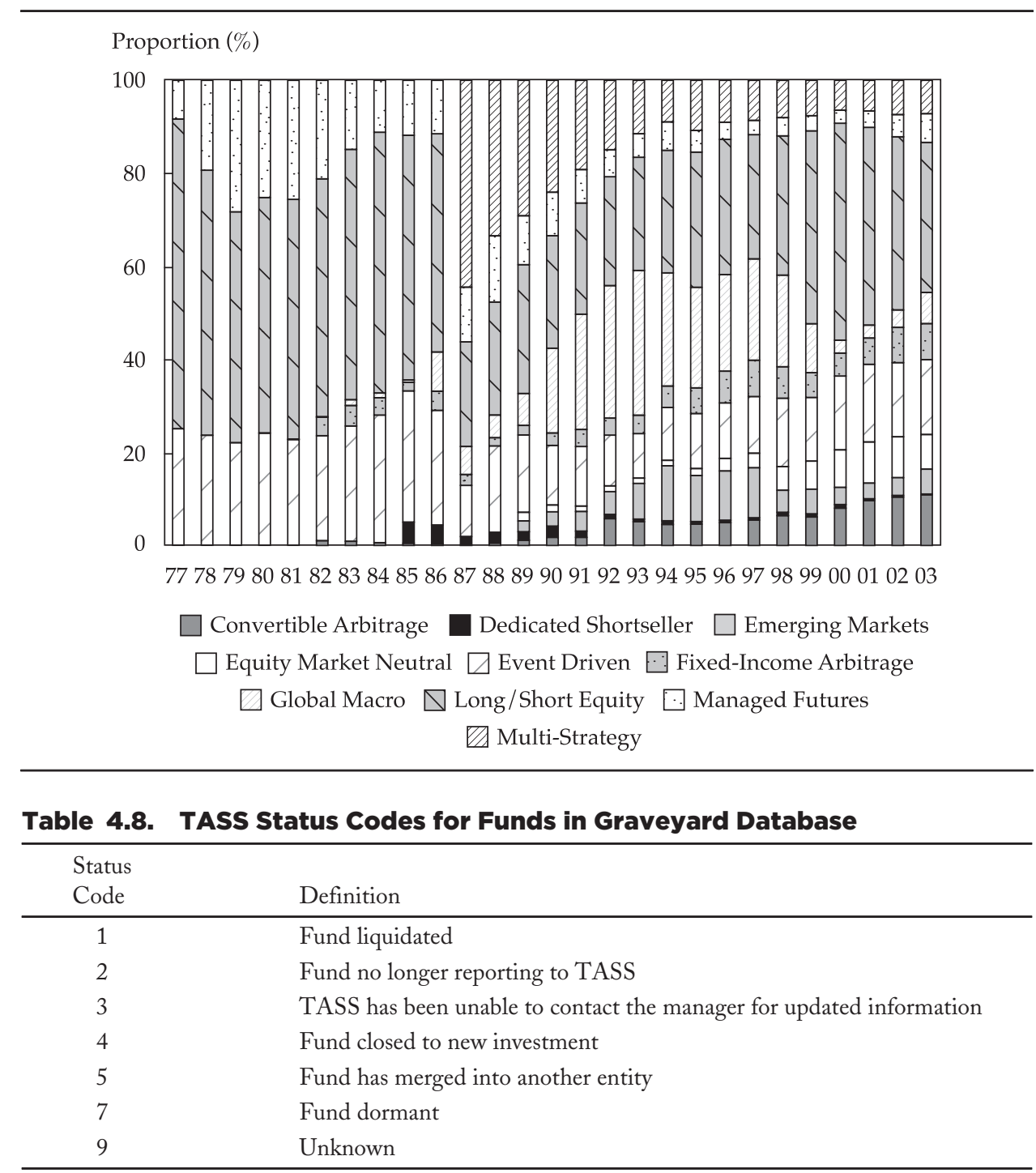

many liquidations in the Graveyard sample. Of course, this is not to say that 7 out of 1,765 is a reasonable estimate of the success rate in the hedge fund industry, because none of the Live funds are included in this calculation. Nevertheless, these seven funds in the Graveyard sample do underscore the fact that hedge fund data are subject to a variety of biases that do not always point in the same direction, and they have been left in to reflect these biases as they occur naturally rather than to create new biases. The remainder of this discussion shall refer to all funds in the TASS Graveyard database as "liquidations" for expositional simplicity.

Figure 4.3 provides a visual comparison of average means, standard deviations, Sharpe ratios, and firstorder autocorrelation coefficients $\rho_{1}$ in the Live and Graveyard databases, and Figure 4.4 displays the histogram of year-to-date returns at the time of liquidation. The fact that the distribution is skewed to the left is consistent with the conventional wisdom that performance is a major factor in determining the fate of a hedge fund. However, note that there is nontrivial weight in the right half of the distribution, suggesting that recent performance is not the only relevant factor.

Finally, Figure 4.5 provides a summary of two key characteristics of the Graveyard funds: the age distribution of funds at the time of liquidation and the distribution of their assets under management. The median age of Graveyard funds is 45 months; hence, half of all liquidated funds never reached their fourth anniversary. The mode of the distribution is 36 months. The median assets under management for funds in the Graveyard database is $\$ 6.3$ million, not an uncommon size for the typical startup hedge fund. 
Table 4.9. Frequency Counts and Assets under Management of Funds in TASS Graveyard Database by Category and Graveyard Inclusion Code (US\$ millions)

\begin{tabular}{|c|c|c|c|c|c|c|c|c|c|c|c|c|}
\hline Code & All Funds & $\begin{array}{c}\text { Convert. } \\
\text { Arb. }\end{array}$ & $\begin{array}{l}\text { Dedicated } \\
\text { Shortseller }\end{array}$ & $\begin{array}{c}\text { Emerging } \\
\text { Mkts. }\end{array}$ & $\begin{array}{l}\text { Equity } \\
\text { Mkt. } \\
\text { Neutral }\end{array}$ & $\begin{array}{l}\text { Event } \\
\text { Driven }\end{array}$ & $\begin{array}{c}\text { Fixed- } \\
\text { Income } \\
\text { Arb. }\end{array}$ & $\begin{array}{l}\text { Global } \\
\text { Macro }\end{array}$ & $\begin{array}{l}\text { Long/ } \\
\text { Short } \\
\text { Equity }\end{array}$ & $\begin{array}{c}\text { Managed } \\
\text { Futures }\end{array}$ & $\begin{array}{l}\text { Multi- } \\
\text { Strategy }\end{array}$ & $\begin{array}{c}\text { Fund of } \\
\text { Funds }\end{array}$ \\
\hline \multicolumn{13}{|c|}{ Frequency count } \\
\hline 1 & 913 & 19 & 7 & 78 & 65 & 50 & 29 & 53 & 257 & 190 & 30 & 135 \\
\hline 2 & 511 & 21 & 4 & 34 & 12 & 56 & 26 & 29 & 187 & 43 & 7 & 92 \\
\hline 3 & 147 & 4 & 1 & 7 & 8 & 17 & 3 & 17 & 54 & 18 & 1 & 17 \\
\hline 4 & 7 & 0 & 0 & 0 & 0 & 1 & 2 & 0 & 3 & 0 & 0 & 1 \\
\hline 5 & 56 & 2 & 1 & 5 & 0 & 6 & 3 & 6 & 16 & 9 & 1 & 7 \\
\hline 7 & 2 & 0 & 0 & 0 & 0 & 1 & 0 & 0 & 1 & 0 & 0 & 0 \\
\hline 9 & 129 & $\underline{3}$ & 2 & 9 & 2 & 3 & 8 & 9 & 14 & 56 & 2 & 21 \\
\hline Total & 1,765 & 49 & 15 & 133 & 87 & 134 & 71 & 114 & 532 & 316 & 41 & 273 \\
\hline \multicolumn{13}{|c|}{ Assets under management } \\
\hline 1 & 18,754 & 1,168 & 62 & 1,677 & 1,656 & 2,047 & 1,712 & 2,615 & 4,468 & 975 & 641 & 1,732 \\
\hline 2 & 36,366 & 6,420 & 300 & 848 & 992 & 7,132 & 2,245 & 678 & 10,164 & 537 & 882 & 6,167 \\
\hline 3 & 4,127 & 45 & 34 & 729 & 133 & 1,398 & 50 & 115 & 931 & 269 & 2 & 423 \\
\hline 4 & 487 & 0 & 0 & 0 & 0 & 100 & 31 & 0 & 250 & 0 & 0 & 106 \\
\hline 5 & 3,135 & 12 & 31 & 143 & 0 & 222 & 419 & 1,775 & 473 & 33 & 3 & 24 \\
\hline 7 & 8 & 0 & 0 & 0 & 0 & 6 & 0 & 0 & 2 & 0 & 0 & 0 \\
\hline 9 & 3,052 & 42 & 18 & 222 & 9 & 159 & 152 & 32 & 193 & 1,671 & 18 & 538 \\
\hline Total & 65,931 & 7,686 & 445 & 3,620 & 2,789 & 11,063 & 4,610 & 5,215 & 16,482 & 3,484 & 1,546 & 8,991 \\
\hline
\end{tabular}

Note: Assets under management are at the time of transfer into the Graveyard database.

To develop a sense of the dynamics of the TASS database and the birth and death rates of hedge funds over the past decade, ${ }^{29}$ Table 4.10 reports annual frequency counts of the funds in the database at the start of each year, funds entering the Live database during the year, funds exiting during the year and moving to the Graveyard database, and funds entering and exiting within the year. The panel labeled "All Funds" contains frequency counts for all funds, and the remaining 11 panels contain the same statistics for each category. Also included in Table 4.10 are attrition rates, defined as the ratio of funds exiting in a given year to the number of existing funds at the start of the year, and the performance of the category as measured by the annual compound return of the $\mathrm{CSFB} /$ Tremont Index for that category.

For the unfiltered sample of all funds in the TASS database, and over the sample period from 1994 to 2003, the average attrition rate is 8.8 percent. 30 This is similar to the 8.5 percent attrition rate obtained by Liang (2001) for the 1994-99 sample period. The aggregate attrition rate rises in 1998, partly due to LTCM's demise and the dislocation caused by its aftermath. The attrition rate increases to a peak of 11.4 percent in 2001, mostly due to the Long/Short Equity category-presumably the result of the bursting of the technology bubble.

${ }^{29}$ Recall that TASS launched its Graveyard database in 1994; hence, this is the beginning of the sample for Table 4.10.

30I do not include 2004 in this average because TASS typically waits 8-10 months before moving a nonreporting fund from the Live to the Graveyard database. Therefore, the attrition rate is severely downward biased for 2004, since the year was not yet complete, and many nonreporting funds in the Live database had not yet been classified as Graveyard funds. Also, note that there is only one new fund in 2004- this figure is grossly downward-biased as well. Hedge funds often go through an "incubation period," when managers trade with limited resources to develop a track record. If successful, the manager will provide the return stream to a database vendor like TASS, and the vendor usually enters the entire track record into the database, providing the fund with an "instant history." According to Fung and Hsieh (2000), the average incubation period — from a fund's inception to its entry into the TASS database-is one year. 


\section{Figure 4.3. Comparison of Average Means, Standard Deviations, Sharpe Ratios, and First-Order Autocorrelation Coefficients for Categories of Funds in the TASS Live and Graveyard Databases, January 1994 to August 2004}

\section{A. Average Mean Return}

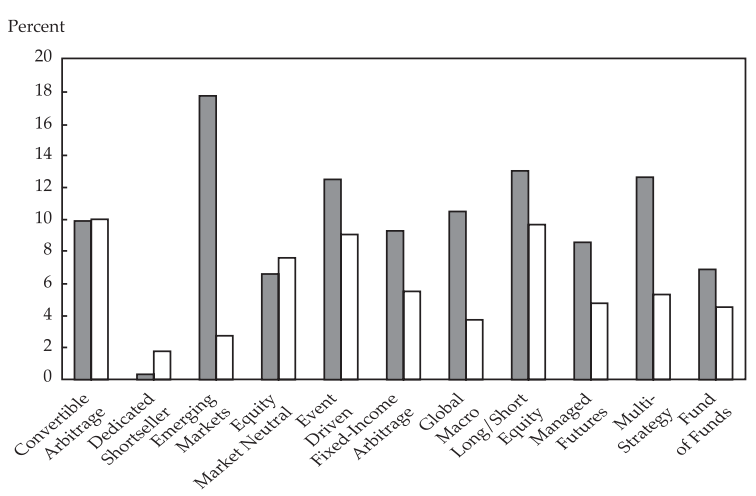

C. Average Sharpe Ratio

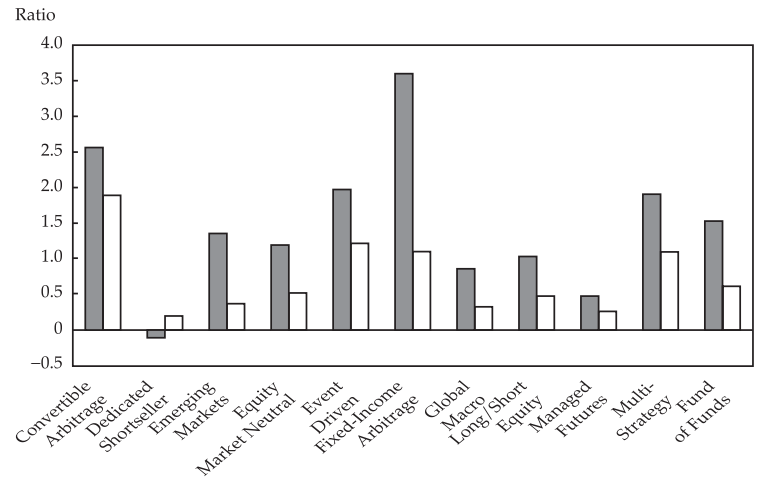

B. Average Standard Deviation

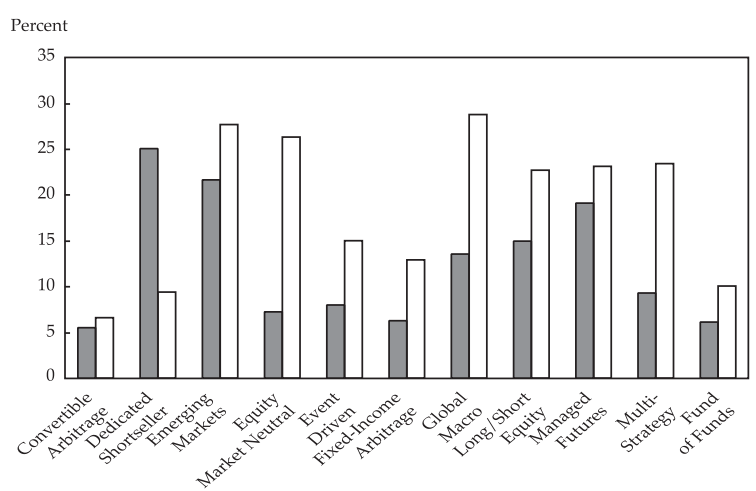

D. Average Autocorrelation

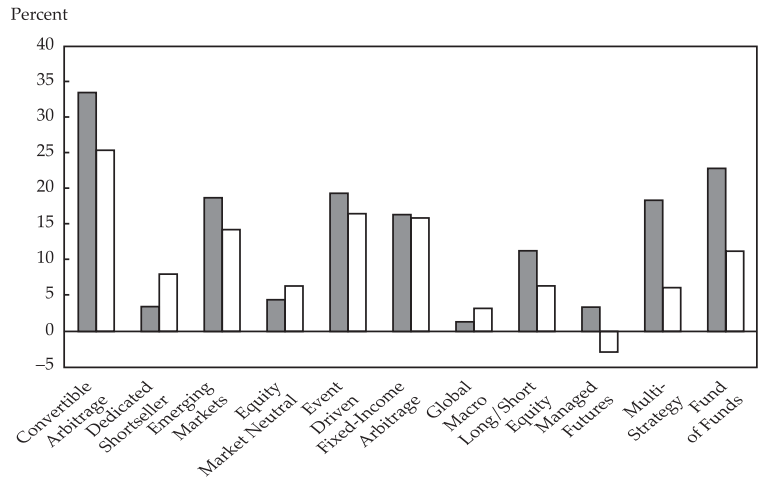

Live $\square$ Dead

Although 8.8 percent is the average attrition rate for the entire TASS database, there is considerable variation in average attrition rates across categories. Averaging the annual attrition rates from 1994-2003 within each category yields the following:

$\begin{array}{lclc}\text { Convertible Arb. } & 5.2 \% & \text { Global Macro } & 12.6 \% \\ \text { Dedicated Shortseller } & 8.0 & \text { Long/Short Equity } & 7.6 \\ \text { Emerging Markets } & 9.2 & \text { Managed Futures } & 14.4 \\ \text { Equity Market Neutral } & 8.0 & \text { Multi-Strategy } & 8.2 \\ \text { Event Driven } & 5.4 & \text { Fund of Funds } & 6.9 \\ \text { Fixed-Income Arb. } & 10.6 & & \end{array}$

These averages illustrate the different risks involved in each of the 11 investment styles. At 5.2 percent, Convertible Arbitrage enjoys the lowest average attrition rate, which is not surprising, since this category has the second-lowest average return volatility of 5.89 percent (see Table 4.6). The highest average attrition rate is 14.4 percent for Managed Futures, which is also consistent with the 18.55 percent average volatility of this category, the highest among all 11 categories. Within each category, the year-to-year attrition rates exhibit different patterns, partly attributable to the relative performance of the categories. For example, Emerging Markets experienced a 16.1 percent attrition rate in 1998, no doubt because of the turmoil in emerging markets in 1997 and 1998, which is reflected in the -37.7 percent return in the CSFB/Tremont Emerging Markets 
Figure 4.4. Histogram of Year-to-Date Return at the Time of Liquidation of Hedge Funds in the TASS Graveyard Database, January 1994 to August 2004

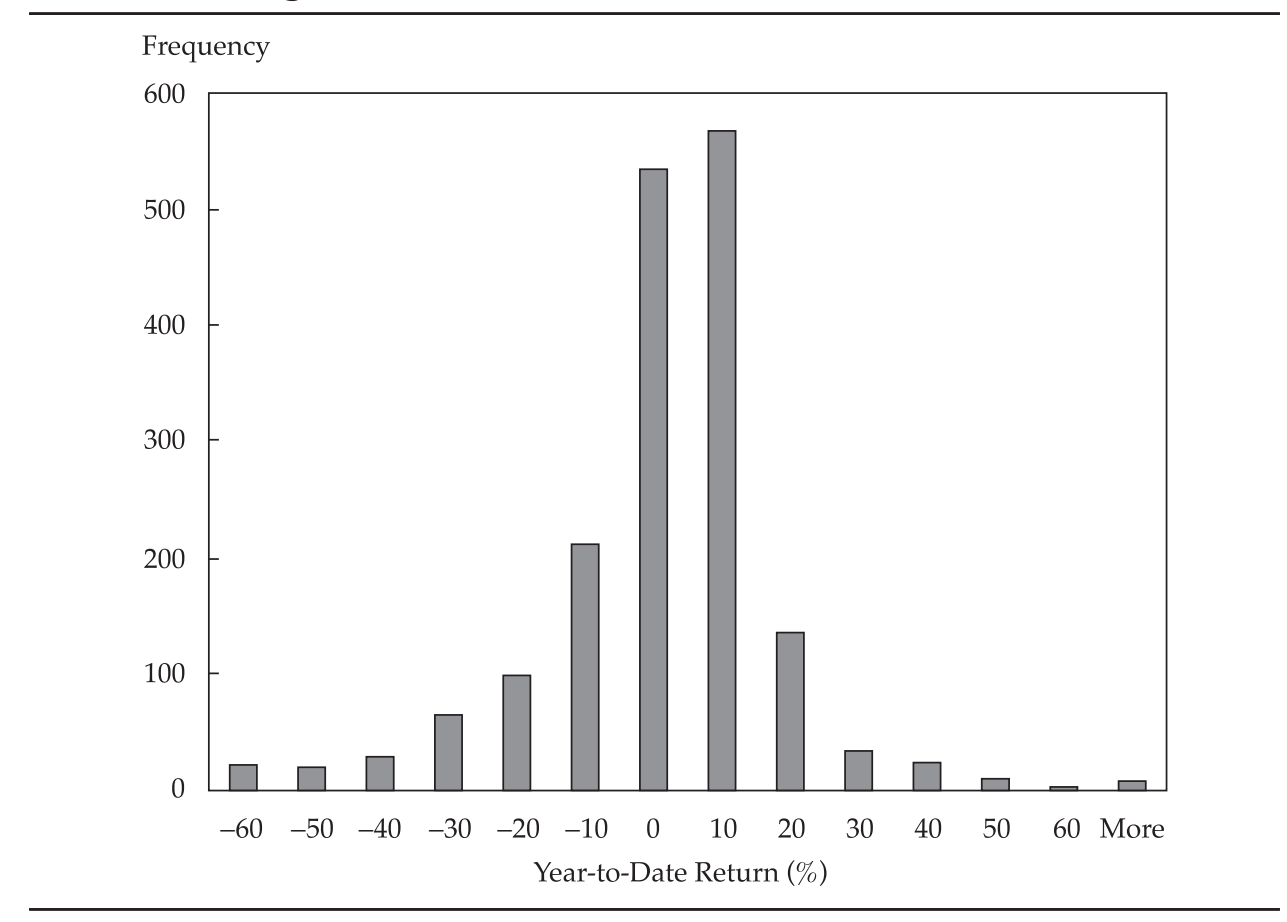

Index for 1998. The opposite pattern is also present-during periods of unusually good performance, attrition rates decline, as in the case of Long/Short Equity from 1995 to 2000, when annual attrition rates were 3.2 percent, 7.4 percent, 3.9 percent, 6.8 percent, 7.4 percent, and 8.0 percent, respectively. Of course, in the three years following the bursting of the technology bubble - 2001 to 2003 - the attrition rates for Long/Short Equity shot up to 13.4 percent, 12.4 percent, and 12.3 percent, respectively. These patterns are consistent with the basic economics of the hedge fund industry: Good performance begets more assets under management, greater business leverage, and staying power; poor performance leads to the Graveyard.

Figure 4.5. Histograms of Age Distribution and Assets under Management at the Time of Liquidation for Funds in the TASS Graveyard Database, January 1994 to August 2004

\section{A. Age Distribution}

Number of Funds

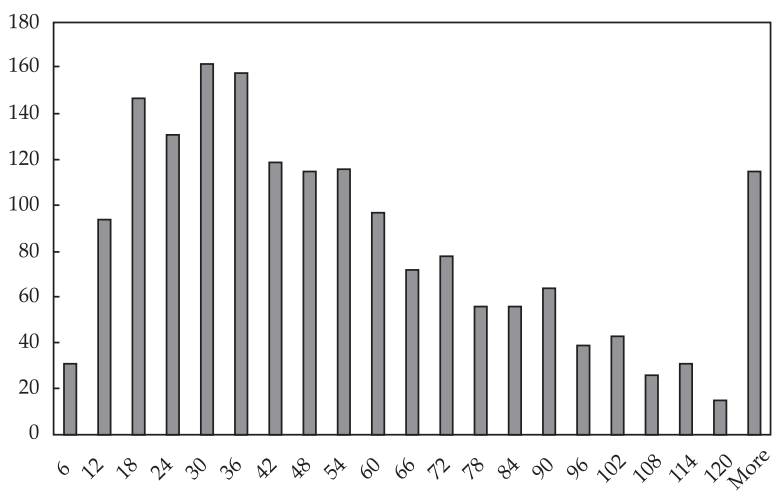

Months
B. Assets under Management

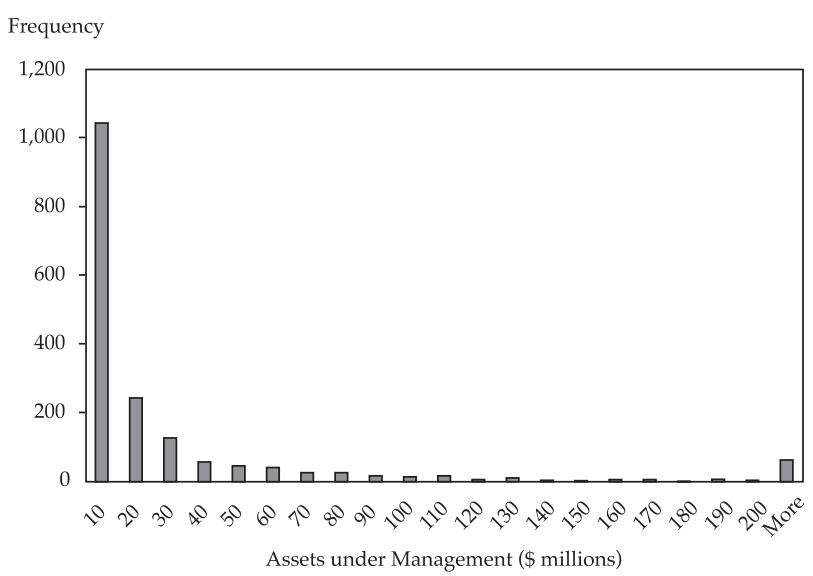




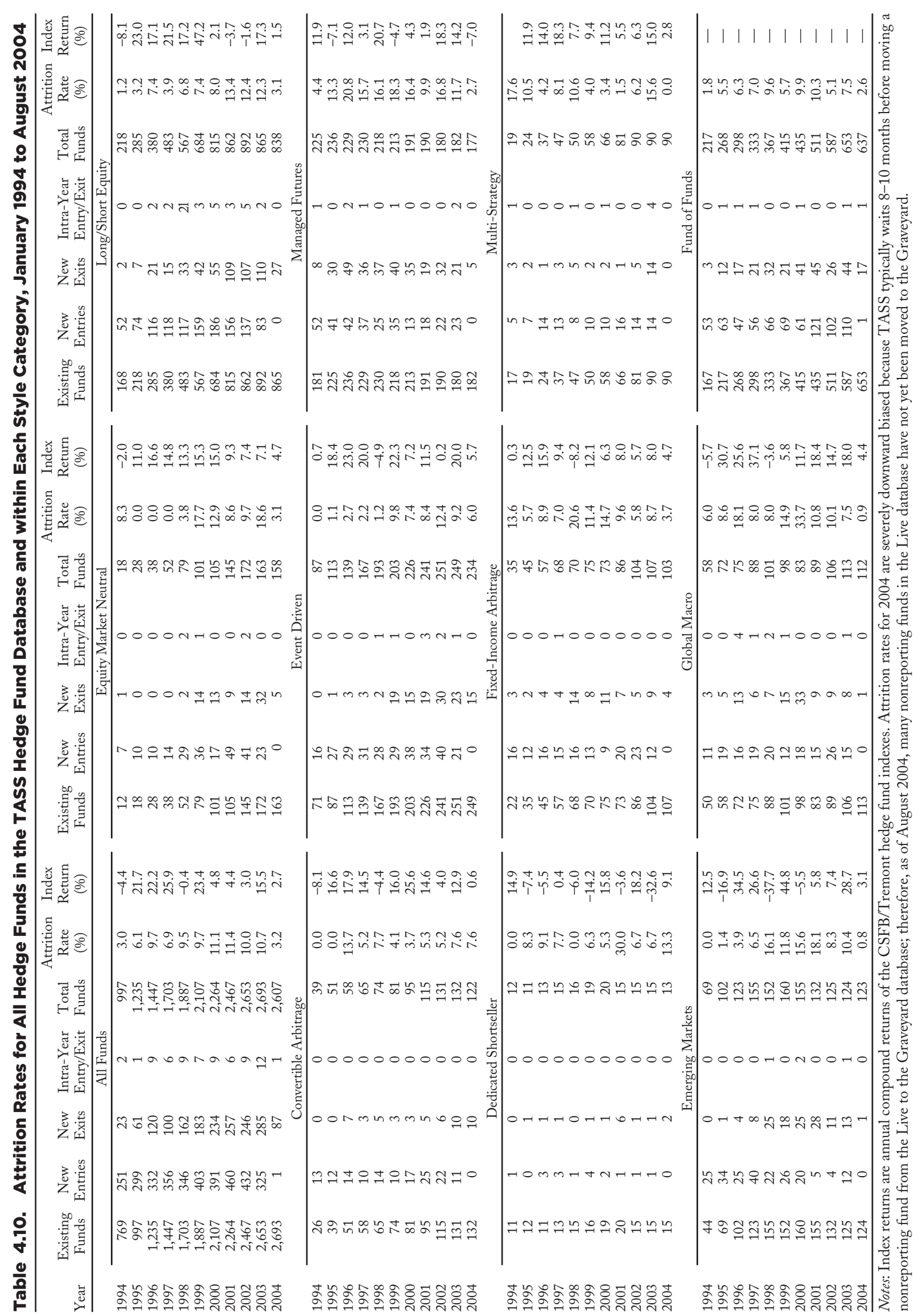


To develop a better sense of the relative magnitudes of attrition across categories, Table 4.11 and Panel A of Figure 4.6 provide a decomposition by category where the attrition rates in each category are renormalized so that when they are summed across categories in a given year, the result equals the aggregate attrition rate for that year. From these renormalized figures, it is apparent that there is an increase in the proportion of the total attrition rate due to Long/Short Equity funds beginning in 2001. In fact, Table 4.11 shows that of the total attrition rates of 11.4 percent, 10.0 percent, and 10.7 percent in years 2001-2003, the Long/Short Equity category was responsible for $4.8,4.3$, and 4.1 percentage points, respectively. Despite the fact that the average attrition rate for the Long/Short Equity category is only 7.6 percent from 1994 to 2003, the funds in this category are more numerous; hence, they contribute more to the aggregate attrition rate. Panel B of Figure 4.6 provides a measure of the impact of these attrition rates on the industry by plotting the total assets under management of funds in the TASS database along with the relative proportions in each category. Long/Short Equity funds are indeed a significant fraction of the industry; hence, the increase in their attrition rates in recent years may be cause for some concern. Chan, Getmansky, Haas, and Lo (2005) provide a more detailed analysis of hedge fund liquidation probabilities using logit analysis and find that a number of factors influence the likelihood of a hedge fund's liquidation, including past performance, assets under management, fund flows, and age. Given these factors, the study's estimates imply that the average liquidation probability for all funds in 2004-given market conditions at the end of 2004-is over 11 percent, which is higher than the historical unconditional attrition rate of 8.8 percent.

Figure 4.6. Attrition Rates and Total Assets under Management for Funds in the TASS Live and Graveyard Databases, January 1994 to August 2004

\section{A. Attrition Rates}

Attrition Rate $(\%)$

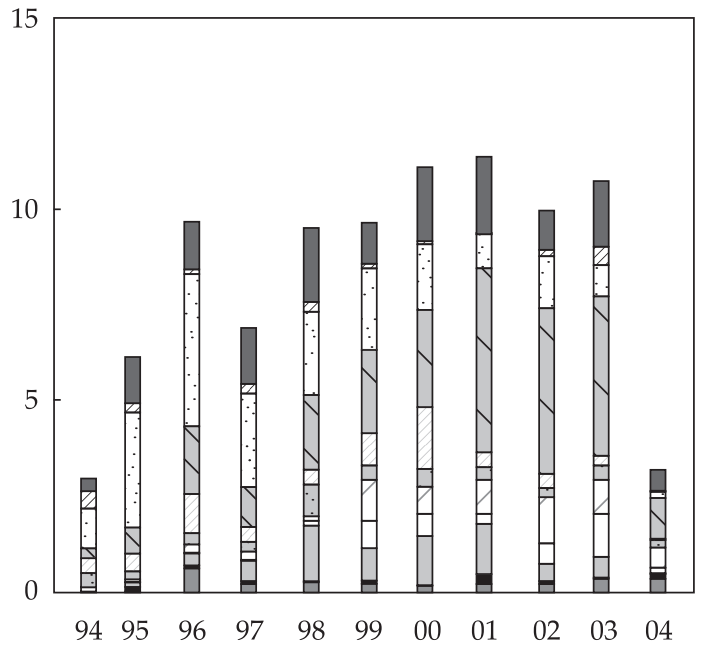

\section{B. Assets under Management}

Relative Proportion of AUM (\%) Total AUM (\$ millions)

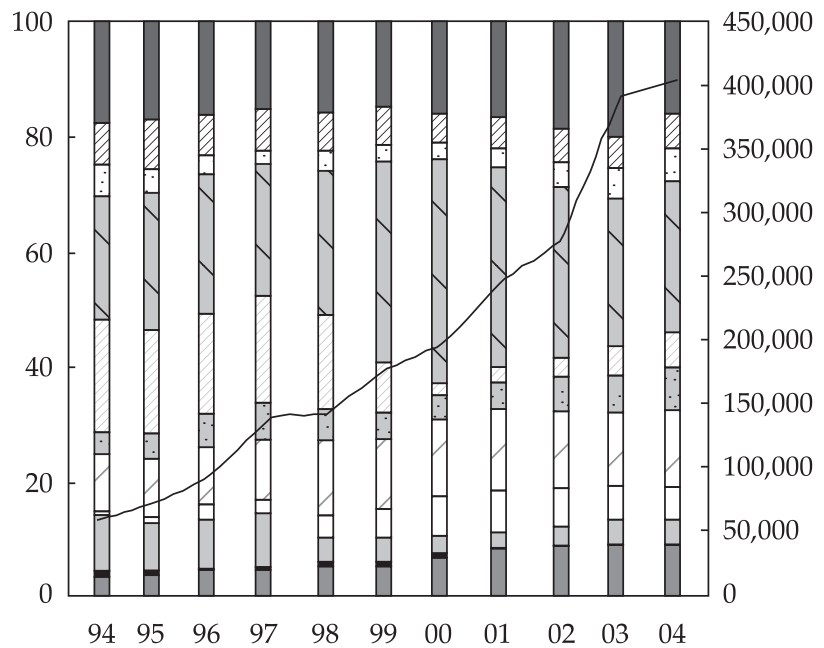

$\square$ Convertible Arbitrage $\square$ Dedicated Shortseller $\square$ Emerging Markets

$\square$ Equity Market Neutral $\square$ Event Driven $\square$ Fixed-Income Arbitrage

Global Macro $\square$ Long/Short Equity $\square$ Managed Futures

$\square$ Multi-Strategy $\square$ Fund of Funds

Note: The data for 2004 are incomplete, and attrition rates for this year are severely downward biased because of an 8- to 10-month lag in transferring nonreporting funds from the Live to the Graveyard database. 
Table 4.11. Decomposition of Attrition Rates

\begin{tabular}{|c|c|c|c|c|c|c|c|c|c|c|c|c|}
\hline Year & All Funds & $\begin{array}{c}\text { Convert. } \\
\text { Arb. }\end{array}$ & $\begin{array}{l}\text { Dedicated } \\
\text { Shortseller }\end{array}$ & $\begin{array}{c}\text { Emerging } \\
\text { Mkts. }\end{array}$ & $\begin{array}{c}\text { Equity } \\
\text { Mkt. } \\
\text { Neutral }\end{array}$ & $\begin{array}{l}\text { Event } \\
\text { Driven }\end{array}$ & $\begin{array}{c}\text { Fixed- } \\
\text { Income } \\
\text { Arb. }\end{array}$ & $\begin{array}{l}\text { Global } \\
\text { Macro }\end{array}$ & $\begin{array}{l}\text { Long/ } \\
\text { Short } \\
\text { Equity }\end{array}$ & $\begin{array}{c}\text { Managed } \\
\text { Futures }\end{array}$ & $\begin{array}{l}\text { Multi- } \\
\text { Strategy }\end{array}$ & $\begin{array}{c}\text { Fund of } \\
\text { Funds }\end{array}$ \\
\hline \multicolumn{13}{|c|}{ Total attrition rates and components by category (in percent) } \\
\hline 1994 & 3.0 & 0.0 & 0.0 & 0.0 & 0.1 & 0.0 & 0.4 & 0.4 & 0.3 & 1.0 & 0.4 & 0.4 \\
\hline 1995 & 6.1 & 0.0 & 0.1 & 0.1 & 0.0 & 0.1 & 0.2 & 0.5 & 0.7 & 3.0 & 0.2 & 1.2 \\
\hline 1996 & 9.7 & 0.6 & 0.1 & 0.3 & 0.0 & 0.2 & 0.3 & 1.1 & 1.7 & 4.0 & 0.1 & 1.4 \\
\hline 1997 & 6.9 & 0.2 & 0.1 & 0.6 & 0.0 & 0.2 & 0.3 & 0.4 & 1.0 & 2.5 & 0.2 & 1.5 \\
\hline 1998 & 9.5 & 0.3 & 0.0 & 1.5 & 0.1 & 0.1 & 0.8 & 0.4 & 1.9 & 2.2 & 0.3 & 1.9 \\
\hline 1999 & 9.7 & 0.2 & 0.1 & 1.0 & 0.7 & 1.0 & 0.4 & 0.8 & 2.2 & 2.1 & 0.1 & 1.1 \\
\hline 2000 & 11.1 & 0.1 & 0.0 & 1.2 & 0.6 & 0.7 & 0.5 & 1.6 & 2.6 & 1.7 & 0.1 & 1.9 \\
\hline 2001 & 11.4 & 0.2 & 0.3 & 1.2 & 0.4 & 0.8 & 0.3 & 0.4 & 4.8 & 0.8 & 0.0 & 2.0 \\
\hline 2002 & 10.0 & 0.2 & 0.0 & 0.4 & 0.6 & 1.2 & 0.2 & 0.4 & 4.3 & 1.3 & 0.2 & 1.1 \\
\hline 2003 & 10.7 & 0.4 & 0.0 & 0.5 & 1.2 & 0.9 & 0.3 & 0.3 & 4.1 & 0.8 & 0.5 & 1.7 \\
\hline 2004 & 3.2 & 0.4 & 0.1 & 0.0 & 0.2 & 0.6 & 0.1 & 0.0 & 1.0 & 0.2 & 0.0 & 0.6 \\
\hline Mean & 8.8 & 0.2 & 0.1 & 0.7 & 0.4 & 0.5 & 0.4 & 0.6 & 2.4 & 1.9 & 0.2 & 1.4 \\
\hline $\mathrm{SD}$ & 2.7 & 0.2 & 0.1 & 0.5 & 0.4 & 0.4 & 0.2 & 0.4 & 1.6 & 1.0 & 0.2 & 0.5 \\
\hline \multicolumn{13}{|c|}{ Annual returns of CSFB/Tremont hedge fund indexes by category (in percent) } \\
\hline 1994 & -4.4 & -8.1 & 14.9 & 12.5 & -2.0 & 0.7 & 0.3 & -5.7 & -8.1 & 11.9 & - & - \\
\hline 1995 & 21.7 & 16.6 & -7.4 & -16.9 & 11.0 & 18.4 & 12.5 & 30.7 & 23.0 & -7.1 & 11.9 & - \\
\hline 1996 & 22.2 & 17.9 & -5.5 & 34.5 & 16.6 & 23.0 & 15.9 & 25.6 & 17.1 & 12.0 & 14.0 & - \\
\hline 1997 & 25.9 & 14.5 & 0.4 & 26.6 & 14.8 & 20.0 & 9.4 & 37.1 & 21.5 & 3.1 & 18.3 & - \\
\hline 1998 & -0.4 & -4.4 & -6.0 & -37.7 & 13.3 & -4.9 & -8.2 & -3.6 & 17.2 & 20.7 & 7.7 & - \\
\hline 1999 & 23.4 & 16.0 & -14.2 & 44.8 & 15.3 & 22.3 & 12.1 & 5.8 & 47.2 & -4.7 & 9.4 & - \\
\hline 2000 & 4.8 & 25.6 & 15.8 & -5.5 & 15.0 & 7.2 & 6.3 & 11.7 & 2.1 & 4.3 & 11.2 & - \\
\hline 2001 & 4.4 & 14.6 & -3.6 & 5.8 & 9.3 & 11.5 & 8.0 & 18.4 & -3.7 & 1.9 & 5.5 & - \\
\hline 2002 & 3.0 & 4.0 & 18.2 & 7.4 & 7.4 & 0.2 & 5.7 & 14.7 & -1.6 & 18.3 & 6.3 & - \\
\hline 2003 & 15.5 & 12.9 & -32.6 & 28.7 & 7.1 & 20.0 & 8.0 & 18.0 & 17.3 & 14.2 & 15.0 & - \\
\hline 2004 & 2.7 & 0.6 & 9.1 & 3.1 & 4.7 & 5.7 & 4.7 & 4.4 & 1.5 & -7.0 & 2.8 & - \\
\hline Mean & 11.6 & 11.0 & -2.0 & 10.0 & 10.8 & 11.8 & 7.0 & 15.3 & 13.2 & 7.5 & 11.0 & - \\
\hline SD & 11.3 & 10.5 & 15.5 & 25.2 & 5.6 & 10.4 & 6.8 & 13.9 & 16.5 & 9.4 & 4.3 & - \\
\hline \multicolumn{13}{|c|}{ Total assets under management (in \$ millions) and percent breakdown by category (in percent) } \\
\hline 1994 & 57,684 & 3.8 & 0.7 & 9.3 & 1.0 & 9.5 & 3.9 & 20.5 & 20.7 & 5.1 & 7.5 & 18.0 \\
\hline 1995 & 69,477 & 3.9 & 0.5 & 8.1 & 1.3 & 10.0 & 4.7 & 18.5 & 22.9 & 4.0 & 9.2 & 17.0 \\
\hline 1996 & 92,513 & 4.2 & 0.4 & 8.7 & 2.3 & 10.1 & 5.9 & 17.9 & 23.4 & 3.2 & 7.8 & 16.1 \\
\hline 1997 & 137,814 & 4.7 & 0.4 & 8.9 & 2.7 & 10.4 & 6.7 & 18.8 & 21.9 & 2.7 & 7.5 & 15.3 \\
\hline 1998 & 142,669 & 5.5 & 0.6 & 4.0 & 4.4 & 12.5 & 5.7 & 16.8 & 24.4 & 3.3 & 6.8 & 16.0 \\
\hline 1999 & 175,223 & 5.3 & 0.6 & 4.6 & 5.2 & 11.7 & 4.6 & 9.1 & 34.5 & 2.8 & 6.6 & 15.1 \\
\hline 2000 & 197,120 & 5.4 & 0.5 & 2.5 & 5.5 & 10.6 & 3.3 & 1.9 & 31.1 & 1.9 & 4.4 & 12.7 \\
\hline 2001 & 246,695 & 8.1 & 0.3 & 2.8 & 7.4 & 13.9 & 4.7 & 2.3 & 35.3 & 3.0 & 5.5 & 16.6 \\
\hline 2002 & 277,695 & 8.5 & 0.3 & 3.1 & 7.2 & 13.0 & 6.2 & 3.1 & 30.2 & 3.9 & 6.1 & 18.4 \\
\hline 2003 & 389,965 & 8.8 & 0.1 & 4.3 & 6.0 & 13.0 & 6.2 & 5.4 & 25.7 & 5.0 & 5.8 & 19.7 \\
\hline 2004 & 403,974 & 8.8 & 0.2 & 4.2 & 5.9 & 13.5 & 7.1 & 6.6 & 26.3 & 5.3 & 6.8 & 15.3 \\
\hline Mean & 178,685 & 5.8 & 0.5 & 5.6 & 4.3 & 11.5 & 5.2 & 11.4 & 27.0 & 3.5 & 6.7 & 16.5 \\
\hline $\mathrm{SD}$ & 103,484 & 1.9 & 0.2 & 2.8 & 2.4 & 1.5 & 1.1 & 7.8 & 5.3 & 1.0 & 1.4 & 2.0 \\
\hline
\end{tabular}

Notes: Decomposition of attribution rates by category for all hedge funds in the TASS hedge fund database from January 1994 to August 2004 and corresponding CSFB/Tremont hedge fund index returns and assets under management. Attrition rates for 2004 are severely downward biased because TASS typically waits 8-10 months before moving a nonreporting fund from the Live to the Graveyard database; therefore, as of August 2004, many nonreporting funds in the Live database have not yet been moved to the Graveyard. Consequently, the reported means and standard deviations in all three panels are computed over the 1994-2003 period. 


\section{Serial Correlation, Smoothed Returns, and Illiquidity}

It is apparent from the basic empirical properties outlined in Chapter 4 that one of the most significant characteristics of hedge fund returns is serial correlation. This is somewhat surprising because serial correlation is often (though incorrectly) associated with market inefficiencies, implying a violation of the Random Walk Hypothesis and the presence of predictability in returns. This seems inconsistent with the popular belief that the hedge fund industry attracts the best and the brightest fund managers in the financial services sector. In particular, if a fund manager's returns are predictable, the implication is that the manager's investment policy is not optimal; if his returns next month can be reliably forecasted to be positive, he should increase his positions this month to take advantage of this forecast, and vice versa for the opposite forecast. By taking advantage of such predictability the fund manager will eventually eliminate it, along the lines of Samuelson's (1965) original "proof that properly anticipated prices fluctuate randomly." Given the outsize financial incentives for hedge fund managers to produce profitable investment strategies, the existence of significant unexploited sources of predictability seems unlikely.

However, Getmansky, Lo, and Makarov (2004) argue that in most cases, serial correlation in hedge fund returns is not due to unexploited profit opportunities but is more likely the result of illiquid securities that are contained in the fund (i.e., securities that are not actively traded and for which market prices are not always readily available). In such cases, the reported returns of funds containing illiquid securities will appear to be smoother than "true" economic returns - returns that fully reflect all available market information concerning those securities - and this, in turn, will impart a downward bias on the estimated return variance and yield positive serial return correlation. The prospect of spurious serial correlation and biased sample moments in reported returns is not new. Such effects have been derived and empirically documented extensively in the literature on "nonsynchronous trading," which refers to security prices recorded at different times but which are erroneously treated as if they were recorded simultaneously. ${ }^{31}$ However, this literature has focused exclusively on equity market microstructure effects as the sources of nonsynchronicity—closing prices that are set at different times or prices that are "stale"-where the temporal displacement is on the order of minutes, hours, or, in extreme cases, several days. ${ }^{32}$ In the context of hedge funds, serial correlation is modeled as the outcome of illiquidity exposure, and while nonsynchronous trading may be one symptom or by-product of illiquidity, it is not the only aspect of illiquidity that affects hedge fund returns. Even if prices are sampled synchronously, they may still yield highly serially correlated returns if the securities are not actively traded. 33 Therefore, although this formal econometric model of illiquidity is similar to those in the nonsynchronous trading literature, the motivation is considerably broader-linear extrapolation of prices for thinly traded

\footnotetext{
31 For example, the daily prices of financial securities quoted in the Wall Street Journal are usually "closing" prices—prices at which the last transaction in each of those securities occurred on the previous business day. If the last transaction in security A occurs at 2:00 p.m. and the last transaction in security B occurs at 4:00 p.m., then included in B's closing price is information not available when A's closing price was set. This discrepancy can create spurious serial correlation in asset returns, since economywide shocks will be reflected first in the prices of the most frequently traded securities, with less frequently traded stocks responding with a lag. Even when there is no statistical relation between securities A and B, their reported returns will appear to be serially correlated and cross-correlated simply because of the mistaken assumption that they are measured simultaneously. One of the first to recognize the potential impact of nonsynchronous price quotes was Fisher (1966). Since then, more explicit models of nontrading have been developed by Atchison, Butler, and Simonds (1987); Dimson (1979); Cohen, Hawawini, Maier, Schwartz, and Whitcomb (1983a, 1983b); Shanken (1987); Cohen, Maier, Schwartz, and Whitcomb (1978, 1979, 1986); Kadlec and Patterson (1999); Lo and MacKinlay (1988, 1990a); and Scholes and Williams (1977). See Campbell, Lo, and MacKinlay (1997, Chapter 3) for a more detailed review of this literature.

32For such application, Lo and MacKinlay (1988, 1990a) and Kadlec and Patterson (1999) show that nonsynchronous trading cannot explain all of the serial correlation in weekly returns of equal- and value-weighted portfolios of U.S. equities during the past three decades. ${ }^{33}$ In fact, for most hedge funds, returns are computed on a monthly basis; hence, the pricing or "mark to market" of a fund's securities typically occurs synchronously on the last day of the month.
} 
securities, the use of smoothed broker/dealer quotes, trading restrictions arising from control positions and other regulatory requirements, and, in some cases, deliberate performance-smoothing behavior-and the corresponding interpretations of the parameter estimates must be modified accordingly.

Regardless of the particular mechanism by which hedge fund returns are smoothed and serial correlation is induced, the common theme and underlying driver is illiquidity exposure, and although the argument is that the sources of serial correlation are spurious for most hedge funds, the economic impact of serial correlation can nevertheless be quite real. For example, spurious serial correlation yields misleading performance statistics such as volatility, Sharpe ratio, correlation, and market beta estimates-statistics commonly used by investors to determine whether or not they will invest in a fund, how much capital to allocate to a fund, what kinds of risk exposures they are bearing, and when to redeem their investments. Moreover, spurious serial correlation can lead to wealth transfers between new, existing, and departing investors, in much the same way that using stale prices for individual securities to compute mutual fund net asset values can lead to wealth transfers between buy-and-hold investors and day traders (see, for example, Boudoukh, Richardson, Subrahmanyam, and Whitelaw 2002).

The next section presents an explicit econometric model of smoothed returns, and the subsequent section discusses its implications for common performance statistics such as the mean, standard deviation, and Sharpe ratio. The analysis shows that the induced serial correlation and impact on the Sharpe ratio can be quite significant even for mild forms of smoothing, and the section provides several specific smoothing profiles to develop further intuition.

\section{An Econometric Model of Smoothed Returns}

There are several potential explanations for serial correlation in financial asset returns (e.g., time-varying expected returns, time-varying leverage, and incentive fees with high-water marks). However, after considering each of these alternatives in detail, Getmansky, Lo, and Makarov (2004) conclude that the most plausible explanation in the context of hedge funds is illiquidity and smoothed returns. Although these are two distinct phenomena, it is important to consider illiquidity and smoothed returns in tandem because one facilitates the other-for actively traded securities, both theory and empirical evidence suggest that in the absence of transaction costs and other market frictions, returns are unlikely to be very smooth.

As discussed above, nonsynchronous trading is a plausible source of serial correlation in hedge fund returns. In contrast to the studies by Lo and MacKinlay (1988, 1990a) and Kadlec and Patterson (1999), whose conclusion is that it is difficult to generate serial correlations in weekly U.S. equity portfolio returns much greater than 10-15 percent through nonsynchronous trading effects alone, the argument here is that in the context of hedge funds, significantly higher levels of serial correlation can be explained by the combination of illiquidity and smoothed returns, of which nonsynchronous trading is a special case. To see why, note that the empirical analysis in the nonsynchronous trading literature is devoted exclusively to exchange-traded equity returns, not hedge fund returns; hence, the conclusions from that analysis may not be relevant in this context. For example, Lo and MacKinlay (1990a) argue that securities would have to go without trading for several days on average to induce serial correlations of 30 percent, and they dismiss such nontrading intervals as unrealistic for most exchange-traded U.S. equity issues. However, such nontrading intervals are considerably more realistic for the types of securities held by many hedge funds (e.g., emerging market debt, real estate, restricted securities, control positions in publicly traded companies, asset-backed securities, and other exotic OTC derivatives). Therefore, nonsynchronous trading of this magnitude is likely to be an explanation for the serial correlation observed in hedge fund returns.

But even when prices are synchronously measured - as they are for many funds that mark their portfolios to market at the end of the month to strike a net asset value at which investors can buy into or cash out of the fund - there are several other channels by which illiquidity exposure can induce serial correlation in the reported returns of hedge funds. Apart from the nonsynchronous trading effect, naive methods for determining the fair market value, or "marks," for illiquid securities can yield serially correlated returns. For example, one approach to valuing illiquid securities is to extrapolate linearly from the most recent transaction price (which, in the case of emerging market debt, might be from several months ago), which yields a price path that is a straight line, or at best a series of straight lines. Returns computed from such marks will be smoother, exhibiting lower 
volatility and higher serial correlation, than true economic returns (i.e., returns computed from mark-to-market prices where the market is sufficiently active to allow all available information to be impounded in the price of the security). Of course, for securities that are more easily traded and with deeper markets, mark-to-market prices are more readily available, extrapolated marks are not necessary, and serial correlation is therefore less of an issue. But for securities that are thinly traded—or not traded at all for extended periods of time-marking them to market is often an expensive and time-consuming procedure that cannot easily be performed frequently. 34 Therefore, I argue in this monograph that serial correlation may serve as a proxy for a fund's illiquidity exposure.

Even if a hedge fund manager does not make use of any form of linear extrapolation to mark the securities in his portfolio, he may still be subject to smoothed returns if he obtains marks from broker/dealers that engage in such extrapolation. For example, consider the case of a conscientious hedge fund manager attempting to obtain the most accurate mark for his portfolio at month-end by getting bid/offer quotes from three independent broker/dealers for every security in his portfolio, and then marking each security at the average of the three quote midpoints. By averaging the quote midpoints, the manager is inadvertently downward-biasing price volatility, and if any of the broker/dealers employ linear extrapolation in formulating their quotes (and many do, through sheer necessity because they have little else to go on for the most illiquid securities), or if they fail to update their quotes because of light volume, serial correlation will also be induced in reported returns.

Finally, a more prosaic channel by which serial correlation may arise in the reported returns of hedge funds is through "performance-smoothing," the unsavory practice of reporting only part of the gains in months when a fund has positive returns so as to partially offset potential future losses and thereby reduce volatility and improve risk-adjusted performance measures such as the Sharpe ratio. For funds containing liquid securities that can be easily marked to market, performance-smoothing is more difficult and, as a result, less of a concern. Indeed, it is only for portfolios of illiquid securities that managers and brokers have any discretion in marking their positions. Such practices are generally prohibited by various securities laws and accounting principles, and great care must be exercised in interpreting smoothed returns as deliberate attempts to manipulate performance statistics. After all, as discussed above, there are many other sources of serial correlation in the presence of illiquidity, none of which is motivated by deceit. Nevertheless, managers do have certain degrees of freedom in valuing illiquid securities - for example, discretionary accruals for unregistered private placements and venture capital investments - and Chandar and Bricker (2002) conclude that managers of certain closed-end mutual funds do use accounting discretion to manage fund returns around a passive benchmark. Therefore, the possibility of deliberate performance-smoothing in the less regulated hedge fund industry must be kept in mind in interpreting any empirical analysis of smoothed returns.

To quantify the impact of all of these possible sources of serial correlation, denote the true economic return of a hedge fund in period $t$ by $R_{t}$, and let $R_{t}$ satisfy the following linear single-factor model:

$$
\begin{aligned}
& R_{t}=\mu+\beta \Lambda_{t}+\varepsilon_{t}, \mathrm{E}\left[\Lambda_{t}\right]=\mathrm{E}\left[\varepsilon_{t}\right]=0, \varepsilon_{t}, \Lambda_{t} \sim \text { IID } \\
& \operatorname{Var}\left[R_{t}\right] \equiv \sigma^{2} .
\end{aligned}
$$

True returns represent the flow of information that would determine the equilibrium value of the fund's securities in a frictionless market. However, true economic returns are not observed. Instead, $R_{t}^{o}$ denotes the reported or observed return in period $t$, and let

$$
\begin{aligned}
& R_{t}^{o}=\theta_{0} R_{t}+\theta_{1} R_{t-1}+\cdots+\theta_{k} R_{t-k}, \\
& \theta_{j} \in[0,1], \quad j=0, \ldots, k, \\
& 1=\theta_{0}+\theta_{1}+\cdots+\theta_{k},
\end{aligned}
$$

which is a weighted average of the fund's true returns over the most recent $k+1$ periods, including the current period.

${ }^{34}$ Liang (2003) presents a sobering analysis of the accuracy of hedge fund returns that underscores the challenges of marking a portfolio to market. 
This averaging process captures the essence of smoothed returns in several respects. From the perspective of illiquidity-driven smoothing, Equation 5.2 is consistent with several models in the nonsynchronous trading literature. For example, Cohen, Maier, Schwartz, and Whitcomb (1986, Chapter 6.1) propose a similar weighted-average model for observed returns. 35 Alternatively, Equation 5.2 can be viewed as the outcome of marking portfolios to simple linear extrapolations of acquisition prices when market prices are unavailable, or "mark-to-model" returns where the pricing model is slowly varying through time. And of course, Equation 5.2 also captures the intentional smoothing of performance.

The constraint (Equation 5.4) that the weights sum to 1 implies that the information driving the fund's performance in period $t$ will eventually be fully reflected in observed returns, but this process could take up to $k+1$ periods from the time the information is generated. 36 This is a sensible restriction in the current context of hedge funds for several reasons. Even the most illiquid securities will trade eventually, and when that occurs, all of the cumulative information affecting that security will be fully impounded into its transaction price. Therefore, the parameter $k$ should be selected to match the kind of illiquidity of the fund (e.g., a fund comprising mostly exchange-traded U.S. equities would require a much lower value of $k$ than a private equity fund). Alternatively, in the case of intentional smoothing of performance, the necessity of periodic external audits of fund performance imposes a finite limit on the extent to which deliberate smoothing can persist. 37

\section{Implications for Performance Statistics}

The smoothing mechanism outlined in the preceding section leads to the following implications for the statistical properties of observed returns.

Proposition 1 (Getmansky, Lo, and Makarov 2004) Under Equations 5.2-5.4, the statistical properties of observed returns are characterized by

$$
\begin{aligned}
& \mathrm{E}\left[R_{t}^{o}\right]=\mu \\
& \operatorname{Var}\left[R_{t}^{o}\right]=c_{\sigma}^{2} \sigma^{2} \leq \sigma^{2} \\
& \mathrm{SR}^{o} \equiv \frac{\mathrm{E}\left[R_{t}^{o}\right]}{\sqrt{\operatorname{Var}\left[R_{t}^{o}\right]}}=c_{s} \mathrm{SR} \geq \mathrm{SR} \equiv \frac{\mathrm{E}\left[R_{t}\right]}{\sqrt{\operatorname{Var}\left[R_{t}\right]}} \\
& \beta_{m}^{o} \equiv \frac{\operatorname{Cov}\left[R_{t}^{o}, \Lambda_{t-m}\right]}{\operatorname{Var}\left[\Lambda_{t-m}\right]}= \begin{cases}c_{\beta, m} \beta & \text { if } 0 \leq m \leq k \\
0 & \text { if } m>k\end{cases}
\end{aligned}
$$

35In particular, their specification for observed returns is $r_{j, t}^{o}=\sum_{l=0}^{N}\left(\gamma_{j, t-l, l} r_{j, t-l}+\theta_{j, t-l}\right)$, where $r_{j, t-l}$ is the true but unobserved return for security $j$ in period $t-l$, the coefficients $\left\{\gamma_{j, t-l, l}\right\}$ are assumed to sum to 1 , and $\theta_{j, t-l}$ are random variables meant to capture "bidask bounce." The authors motivate their specification of nonsynchronous trading in the following way: "Alternatively stated, the $\gamma_{j, t, 0}, \gamma_{j, t, 1}, \ldots, \gamma_{j, t, N}$ comprise a delay distribution that shows how the true return generated in period $t$ impacts on the returns actually observed during $t$ and the next $N$ periods" (p. 116). In other words, the essential feature of nonsynchronous trading is the fact that information generated at date $t$ may not be fully impounded into prices until several periods later.

36In Lo and MacKinlay's (1990a) model of nonsynchronous trading, a stochastic nontrading horizon is proposed so that observed returns are an infinite-order moving average of past true returns, where the coefficients are stochastic. In that framework, the waiting time for information to become fully impounded into future returns may be arbitrarily long (but with increasingly remote probability). 37In fact, if a fund allows investors to invest and withdraw capital only at prespecified intervals, imposing lockups in between, and external audits are conducted at these same prespecified intervals, then it may be argued that performance-smoothing is irrelevant. For example, no investor should be disadvantaged by investing in a fund that offers annual liquidity and engages in annual external audits with which the fund's net asset value is determined by a disinterested third party for purposes of redemptions and new investments. However, there are at least two additional concerns that remain - historical track records are still affected by smoothed returns, and estimates of a fund's illiquidity exposure are also affected-both of which are important factors in the typical hedge fund investor's overall investment process. Moreover, there is the additional concern of whether third-party auditors are truly objective and free of all conflicts of interest. 


$$
\begin{aligned}
& \operatorname{Cov}\left[R_{t}^{o}, R_{t-m}^{o}\right]= \begin{cases}\left(\sum_{j=0}^{k-m} \theta_{j} \theta_{j+m}\right) \sigma^{2} & \text { if } 0 \leq m \leq k \\
0 & \text { if } m>k\end{cases} \\
& \operatorname{Corr}\left[R_{t}^{o}, R_{t-m}^{o}\right]=\frac{\operatorname{Cov}\left[R_{t}^{o}, R_{t-m}^{o}\right]}{\operatorname{Var}\left[R_{t}^{o}\right]}= \begin{cases}\frac{\sum_{j=0}^{k-m} \theta_{j} \theta_{j+m}}{\sum_{j=0}^{k} \theta_{j}^{2}} & \text { if } 0 \leq m \leq k, \\
0 & \text { if } m>k\end{cases}
\end{aligned}
$$

where

$$
\begin{aligned}
& c_{\mu} \equiv \theta_{0}+\theta_{1}+\ldots+\theta_{k} \\
& c_{\sigma}^{2} \equiv \theta_{0}^{2}+\theta_{1}^{2}+\ldots+\theta_{k}^{2} \\
& c_{s} \equiv 1 / \sqrt{\theta_{0}^{2}+\cdots+\theta_{k}^{2}} \\
& c_{\beta, m} \equiv \theta_{m} .
\end{aligned}
$$

Proposition 1 shows that smoothed returns of the form in Equations 5.2-5.4 do not affect the expected value of $R_{t}^{o}$ but reduce its variance, hence boosting the Sharpe ratio of observed returns by a factor of $c_{s}$. Equation 5.8 shows that smoothing also affects $\beta_{0}^{o}$, the contemporaneous market beta of observed returns, biasing it toward 0 or "market neutrality," and induces correlation between current observed returns and lagged market returns up to lag $k$. This result provides a formal interpretation of the empirical analysis of Asness, Krail, and Liew (2001), in which many hedge funds were found to have significant lagged market exposure despite relatively low contemporaneous market betas.

Smoothed returns also exhibit positive serial correlation up to order $k$ according to Equation 5.10, and the magnitude of the effect is determined by the pattern of weights $\left\{\theta_{j}\right\}$. If, for example, the weights are disproportionately centered on a small number of lags, relatively little serial correlation will be induced. However, if the weights are evenly distributed among many lags, this will result in higher serial correlation. A useful summary statistic for measuring the concentration of weights is

$$
\xi \equiv \sum_{j=0}^{k} \theta_{j}^{2} \in[0,1],
$$

which is simply the denominator of Equation 5.10. This measure is well known in the industrial organization literature as the Herfindabl index, a measure of the concentration of firms in a given industry where $\theta_{j}$ represents the market share of firm $j$. Because $\theta_{j} \in[0,1], \xi$ is also confined to the unit interval and is minimized when all the $\theta_{j}$ s are identical, which implies a value of $1 /(k+1)$ for $\xi$, and is maximized when one coefficient is 1 and the rest are 0 , in which case $\xi=1$. In the context of smoothed returns, a lower value of $\xi$ implies more smoothing, and the upper bound of 1 implies no smoothing; hence, $\xi$ shall be referred to as a "smoothing index."

In the special case of equal weights, $\theta_{j}=1 /(k+1)$ for $j=0, \ldots, k$, the serial correlation of observed returns takes on a particularly simple form:

$$
\operatorname{Corr}\left[R_{t}^{o}, R_{t-m}^{o}\right]=1-\frac{m}{k+1}, 1 \leq m \leq k,
$$

which declines linearly in the lag $m$. This can yield substantial correlations even when $k$ is small-for example, if $k=2$ so that smoothing takes place only over a current quarter (i.e., this month and the previous two months), the first-order autocorrelation of monthly observed returns is 66.7 percent.

To develop a sense for just how much observed returns can differ from true returns under the smoothedreturn mechanism (Equations 5.2-5.4), let $\Delta(T)$ denote the difference between the cumulative observed and true returns over $T$ holding periods, assuming that $T>k$ :

$$
\Delta(T) \equiv\left(R_{1}^{o}+R_{2}^{o}+\ldots+R_{T}^{o}\right)-\left(R_{1}+R_{2}+\ldots+R_{T}\right)
$$




$$
=\sum_{j=0}^{k-1}\left(R_{-j}-R_{T-j}\right)\left(1-\sum_{i=0}^{j} \theta_{i}\right) .
$$

Proposition 2 (Getmansky, Lo, and Makarov 2004) Under Equations 5.2-5.4 and for $T>k$,

$$
\begin{aligned}
& \mathrm{E}[\Delta(T)]=0, \\
& \operatorname{Var}[\Delta(T)]=2 \sigma^{2} \sum_{j=0}^{k-1}\left(1-\sum_{l=0}^{j} \theta_{l}\right)^{2}=2 \sigma^{2} \zeta \\
& \zeta \equiv \sum_{j=0}^{k-1}\left(1-\sum_{l=0}^{j} \theta_{l}\right)^{2} \leq k .
\end{aligned}
$$

Proposition 2 shows that the cumulative difference between observed and true returns has 0 expected value, and its variance is bounded above by $2 k \sigma^{2}$.

To develop further intuition for the impact of smoothed returns on observed returns, Getmansky, Lo, and Makarov (2004) consider the following three specific sets of weights $\left\{\theta_{j}\right\}$ or "smoothing profiles": 38

$$
\begin{aligned}
\theta_{j} & =\frac{1}{k+1} \text { (straight-line), } \\
\theta_{j} & =\frac{k+1-j}{(k+1)(k+2) / 2} \text { (sum-of-years), } \\
\theta_{j} & =\frac{\delta^{j}(1-\delta)}{1-\delta^{k+1}}, \delta \in(0,1) \text { (geometric). }
\end{aligned}
$$

The straight-line profile weights each return equally. In contrast, the sum-of-years and geometric profiles weight the current return the most heavily and then have monotonically declining weights for lagged returns, with the sum-of-years weights declining linearly and the geometric weights declining more rapidly (see Figure 5.1).

More detailed information about the three smoothing profiles is contained in Table 5.1. The first panel reports the smoothing coefficients $\left\{\theta_{j}\right\}$, constants $c_{\beta, 0}, c_{\sigma}, c_{s}, \zeta$, and the first three autocorrelations of observed returns for the straight-line profile for $k=0,1, \ldots, 5$. Consider the case where $k=2$. Despite the relatively short smoothing period of three months, the effects are dramatic: Smoothing reduces the market beta by 67 percent, increases the Sharpe ratio by 73 percent, and induces first- and second-order serial correlations of 67 percent and 33 percent, respectively, in observed returns. Moreover, the variance of the cumulative discrepancy between observed and true returns, $2 \sigma^{2} \zeta$, is only slightly larger than the variance of monthly true returns, $\sigma^{2}$, suggesting that it may be difficult to detect this type of smoothed returns even over time.

As $k$ increases, the effects become more pronounced-for $k=5$, the market beta is reduced by 83 percent, the Sharpe ratio is increased by 145 percent, and first three autocorrelation coefficients are 83 percent, 67 percent, and 50 percent, respectively. However, in this extreme case, the variance of the discrepancy between true and observed returns is approximately three times the monthly variance of true returns, in which case it may be easier to identify smoothing from realized returns.

The sum-of-years profile is similar to, although somewhat less extreme than, the straight-line profile for the same values of $k$ because more weight is being placed on the current return. For example, even in the extreme case of $k=5$, the sum-of-years profile reduces the market beta by 71 percent, increases the Sharpe ratio by 120 percent, induces autocorrelations of 77 percent, 55 percent, and 35 percent, respectively, in the first three lags, and has a discrepancy variance that is approximately 1.6 times the monthly variance of true returns.

38 Students of accounting will recognize these profiles as commonly used methods for computing depreciation. The motivation for these depreciation schedules is not entirely without relevance in the smoothed-return context. 
Figure 5.1. Straight-Line, Sum-of-Years, and Geometric Smoothing Profiles for $k=10$

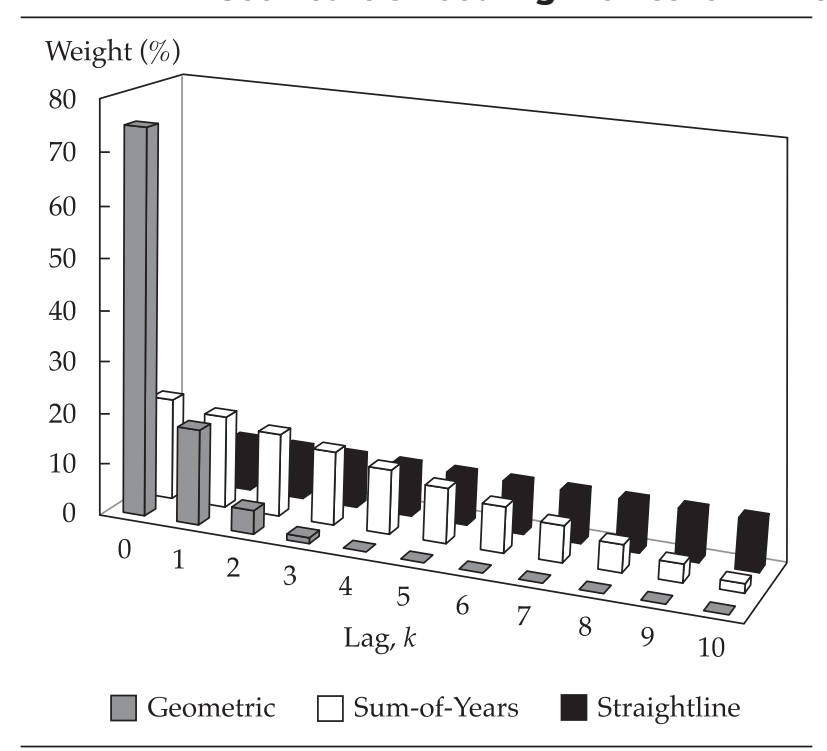

The last two panels of Table 5.1 contain results for the geometric smoothing profile for two values of $\delta$, 0.25 and 0.50 . For $\delta=0.25$, the geometric profile places more weight on the current return than the other two smoothing profiles for all values of $k$; hence, the effects tend to be less dramatic. Even in the extreme case of $k=5,75$ percent of current true returns are incorporated into observed returns, the market beta is reduced by only 25 percent, the Sharpe ratio is increased by only 29 percent, the first three autocorrelations are 25 percent, 6 percent, and 1 percent, respectively, and the discrepancy variance is approximately 13 percent of the monthly variance of true returns. As $\delta$ increases, less weight is placed on the current observation and the effects on performance statistics become more significant. When $\delta=0.50$ and $k=5$, geometric smoothing reduces the market beta by 49 percent, increases the Sharpe ratio by 71 percent, induces autocorrelations of 50 percent, 25 percent, and 12 percent, respectively, for the first three lags, and yields a discrepancy variance that is approximately 63 percent of the monthly variance of true returns.

The results in Table 5.1 show that a rich set of biases can be generated by even simple smoothing profiles, and even the most casual empirical observation suggests that smoothed returns may be an important source of serial correlation in hedge fund returns. To address this issue directly, the next two sections propose methods for estimating the smoothing profile and adjusting performance statistics accordingly.

\section{Estimation of Smoothing Profiles}

Although the parameters of the three smoothing profiles (Equation 5.22) in the preceding section can all be easily estimated from the sample moments of fund returns (e.g., means, variances, and autocorrelations), one should be able to estimate more general forms of smoothing. Therefore, this section proposes two estimation procedures - maximum likelihood and linear regression - that place fewer restrictions on a fund's smoothing profile than the three examples above (Equation 5.22). It starts by reviewing the steps for maximum likelihood estimation of an $\mathrm{MA}(k)$ process, slightly modified to accommodate this context and constraints. To that end, define the de-meaned observed returns process, $X_{t}$, as

$$
X_{t}=R_{t}^{o}-\mu
$$

and observe that Equations 5.2-5.4 imply the following properties for $X_{t}$ :

$$
\begin{aligned}
& X_{t}=\theta_{0} \eta_{t}+\theta_{1} \eta_{t-1}+\cdots+\theta_{k} \eta_{t-k}, \\
& 1=\theta_{0}+\theta_{1}+\cdots+\theta_{k}, \\
& \eta_{k} \sim \mathcal{N}\left(0, \sigma_{\eta}^{2}\right) .
\end{aligned}
$$


Table 5.1. Implications of Smoothing Profiles for Performance Statistics

\begin{tabular}{|c|c|c|c|c|c|c|c|c|c|c|c|c|c|c|c|}
\hline$k$ & $\begin{array}{c}\theta_{0} \\
(\%)\end{array}$ & $\begin{array}{c}\theta_{1} \\
(\%)\end{array}$ & $\begin{array}{c}\theta_{2} \\
(\%) \\
\end{array}$ & $\begin{array}{c}\theta_{3} \\
(\%)\end{array}$ & $\begin{array}{c}\theta_{4} \\
(\%) \\
\end{array}$ & $\begin{array}{c}\theta_{5} \\
(\%)\end{array}$ & $c_{\beta}$ & $c_{\sigma}$ & $c_{\mathrm{s}}$ & $\begin{array}{l}\rho_{1}^{0} \\
(\%)\end{array}$ & $\begin{array}{l}\rho_{2}^{0} \\
(\%)\end{array}$ & $\begin{array}{l}\rho_{3}^{0} \\
(\%)\end{array}$ & $\begin{array}{l}\rho_{4}^{0} \\
(\%)\end{array}$ & $\begin{array}{l}\rho_{5}^{0} \\
(\%)\end{array}$ & $\begin{array}{c}\zeta \\
(\%)\end{array}$ \\
\hline \multicolumn{16}{|c|}{ Straight-line smoothing } \\
\hline 0 & 100.0 & - & - & - & - & - & 1.00 & 1.00 & 1.00 & 0.0 & 0.0 & 0.0 & 0.0 & 0.0 & - \\
\hline 1 & 50.0 & 50.0 & - & - & - & - & 0.50 & 0.71 & 1.41 & 50.0 & 0.0 & 0.0 & 0.0 & 0.0 & 25.0 \\
\hline 2 & 33.3 & 33.3 & 33.3 & - & - & - & 0.33 & 0.58 & 1.73 & 66.7 & 33.3 & 0.0 & 0.0 & 0.0 & 55.6 \\
\hline 3 & 25.0 & 25.0 & 25.0 & 25.0 & - & - & 0.25 & 0.50 & 2.00 & 75.0 & 50.0 & 25.0 & 0.0 & 0.0 & 87.5 \\
\hline 4 & 20.0 & 20.0 & 20.0 & 20.0 & 20.0 & - & 0.20 & 0.45 & 2.24 & 80.0 & 60.0 & 40.0 & 20.0 & 0.0 & 120.0 \\
\hline 5 & 16.7 & 16.7 & 16.7 & 16.7 & 16.7 & 16.7 & 0.17 & 0.41 & 2.45 & 83.3 & 66.7 & 50.0 & 33.3 & 16.7 & 152.8 \\
\hline \multicolumn{16}{|c|}{ Sum-of-years smoothing } \\
\hline 0 & 100.0 & - & - & - & - & - & 1.00 & 1.00 & 1.00 & 0.0 & 0.0 & 0.0 & 0.0 & 0.0 & - \\
\hline 1 & 66.7 & 33.3 & - & - & - & - & 0.67 & 0.75 & 1.34 & 40.0 & 0.0 & 0.0 & 0.0 & 0.0 & 11.1 \\
\hline 2 & 50.0 & 33.3 & 16.7 & - & - & - & 0.50 & 0.62 & 1.60 & 57.1 & 21.4 & 0.0 & 0.0 & 0.0 & 27.8 \\
\hline 3 & 40.0 & 30.0 & 20.0 & 10.0 & - & 一 & 0.40 & 0.55 & 1.83 & 66.7 & 36.7 & 13.3 & 0.0 & 0.0 & 46.0 \\
\hline 4 & 33.3 & 26.7 & 20.0 & 13.3 & 6.7 & - & 0.33 & 0.49 & 2.02 & 72.7 & 47.3 & 25.5 & 9.1 & 0.0 & 64.9 \\
\hline 5 & 28.6 & 23.8 & 19.0 & 14.3 & 9.5 & 4.8 & 0.29 & 0.45 & 2.20 & 76.9 & 54.9 & 35.2 & 18.7 & 6.6 & 84.1 \\
\hline \multicolumn{16}{|c|}{ Geometric smoothing $(\delta=0.25)$} \\
\hline 0 & 100.0 & - & - & - & - & - & 1.00 & 1.00 & 1.00 & 0.0 & 0.0 & 0.0 & 0.0 & 0.0 & - \\
\hline 1 & 80.0 & 20.0 & - & - & - & - & 0.80 & 0.82 & 1.21 & 23.5 & 0.0 & 0.0 & 0.0 & 0.0 & 4.0 \\
\hline 2 & 76.2 & 19.0 & 4.8 & - & - & - & 0.76 & 0.79 & 1.27 & 24.9 & 5.9 & 0.0 & 0.0 & 0.0 & 5.9 \\
\hline 3 & 75.3 & 18.8 & 4.7 & 1.2 & - & - & 0.75 & 0.78 & 1.29 & 25.0 & 6.2 & 1.5 & 0.0 & 0.0 & 6.5 \\
\hline 4 & 75.1 & 18.8 & 4.7 & 1.2 & 0.3 & - & 0.75 & 0.78 & 1.29 & 25.0 & 6.2 & 1.6 & 0.4 & 0.0 & 6.6 \\
\hline 5 & 75.0 & 18.8 & 4.7 & 1.2 & 0.3 & 0.1 & 0.75 & 0.77 & 1.29 & 25.0 & 6.2 & 1.6 & 0.4 & 0.1 & 6.7 \\
\hline \multicolumn{16}{|c|}{ Geometric smoothing $(\delta=0.50)$} \\
\hline 0 & 100.0 & - & - & - & - & - & 1.00 & 1.00 & 1.00 & 0.0 & 0.0 & 0.0 & 0.0 & 0.0 & - \\
\hline 1 & 66.7 & 33.3 & - & - & - & - & 0.67 & 0.75 & 1.34 & 40.0 & 0.0 & 0.0 & 0.0 & 0.0 & 11.1 \\
\hline 2 & 57.1 & 28.6 & 14.3 & - & - & - & 0.57 & 0.65 & 1.53 & 47.6 & 19.0 & 0.0 & 0.0 & 0.0 & 20.4 \\
\hline 3 & 53.3 & 26.7 & 13.3 & 6.7 & - & - & 0.53 & 0.61 & 1.63 & 49.4 & 23.5 & 9.4 & 0.0 & 0.0 & 26.2 \\
\hline 4 & 51.6 & 25.8 & 12.9 & 6.5 & 3.2 & - & 0.52 & 0.60 & 1.68 & 49.9 & 24.6 & 11.7 & 4.7 & 0.0 & 29.6 \\
\hline 5 & 50.8 & 25.4 & 12.7 & 6.3 & 3.2 & 1.6 & 0.51 & 0.59 & 1.71 & 50.0 & 24.9 & 12.3 & 5.9 & 2.3 & 31.4 \\
\hline
\end{tabular}

Note: Implications of three different smoothing profiles for observed betas, standard deviations, Sharpe ratios, and serial correlation coefficients for a fund with IID true returns. Straight-line smoothing is given by $\theta_{j}=1 /(k+1)$; sum-of-years smoothing is given by $\theta_{j}=$ $(k+1-j) /[(k+1)(k+2) / 2]$; geometric smoothing is given by $\theta_{j}=\delta^{j}(1-\delta) /\left(1-\delta^{k+1}\right)$. The variables $c_{\beta}, c_{\sigma}$, and $c_{s}$ denote multipliers associated with the beta, standard deviation, and Sharpe ratio of observed returns, respectively, $\rho_{j}^{o}$ denotes the $j$ th autocorrelation coefficient of observed returns, and $\zeta$ is proportional to the variance of the discrepancy between true and observed multiperiod returns.

where, for purposes of estimation, the parametric assumption (Equation 5.26) that $\eta_{k}$ is normally distributed has been added. From Equation 5.24, it is apparent that $X_{t}$ is a moving-average process of order $k$, or an "MA(k)." For a given set of observations $\mathbf{X} \equiv\left[\mathrm{X}_{1} \ldots X_{T}\right]$ ', the likelihood function is well known to be

$$
\mathcal{L}\left(\boldsymbol{\theta}, \sigma_{\eta}\right)=(2 \pi)^{-T / 2}(\operatorname{det} \boldsymbol{\Gamma})^{-1 / 2} \exp \left(-\frac{1}{2} \mathbf{X}^{\prime} \boldsymbol{\Gamma}^{-1} \mathbf{X}\right), \boldsymbol{\Gamma} \equiv \mathrm{E}\left[\mathbf{X} \mathbf{X}^{\prime}\right],
$$

where $\boldsymbol{\theta} \equiv\left[\begin{array}{lll}\theta_{0} & \ldots & \theta_{k}\end{array}\right]^{\prime}$ and the covariance matrix $\boldsymbol{\Gamma}$ is a function of the parameters $\boldsymbol{\theta}$ and $\sigma_{\eta}$. It can be shown that for any constant $\kappa$,

$$
\mathcal{L}\left(\kappa \boldsymbol{\theta}, \sigma_{\eta} / \kappa\right)=\mathcal{L}\left(\boldsymbol{\theta}, \sigma_{\eta}\right)
$$

therefore, an additional identification condition is required. The most common identification condition imposed in the time-series literature is the normalization $\theta_{0} \equiv 1$. However, in this context, the condition (Equation 5.25) that the MA coefficients sum to 1 is imposed-an economic restriction that smoothing takes place over only 
the most recent $k+1$ periods - and this is sufficient to identify the parameters $\boldsymbol{\theta}$ and $\sigma_{\eta}$. The likelihood function (Equation 5.27) may be then evaluated and maximized via the "innovations algorithm" of Brockwell and Davis (1991, Section 8.3), 39 and the properties of the estimator are given by the following proposition.

Proposition 3 (Getmansky, Lo, and Makarov 2004) Under the specification Equations 5.24-5.26, $X_{t}$ is invertible on the set $\left\{\boldsymbol{\theta}: \theta_{0}+\theta_{1}+\theta_{2}=1, \theta_{1}<1 / 2, \theta_{1}<1-2 \theta_{2}\right\}$, and the maximum likelibood estimator $\hat{\boldsymbol{\theta}}$ satisfies the following properties:

$$
\begin{aligned}
& 1=\hat{\theta}_{0}+\hat{\theta}_{1}+\hat{\theta}_{2}, \\
& \sqrt{T}\left(\left[\begin{array}{c}
\hat{\theta}_{1} \\
\hat{\theta}_{2}
\end{array}\right]-\left[\begin{array}{c}
\theta_{1} \\
\theta_{2}
\end{array}\right]\right) \underset{\sim}{a} \mathcal{N}\left(0, \mathbf{V}_{\theta}\right), \\
& \mathbf{V}_{\theta}=\left[\begin{array}{cc}
-\left(-1+\theta_{1}\right)\left(-1+2 \theta_{1}\right)\left(-1+\theta_{1}+2 \theta_{2}\right) & -\theta_{2}\left(-1+2 \theta_{1}\right)\left(-1+\theta_{1}+2 \theta_{2}\right) \\
-\theta_{2}\left(-1+2 \theta_{1}\right)\left(-1+\theta_{1}+2 \theta_{2}\right) & \left(-1+\theta_{1}-2\left(-1+\theta_{2}\right) \theta_{2}\right)\left(-1+\theta_{1}+2 \theta_{2}\right)
\end{array}\right] .
\end{aligned}
$$

Applying the above procedure to observed de-meaned returns produces estimates of the smoothing profile $\hat{\boldsymbol{\theta}}$ for each fund. 40 Because of the scaling property (Equation 5.28) of the $\mathrm{MA}(k)$ likelihood function, a simple procedure for obtaining estimates of the smoothing model with the normalization (Equation 5.25) is to transform estimates $(\breve{\boldsymbol{\theta}}, \breve{\sigma})$ from standard $\mathrm{MA}(k)$ estimation packages, such as SAS or RATS, by dividing each $\breve{\theta}_{i}$ by $1+\breve{\theta}_{1}+\cdots+\breve{\theta}_{k}$ and multiplying $\breve{\sigma}$ by the same factor. The likelihood function remains unchanged, but the transformed smoothing coefficients will now satisfy Equation 5.25.

Now suppose that one is willing to impose additional structure upon the return-generating process for true returns (i.e., a linear single-factor model-Equation 5.1). In that case, a simpler method for estimating the smoothing profile is available. By substituting Equation 5.1 into Equation 5.2, observed returns can be re-expressed as

$$
\begin{aligned}
& R_{t}^{o}=\mu+\beta\left(\theta_{0} \Lambda_{t}+\theta_{1} \Lambda_{t-1}+\cdots+\theta_{k} \Lambda_{t-k}\right)+u_{t}, \\
& u_{t}=\theta_{0} \varepsilon_{t}+\theta_{1} \varepsilon_{t-1}+\cdots+\theta_{k} \varepsilon_{t-k} .
\end{aligned}
$$

Suppose one estimates the following linear regression of observed returns on contemporaneous and lagged market returns:

$$
R_{t}^{o}=\mu+\gamma_{0} \Lambda_{t}+\gamma_{1} \Lambda_{t-1}+\cdots+\gamma_{k} \Lambda_{t-k}+u_{t},
$$

as in Asness, Krail, and Liew (2001). Using the normalization (Equation 5.4) from the smoothing model, one can readily obtain estimators for $\beta$ and $\left\{\theta_{j}\right\}$ :

$$
\hat{\beta}=\hat{\gamma}_{0}+\hat{\gamma}_{1}+\cdots+\hat{\gamma}_{k}, \hat{\theta}_{j}=\hat{\gamma}_{j} / \hat{\beta}
$$

Moreover, a specification check for Equations 5.32-5.33 can be performed by testing the following set of equalities:

$$
\beta=\frac{\gamma_{0}}{\theta_{0}}=\frac{\gamma_{1}}{\theta_{1}}=\cdots=\frac{\gamma_{k}}{\theta_{k}}
$$

\footnotetext{
${ }^{39}$ See Getmansky, Lo, and Makarov (2004) for further details.

40Recall from Proposition 1 that the smoothing process (Equations 5.2-5.4) does not affect the expected return (i.e., the sample mean of observed returns is a consistent estimator of the true expected return). Therefore, I may use $R_{t}^{o}-\hat{\mu}$ in place of $X_{t}$ in the estimation process without altering any of the asymptotic properties of the maximum likelihood estimator.
} 
Because of serial correlation in $u_{t}$, ordinary least-squares estimates (Equation 5.35) will not be efficient and the usual standard errors are incorrect, but the estimates are still consistent and may be a useful first approximation for identifying smoothing in hedge fund returns. ${ }^{41}$

There is yet another variation of the linear single-factor model that may help to disentangle the effects of illiquidity from return-smoothing. Suppose that a fund's true economic return $R_{t}$ satisfies

$$
R_{t}=\mu+\beta \Lambda_{t}+\varepsilon_{t}, \varepsilon_{t} \sim \operatorname{IID}\left(0, \sigma_{\varepsilon}^{2}\right),
$$

but instead of assuming that the common factor $\Lambda_{t}$ is IID as in Equation 5.1, let $\Lambda_{t}$ be serially correlated. While this alternative may seem to be a minor variation of the smoothing model (Equations 5.2-5.4), the difference in interpretation is significant. A serially correlated $\Lambda_{t}$ captures the fact that a fund's returns may be autocorrelated because of an illiquid common factor, even in the absence of any smoothing process such as Equations 5.2-5.4. Of course, this still begs the question of what the ultimate source of serial correlation in the common factor might be, but by combining Equation 5.37 with the smoothing process (Equations 5.2-5.4), it may be possible to distinguish between "systematic" and "idiosyncratic" smoothing, the former attributable to the asset class and the latter resulting from fund-specific characteristics.

To see why the combination of Equation 5.37 and Equations 5.2-5.4 may have different implications for observed returns, suppose for the moment that there is no smoothing (i.e., $\theta_{0}=1$ and $\theta_{k}=0$ for $k>0$ in Equations 5.2-5.4). Then observed returns are simply given by

$$
R_{t}^{o}=\mu+\beta \Lambda_{t}+\varepsilon_{t}, \varepsilon_{t} \sim \operatorname{IID}\left(0, \sigma_{\varepsilon}^{2}\right),
$$

where $R_{t}^{o}$ is now serially correlated solely through $\Lambda_{t}$. This specification implies that the ratios of observed return autocovariances will be identical across all funds with the same common factor:

$$
\frac{\operatorname{Cov}\left[R_{t}^{o}, R_{t-k}^{o}\right]}{\operatorname{Cov}\left[R_{t}^{o}, R_{t-l}^{o}\right]}=\frac{\beta \operatorname{Cov}\left[\Lambda_{t}, \Lambda_{t-k}\right]}{\beta \operatorname{Cov}\left[\Lambda_{t}, \Lambda_{t-l}\right]}=\frac{\operatorname{Cov}\left[\Lambda_{t}, \Lambda_{t-k}\right]}{\operatorname{Cov}\left[\Lambda_{t}, \Lambda_{t-l}\right]}
$$

Moreover, Equation 5.37 implies that in the regression Equation 5.34, the coefficients of the lagged factor returns are zero and the error term is not serially correlated.

More generally, consider the combination of a serially correlated common factor (Equation 5.37) and smoothed returns (Equations 5.2-5.4). This more general econometric model of observed returns implies that the appropriate specification of the regression equation is

$$
\begin{aligned}
& R_{t}^{o}=\mu+\gamma_{0} \Lambda_{t}+\gamma_{1} \Lambda_{t-1}+\cdots+\gamma_{k} \Lambda_{t-k}+u_{t}, \\
& u_{t}=\theta_{0} \varepsilon_{t}+\theta_{1} \varepsilon_{t-1}+\cdots+\theta_{k} \varepsilon_{t-k}, \varepsilon_{t} \sim \operatorname{IID}\left(0, \sigma_{\varepsilon}^{2}\right), \\
& 1=\theta_{0}+\theta_{1}+\cdots+\theta_{k} .
\end{aligned}
$$

To the extent that serial correlation in $R_{t}^{o}$ can be explained mainly by the common factor, the lagged coefficient estimates of Equation 5.40 will be statistically insignificant, the residuals will be serially uncorrelated, and the ratios of autocovariance coefficients will be roughly constant across funds with the same common factor. To the extent that the smoothing process (Equations 5.2-5.4) is responsible for serial correlation in $R_{t}^{o}$ the lagged coefficient estimates of Equation 5.40 will be significant, the residuals will be serially correlated, and the ratios $\hat{\gamma}_{j} / \hat{\theta}_{j}$ will be roughly the same for all $j \geq 0$ and will be a consistent estimate of the factor loading or beta of the fund's true economic returns with respect to the factor $\Lambda_{t}$.

Perhaps the most difficult challenge in estimating Equations 5.40-5.42 is to correctly identify the common factor $\Lambda_{t}$. Unlike a simple market-model regression that is meant to estimate the sensitivity of a fund's returns to a broad-based market index, the ability to distinguish between the effects of systematic illiquidity and

${ }^{41}$ To obtain efficient estimates of the smoothing coefficients, a procedure like the maximum likelihood estimator described in this section must be used. 
idiosyncratic return-smoothing via Equation 5.40 relies heavily on the correct specification of the common factor. Using a common factor in Equation 5.40 that is highly serially correlated but not the appropriate factor for a given fund may yield misleading estimates for the degree of smoothing in that fund's observed returns. Therefore, the common factor $\Lambda_{t}$ must be selected or constructed carefully to match the specific risk exposures of the fund, and the parameter estimates of Equation 5.40 must be interpreted cautiously and with several specific alternative hypotheses at hand. 42

The choice between maximum likelihood and linear regression analysis depends primarily on the plausibility of the assumptions required by each approach. Maximum likelihood estimation has a number of attractive statistical properties like consistency and asymptotic normality under certain regularity conditions, but it may not perform well in small samples or when the underlying distribution of true returns is not normal, as hypothesized. 43 Moreover, even if normality is satisfied and a sufficient sample size is available, the proposed smoothing model (Equations 5.2-5.4) may simply not apply to some of the funds in this sample. Therefore, Getmansky, Lo, and Makarov (2004) have proposed several "specification checks" to assess the validity of the maximum likelihood estimation procedure. On the other hand, linear regression analysis is not without its own limitations, the most significant being the assumption of a linear factor model for the return-generating process. While such models are the basis of the most popular financial paradigms - the Capital Asset Pricing Model and the Arbitrage Pricing Theory - they clearly do not apply as readily to hedge fund returns, as the examples of Chapter 3 have shown. Therefore, both estimation procedures have advantages and disadvantages that must be weighed against each other on a case-by-case basis. For practical purposes, it may be best to use both techniques and compare the two sets of results as a final robustness check.

\section{Smoothing-Adjusted Sharpe Ratios}

One of the main implications of smoothed returns is that Sharpe ratios are biased upward, in some cases substantially (see Proposition 1, above). ${ }^{44}$ The mechanism by which this bias occurs is the reduction in volatility because of the smoothing process, but there is an additional bias that occurs when monthly Sharpe ratios are annualized by multiplying by $\sqrt{12}$. If monthly returns are independently and identically distributed, this is the correct procedure, but Lo (2002) shows that for non-IID returns, an alternative procedure must be used-one that accounts for serial correlation in returns in a very specific manner. ${ }^{45}$

Specifically, let $R_{t}(q)$ denote the following $q$-period return:

$$
R_{t}(q) \equiv R_{t}+R_{t-1}+\cdots+R_{t-q+1},
$$

where the effects of compounding are ignored for computational convenience. 46 For IID returns, the variance of $R_{t}(q)$ is directly proportional to $q$; hence, the Sharpe ratio satisfies the simple relation

$$
\operatorname{SR}(q)=\frac{\mathrm{E}\left[R_{t}(q)\right]-R_{f}(q)}{\sqrt{\operatorname{Var}\left[R_{t}(q)\right]}}=\frac{q\left(\mu-R_{f}\right)}{\sqrt{q} \sigma}=\sqrt{q} \mathrm{SR} .
$$

42 See Getmansky, Lo, and Makarov (2004, Section 6.4) for an empirical example that highlights the pitfalls and opportunities of the common factor specification (Equations 5.40-5.42).

43 In fact, there is substantial evidence that financial asset returns are not normally distributed but characterized by skewness, leptokurtosis, and other non-Gaussian properties (see, for example, Lo and MacKinlay 1999). Given the dynamic nature of hedge fund strategies, it would be even less plausible for their returns to be normally distributed.

44There are a number of other concerns regarding the use and interpretation of Sharpe ratios in the context of hedge funds. See Agarwal and Naik (2000a, 2004); Goetzmann, Ingersoll, Spiegel, and Welch (2002); Lo (2001); Sharpe (1994); Spurgin (2001); and Weisman (2002) for examples in which Sharpe ratios can be misleading indicators of the true risk-adjusted performance of hedge fund strategies and for alternate methods of constructing optimal portfolios of hedge funds.

45See also Jobson and Korkie (1981), who were perhaps the first to derive rigorous statistical properties of performance measures such as the Sharpe ratio and the Treynor measure.

${ }^{46}$ The exact expression is, of course, $R_{t}(q) \equiv \prod_{j=0}^{q-1}\left(1+R_{t-j}\right)-1$. For most (but not all) applications, Equation 5.43 is an excellent approximation. Alternatively, if $R_{t}$ is defined to be the continuously compounded return [i.e., $R_{t} \equiv \log \left(P_{t} / P_{t-1}\right)$, where $P_{t}$ is the price or net asset value at time $t$, then Equation 5.43 is exact. 
Using Hansen's (1982) generalized method of moments (GMM) estimator, Lo (2002) derives the asymptotic distribution of $\widehat{\mathrm{SR}}(q)$ as

$$
\sqrt{T}(\widehat{\mathrm{SR}}(q)-\sqrt{q} \mathrm{SR}) \underset{\sim}{a} \mathcal{N}\left(0, V_{\mathrm{IID}}(q)\right), V_{\mathrm{IID}}(q)=q V_{\mathrm{IID}}=q\left(1+\frac{1}{2} \mathrm{SR}^{2}\right) .
$$

For non-IID returns, the relation between $\mathrm{SR}$ and $\mathrm{SR}(q)$ is somewhat more involved because the variance of $R_{t}(q)$ is not just the sum of the variances of component returns but also includes all the covariances. Specifically, under the assumption that returns $\left\{R_{t}\right\}$ are stationary,

$$
\operatorname{Var}\left[R_{t}(q)\right]=\sum_{i=0}^{q-1} \sum_{j=0}^{q-1} \operatorname{Cov}\left[R_{t-i,} R_{t-j}\right]=q \sigma^{2}+2 \sigma^{2} \sum_{k=1}^{q-1}(q-k) \rho_{k},
$$

where $\rho_{k} \equiv \operatorname{Cov}\left[R_{t}, R_{t-k}\right] / \operatorname{Var}\left[R_{t}\right]$. This yields the following relation between $\operatorname{SR}$ and $\operatorname{SR}(q)$ :

$$
\operatorname{SR}(q)=\eta(q) \operatorname{SR}, \eta(q) \equiv \frac{q}{\sqrt{q+2 \sum_{k=1}^{q-1}(q-k) \rho_{k}}} .
$$

Note that Equation 5.47 reduces to Equation 5.44 if the autocorrelations $\left\{\rho_{k}\right\}$ are zero, as in the case of IID returns. However, for non-IID returns, the adjustment factor for time-aggregated Sharpe ratios is generally not $\sqrt{q}$ but a function of the first $q-1$ autocorrelations of returns, which is readily estimated from the sample autocorrelations of returns; hence,

$$
\widehat{\mathrm{SR}}(q)=\hat{\eta}(q) \widehat{\mathrm{SR}}, \hat{\eta}(q) \equiv \frac{q}{\sqrt{q+2 \sum_{k=1}^{q-1}(q-k) \hat{\rho}_{k}}},
$$

where $\hat{\rho}_{k}$ is the sample $k$ th-order autocorrelation coefficient.

Lo (2002) also derives the asymptotic distribution of Equation 5.48 under fairly general assumptions for the returns process (stationarity and ergodicity) using GMM (Lo 2002). However, in the context of hedge fund returns, the usual asymptotic approximations may not be satisfactory because of the small sample sizes that characterize hedge fund data - a five-year track record, which amounts to only 60 monthly observations, is considered quite a long history in this fast-paced industry. Therefore, Getmansky, Lo, and Makarov (2004) derive an alternate asymptotic distribution using the continuous record asymptotics of Richardson and Stock (1989). Specifically, as the sample size $T$ increases without bound, let $q$ grow as well so that the ratio converges to some finite limit between 0 and 1 :

$$
\lim _{q, T \rightarrow \infty} q / T=\tau \in(0,1)
$$

This condition is meant to provide an asymptotic approximation that may be more accurate for small-sample situations (i.e., situations where $q$ is a significant fraction of $T$ ). For example, in the case of a fund with a fiveyear track record, computing an annual Sharpe ratio with monthly data corresponds to a value of 0.20 for the ratio $q / T$.

Now, as $q$ increases without bound, $\operatorname{SR}(q)$ also tends to infinity; hence, it must be renormalized to obtain a well-defined asymptotic sampling theory. In particular, observe that

$$
\begin{aligned}
& \operatorname{SR}(q)=\frac{\mathrm{E}\left[R_{t}(q)\right]-R_{f}(q)}{\sqrt{\operatorname{Var}\left[R_{t}(q)\right]}}=\frac{q\left(\mu-R_{f}\right)}{\sqrt{\operatorname{Var}\left[R_{t}(q)\right]}}, \\
& \operatorname{SR}(q) / \sqrt{q}=\frac{\mu-R_{f}}{\sqrt{\operatorname{Var}\left[R_{t}(q)\right] / q}},
\end{aligned}
$$




$$
\lim _{q \rightarrow \infty} \operatorname{SR}(q) / \sqrt{q}=\frac{\mu-R_{f}}{\bar{\sigma}}
$$

where $\bar{\sigma}$ can be viewed as a kind of long-run average return standard deviation, which is generally not identical to the unconditional standard deviation $\sigma$ of monthly returns, except in the IID case. To estimate $\bar{\sigma}$, one can either follow Lo (2002) and use sample autocorrelations, as in Equation 5.48, or estimate $\bar{\sigma}$ directly accordingly to Newey and West (1987):

$$
\hat{\bar{\sigma}}_{\mathrm{NW}}^{2} \equiv \frac{1}{T} \sum_{1}^{T}\left(R_{t}-\hat{\mu}\right)^{2}+\frac{2}{T} \sum_{j=1}^{m}\left(1-\frac{j}{m+1}\right) \sum_{t=j+1}^{T}\left(R_{t}-\hat{\mu}\right)\left(R_{t-j}-\hat{\mu}\right),
$$

where $\hat{\mu}$ is the sample mean of $\left\{R_{t}\right\}$. This estimator of $\bar{\sigma}$ leads to the following asymptotic result.

Proposition 4 (Getmansky, Lo, and Makarov 2004) As $m$ and $T$ increase without bound so that $m / T \rightarrow$ $\lambda \in(0,1), \hat{\sigma}_{N W}^{2}$ converges weakly to the following functional $f(W)$ of standard Brownian motion on $[0,1]: 47$

$$
\begin{aligned}
f(W) \equiv & \frac{2 \bar{\sigma}^{2}}{\lambda}\left(\int_{0}^{1} W(r)[W(r)-W(\operatorname{Min}(r+\lambda, 1))] d r\right. \\
& \left.-W(1) \int_{0}^{\lambda}(\lambda-r)(W(1-r)-W(r)) d r+\frac{\lambda\left(1-\lambda^{2} / 3\right)}{2} W^{2}(1)\right) .
\end{aligned}
$$

From Equation 5.54, a straightforward computation yields the following expectations:

$$
\mathrm{E}\left[\hat{\bar{\sigma}}_{\mathrm{NW}}^{2}\right]=1-\lambda+\frac{\lambda^{2}}{3}, \mathrm{E}\left[1 / \hat{\bar{\sigma}}_{\mathrm{NW}}\right] \approx \sqrt{\frac{1+\lambda}{1-\lambda+\lambda^{2} / 3}}
$$

hence, the following bias-corrected estimator for the Sharpe ratio is proposed for small samples:

$$
\widehat{\operatorname{SR}}(q)=\frac{\sqrt{q}\left(\hat{\mu}-R_{f}\right)}{\hat{\bar{\sigma}}_{\mathrm{NW}}} \sqrt{\frac{1-\lambda+\lambda^{3} / 2}{1+\lambda}},
$$

and its asymptotic distribution is given by the following proposition.

Proposition 5 (Getmansky, Lo, and Makarov 2004) As $m$, $q$, and T increase without bound so that $m / T \rightarrow$ $\lambda \in(0,1)$ and $q / T \rightarrow \tau \in(0,1)$, the Sharpe ratio estimator $\widehat{\mathrm{SR}}(q)$ converges weakly to the following random variable:

$$
\widehat{\mathrm{SR}}(q) \Rightarrow\left(\frac{\mathrm{SR}(q)}{f(W)}+\frac{\sqrt{\tau} W(1)}{f(W)}\right) \sqrt{\frac{1-\lambda+\lambda^{3} / 2}{1+\lambda}},
$$

where $f(W)$ is given by Equation 5.54, SR $(q)$ is given by Equation 5.50, and $W(\cdot)$ is standard Brownian motion defined on $[0,1]$.

Monte Carlo simulations show that the second term of Equation 5.57 does not account for much bias when $\tau \in[0,1 / 2]$, and that Equation 5.57 is an excellent approximation to the small-sample distributions of Sharpe ratios for non-IID returns. 48

\footnotetext{
47 See Billingsley (1968) for the definition of weak convergence and related results.

${ }^{48}$ Getmansky, Lo, and Makarov (2004) have tabulated the percentiles of the distribution of Equation 5.57 by Monte Carlo simulation for an extensive combination of values of $q$, $\tau$, and $\lambda$ and have offered to provide them to interested readers upon request.
} 


\section{Empirical Analysis of Smoothing and Illiquidity}

Using the method of maximum likelihood, Getmansky, Lo, and Makarov (2004) estimate the smoothing model (Equations 5.2-5.4) by estimating an $\mathrm{MA}(2)$ process for observed returns assuming normally distributed errors, with the additional constraint that the MA coefficients sum to 1,49 and the same procedure is applied here to the updated and enlarged sample of funds in the TASS Combined hedge fund database from February 1977 to August 2004. For purposes of estimating Equation 5.2, an additional filter is imposed on the data, eliminating funds with less than five years of nonmissing monthly returns. This leaves a sample of 1,840 funds for which the MA(2) smoothing model is estimated. The maximum likelihood estimation procedure did not converge for three of these funds, indicating some sort of misspecification or data errors; hence, there are results for 1,837 funds. 50 Table 5.2 contains summary statistics for maximum likelihood estimates of the smoothing parameters $\left(\theta_{0}, \theta_{1}, \theta_{2}\right)$ and smoothing index $\xi$, and Table 5.3 presents the maximum likelihood estimates of the smoothing model for the 50 most illiquid funds of the 1,837 funds, as ranked by $\hat{\theta}_{0}$.

Table 5.2 shows that three categories seem to exhibit smaller average values of $\hat{\theta}_{0}$ than the restConvertible Arbitrage (0.719), Event Driven (0.786), and Fixed-Income Arbitrage (0.775). Consider, in particular, the Convertible Arbitrage category, which has a mean of 0.719 for $\hat{\theta}_{0}$. This is, of course, the average across all 79 funds in this category, but if it were the point estimate of a given fund, it would imply that only 71.9 percent of that fund's true current monthly return would be reported, with the remaining 28.1 percent distributed over the next two months (recall the constraint that $\hat{\theta}_{0}+\hat{\theta}_{1}+\hat{\theta}_{2}=1$ ). The estimates 0.201 and 0.080 for $\hat{\theta}_{1}$ and $\hat{\theta}_{2}$ imply that on average, the current reported return also includes 20 percent of last month's true return and 8 percent of the true return two months ago. 51

To develop a more formal statistical sense of the significance of these average values of $\hat{\theta}_{0}$, one can compute a $z$-statistic for the null hypothesis that the expected value of $\hat{\theta}_{0}$ is 1 by dividing the difference between 1 and each mean by its corresponding standard error, which can be approximated by the crosssectional standard deviation divided by the square root of the number of funds in the average, assuming that

Table 5.2. Summary Statistics for Maximum Likelihood Estimate of Smoothing Parameters $\left(\theta_{0}, \theta_{1}, \theta_{2}\right)$ and Smoothing Index $\xi$

\begin{tabular}{|c|c|c|c|c|c|c|c|c|c|c|}
\hline \multirow[b]{3}{*}{ Category } & \multirow{3}{*}{$\begin{array}{l}\text { No. of } \\
\text { Funds }\end{array}$} & \multicolumn{6}{|c|}{ MA(2) Coefficient Estimates } & & & \multirow{3}{*}{$\begin{array}{c}\text { Test Statistic } \\
z\left(\theta_{0}\right) \text { for } H: \\
\theta_{0}=1\end{array}$} \\
\hline & & \multicolumn{2}{|c|}{$\theta_{0}$} & \multicolumn{2}{|c|}{$\theta_{1}$} & \multicolumn{2}{|c|}{$\theta_{2}$} & \multicolumn{2}{|c|}{$\xi$} & \\
\hline & & Mean & $\mathrm{SD}$ & Mean & $\mathrm{SD}$ & Mean & $\mathrm{SD}$ & Mean & $\mathrm{SD}$ & \\
\hline Convert. Arb. & 79 & 0.719 & 0.161 & 0.201 & 0.148 & 0.080 & 0.101 & 0.621 & 0.327 & 15.558 \\
\hline Dedicated Shortseller & 16 & 1.070 & 0.484 & 0.045 & 0.166 & -0.115 & 0.331 & 1.508 & 2.254 & -0.579 \\
\hline Emerging Mkts. & 136 & 0.836 & 0.145 & 0.146 & 0.098 & 0.018 & 0.106 & 0.762 & 0.285 & 13.179 \\
\hline Equity Mkt. Neutral & 65 & 0.891 & 0.203 & 0.047 & 0.189 & 0.062 & 0.138 & 0.895 & 0.396 & 4.326 \\
\hline Event Driven & 183 & 0.786 & 0.143 & 0.158 & 0.105 & 0.056 & 0.102 & 0.687 & 0.235 & 20.307 \\
\hline Fixed-Income Arb. & 65 & 0.775 & 0.169 & 0.147 & 0.104 & 0.078 & 0.120 & 0.682 & 0.272 & 10.714 \\
\hline Global Macro & 88 & 0.999 & 0.202 & 0.047 & 0.161 & -0.047 & 0.147 & 1.090 & 0.501 & 0.036 \\
\hline Long/Short Equity & 532 & 0.880 & 0.179 & 0.092 & 0.125 & 0.028 & 0.142 & 0.851 & 0.398 & 15.453 \\
\hline Managed Futures & 230 & 1.112 & 0.266 & -0.032 & 0.193 & -0.080 & 0.162 & 1.379 & 0.942 & -6.406 \\
\hline Multi-Strategy & 47 & 0.805 & 0.157 & 0.113 & 0.128 & 0.082 & 0.076 & 0.713 & 0.270 & 8.503 \\
\hline Fund of Funds & 396 & 0.874 & 0.638 & 0.102 & 0.378 & 0.024 & 0.292 & 1.409 & 10.917 & 3.931 \\
\hline All & 1,837 & 0.890 & 0.357 & 0.092 & 0.223 & 0.017 & 0.188 & 1.014 & 5.096 & \\
\hline
\end{tabular}

Notes: Means and standard deviations of maximum likelihood estimates of MA(2) smoothing process $R_{t}^{o}=\theta_{0} R_{t}+\theta_{1} R_{t-1}+\theta_{2} R_{t-2}$, subject to the normalization $1=\theta_{0}+\theta_{1}+\theta_{2}$, where $\xi \equiv \theta_{0}^{2}+\theta_{1}^{2}+\theta_{2}^{2}$, for 1,837 hedge funds in the TASS Combined database with at least five years of returns history during the period from February 1977 to August 2004.

${ }^{49}$ However, I do not impose the constraint that $\theta_{i} \in[0,1]$ so as to obtain an indication of potential misspecification (i.e., estimates that fall outside the unit interval). See Getmansky, Lo, and Makarov (2004, Section 5.3) for additional specification tests of their smoothing model. 50The reference numbers for the funds that did not yield maximum likelihood estimates are 1018, 1405, and 4201.

51 The averages do not always sum to 1 exactly because of rounding errors. 
Table 5.3. Maximum Likelihood Estimates of the Smoothing Model for the 50 Most Illiquid Funds

\begin{tabular}{|c|c|c|c|c|c|c|c|c|c|}
\hline Category & Start & End & $T$ & $\theta_{0}$ & $\operatorname{SE}\left(\theta_{0}\right)$ & $\theta_{1}$ & $\operatorname{SE}\left(\theta_{1}\right)$ & $\theta_{2}$ & $\operatorname{SE}\left(\theta_{2}\right)$ \\
\hline Equity Market Neutral & Jan 1995 & Aug 2004 & 116 & 0.456 & 0.029 & 0.324 & 0.022 & 0.220 & 0.026 \\
\hline Equity Market Neutral & Jan 1995 & Aug 2004 & 116 & 0.456 & 0.029 & 0.330 & 0.022 & 0.214 & 0.026 \\
\hline Event Driven & Jan 1995 & Nov 2000 & 71 & 0.468 & 0.041 & 0.336 & 0.029 & 0.196 & 0.037 \\
\hline Long/Short Equity & Jun 1989 & Aug 1996 & 87 & 0.480 & 0.040 & 0.343 & 0.027 & 0.177 & 0.036 \\
\hline Convertible Arb. & Sep 1994 & Aug 2004 & 120 & 0.485 & 0.036 & 0.368 & 0.022 & 0.147 & 0.033 \\
\hline Fixed-Income Arb. & Jan 1995 & Jun 2001 & 78 & 0.495 & 0.033 & 0.187 & 0.034 & 0.318 & 0.029 \\
\hline Fixed-Income Arb. & Dec 1993 & May 2000 & 78 & 0.506 & 0.032 & 0.144 & 0.035 & 0.350 & 0.028 \\
\hline Convertible Arb. & Sep 1994 & Dec 2000 & 76 & 0.512 & 0.037 & 0.172 & 0.037 & 0.316 & 0.032 \\
\hline Convertible Arb. & Jan 1998 & Jan 2004 & 73 & 0.512 & 0.046 & 0.268 & 0.037 & 0.220 & 0.039 \\
\hline Emerging Markets & Aug 1998 & Aug 2004 & 73 & 0.513 & 0.049 & 0.300 & 0.035 & 0.187 & 0.042 \\
\hline Convertible Arb. & Oct 1995 & Aug 2004 & 107 & 0.516 & 0.043 & 0.336 & 0.027 & 0.148 & 0.038 \\
\hline Event Driven & Jan 1999 & Aug 2004 & 68 & 0.518 & 0.050 & 0.288 & 0.038 & 0.195 & 0.044 \\
\hline Fund of Funds & Oct 1994 & Mar 2001 & 78 & 0.526 & 0.059 & 0.442 & 0.020 & 0.032 & 0.056 \\
\hline Long/Short Equity & Oct 1995 & Aug 2004 & 107 & 0.528 & 0.046 & 0.352 & 0.027 & 0.120 & 0.041 \\
\hline Convertible Arb. & Jun 1997 & Aug 2004 & 87 & 0.532 & 0.050 & 0.321 & 0.033 & 0.146 & 0.044 \\
\hline Fund of Funds & Jan 1995 & Jan 2000 & 61 & 0.532 & 0.066 & 0.403 & 0.030 & 0.065 & 0.060 \\
\hline Fund of Funds & Jul 1999 & Aug 2004 & 62 & 0.534 & 0.061 & 0.336 & 0.038 & 0.129 & 0.054 \\
\hline Long/Short Equity & Nov 1998 & Aug 2004 & 70 & 0.536 & 0.055 & 0.302 & 0.038 & 0.162 & 0.048 \\
\hline Fund of Funds & Jan 1996 & Jan 2004 & 97 & 0.537 & 0.044 & 0.252 & 0.035 & 0.212 & 0.037 \\
\hline Long/Short Equity & Feb 1999 & Aug 2004 & 67 & 0.541 & 0.058 & 0.298 & 0.040 & 0.161 & 0.050 \\
\hline Fixed-Income Arb. & Oct 1996 & Dec 2003 & 87 & 0.541 & 0.046 & 0.226 & 0.039 & 0.232 & 0.038 \\
\hline Fund of Funds & Apr 1997 & Jan 2004 & 82 & 0.542 & 0.050 & 0.268 & 0.038 & 0.189 & 0.043 \\
\hline Event Driven & Mar 1999 & Jul 2004 & 65 & 0.543 & 0.063 & 0.356 & 0.035 & 0.101 & 0.056 \\
\hline Equity Market Neutral & Jan 1995 & Jun 2000 & 66 & 0.544 & 0.056 & 0.266 & 0.043 & 0.190 & 0.048 \\
\hline Fund of Funds & Mar 1999 & Aug 2004 & 66 & 0.544 & 0.069 & 0.445 & 0.022 & 0.011 & 0.066 \\
\hline Fixed-Income Arb. & Jul 1982 & Oct 1998 & 196 & 0.545 & 0.031 & 0.238 & 0.026 & 0.218 & 0.027 \\
\hline Fund of Funds & Jan 1999 & Jul 2004 & 67 & 0.549 & 0.064 & 0.354 & 0.036 & 0.097 & 0.056 \\
\hline Fund of Funds & Sep 1997 & Aug 2004 & 84 & 0.550 & 0.048 & 0.222 & 0.041 & 0.229 & 0.040 \\
\hline Convertible Arb. & Mar 1999 & Aug 2004 & 66 & 0.551 & 0.060 & 0.285 & 0.042 & 0.163 & 0.051 \\
\hline Convertible Arb. & Feb 1999 & Aug 2004 & 67 & 0.554 & 0.060 & 0.288 & 0.042 & 0.158 & 0.051 \\
\hline Long/Short Equity & Nov 1997 & Aug 2004 & 82 & 0.554 & 0.047 & 0.192 & 0.043 & 0.254 & 0.040 \\
\hline Fund of Funds & Jan 1997 & Sep 2003 & 81 & 0.554 & 0.055 & 0.295 & 0.038 & 0.150 & 0.047 \\
\hline Fixed-Income Arb. & Nov 1997 & Nov 2002 & 61 & 0.555 & 0.067 & 0.336 & 0.040 & 0.110 & 0.058 \\
\hline Long/Short Equity & Feb 1998 & Aug 2004 & 79 & 0.555 & 0.051 & 0.226 & 0.042 & 0.218 & 0.043 \\
\hline Multi-Strategy & Aug 1999 & Aug 2004 & 61 & 0.557 & 0.060 & 0.241 & 0.048 & 0.201 & 0.050 \\
\hline Fund of Funds & Jan 1998 & Aug 2004 & 80 & 0.558 & 0.055 & 0.266 & 0.040 & 0.175 & 0.046 \\
\hline Fund of Funds & Jan 1999 & Jul 2004 & 67 & 0.559 & 0.053 & 0.185 & 0.048 & 0.257 & 0.044 \\
\hline Fund of Funds & Jan 1999 & Jul 2004 & 67 & 0.559 & 0.062 & 0.290 & 0.043 & 0.151 & 0.053 \\
\hline Fund of Funds & Jun 1999 & Aug 2004 & 63 & 0.559 & 0.060 & 0.238 & 0.048 & 0.203 & 0.050 \\
\hline Event Driven & Dec 1997 & Aug 2004 & 81 & 0.563 & 0.064 & 0.400 & 0.028 & 0.038 & 0.058 \\
\hline Long/Short Equity & Mar 1992 & Jun 2004 & 148 & 0.565 & 0.046 & 0.359 & 0.024 & 0.076 & 0.041 \\
\hline Event Driven & Dec 1991 & Aug 2004 & 153 & 0.567 & 0.044 & 0.326 & 0.027 & 0.107 & 0.038 \\
\hline Convertible Arb. & Jul 1988 & Aug 1996 & 98 & 0.567 & 0.054 & 0.307 & 0.035 & 0.125 & 0.046 \\
\hline Fixed-Income Arb. & Mar 1999 & Aug 2004 & 66 & 0.568 & 0.059 & 0.224 & 0.048 & 0.207 & 0.049 \\
\hline Fund of Funds & Jan 1998 & Aug 2004 & 80 & 0.569 & 0.058 & 0.279 & 0.041 & 0.152 & 0.049 \\
\hline Fixed-Income Arb. & Mar 1999 & Aug 2004 & 66 & 0.569 & 0.060 & 0.225 & 0.048 & 0.207 & 0.050 \\
\hline Event Driven & Apr 1993 & Jan 1999 & 70 & 0.571 & 0.065 & 0.312 & 0.041 & 0.118 & 0.056 \\
\hline Long/Short Equity & Oct 1996 & Aug 2004 & 95 & 0.575 & 0.048 & 0.177 & 0.043 & 0.248 & 0.039 \\
\hline Fund of Funds & Oct 1995 & Jul 2004 & 106 & 0.576 & 0.049 & 0.238 & 0.038 & 0.187 & 0.041 \\
\hline Multi-Strategy & Oct 1994 & Aug 2004 & 119 & 0.579 & 0.048 & 0.249 & 0.036 & 0.172 & 0.040 \\
\hline
\end{tabular}

Notes: First 50 funds of ranked list of 1,837 hedge funds in the TASS Combined hedge fund database with at least five years of returns history during the period from February 1977 to August 2004, ranked in increasing order of the estimated smoothing parameter $\hat{\theta}_{0}$ of the MA(2) smoothing process $R_{t}^{o}=\theta_{0} R_{t}+\theta_{1} R_{t-1}+\theta_{2} R_{t-2}$, subject to the normalization $1=\theta_{0}+\theta_{1}+\theta_{2}$, and estimated via maximum likelihood.

$\mathrm{SE}=$ standard error. 
the $\hat{\theta} 0$ 's are cross-sectionally independently and identically distributed (IID). 52 Under the null hypothesis of no smoothing, the $z$-statistic is asymptotically standard normal. These $z$-statistics are reported in the last column of Table 5.2 and confirm the intuition that the categories with the lowest average $\hat{\theta}_{0}$ 's are significantly different from 1 (recall that the 99 percent critical value for a standard normal distribution is 2.33). Overall, the summary statistics in Table 5.2 are broadly consistent with common intuition about the nature of the strategies and securities involved in these fund categories, which contain the most illiquid securities and, therefore, have the most potential for smoothed returns and serial correlation.

Table 5.3 contains the smoothing parameter estimates for the top 50 funds ranked in order of increasing $\hat{\theta}_{0}$, which provides a more direct view of illiquidity and smoothed returns. In contrast to the averages of Table 5.2 , the parameter estimates of $\theta_{0}$ among these 50 funds range from 0.456 to 0.579 , implying that only onehalf to two-thirds of the current month's true returns are reflected in observed returns. The asymptotic standard errors are generally quite small, ranging from 0.029 to 0.069 ; hence, the smoothing parameters seem to be estimated reasonably precisely.

The funds in Table 5.3 fall mainly into five categories: Fund of Funds (15), Convertible Arbitrage (8), Long/Short Equity (8), Fixed-Income Arbitrage (7), and Event Driven (6). Together, these five categories account for 44 of the 50 funds in Table 5.3. A more complete summary of the distribution of smoothing parameter estimates across the different fund categories is provided in Figure 5.2, which contains a graph of the smoothing coefficients $\hat{\theta}_{0}$ by category, where 9 out of the 1,837 funds were omitted because their $\hat{\theta}_{0}$ 's were larger than 2.0 so as to preserve the resolution of the graph.

\section{Figure 5.2. Estimated Smoothing Coefficients $\hat{\boldsymbol{\theta}}_{0}$ in the Interval $[0,2]$ for 1,837 Funds in the TASS Hedge Fund Database with at Least Five Years of Returns during the Period from February 1977 to August 2004}

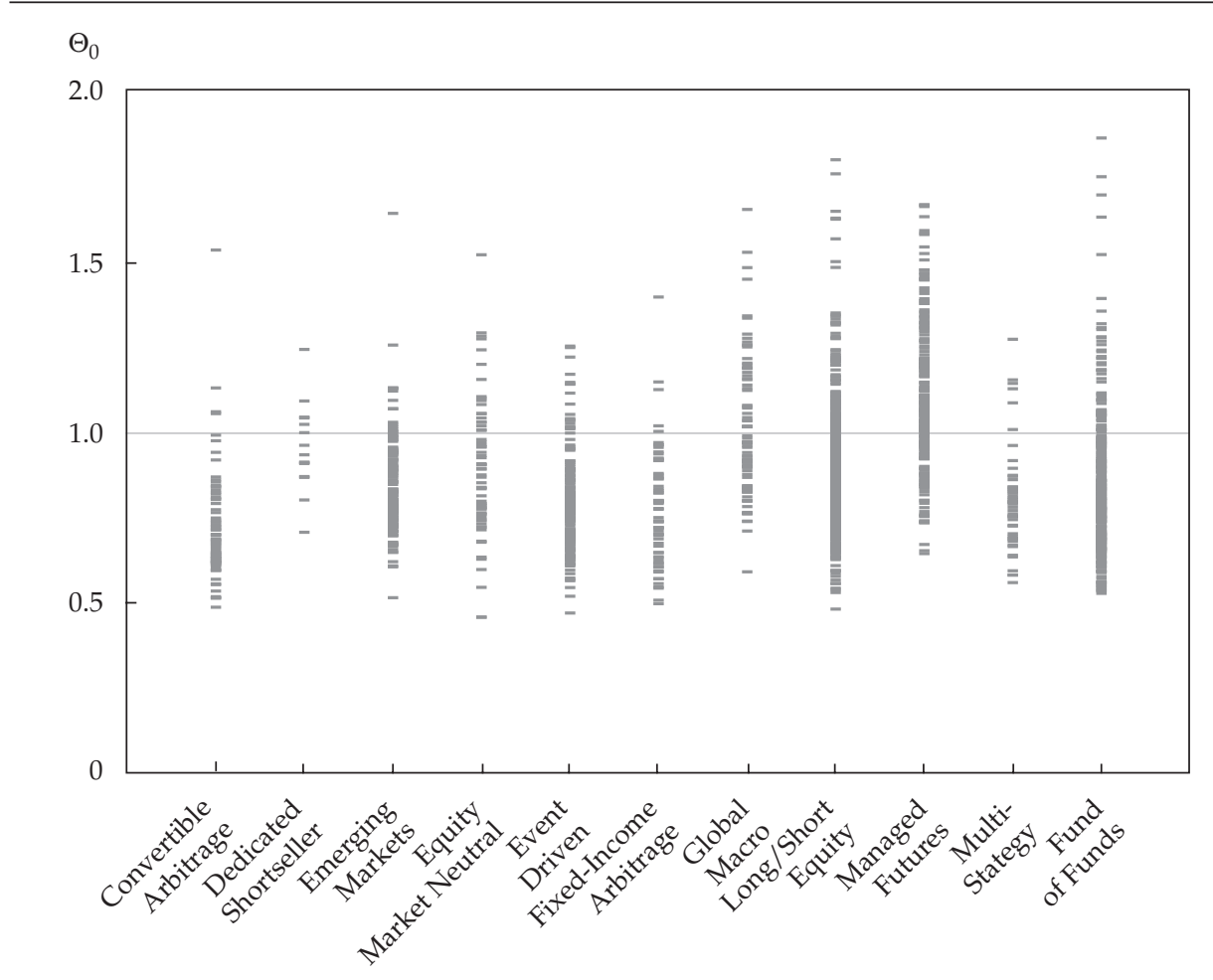

Category

Note: Of the 1,837 funds in the sample, only 9 funds yielded $\hat{\theta}_{0}$ 's greater than 2 and have been omitted to preserve the resolution of the graph.

\footnotetext{
52The IID assumption is almost surely violated in the cross section (after all, the categories are supposed to group funds by certain common characteristics), but the relative rankings of the $z$-statistics across categories may still contain useful information.
} 
This figure shows that although there is considerable variation within each category, nevertheless, some clear differences emerge between categories. For example, Convertible Arbitrage, Emerging Markets, Event Driven, Fixed-Income Arbitrage, and Multi-Strategy have clearly discernible concentrations of $\hat{\theta}_{0}$ 's that are lower than 1-and lower than the other categories—suggesting more illiquid funds and more smoothed returns. On the other hand, Dedicated Shortseller, Global Macro, and Managed Futures have concentrations that are at or above 1, suggesting just the opposite - more liquidity and less return-smoothing.

To develop further intuition for the smoothing model (Equations 5.2-5.4) and the possible interpretations of the smoothing parameter estimates, this analysis reproduces the analysis in Getmansky, Lo, and Makarov (2004), where they apply the same estimation procedure to the returns of the Ibbotson stock and bond indexes, the Merrill Lynch Convertible Securities Index, 53 the CSFB/Tremont hedge fund indexes, and two mutual funds: the highly liquid Vanguard 500 Index Fund and the considerably less liquid American Express Extra Income Fund (now called the American Express High Yield Bond Fund). 54 Table 5.4 contains summary statistics, market betas (where the market return is taken to be the S\&P 500 total return), contemporaneous and lagged market betas as in Asness, Krail, and Liew (2001), and smoothing coefficient estimates for these index and mutual fund returns. 55

Consistent with the interpretation of $\hat{\theta}_{0}$ as an indicator of liquidity, the returns of the most liquid portfolios in the first panel of Table 5.4-the Ibbotson Large Company Index, the Vanguard 500 Index Fund (which is virtually identical to the Ibbotson Large Company Index, except for sample period and tracking error), and the Ibbotson Long-Term Government Bond Index-have smoothing parameter estimates near unity: 0.92 for the Ibbotson Large Company Index, 1.12 for the Vanguard 500 Index Fund, and 0.92 for the Ibbotson Long-Term Government Bond Index. The first-order autocorrelation coefficients and lagged market betas also confirm their lack of serial correlation: 9.8 percent first-order autocorrelation for the Ibbotson Large Company Index , -2.3 percent for the Vanguard 500 Index Fund, and 6.7 percent for the Ibbotson Long-Term Government Bond Index, and lagged market betas that are statistically indistinguishable from 0 . However, the values of $\hat{\theta}_{0}$ for the less liquid portfolios are less than 1.00 ( 0.82 for the Ibbotson Small Company Index, 0.84 for the Ibbotson Long-Term Corporate Bond Index, 0.82 for the Merrill Lynch Convertible Securities Index, and 0.67 for the American Express Extra Income Fund), and their first-order serial correlation coefficients are 15.6 percent, 15.6 percent, 6.4 percent, and 35.4 percent, respectively, which, with the exception of the Merrill Lynch Convertible Securities Index, are considerably higher than those of the more liquid portfolios. ${ }^{56}$ Also, the lagged market betas are statistically significant at the 5 percent level for the Ibbotson Small Company Index ( $t$-statistic for $\left.\hat{\beta}_{1}: 5.41\right)$, the Ibbotson Long-Term Government Bond Index ( $t$-statistic for $\left.\hat{\beta}_{1}:-2.30\right)$, the Merrill Lynch Convertible Securities Index ( $t$-statistic for $\left.\hat{\beta}_{1}: 3.33\right)$, and the AXP Extra Income Fund ( $t$-statistic for $\left.\hat{\beta}_{1}: 4.64\right)$. The results for the CSFB/Tremont hedge fund indexes in the second panel of Table 5.4 are also consistent with the empirical results in Tables 5.2 and 5.3-indexes corresponding to hedge fund strategies involving less-liquid securities tend to have lower $\hat{\theta}_{0}$ 's. For example, the smoothing parameter estimates $\hat{\theta}_{0}$ of the Convertible Arbitrage, Emerging Markets, and Fixed-Income Arbitrage indexes are $0.49,0.75$, and 0.63 , respectively, and the first-order serial correlation coefficients are

53This is described by Merrill Lynch as a "market value-weighted index that tracks the daily price only, income and total return performance of corporate convertible securities, including U.S. domestic bonds, Eurobonds, preferred stocks and Liquid Yield Option Notes."

54 As of 31 January 2003, http://finance.yahoo.com/ gives the net assets of the Vanguard 500 Index Fund (ticker symbol: VFINX) and the AXP Extra Income Fund (ticker symbol: INEAX) as $\$ 59.7$ billion and $\$ 1.5$ billion, respectively, and describes the two funds as follows: "The Vanguard 500 Index Fund seeks investment results that correspond with the price and yield performance of the S\&P 500 Index. The fund employs a passive management strategy designed to track the performance of the S\&P 500 Index, which is dominated by the stocks of large U.S. companies. It attempts to replicate the target index by investing all or substantially all of its assets in the stocks that make up the index." "AXP Extra Income Fund seeks high current income; capital appreciation is secondary. The fund ordinarily invests in long-term high-yielding, lower-rated corporate bonds. These bonds may be issued by U.S. and foreign companies and governments. The fund may invest in other instruments such as: money market securities, convertible securities, preferred stocks, derivatives (such as futures, options and forward contracts), and common stocks."

55 Market betas were obtained by regressing returns on a constant and the total return of the S\&P 500, and contemporaneous and lagged market betas were obtained by regressing returns on a constant, the contemporaneous total return of the S\&P 500, and the first two lags. 56However, note that the second-order autocorrelation of the Merrill Lynch Convertible Securities Index is 12.0 percent, which is second only to the AXP Extra Income Fund in absolute magnitude, two orders of magnitude larger than the second-order autocorrelation of the Ibbotson bond indexes, and one order of magnitude larger than that of the Ibbotson stock indexes. 


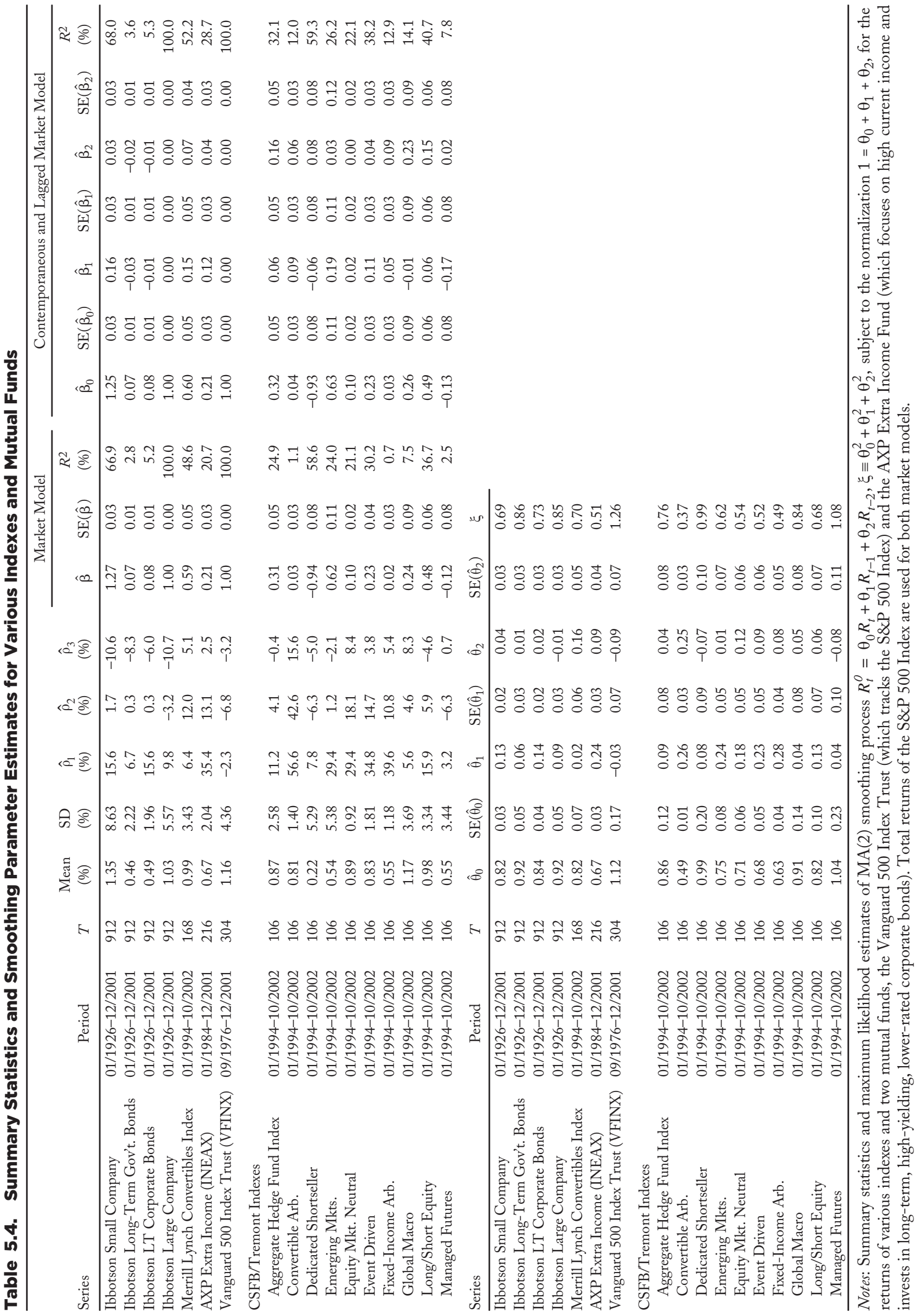


56.6 percent, 29.4 percent, and 39.6 percent, respectively. In contrast, the smoothing parameter estimates of Dedicated Shortseller and Managed Futures-more-liquid hedge fund strategies-are 0.99 and 1.04, respectively, with first-order serial correlation coefficients of 7.8 percent and 3.2 percent, respectively.

While these findings are generally consistent with the results in Tables 5.2 and 5.3, it should be noted that the process of aggregation can change the statistical behavior of any time series. For example, Granger (1980, 1988) observes that the aggregation of a large number of stationary autoregressive processes can yield a time series that exhibits long-term memory, characterized by serial correlation coefficients that decay very slowly (hyperbolically, as opposed to geometrically, as in the case of a stationary autoregressive-moving-average [ARMA] process). Therefore, while it is true that the aggregation of a collection of illiquid funds will generally yield an index with smoothed returns, 57 the reverse need not be true-smoothed index returns need not imply that all of the funds comprising the index are illiquid. The latter inference can only be made with the benefit of additional information - essentially identification restrictions - about the statistical relations among the funds in the index (i.e., covariances and possibly other higher-order co-moments, or the existence of common factors driving fund returns).

It is interesting to note that the first lagged market beta, $\hat{\beta}_{1}$, for the CSFB/Tremont indexes is statistically significant at the 5 percent level in only three cases (Convertible Arbitrage, Event Driven, and Managed Futures), but the second lagged beta, $\hat{\beta}_{2}$, is significant in five cases (the overall index, Convertible Arbitrage, Fixed Income Arbitrage, Global Macro, and Long/Short Equity). Obviously, the S\&P 500 Index is likely to be inappropriate for certain styles (e.g., Emerging Markets), and these somewhat inconsistent results suggest that using a lagged-market-beta adjustment may not completely account for the impact of illiquidity and smoothed returns.

Overall, the patterns in Table 5.4 confirm the interpretation of smoothing coefficients and serial correlation as proxies for liquidity and suggest that there may be broader applications of this model of smoothed returns to other investment strategies and asset classes.

To illustrate the potential impact of serial correlation on performance statistics such as Sharpe ratios, the serial-correlation-adjusted Sharpe ratio estimator (Equation 5.48) from the preceding section is applied to the mutual and hedge fund returns data of Table 3.10. Table $\mathbf{5 . 5}$ shows that the 10 mutual funds have very little serial correlation in returns, with $p$-values of $Q$-statistics ranging from 13.2 percent to 80.2 percent. Indeed, the largest absolute level of autocorrelation among the 10 mutual funds is the 12.4 percent first-order autocorrelation of the Fidelity Magellan Fund. Using a risk-free rate $R_{f}$ of 5 percent/12 per month, the monthly Sharpe ratios of these 10 funds range from 0.14 (Growth Fund of America) to 0.32 (Janus Worldwide), with robust standard errors of 0.05 and 0.11 , respectively. Because of the lack of serial correlation in the monthly returns of these mutual funds, there is little difference between the IID estimator for the annual Sharpe ratio, $\sqrt{q} \widehat{\mathrm{SR}}$, and the robust estimator $\widehat{\mathrm{SR}}(12)$ that accounts for serial correlation. For example, even in the case of the Fidelity Magellan Fund, which has the highest first-order autocorrelation among the 10 mutual funds, the difference between $\sqrt{q} \widehat{\mathrm{SR}}=0.73$ and $\widehat{\mathrm{SR}}(12)=0.66$ is not substantial (and certainly not statistically significant). Note that the robust estimator is marginally lower than the IID estimator, indicating the presence of positive serial correlation in the monthly returns of the Magellan Fund. In contrast, for Washington Mutual Investors, the IID estimate of the annual Sharpe ratio is $\sqrt{q} \widehat{\mathrm{SR}} \mid=0.60$, but the robust estimate $\widehat{\operatorname{SR}}(12)=0.65$ is larger, due to negative serial correlation in the fund's monthly returns (recall that negative serial correlation implies that the variance of the sum of 12 monthly returns is less than 12 times the variance of monthly returns).

The robust standard errors $\mathrm{SE}_{3}(12)$ with $m=3$ for $\widehat{\mathrm{SR}}(12)$ range from 0.17 (Janus) to 0.47 (Fidelity Growth and Income) and take on similar values when $m=6$, which indicates that the robust estimator is reasonably well behaved for this dataset. The magnitudes of the standard errors yield 95 percent confidence intervals for annual Sharpe ratios that do not contain zero for any of the 10 mutual funds. For example, the 95 percent

57 It is, of course, possible that the smoothing coefficients of some funds may exactly offset those of other funds so as to reduce the degree of smoothing in an aggregate index. However, such a possibility is extremely remote and pathological if each of the component funds exhibits a high degree of smoothing. 


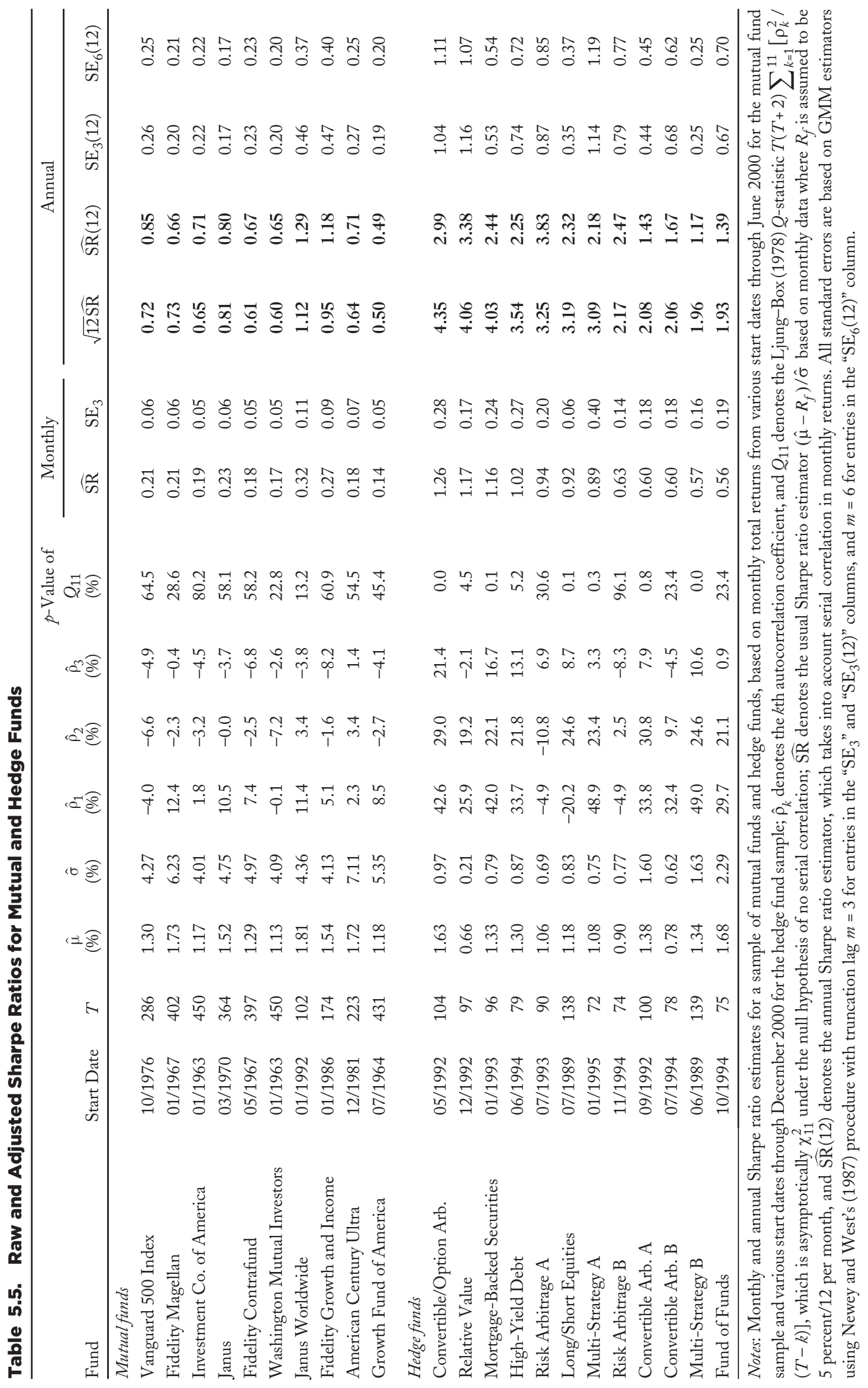


confidence interval for the Vanguard 500 Index is $0.85 \pm(1.96 \times 0.26)$, which is $[0.33,1.36]$. These results indicate Sharpe ratios for the 10 mutual funds that are statistically different from zero at the 95 percent confidence level.

The results for the 12 hedge funds are different in several respects. The mean returns are higher, and the standard deviations are lower, implying much higher Sharpe ratio estimates for hedge funds than for mutual funds. The monthly Sharpe ratio estimates $\widehat{S R}$ range from 0.60 (Convertible Arbitrage A and B Funds) to 1.26 (Convertible/Option Arbitrage Fund), in contrast to the range of 0.14 to 0.32 for the 10 mutual funds. However, the serial correlation in hedge fund returns is also much higher. For example, the first-order autocorrelation coefficient ranges from -20.2 percent to 49.0 percent among the 12 hedge funds, whereas the highest firstorder autocorrelation among the 10 mutual funds is 12.4 percent. The $p$-values provide a more complete summary of the presence of serial correlation: All but 4 out of the 12 hedge funds have $p$-values less than 5 percent, and several are less than 1 percent.

The impact of serial correlation on the annual Sharpe ratios of hedge funds is dramatic. Using the IID estimator $\sqrt{12} \widehat{S R}$ for the annual Sharpe ratio, the Convertible/Option Arbitrage Fund has a Sharpe ratio estimate of 4.35 , but when serial correlation is properly taken into account by $\widehat{\operatorname{SR}}(12)$, the estimate drops to 2.99 , implying that the IID estimator overstates the annual Sharpe ratio by 45 percent. The annual Sharpe ratio estimate for the Mortgage-Backed Securities Fund drops to 2.44 from 4.03 when serial correlation is taken into account, implying an overstatement of 65 percent. However, the annual Sharpe ratio estimate of the Risk Arbitrage A Fund increases to 3.83 from 3.25 because of negative serial correlation in its monthly returns.

The sharp differences between the annual IID and robust Sharpe ratio estimates underscore the importance of correctly accounting for serial correlation in analyzing the performance of hedge funds. Naively estimating the annual Sharpe ratios by multiplying $\widehat{\mathrm{SR}}$ by $\sqrt{12}$ will yield the rank ordering given in the bottom panel of Table 5.5, but once serial correlation is taken into account, the rank ordering changes to 3, 2, 5, 7, 1, 6, 8, 4, $10,9,12,11$. The robust standard errors for the annual robust Sharpe ratio estimates of the 12 hedge funds range from 0.25 to 1.14 , which, although larger than those in the mutual fund sample, nevertheless imply 95 percent confidence intervals that generally do not include zero. For example, even in the case of the MultiStrategy B Fund, which has the lowest robust Sharpe ratio estimate of 1.17, its 95 percent confidence interval is $1.17 \pm(1.96 \times 0.25)$, which is $[0.68,1.66]$. This is also consistent with previous studies that document the fact that hedge funds do seem to exhibit statistically significant excess returns. 58 The similarity of the standard errors in the $m=3$ and $m=6$ cases for the hedge fund sample indicates that the robust estimator is also well behaved in this instance, despite the presence of significant serial correlation in monthly returns.

The empirical examples in this chapter illustrate the potential impact that serial correlation can have on performance measures such as the Sharpe ratio and the importance of properly accounting for departures from the standard IID framework. In particular, robust Sharpe ratio estimators contain significant additional information about the risk/reward trade-offs for hedge funds and should be used in place of more traditional measures.

${ }^{58}$ See, for example, Ackermann, McEnally, and Ravenscraft (1999); Brown, Goetzmann, and Ibbotson (1999); Brown, Goetzmann, and Park (1997); Fung and Hsieh (1997a, 1997b, 2000); and Liang (1999, 2000, 2001). 


\section{Optimal Liquidity}

It should be apparent from Chapter 5 that liquidity is an important risk factor for hedge funds. Many studiesboth in academic journals and in more applied forums - have made considerable progress in defining liquidity, measuring the cost of immediacy and price impact, deriving optimal portfolio rules in the presence of transaction costs, investigating the relationship between liquidity and arbitrage, and estimating liquidity risk premia in the context of various partial and general equilibrium asset-pricing models. ${ }^{59}$ However, relatively little attention has been paid to the more practical problem of integrating liquidity directly into the portfolio construction process. 60

This chapter presents the results of Lo, Petrov, and Wierzbicki (2003), in which they model liquidity using simple measures, such as trading volume and percentage bid/offer spreads, and then introduce these measures into the standard mean-variance portfolio optimization process to yield optimal mean-variance-liquidity portfolios. They begin by proposing several measures of the liquidity $\ell_{i}$ of an individual security, from which they define the liquidity $\ell_{p}$ of a portfolio $\omega_{p} \equiv\left[\begin{array}{llll}\omega_{p 1} & \omega_{p 2} & \ldots & \omega_{p n}\end{array}\right]^{\prime}$ as the weighted average $\Sigma_{i} \ell_{i} \omega_{p i}$ of the individual securities' liquidities. Using these liquidity measures, they construct three types of "liquidity-optimized" portfolios: (1) a mean-variance-efficient portfolio subject to a liquidity filter that each security in the portfolio have a minimum level of liquidity $\ell_{o} ;(2)$ a mean-variance-efficient portfolio subject to a constraint that the portfolio have a minimum level of liquidity $\ell_{0}$; and (3) a mean-variance-liquidity-efficient portfolio, where the optimization problem has three terms in its objective function-mean, variance, and liquidity. Using three different definitions of liquidity - turnover, percentage bid/offer spread, and a nonlinear function of market capitalization and trade size-they show empirically that liquidity-optimized portfolios have some very attractive properties and that even simple forms of liquidity optimization can yield significant benefits in terms of reducing a portfolio's liquidity-risk exposure without sacrificing a great deal of expected return per unit risk.

The first section, titled "Liquidity Metrics," describes their simple measures of liquidity and proposes an additional measure that is particularly relevant for hedge fund investments— the first-order serial correlation coefficient. Using these liquidity measures, the section "Liquidity-Optimized Portfolios" defines the three types of liquidity-optimized portfolios, and then the section "Empirical Examples" reviews some empirical examples of liquidity-optimized portfolios. Finally, extensions and open issues are discussed in the section "Extensions and Open Issues."

\section{Liquidity Metrics}

The natural starting point of any attempt to integrate liquidity into the portfolio optimization process is to develop a quantitative measure of liquidity (i.e., a liquidity metric). Liquidity is a multifaceted concept, involving at least three distinct attributes of the trading process - price, time, and size. Hence, a liquid security is one that can be traded quickly, with little price impact, and in large quantities. Therefore, it is unlikely that a single

\footnotetext{
59 See, for example, Acharya and Pedersen (2002); Aiyagari and Gertler (1991); Atkinson and Wilmott (1995); Amihud and Mendelson (1986b); Bertsimas and Lo (1998); Boyle and Vorst (1992); Chordia, Roll, and Subrahmanyam (2000, 2001, 2002); Chordia, Subrahmanyam, and Anshuman (2001); Cohen, Maier, Schwartz, and Whitcomb (1981); Constantinides (1986); Davis and Norman (1990); Dumas and Luciano (1991); Epps (1976); Garman and Ohlson (1981); Gromb and Vayanos (2002); Grossman and Laroque (1990); Grossman and Vila (1992); Heaton and Lucas (1996, 1997); Hodges and Neuberger (1989); Holmström and Tirole (2001); Huang (2003); Litzenberger and Rolfo (1984); Leland (1985); Liu and Longstaff (2000); Lo, Mamaysky, and Wang (2004); Magill and Constantinides (1976); Morton and Pliska (1995); Pastor and Stambaugh (2003); Sadka (2003); Shleifer and Vishny (1997); Tuckman and Vila (1992); Vayanos (1998); Vayanos and Vila (1999); and Willard and Dybvig (1999).

60 Of course, many studies have considered the practical significance of trading costs or "slippage" in investment management [e.g., Arnott and Wagner (1990); Bertsimas and Lo (1998); Bodurtha and Quinn (1990); Brinson, Hood, and Beebower (1986); Brinson, Singer, and Beebower (1991); Chan and Lakonishok (1993, 1995); Collins and Fabozzi (1991); Cuneo and Wagner (1975); Gammill and Pérold (1989); Hasbrouck and Schwartz (1988); Keim and Madhavan (1997); Leinweber (1993, 1994); Loeb (1983); Pérold (1988); Schwartz and Whitcomb (1988); Stoll (1993); Treynor (1981); Wagner and Banks (1992); Wagner and Edwards (1993); and the papers in Sherrerd (1993)]. None of these studies focuses squarely on the quantitative trade-off between expected return, risk, and liquidity. However, Michaud (1989; 1998, Chapter 12) observes that standard mean-variance portfolio optimization does not take liquidity into account, and Michaud (1998, Chapter 12) proposes liquidity constraints and quadratic penalty functions in a mean-variance framework.
} 
statistic can be found that summarizes all of these attributes. To represent these distinct features, Lo, Petrov, and Wierzbicki (2003) start with the following five quantities on which their liquidity metrics are based:

Trading volume $\equiv$ Total number of shares traded at time $t$,

Logarithm of trading volume $\equiv \log ($ Trading volume $)$,

Turnover $\equiv \frac{\text { Trading volume }}{\text { Shares outstanding }}$

Percentage bid/ask spread $\equiv \frac{\text { Ask }- \text { Bid }}{(\text { Ask }+ \text { Bid }) / 2}$,

Loeb price-impact function $\equiv f($ Trade size, Market cap $)$,

where the first three variables measure the amount of trading and the last two measure the cost. 61

Perhaps the most common measure of the liquidity of a security is its trading volume. It is almost tautological to say that a security is more liquid if it is traded more frequently and in greater quantities. Both trading volume and turnover capture this aspect of liquidity, and because these two variables are so highly correlated (see, for example, Lo and Wang 2000), only one of the three measures of trading activity (Equations 6.1-6.3) is used in this empirical analysis. Given Lo and Wang's (2000) motivation for turnover in the context of modern assetpricing models, such as the Capital Asset Pricing Model and the Arbitrage Pricing Theory, turnover (Equation 6.3) shall be adopted as the measure of trading activity.

Another popular measure of the liquidity of a security is the cost of transacting in it, either as buyer or seller; hence, the bid/ask spread is the natural candidate. Smaller bid/ask spreads imply lower costs of trading, whereas larger bid/ask spreads are partly attributable to a liquidity premium demanded by market makers for making markets in illiquid securities. 62

Market capitalization - the market value of total outstanding equity - has also been proposed as an important proxy for liquidity. Larger amounts of outstanding equity tend to be traded more frequently and at a lower cost because there will be a larger market for the stock. Of course, even a large amount of outstanding equity can be distributed among a small number of major shareholders, yielding little liquidity for the stock, but this seems to be the exception rather than the rule. Adopted here is the specification proposed by Loeb (1983), in which he provides estimates of the percentage round-trip total trading cost including (1) the market maker's spread, (2) the price concession, and (3) the brokerage commission. The total trading cost is an array with nine capitalization categories and nine block sizes (see Loeb 1983, Table II). This matrix provides a good approximation for liquidity, but to account for the continuous nature of market capitalization and block sizes beyond his original specification, Loeb's table is interpolated and extrapolated using a two-dimensional spline. ${ }^{63}$ Figure 6.1 contains a graphical representation of the parametrization of Loeb's specification, and the MATLAB source code is provided in Appendix A. To minimize the impact of ad hoc extrapolation procedures such as the one used to extend Loeb (1983) (see Note 63), Lo, Petrov, and Wierzbicki (2003) use a fixed block size of $\$ 250,000$ in all their calculations involving Loeb's liquidity metric, and for this size, the extrapolation/capping of the trading cost is used rather infrequently.

61 The third dimension of liquidity — time to completion of a purchase or sale — is obviously missing from this list, but only because of lack of data. With access to time-stamped orders of a large institutional trading desk, time-based measures of liquidity can easily be constructed as well.

62 See, for example, Amihud and Mendelson (1986a, 1986b); Glosten and Milgrom (1985); Lo, Mamaysky, and Wang (2004); Tiniç (1972); and Vayanos (1998).

63 Loeb's original matrix does not allow for block sizes in excess of 5 percent of a stock's total market capitalization, which, in this sample, would imply a maximum block size of 5 percent $\times \$ 2.84$ million $=\$ 0.142$ million, a relatively small number. To relax this restriction, the total cost function is extrapolated to allow for block sizes of up to 20 percent of market capitalization, where the extrapolation is performed linearly by fixing the capitalization level and using the last two available data points along the block-size dimension. The maximum total cost is capped at 50 percent, an arbitrary large number. For example, for the $\$ 0$ million to $\$ 10$ million capitalization sector (see Loeb 1983 , Table II) and block sizes of $\$ 5,000, \$ 25,000$, and $\$ 250,000$, the total spread/price costs are 17.3 percent, 27.3 percent, and 43.8 percent, respectively. The cost at the next block size of $\$ 500,000$ is computed as Min[50\%, $43.8 \%+(500,000-250,000) \times(43.8 \%-27.3 \%) /(50,000-25,000)]=50 \%$. 


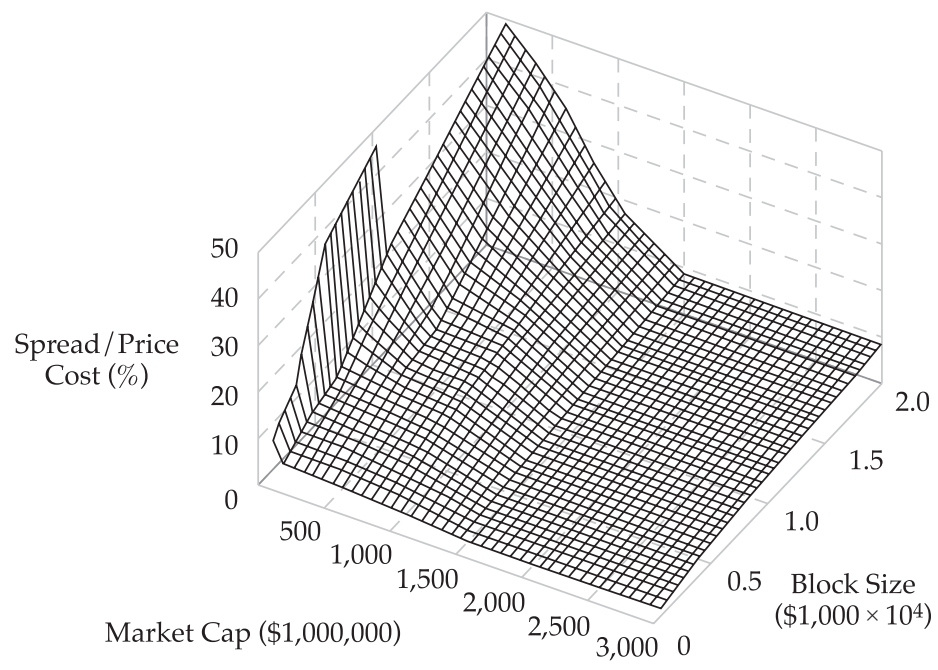

Note: Loeb's (1983) price-impact function gives the percentage total cost as a function of block size and market capitalization, with spline interpolation and linear extrapolation.

However, Lo, Petrov, and Wierzbicki (2003) developed these liquidity measures primarily for equity portfolios, not hedge fund investments. In particular, measures such as market capitalization and bid/ask spreads do not have any obvious analogues for ownership interests in private partnerships. Therefore, a different liquidity metric is required for hedge fund investments, and the analysis in Chapter 5 yields a natural alternative- the first-order serial correlation coefficient.

Liquidity Metrics for Individual Securities. The construction of liquidity metrics begins by computing Equations 6.1-6.5 with daily data and then aggregating the daily measures to yield monthly quantities. Monthly trading volume is defined as the sum of the daily trading volume for all the days within the month, and monthly log-volume is simply the natural logarithm of monthly trading volume. Monthly turnover is defined as the sum of daily turnover for all the days within the month (see Lo and Wang 2000 for further discussion). The monthly bid/ask spread measure is defined as a mean of the daily bid/ask spreads for all the days within the month. And finally, the average monthly Loeb price-impact measure is defined as a mean of the corresponding daily measures for all days within the month.

Having defined monthly counterparts to the daily variables (Equations 6.1-6.5), the five monthly measures are renormalized to yield quantities that are of comparable scale. Let $\tilde{\ell}_{i t}$ represent one of the five liquidity variables for security $i$ in month $t$. Then the corresponding liquidity metric $\ell_{i t}$ is defined as

$$
\ell_{i t} \equiv \frac{\tilde{\ell}_{i t}-\operatorname{Min}_{k, \tau} \tilde{\ell}_{k \tau}}{\operatorname{Max}_{k, \tau} \tilde{\ell}_{k \tau}-\operatorname{Min}_{k, \tau} \tilde{\ell}_{k \tau}},
$$

where the maximum and minimum in Equation 6.6 are computed over all stocks $k$ and all dates $\tau$ in the sample so that each of the five normalized measures-which is now referred to as a liquidity metric to distinguish it from the unnormalized variable - takes on values strictly between 0 and 1 . Therefore, if the turnover-based liquidity metric for a given security is 0.50 in a particular month, this implies that the level of turnover exceeds the minimum turnover by 50 percent of the difference between the maximum and minimum turnover for all securities and across all months in the sample. Note that for consistency, the reciprocal of the monthly bid/ask spread measure is used in defining $\ell_{i t}$ for bid/ask spreads so that larger numerical values imply more liquidity, as is the case with the other four measures. 
For hedge fund investments, the liquidity metric in month $t$ is:

$$
\hat{\rho}_{1 t}=\frac{\sum_{k=2}^{T}\left(R_{t-k}-\hat{\mu}_{t}\right)\left(R_{t-k-1}-\hat{\mu}_{t}\right)}{\sum_{k=1}^{T}\left(R_{t-k}-\hat{\mu}_{t}\right)^{2}}, \hat{\mu}_{t} \equiv \frac{1}{T} \sum_{k=1}^{T} R_{t-k},
$$

which is a $T$-month rolling-window estimate of the first-order autocorrelation of $\left(R_{t}\right)$, using returns from month $t-1$ to $t-T-1$.

Liquidity Metrics for Portfolios. Now consider a portfolio $p$ of securities defined by the vector of portfolio weights $\boldsymbol{\omega}_{p} \equiv\left[\omega_{p 1} \omega_{p 2} \ldots \omega_{p n}\right]^{\prime}$, where $\boldsymbol{\omega}_{p}^{\prime} \imath=1$ and $\imath \equiv[1 \ldots 1]^{\prime}$. Assume for the moment that this is a long-only portfolio so that $\boldsymbol{\omega}_{p} \geq 0$. Then a natural definition of the liquidity $\ell_{p t}$ of this portfolio is simply

$$
\ell_{p t} \equiv \sum_{i=1}^{n} \omega_{p i} \ell_{i t}
$$

which is a weighted average of the liquidities of the securities in the portfolio.

For portfolios that allow short positions, Equation 6.8 is not appropriate because short positions in illiquid securities may cancel out long positions in equally illiquid securities, yielding a very misleading picture of the overall liquidity of the portfolio. To address this concern, the following definition is proposed for the liquidity metric of a portfolio with short positions, along the lines of Lo and Wang's (2000) definition of portfolio turnover:

$$
\ell_{p t} \equiv \sum_{i=1}^{n} \frac{\left|\omega_{p i}\right|}{\sum_{j=1}^{n}\left|\omega_{p j}\right|} \ell_{i t} .
$$

In the absence of short positions, Equation 6.9 reduces to Equation 6.8, but when short positions are present, their liquidity metrics are given positive weight, as with the long positions, and then all the weights are renormalized by the sum of the absolute values of the weights.

Qualifications. Although the liquidity metrics described above are convenient definitions for purposes of mean-variance portfolio optimization, they have a number of limitations that should be kept in mind. First, Equation 6.8 implicitly assumes that there are no interactions or cross-effects in liquidity among securities, which need not be the case. For example, two securities in the same industry may have similar liquidity metrics individually but may become somewhat more difficult to trade when combined in a portfolio because they are considered close substitutes by investors. This assumption can be relaxed by specifying a more complex "liquidity matrix" in which $\ell_{i t}$ are the diagonal entries but where interaction terms $\ell_{i j t}$ are specified in the off-diagonal entries. In that case, the liquidity metric for the portfolio $p$ is simply the quadratic form

$$
\ell_{p t} \equiv \sum_{i=1}^{n} \sum_{j=1}^{n} \omega_{p i} \omega_{p j} \ell_{i j t} .
$$

The off-diagonal liquidity metrics are likely to involve subtleties of the market microstructure of securities in the portfolio as well as more fundamental economic links among the securities; hence, for current purposes, assume that they are zero.

For the hedge fund liquidity measure, $\hat{\rho}_{1 t}$, the portfolio measure (Equation 6.10) is still incorrect because correlation is not a linear-quadratic operator. In particular, if $\mathbf{R}_{t} \equiv\left[R_{1 t} \ldots R_{n t}\right]^{\prime}$ denotes the vector of month $t$ returns for $n$ hedge funds and $\boldsymbol{\omega}_{p} \equiv\left[\omega_{p 1} \ldots \omega_{p t}\right]^{\prime}$, a portfolio $P$ of those funds, then the serial correlation coefficient of the portfolio return $R_{p t}$ is given by

$$
\rho_{p 1}=\frac{\operatorname{Cov}\left[R_{p t}, R_{p t-1}\right]}{\operatorname{Var}\left[R_{p t}\right]}=\frac{\boldsymbol{\omega}^{\prime} \boldsymbol{\Gamma}_{1} \boldsymbol{\omega}}{\boldsymbol{\omega}^{\prime} \boldsymbol{\Gamma}_{0} \boldsymbol{\omega}}
$$


where

$$
\boldsymbol{\Gamma}_{i} \equiv \mathrm{E}\left[\left(\mathbf{R}_{t}-\boldsymbol{\mu}\right)\left(\mathbf{R}_{t-i}-\boldsymbol{\mu}\right)^{\prime}\right], \boldsymbol{\mu} \equiv \mathrm{E}\left[\mathbf{R}_{t}\right]
$$

Note that $\boldsymbol{\Gamma}_{i}$ is the $i$ th-order autocovariance matrix of the vector time series $\left\{\mathbf{R}_{t}\right\}$ and need not be symmetric except when $i=0$, in which case $\boldsymbol{\Gamma}_{0}$ reduces to the covariance matrix of $\left\{\mathbf{R}_{t}\right\}$. Even in the absence of any crossautocorrelation between funds, Equation 6.11 does not reduce to either Equation 6.8 or Equation 6.10. To see why, denote the $i$ th-order autocorrelation matrix by $\mathbf{Y}_{i}$; hence,

$$
\mathbf{Y}_{i}=\mathbf{D}^{-1 / 2} \boldsymbol{\Gamma}_{i} \mathbf{D}^{-1 / 2}, \mathbf{D}=\operatorname{diag}\left(\sigma_{1}^{2}, \ldots, \sigma_{n}^{2}\right),
$$

where $\mathbf{D}$ is a diagonal matrix with the variances of the funds along the diagonal. Then Equation 6.11 may be rewritten in terms of the autocorrelation matrix $\mathbf{Y}_{1}$ as

$$
\rho_{p 1}=\frac{\boldsymbol{\omega}^{\prime} \mathbf{D}^{1 / 2} \mathbf{D}^{-1 / 2} \boldsymbol{\Gamma}_{\mathbf{1}} \mathbf{D}^{-1 / 2} \mathbf{D}^{1 / 2} \boldsymbol{\omega}}{\boldsymbol{\omega}^{\prime} \mathbf{D}^{1 / 2} \mathbf{D}^{-1 / 2} \boldsymbol{\Gamma}_{0} \mathbf{D}^{-1 / 2} \mathbf{D}^{1 / 2} \boldsymbol{\omega}}=\frac{\tilde{\omega}^{\prime} \mathbf{Y}_{\mathbf{1}} \tilde{\boldsymbol{\omega}}}{\tilde{\omega}^{\prime} \mathbf{Y}_{0} \tilde{\boldsymbol{\omega}}}, \tilde{\boldsymbol{\omega}} \equiv \mathbf{D}^{1 / 2} \boldsymbol{\omega} .
$$

Even if $\mathbf{Y}_{i}$ is diagonal, Equation 6.13 does not simplify to Equation 6.8 but reduces instead to

$$
\rho_{p 1}=\frac{\sum_{i=1}^{n} \tilde{\omega}^{2} \rho_{i 1}}{\sum_{j=1}^{n} \tilde{\omega}_{j}^{2}}=\sum_{i=1}^{n} \delta_{i} \rho_{i 1}, \quad \delta_{i} \equiv \frac{\sigma_{i}^{2}}{\sum_{j=1}^{n} \omega_{j}^{2} \sigma_{j}^{2}} \omega_{i}^{2} .
$$

If, in addition to being mutually uncorrelated at all leads and lags, all $n$ funds also have equal variances, then Equation 6.14 becomes

$$
\rho_{p 1}=\sum_{i=1}^{n} \delta_{i} \rho_{i 1}, \quad \delta_{i} \equiv \frac{\omega_{i}^{2}}{\sum_{j=1}^{n} \omega_{j}^{2}},
$$

which is related to Equation 6.8 in a nonlinear fashion.

Second, because Equation 6.8 is a function only of the portfolio weights and not of the dollar value of the portfolio, $\ell_{p t}$ is scale-independent. While this also holds true for mean-variance analysis as a whole, the very nature of liquidity is dependent on scale to some degree. Consider the case in which IBM Corporation comprises 10 percent of two portfolios $p$ and $q$. According to Equation 6.8, the contribution of IBM to the liquidity of the overall portfolio would be the same in these two cases -10 percent times the liquidity metric of IBM. However, suppose that the dollar value of portfolio $p$ is $\$ 100,000$ and the dollar value of portfolio $q$ is $\$ 100$ million-is a $\$ 10,000$ position in IBM identical to a $\$ 10$ million position in terms of liquidity? At issue is the fact that, except for Loeb's measure of price impact, the liquidity metrics defined by the variables defined in Equations 6.1-6.4 and 6.7 are not functions of trade size and hence are scale-independent. Of course, this is easily remedied by reparametrizing the liquidity metric $\ell_{i t}$ so that it varies with trade size, much like Loeb's price-impact function, but this creates at least three additional challenges: (1) There is little empirical evidence to determine the appropriate functional specification;64 (2) trade size may not be the only variable that affects liquidity; and (3) making $\ell_{i t}$ a function of trade size complicates the portfolio optimization problem considerably, rendering virtually all of the standard mean-variance results scale-dependent. For these reasons, the assumption shall continue to be scale independence for $\ell_{i t}$ throughout this study (even for Loeb's price-impact function, for which the trade size is fixed at $\$ 250,000$ ) and the more challenging case will be left for future research.

${ }^{64}$ However, see Bertsimas and Lo (1998); Chan and Lakonishok (1993, 1995); Hausman, Lo, and MacKinlay (1992); Kraus and Stoll (1972); Lillo, Farmer, and Mantegna (2003); and Loeb (1983) for various approximations in a number of contexts. 
More generally, the liquidity variables (Equations 6.1-6.5 and 6.7) are rather simple proxies for liquidity and do not represent liquidity premia derived from dynamic equilibrium models of trading behavior, 65 nor is Equation 6.7 meant to be a portfolio serial correlation coefficient. Therefore, these variables may not be stable through time and over very different market regimes. However, given their role in influencing the price, time, and size of transactions in equity markets, the liquidity metrics defined by Equations 6.1-6.5 and 6.7 are likely to be highly correlated with equilibrium liquidity premia under most circumstances and should serve as reasonable local approximations to the liquidity of a portfolio.

Finally, because these liquidity metrics are ad hoc and not the by-product of expected utility maximization, they have no objective interpretation and must be calibrated to suit each individual application. Of course, I might simply assert that liquidity is a sufficiently distinct characteristic of a financial security that investors will exhibit specific preferences along this dimension, much as for a security's mean and variance. However, unlike the case of mean-variance preferences, it is difficult to identify plausible preference rankings for securities of varying liquidity levels. Moreover, there are approximation theorems that derive mean-variance preferences from expected utility theory (see, for example, Levy and Markowitz 1979), and corresponding results for the liquidity metrics have yet to be developed.

Nevertheless, liquidity is now recognized to be such a significant factor in investment management that despite the qualifications described above, there is considerable practical value in incorporating even ad hoc measures of liquidity into standard mean-variance portfolio theory. This challenge is addressed in the next section.

\section{Liquidity-Optimized Portfolios}

Armed with quantitative liquidity metrics $\left\{\ell_{i t}\right\}$ for individual securities and portfolios, liquidity can now be incorporated directly into the portfolio construction process. There are at least three methods for doing so: (1) imposing a liquidity "filter" for securities to be included in a portfolio optimization program; (2) constraining the portfolio optimization program to yield a mean-variance-efficient portfolio with a minimum level of liquidity; and (3) adding the liquidity metric into the mean-variance objective function directly. Each of these methods is described in more detail in the following sections, and portfolios obtained from these procedures are referred to as "mean-variance-liquidity (MVL) optimal" portfolios. 66

Liquidity Filters. In this formulation, the portfolio optimization process is applied only to those securities with liquidity metrics greater than some threshold level $\ell_{0}$. Denote by $U$ the universe of all securities to be considered in the portfolio optimization process, and let $\mathrm{U}_{o}$ denote the subset of securities in $\mathrm{U}$ for which $\ell_{i t} \geq \ell_{0}$ :

$$
\mathrm{U}_{o} \equiv\left\{i \in \mathrm{U}: \ell_{i t} \geq \ell_{o}\right\} \text {. }
$$

The standard mean-variance optimization process can now be applied to the securities in $\mathrm{U}_{0}$ to yield meanvariance-efficient liquidity-filtered portfolios:

$$
\operatorname{Min}_{\{\boldsymbol{\omega}\}} \frac{1}{2} \boldsymbol{\omega}^{\prime} \Sigma_{o} \boldsymbol{\omega}
$$

subject to

$$
\begin{aligned}
& \mu_{p}=\boldsymbol{\omega}^{\prime} \boldsymbol{\mu}_{o}, \\
& 1=\boldsymbol{\omega}^{\prime} \mathbf{\iota},
\end{aligned}
$$

where $\boldsymbol{\mu}_{0}$ is the vector of expected returns of securities in $\mathrm{U}_{0}, \boldsymbol{\Sigma}_{0}$ is the return covariance matrix of securities in $\mathrm{U}_{o}$, and as $\mu_{p}$ is varied, the set of $\boldsymbol{\omega}_{p}^{*}$ that solve Equation 6.17 yields the $\ell_{o}$-liquidity-filtered mean-varianceefficient frontier.

65 This literature is vast and overlaps with the literature on financial asset-pricing models with transaction costs. Some of the more relevant examples include Amihud and Mendelson (1986b); Bagehot (1971); Constantinides (1986); Demsetz (1968); Gromb and Vayanos (2002); Lo, Mamaysky, and Wang (2004); Tiniç (1972); Vayanos (1998); and Vayanos and Vila (1999). For a more complete list of citations, see the references contained in Lo, Mamaysky, and Wang (2004).

66 For expositional convenience, all of the tables and graphs in this chapter use standard deviations in place of variances as risk measures. Nevertheless, I shall continue to refer to graphs of efficient frontiers as "mean-variance-liquidity efficient frontiers," despite the fact that standard deviation, not variance, is the $x$-axis. I follow this convention because the objective functions on which the efficient frontiers are based are mean-variance objective functions, and because "mean-standard deviation-liquidity" is simply too cumbersome a phrase to use more than once. 
Liquidity Constraints. An alternative to imposing a liquidity filter is to impose an additional constraint in the mean-variance optimization problem:

$$
\underset{\{\boldsymbol{\omega}\}}{\operatorname{Min}} \frac{1}{2} \boldsymbol{\omega}^{\prime} \mathbf{\Sigma} \boldsymbol{\omega}
$$

subject to

$$
\begin{aligned}
& \mu_{p}=\boldsymbol{\omega}^{\prime} \boldsymbol{\mu}, \\
& \ell_{o}= \begin{cases}\boldsymbol{\omega}^{\prime} \ell_{t} & \text { if } \boldsymbol{\omega} \geq 0 \\
\sum_{i=1}^{n} \frac{\left|\omega_{p i}\right|}{\sum_{j=1}^{n}\left|\omega_{p j}\right|} \ell_{i t} & \text { otherwise, }\end{cases} \\
& 1=\boldsymbol{\omega}^{\prime} \mathbf{\iota},
\end{aligned}
$$

where $\boldsymbol{\mu}$ is the vector of expected returns of securities in the unconstrained universe $U, \boldsymbol{\Sigma}$ is the return covariance matrix of securities in $\mathrm{U}, \ell_{t} \equiv\left[\ell_{1 t} \ldots \ell_{n t}\right]^{\prime}$ is the vector of liquidity metrics for securities in $\mathrm{U}$, and as $\mu_{p}$ is varied, the set of $\boldsymbol{\omega}_{p}^{*}$ that solves Equation 6.18 yields the $\ell_{o}$-liquidity-constrained mean-variance-efficient frontier. Note that the liquidity constraint (Equation 6.18c) is in two parts, depending on whether $\boldsymbol{\omega}$ is long-only or long/short. For simplicity, a non-negativity restriction is imposed on $\boldsymbol{\omega}$ in the empirical example so that the constraint reduces to $\ell_{p}=\boldsymbol{\omega}^{\prime} \ell_{t}$.

Mean-Variance-Liquidity Objective Function. Perhaps the most direct method of incorporating liquidity into the mean-variance portfolio optimization process is to include the liquidity metric in the objective function 67

$$
\operatorname{Max}_{\{\omega\}} \omega^{\prime} \boldsymbol{\mu}-\frac{\lambda}{2} \boldsymbol{\omega}^{\prime} \mathbf{\Sigma} \boldsymbol{\omega}+\phi \boldsymbol{\omega}^{\prime} \boldsymbol{\ell}_{t}
$$

subject to

$$
1=\boldsymbol{\omega}^{\prime} \mathbf{\imath}, 0 \leq \boldsymbol{\omega},
$$

where $\lambda$ is the risk tolerance parameter, $\phi$ determines the weight placed on liquidity, and $\boldsymbol{\omega}$ is constrained to be non-negative so as to simplify the expression for the liquidity of the portfolio.

\section{Empirical Examples}

To illustrate the practical relevance of liquidity metrics for investment management, consider two empirical examples: Lo, Petrov, and Wierzbicki's (2003) liquidity-optimized portfolios of 50 randomly selected U.S. stocks and liquidity-optimized portfolios of the $13 \mathrm{CSFB} / T$ remont hedge fund indexes.

Liquidity-Optimized Portfolios of 50 Stocks. Lo, Petrov, and Wierzbicki (2003) construct the three types of liquidity-optimized portfolios described earlier in this chapter using historical data for 50 U.S. stocks selected from the University of Chicago's Center for Research in Security Prices (CRSP) and the New York Stock Exchange's Trades and Quotes (TAQ) database for the sample period from 2 January 1997 to 31 December 2001. These 50 stocks were drawn randomly from 10 market-capitalization brackets, based on 31 December 1996 closing prices, so as to yield a representative portfolio with sufficiently diverse liquidity characteristics (see Lo, Petrov, and Wierzbicki 2003 for details on their sampling procedure). Lo, Petrov, and Wierzbicki (2003) compute correlation matrices for turnover, volume, Loeb's metric, and the bid/ask spread, and conclude that the correlations between the various liquidity measures are generally consistent with each other but are not all perfectly correlated; hence, each measure seems to capture certain aspects of liquidity not reflected in the others. The single exception is volume and turnover, which are extremely highly correlated, so they eliminate volume and log-volume from consideration and confine their attention to turnover, bid/ask spreads, and Loeb's metric in their empirical analysis.

67 See, for example, Michaud (1998, Chapter 12). 
To compute mean-variance-liquidity frontiers, they require estimates of the expected return $\boldsymbol{\mu}$ and covariance matrix $\mathbf{\Sigma}$ of the 50 stocks in their sample. Using daily returns data from 2 January 1997 to 31 December 2001, they compute the following standard estimators:

$$
\begin{gathered}
\hat{\boldsymbol{\mu}}=\frac{1}{T} \sum_{t=1}^{T} \mathbf{R}_{t}, \\
\widehat{\mathbf{\Sigma}}=\frac{1}{T-1} \sum_{t=1}^{T}\left(\mathbf{R}_{t}-\hat{\boldsymbol{\mu}}\right)\left(\mathbf{R}_{t}-\hat{\boldsymbol{\mu}}\right)^{\prime},
\end{gathered}
$$

where $\mathbf{R}_{t} \equiv\left[R_{1 t} \ldots R_{50 t}\right]^{\prime}$ is the vector of date- $t$ returns of the 50 stocks in the sample. They convert these estimates to a monthly frequency by multiplying by 21 , the number of trading days per month. Liquidityoptimized portfolios may then be constructed with these estimates and any one of the liquidity metrics defined earlier in this chapter. To underscore the fact that liquidity can vary considerably from one month to the next, they construct liquidity-optimized portfolios for eight particular months, listed in Table 6.1, which includes the start and end of the sample as controls, as well as months that contain significant liquidity events, such as the default of Russian government debt in August 1998 and the terrorist attacks of 11 September 2001. Lo, Petrov, and Wierzbicki (2003) construct liquidity-filtered, liquidity-constrained, and mean-variance-liquidity optimized portfolios for the data, but to conserve space, presented here is only a small subset of their resultsthe liquidity-constrained portfolio results.

Table 6.2 summarizes the characteristics of liquidity-constrained portfolios using monthly normalized turnover as the liquidity metric. The results in Table 6.2 show that initial levels of liquidity constraints have little impact on performance. In fact, for every month in Table 6.1, imposing a liquidity constraint of 2.29 has virtually no impact on the Sharpe ratio, and in some months (e.g., March 2000), the threshold can be increased well beyond 2.29 without any loss in performance for the tangency portfolio.

To fully appreciate the impact of adding a liquidity dimension to traditional mean-variance analysis, a three-dimensional graphical representation of the mean-variance-liquidity surface is necessary. Figure 6.2 contains liquidity-constrained mean-variance-liquidity (MVL) efficient frontiers for each of the months in Table 6.1. At the "ground level" of each of the three-dimensional coordinate cubes in Figure 6.2 are the familiar expected return and standard deviation axes. The liquidity threshold $\ell_{0}$ of Equation 6.16 is measured along the vertical axis. In the plane of the ground level, the liquidity level is zero; hence, the efficient frontier is the standard Markowitz mean-variance-efficient frontier, and this frontier will be identical across all the months in the sample, since estimated mean $\hat{\boldsymbol{\mu}}$ and covariance matrix $\widehat{\boldsymbol{\Sigma}}$ are based on the entire sample of daily data from 2 January 1997 to 31 December 2001 and do not vary over time. However, as the liquidity metric is used to constrain the portfolios in constructing the mean-variance-efficient frontier, the risk/reward profile of the frontier will change. By construction, the liquidity of a constrained portfolio is always equal to the liquidity threshold $\ell_{0}$, and since the normalization of all liquidity metrics is performed cross-sectionally as well as through time, the heights of the frontiers at different dates have the same meaning and can be compared to one another.

\begin{tabular}{ll} 
Table 6.1. & $\begin{array}{l}\text { Significant Months during the Sample } \\
\text { Period }\end{array}$ \\
\hline Date & \multicolumn{1}{c}{ Event } \\
\hline $12 / 1996$ & Beginning of sample \\
$08 / 1998$ & Russian default, LTCM \\
$10 / 1998$ & Fall of 1998 \\
$03 / 2000$ & First peak of S\&P 500 \\
$07 / 2000$ & Second peak of S\&P 500 \\
$04 / 2001$ & First bottom of S\&P 500 \\
$09 / 2001$ & 9/11 terrorist attacks, second bottom of S\&P 500 \\
$12 / 2001$ & End of sample \\
\hline
\end{tabular}


Table 6.2. Monthly Means and Standard Deviations of Tangency and MinimumVariance Portfolios of Liquidity-Constrained Mean-VarianceLiquidity Efficient Frontiers for 50 Randomly Selected Stocks

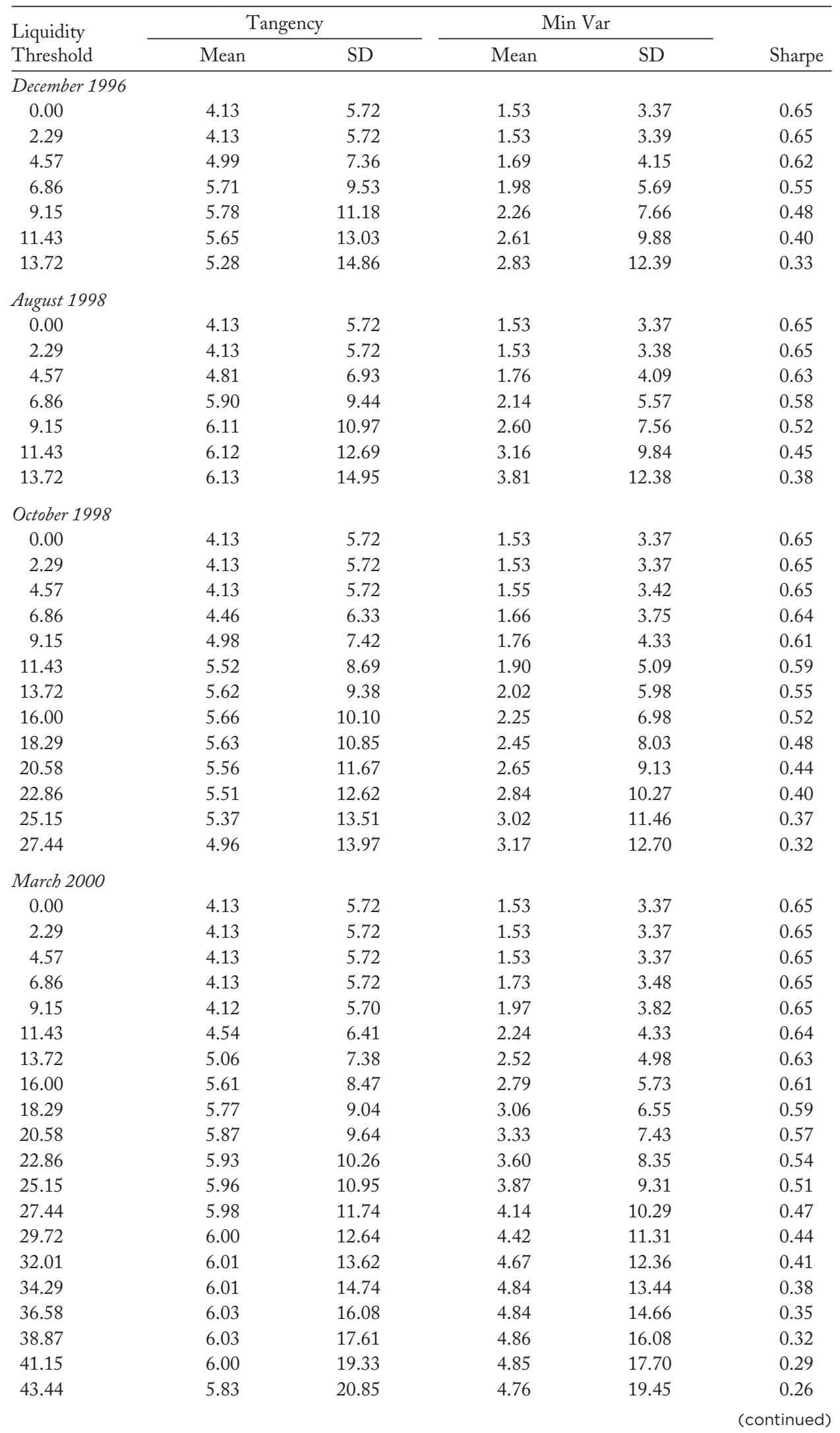


Table 6.2. Monthly Means and Standard Deviations of Tangency and MinimumVariance Portfolios of Liquidity-Constrained Mean-VarianceLiquidity Efficient Frontiers for 50 Randomly Selected Stocks (continued)

\begin{tabular}{|c|c|c|c|c|c|}
\hline \multirow{2}{*}{$\begin{array}{l}\text { Liquidity } \\
\text { Threshold }\end{array}$} & \multicolumn{2}{|c|}{ Tangency } & \multicolumn{2}{|c|}{ Min Var } & \multirow[b]{2}{*}{ Sharpe } \\
\hline & Mean & $\mathrm{SD}$ & Mean & SD & \\
\hline \multicolumn{6}{|l|}{$\overline{\text { July } 2000}$} \\
\hline 0.00 & 4.13 & 5.72 & 1.53 & 3.37 & 0.65 \\
\hline 2.29 & 4.13 & 5.72 & 1.53 & 3.37 & 0.65 \\
\hline 4.57 & 4.12 & 5.70 & 1.73 & 3.62 & 0.65 \\
\hline 6.86 & 4.96 & 7.23 & 1.97 & 4.42 & 0.63 \\
\hline 9.15 & 5.92 & 9.38 & 2.33 & 5.61 & 0.59 \\
\hline 11.43 & 6.14 & 10.61 & 2.70 & 7.06 & 0.54 \\
\hline 13.72 & 6.17 & 11.78 & 3.09 & 8.67 & 0.49 \\
\hline 16.00 & 6.24 & 13.25 & 3.50 & 10.37 & 0.44 \\
\hline 18.29 & 6.36 & 15.08 & 3.91 & 12.15 & 0.39 \\
\hline 20.58 & 6.51 & 17.26 & 4.32 & 14.00 & 0.35 \\
\hline \multicolumn{6}{|l|}{ April 2001} \\
\hline 0.00 & 4.13 & 5.72 & 1.53 & 3.37 & 0.65 \\
\hline 2.29 & 4.13 & 5.72 & 1.53 & 3.37 & 0.65 \\
\hline 4.57 & 4.16 & 5.77 & 1.63 & 3.66 & 0.65 \\
\hline 6.86 & 5.33 & 7.95 & 1.69 & 4.45 & 0.61 \\
\hline 9.15 & 5.90 & 9.53 & 1.94 & 5.59 & 0.57 \\
\hline 11.43 & 5.92 & 10.45 & 2.09 & 6.95 & 0.53 \\
\hline 13.72 & 5.80 & 11.48 & 2.31 & 8.48 & 0.47 \\
\hline 16.00 & 5.55 & 12.63 & 2.55 & 10.10 & 0.40 \\
\hline 18.29 & 5.28 & 14.19 & 2.78 & 11.80 & 0.34 \\
\hline \multicolumn{6}{|c|}{ September 2001} \\
\hline 0.00 & 4.13 & 5.72 & 1.53 & 3.37 & 0.65 \\
\hline 2.29 & 4.13 & 5.72 & 1.53 & 3.37 & 0.65 \\
\hline 4.57 & 4.13 & 5.72 & 1.79 & 3.65 & 0.65 \\
\hline 6.86 & 4.63 & 6.57 & 2.10 & 4.42 & 0.64 \\
\hline 9.15 & 5.49 & 8.23 & 2.50 & 5.52 & 0.61 \\
\hline 11.43 & 6.05 & 9.65 & 2.92 & 6.86 & 0.58 \\
\hline 13.72 & 6.34 & 10.87 & 3.40 & 8.36 & 0.54 \\
\hline 16.00 & 6.44 & 11.99 & 4.04 & 10.01 & 0.50 \\
\hline 18.29 & 6.55 & 13.48 & 4.75 & 11.83 & 0.45 \\
\hline \multicolumn{6}{|c|}{ December 2001} \\
\hline 0.00 & 4.13 & 5.72 & 1.53 & 3.37 & 0.65 \\
\hline 2.29 & 4.13 & 5.72 & 1.53 & 3.37 & 0.65 \\
\hline 4.57 & 4.11 & 5.70 & 1.67 & 3.64 & 0.65 \\
\hline 6.86 & 4.96 & 7.19 & 1.91 & 4.52 & 0.63 \\
\hline 9.15 & 5.88 & 9.14 & 2.33 & 5.81 & 0.59 \\
\hline 11.43 & 6.35 & 10.68 & 2.87 & 7.35 & 0.55 \\
\hline 13.72 & 6.55 & 12.02 & 3.47 & 9.06 & 0.51 \\
\hline 16.00 & 6.69 & 13.49 & 4.24 & 10.97 & 0.46 \\
\hline 18.29 & 6.80 & 15.13 & 5.07 & 13.11 & 0.42 \\
\hline
\end{tabular}

Notes: Monthly means and standard deviations of tangency and minimum-variance portfolios of liquidityconstrained mean-variance-liquidity efficient frontiers for 50 randomly selected stocks ( 5 from each of 10 market-capitalization brackets) based on a monthly normalized turnover liquidity metric for the months of December 1996, August 1998, October 1998, March 2000, July 2000, April 2001, September 2001, and December 2001. Expected returns and covariances of the 50 individual securities are estimated with daily returns data from 2 January 1997 to 31 December 2001 and do not vary from month to month. 
Figure 6.2. Liquidity-Constrained Mean-Variance-Liquidity Efficient Frontiers for 50 Randomly Selected Stocks

A. December 1996

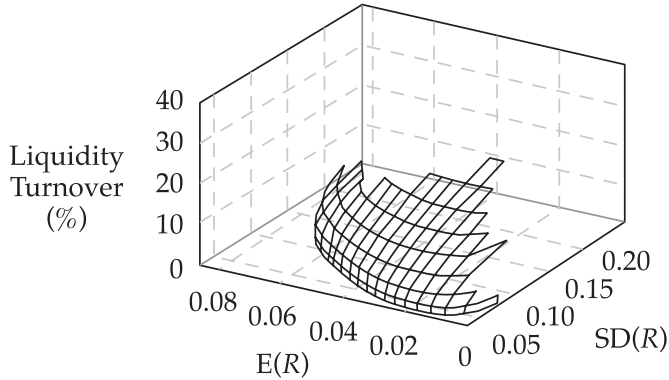

C. October 1998

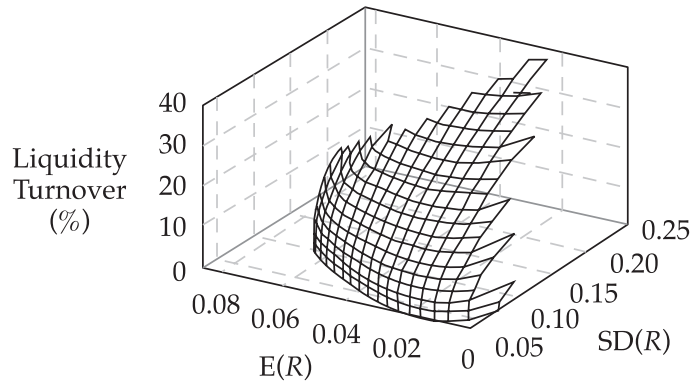

E. July 2000

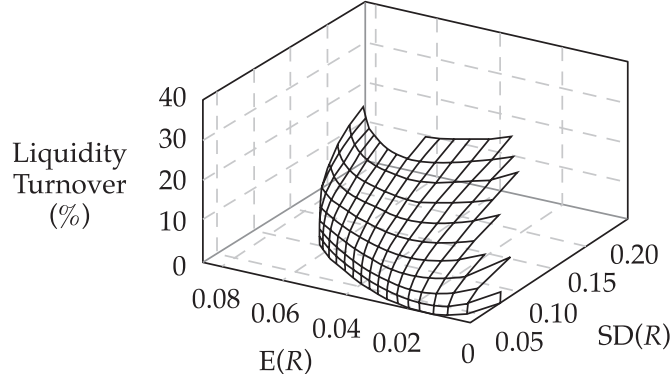

G. September 2001

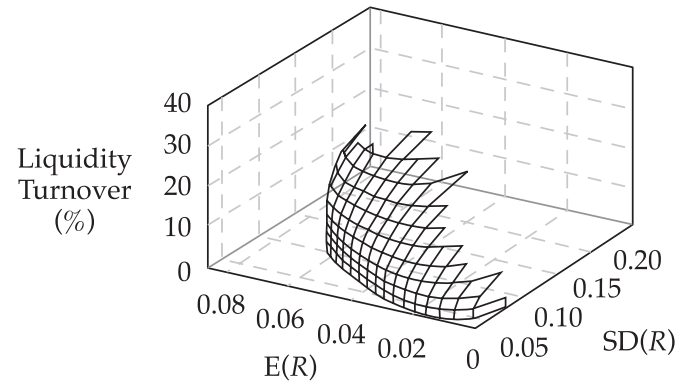

B. August 1998

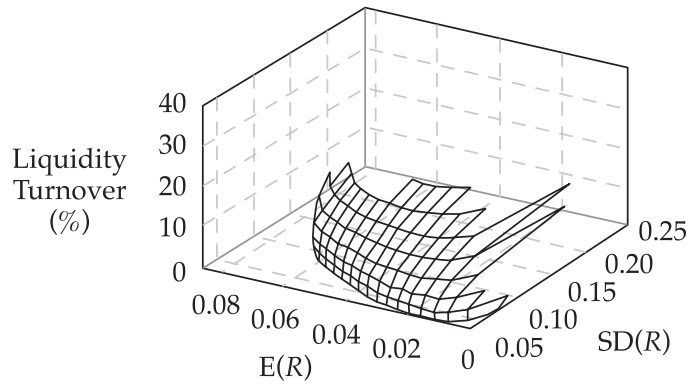

D. March 2000

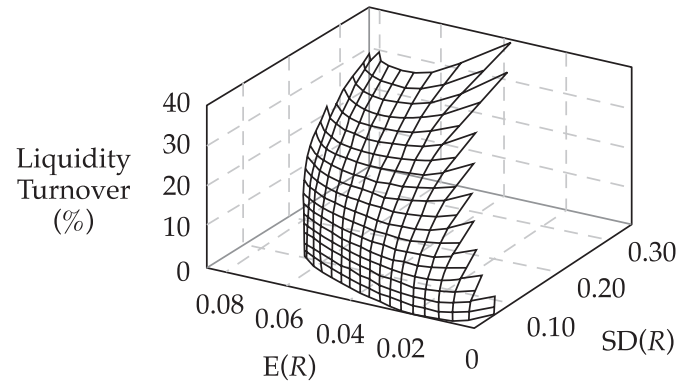

F. April 2001

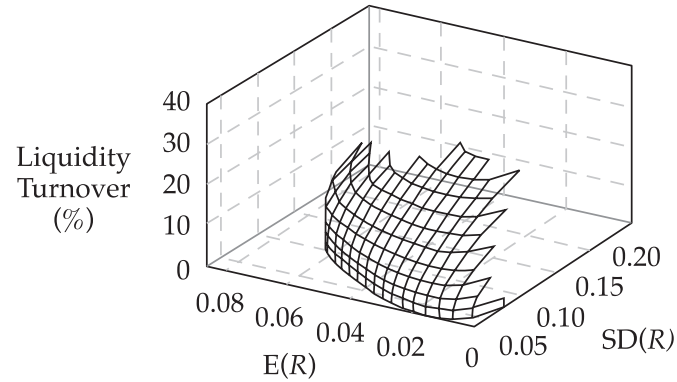

H. December 2001

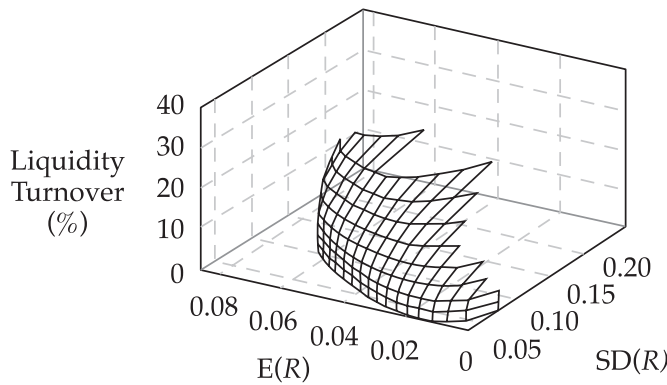

Note: Liquidity-constrained mean-variance-liquidity efficient frontiers for 50 randomly selected stocks ( 5 from each of 10 market-capitalization brackets) based on a monthly normalized turnover liquidity metric for the months of December 1996, August 1998, October 1998, March 2000, July 2000, April 2001, September 2001, and December 2001. Expected returns and covariances of the 50 individual securities are estimated with daily returns data from 2 January 1997 to 31 December 2001 and do not vary from month to month.

Source: Lo, Petrov, and Wierzbicki (2003). 
In Panel A of Figure 6.2, which contains the MVL frontier for December 1996, the period when the distribution of average turnover was at its historically low mean and standard deviation, the sail-like surface is rather flat and has relatively little surface area. The infeasibility of the constrained portfolio optimization problem at higher liquidity thresholds is responsible for the tattered edges of the surface starting at the fourth liquidity level (note that the size of the liquidity increments is identical across all months and the axes all have the same scale). At the highest levels of liquidity, only the most liquid segments of the MVL frontier appear in Figure 6.2. Because of the generally positive correlation between liquidity and market capitalization, and the fact that the large-cap stocks in the sample have modest expected returns and volatilities as compared to the smaller-cap stocks, at higher liquidity threshold levels, portfolios on the MVL frontier consist mostly of defensive large-cap equities.

In Panel B of Figure 6.2 (August 1998), liquidity conditions have improved-the MVL frontier rises up from the ground-level plane almost vertically, and up to the third liquidity threshold, the shape of the frontier remains almost unaffected by the liquidity constraint. Panel $\mathrm{C}$ of Figure 6.2 shows a dramatic increase in liquidity - the MVL frontier is twice as tall as the December 1996 frontier, and the level of liquidity at which the surface starts bending to the right is significantly higher than in the previous panels. In Panel D of Figure 6.2, corresponding to the first peak in the S\&P 500 (March 2000), the MVL frontier is at its tallest and it is apparent that the liquidity constraint is irrelevant up to a very high liquidity threshold.

Panels E-H of Figure 6.2 tell a very different story. The shape and height of the MVL frontier change dramatically starting with Panel E (July 2000, the second peak of the S\&P 500), and the trend continues in Panel F (April 2001, the first bottom of the S\&P 500), Panel G (September 2001, including the terrorist attacks on 9/11), and Panel H (December 2001, the last month of the sample). In the face of the bear market of 2000-2001, liquidity conditions have clearly deteriorated, and Figure 6.2 provides a detailed road map of the dynamics of this trend.

An alternative to describing the evolution of the MVL surface is to select a small number of characteristic points on this surface and to plot the trajectories of these points in mean-standard deviation-liquidity space through time. For any mean-variance-efficient frontier, the most relevant point is, of course, the tangency portfolio. In Figure 6.3, the trajectories of the tangency portfolio are plotted for various levels of the liquidity constraint and over time. Each point along the trajectory corresponds to the tangency portfolio of the efficient frontier for a given liquidity threshold $\ell_{0}$. The numerical value of the threshold (in percent) is displayed next to the tangency point, and the position of each point is projected onto the ground-level plane for visual clarity. In addition, two sets of lines are drawn on the ground-level plane: a straight line connecting the riskless portfolio to each tangency portfolio (whose slope is the Sharpe ratio of the tangency portfolio), and curved lines which are MVL frontiers for various levels of the liquidity filter. For each panel, the trajectory of the tangency point starts at the same location on the ground-level plane.

In the absence of any liquidity effects, the trajectory of the tangency portfolio would be vertical and its projection onto the ground-level plane would coincide with its starting point, but because the liquidity constraint does have an impact on the mean-variance combinations that are feasible, Figure 6.3 shows that for successively higher liquidity constraints, the risk/reward profile of the efficient frontier-as measured by the tangency portfolio-worsens, but at different rates for different months. In particular, as the threshold increases, the trajectory of the tangency portfolio moves eastward and away from the viewer. The ground-level projection of the tangency trajectory moves initially in the east-northeast direction but always yielding less desirable Sharpe ratios. In some cases, as the liquidity threshold increases, the ground-level projection of the tangency portfolio turns southeast, yielding tangency portfolios with higher volatility and lower expected return but with higher levels of liquidity. At some point, when it becomes impossible for any of the 50 randomly selected securities to satisfy the liquidity constraint, the trajectory terminates. The dynamics of the trajectory of the tangency portfolio are a qualitative alternative to assessing the impact of liquidity on the characteristics of a mean-variance optimal portfolio.

Figure 6.4 summarizes the trajectories of Figure 6.3 by plotting the Sharpe ratio as a function of the liquidity threshold for each of the months in Table 6.1. This two-dimensional representation of a threedimensional object is a simple way to highlight the trade-off between liquidity and investment performance. The liquidity-constrained trajectories of Figure 6.4 are all concave, and each trajectory is comprised of three 
distinct segments. The first segment - beginning at the left boundary of the graph-is parallel to the liquidity axis, indicating that liquidity constraints have no effect on the tangency portfolio's Sharpe ratio. The second segment is decreasing and concave, implying Sharpe ratios that decline at increasingly faster rates as the liquidity threshold is increased. The third segment is decreasing but linear, implying Sharpe ratios that decline with increasing liquidity thresholds but at a constant rate.

Intuitively, an optimal mean-variance-liquidity portfolio-one that balances all three characteristics in some fashion-should be located somewhere along the second segments of the Sharpe ratio curves in Figure 6.4. It is along these segments that marginal increases in the liquidity threshold yield increasingly higher costs in terms of poorer Sharpe ratios; hence, there should be some liquidity threshold along this segment that balances an investor's preference for liquidity and the risk/reward profile of the tangency portfolio. Of course, turning this heuristic argument into a formal procedure for constructing MVL-optimal portfolios requires the specification of preferences for mean, variance, and liquidity, which is precisely the approach developed in the optimization problem (Equation 6.19) presented earlier in this chapter.

Liquidity-Optimized Portfolios of Hedge Fund Indexes. The mean-variance-liquidity optimization framework presented above can also be applied to hedge fund returns, and as an illustration of this approach, consider a portfolio containing the $13 \mathrm{CSFB} /$ Tremont hedge fund indexes considered in Chapter 4. Using monthly data from January 1994 to February 2004, one can estimate the means, variances, and covariances of the 13 index return series and then construct liquidity-filtered and liquidity-constrained portfolios, as described earlier in this chapter, using the first-order autocorrelation coefficient, $\hat{\rho}_{1}$, as well as the $p$-value of the LjungBox (1978) $Q$-statistic (Equation 3.17) with three autocorrelation coefficients (see Chapter 3).

Table 6.3 reports summary statistics for the tangency and minimum-variance portfolios corresponding to liquidity-filtered and liquidity-constrained mean-variance-liquidity efficient frontiers for different liquidity thresholds and for two different liquidity metrics, $\hat{\rho}_{1}$ and $Q$. When no liquidity restrictions are imposed, the optimal portfolio yields a Sharpe ratio of 3.37, considerably higher than the Sharpe ratios in Table 6.2 but not unusual for a portfolio of hedge fund indexes (recall the power of diversification and the fact that hedge funds often yield higher Sharpe ratios than individual stocks because of the nature of their investment strategies and risk exposures). As liquidity restrictions become more severe, the performance of the tangency portfolio decays, but as in Table 6.2, the decay is remarkably mild for liquidity-constrained portfolios, with the Sharpe ratio declining only by 0.37 to 3.00 for a constraint of 36.26 percent for the portfolio's $\hat{\rho}_{1}$. Not surprisingly, the performance of liquidity-filtered portfolios declines more rapidly and discontinuously because filtering eliminates certain indexes altogether whereas constraints change the weightings of the indexes but allow all of them to be included in the portfolio. These results suggest that a potentially significant amount of liquidity risk in portfolios of hedge funds may be reduced through mean-variance-liquidity optimization.

To show how the portfolio weights change as a function of the liquidity threshold, Figure 6.5 depicts the tangency portfolio weights for four liquidity thresholds. It is clear from these graphs that liquidity constraints do have an impact on portfolio weights, with some indexes getting zero weight at certain liquidity thresholds, and that as the liquidity thresholds change, the weights can change significantly as well.

Figure 6.6 contains plots of the corresponding three-dimensional mean-variance-liquidity efficient frontiers, and Figure 6.7 shows the trajectories of the tangency portfolio as the liquidity threshold varies. The steepness of the surfaces and trajectories in Figures 6.6 and 6.7, respectively, confirm the patterns in Table 6.3there is relatively little performance loss in imposing mild liquidity constraints on hedge fund portfolios. The two-dimensional mean-variance frontiers in Figure 6.8 and the summary graph of the Sharpe ratios of the tangency portfolios in Figure 6.9 provide a more detailed view of this phenomenon. As liquidity thresholds increase, it is clear that the slopes of the tangent lines to the efficient frontiers of the liquidity-constrained portfolios in Panels B and D do not decline a great deal. 


\section{Figure 6.3. Trajectories of the Tangency Portfolio for Liquidity-Constrained Mean-Variance-Liquidity Efficient Frontiers for 50 Randomly Selected Stocks}

A. December 1996

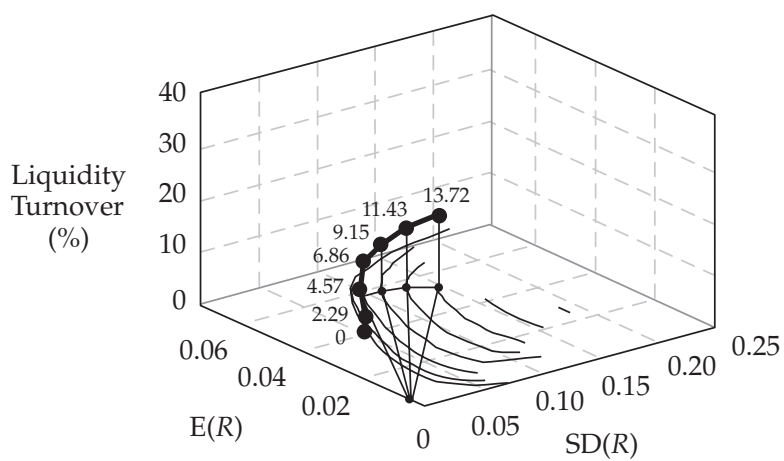

C. October 1998

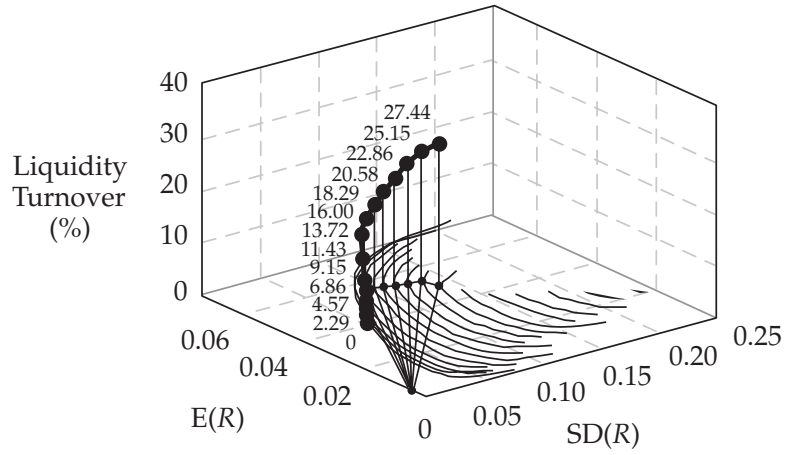

B. August 1998

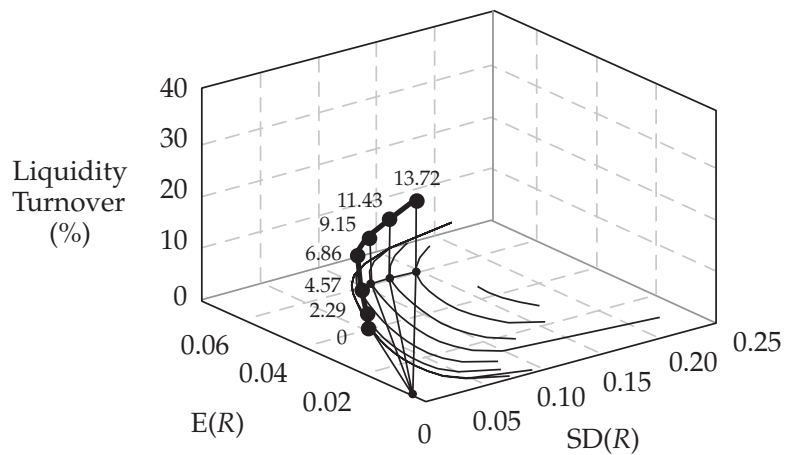

D. March 2000

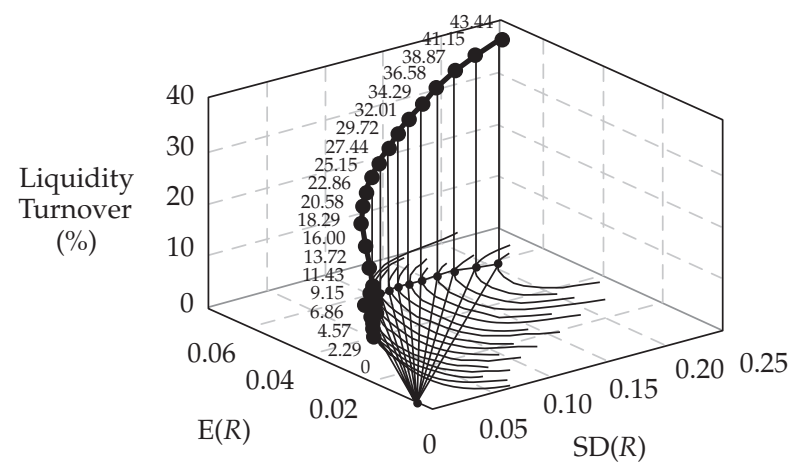

(continued)

\section{Extensions and Open Issues}

Because the integration of liquidity directly into portfolio management processes has not become standard practice, many aspects of the present analysis can be improved upon and extended. The liquidity metrics are clearly simplistic and not based on any equilibrium considerations, and the definition of portfolio liquidity as the weighted average of individual securities' liquidity measures may not be the best definition in all contexts. Better methods of measuring liquidity will obviously lead to better MVL portfolios. ${ }^{68}$ The dynamics of liquidity should also be modeled explicitly, in which case static mean-variance optimization may no longer be appropriate but should be replaced by dynamic optimization methods such as stochastic dynamic programming. Preferences for liquidity must be investigated in more detail: Do such preferences exist, and if so, are they stable and how should they best be parametrized? Finally, estimation error has been ignored in the portfolio construction process, and just as sampling variation affects mean and covariance matrix estimators, liquidity estimators will also be subject to sampling variation, and this may have significant impact on the empirical properties of MVL portfolios. ${ }^{69}$ This is especially relevant for hedge fund applications because of their higher volatility, shorter samples, and dynamic risk exposures, all of which increase estimation error.

${ }^{68}$ See, for example, Chordia, Roll, and Subrahmanyam (2000, 2001, 2002); Getmansky, Lo, and Makarov (2004); Glosten and Harris (1988); Lillo, Farmer, and Mantegna (2003); Lo, Mamaysky, and Wang (2004); Pastor and Stambaugh (2003); and Sadka (2003) for alternate measures of liquidity.

${ }^{69}$ See, for example, Jobson and Korkie (1980, 1981); Klein and Bawa (1976, 1977); and Michaud (1998). 
Figure 6.3. Trajectories of the Tangency Portfolio for Liquidity-Constrained Mean-Variance-Liquidity Efficient Frontiers for 50 Randomly Selected Stocks (continued)

E. July 2000

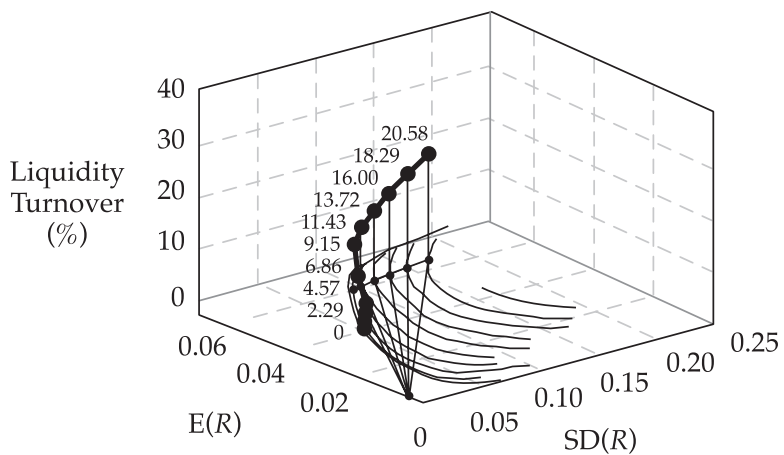

G. September 2001

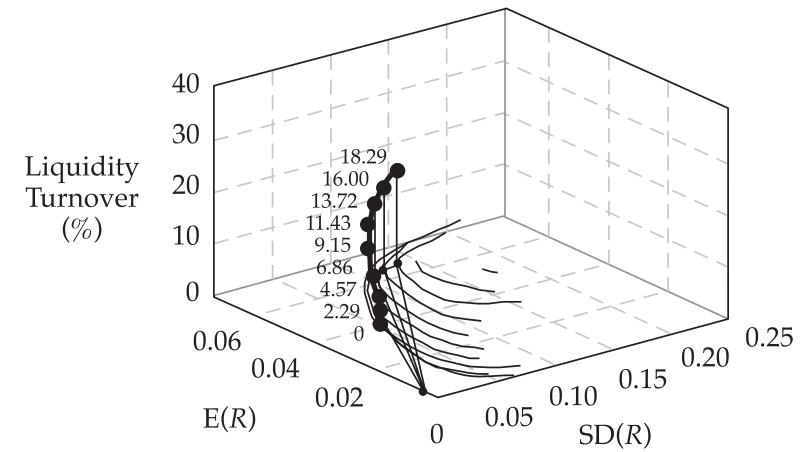

F. April 2001

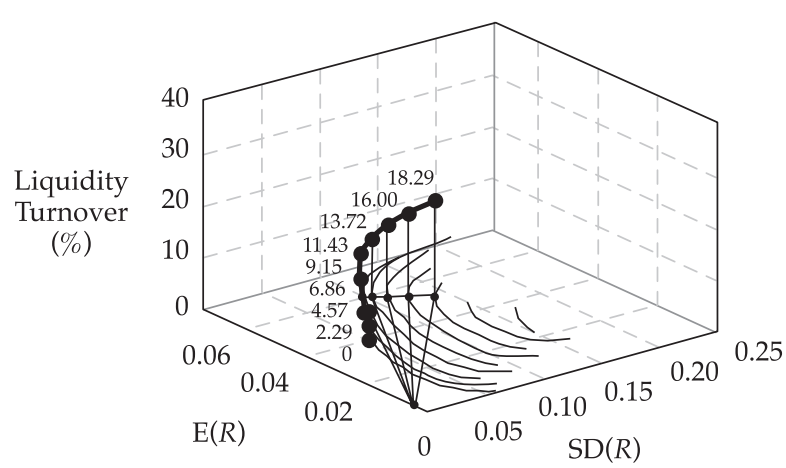

\section{H. December 2001}

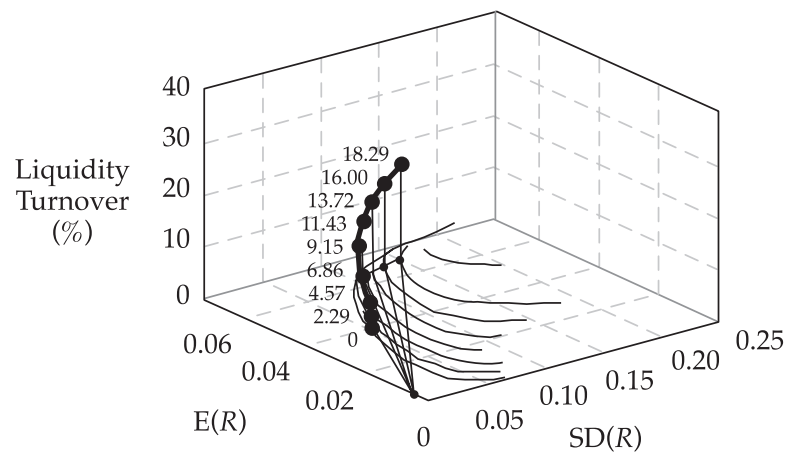

Note: Trajectories of the tangency portfolio for liquidity-constrained mean-variance-liquidity efficient frontiers for 50 randomly selected stocks ( 5 from each of 10 market-capitalization brackets) based on a monthly normalized turnover liquidity metric for the months of December 1996, August 1998, October 1998, March 2000, July 2000, April 2001, September 2001, and December 2001. Expected returns and covariances of the 50 individual securities are estimated with daily returns data from 2 January 1997 to 31 December 2001 and do not vary from month to month. 
Figure 6.4. Sharpe Ratio Trajectories of Tangency Portfolios of Liquidity-Constrained Mean-Variance-Liquidity Efficient Frontiers for 50 Randomly Selected Stocks

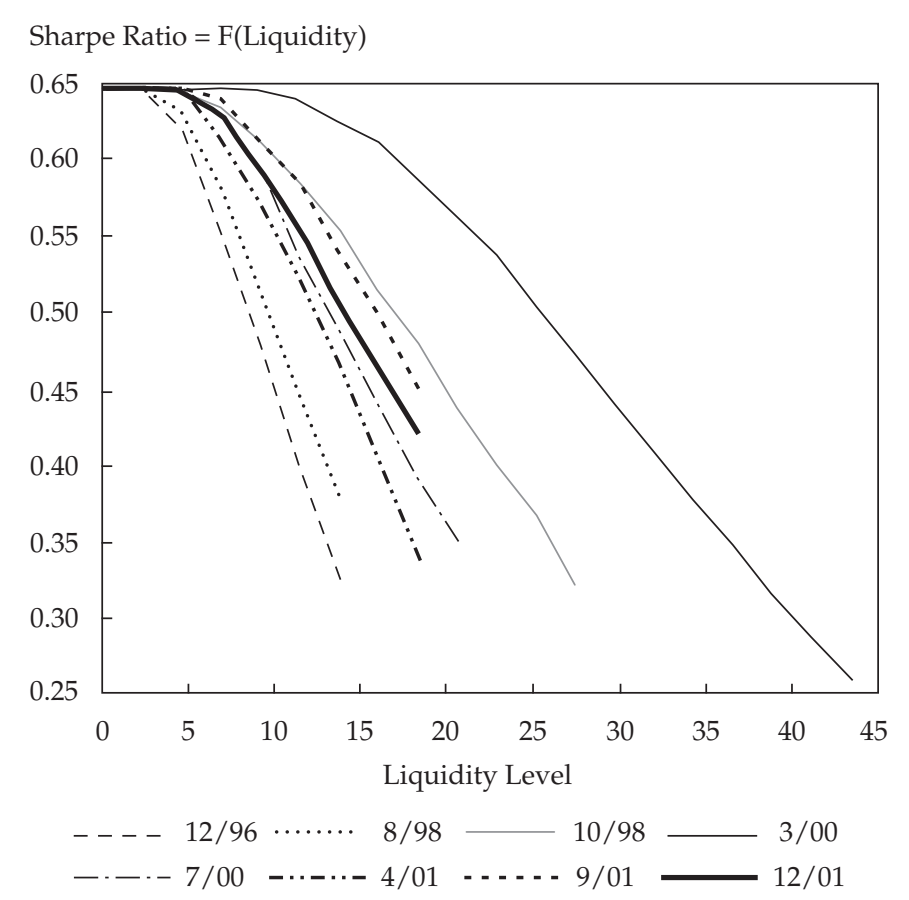

Notes: Sharpe ratio trajectories of tangency portfolios of liquidity-constrained mean-variance-liquidity efficient frontiers for 50 randomly selected stocks (5 from each of 10 market-capitalization brackets) based on a monthly normalized turnover liquidity metric, as a function of the liquidity threshold, for the months of December 1996, August 1998, October 1998, March 2000, July 2000, April 2001, September 2001, and December 2001. Expected returns and covariances of the 50 individual securities are estimated with daily returns data from 2 January 1997 to 31 December 2001 and do not vary from month to month. Thicker lines are used to represent trajectories from more recent months. 
Table 6.3. Monthly Means and Standard Deviations of Tangency and Minimum-Variance Portfolios of Liquidity-Filtered and Liquidity-Constrained Mean-Variance-Liquidity Efficient Frontiers for 13 CSFB/Tremont Hedge Fund Indexes, January 1994 to February 2004

\begin{tabular}{|c|c|c|c|c|c|c|c|c|c|c|c|}
\hline \multirow{2}{*}{$\begin{array}{l}\text { Liquidity } \\
\text { Level }\end{array}$} & \multicolumn{2}{|c|}{$\begin{array}{l}\text { Tangency } \\
\text { Portfolio }\end{array}$} & \multicolumn{2}{|c|}{$\begin{array}{l}\text { Min Var } \\
\text { Portfolio }\end{array}$} & \multirow[b]{2}{*}{ Sharpe } & \multirow{2}{*}{$\begin{array}{l}\text { Liquidity } \\
\text { Level }\end{array}$} & \multicolumn{2}{|c|}{$\begin{array}{l}\text { Tangency } \\
\text { Portfolio }\end{array}$} & \multicolumn{2}{|c|}{$\begin{array}{l}\text { Min Var } \\
\text { Portfolio }\end{array}$} & \multirow[b]{2}{*}{ Sharpe } \\
\hline & $\mathrm{E}(R)$ & $\mathrm{SD}(R)$ & $\mathrm{E}(R)$ & $\mathrm{SD}(R)$ & & & $\mathrm{E}(R)$ & $\mathrm{SD}(R)$ & $\mathrm{E}(R)$ & $\mathrm{SD}(R)$ & \\
\hline \multicolumn{6}{|c|}{$\hat{\rho}_{1}$ Measure of Liquidity, Filtered Portfolios } & \multicolumn{6}{|c|}{$Q$-Statistic Measure of Liquidity, Filtered Portfolios } \\
\hline-2.61 & 9.18 & 2.13 & 8.23 & 1.98 & 3.37 & 1.30 & 9.18 & 2.13 & 8.23 & 1.98 & 3.37 \\
\hline 0.38 & 9.12 & 2.18 & 8.16 & 2.02 & 3.26 & 3.03 & 9.60 & 2.49 & 8.85 & 2.35 & 3.05 \\
\hline 3.37 & 9.12 & 2.18 & 8.16 & 2.02 & 3.26 & 4.77 & 9.55 & 2.58 & 8.77 & 2.43 & 2.93 \\
\hline 6.36 & 9.16 & 2.20 & 8.18 & 2.03 & 3.26 & 6.50 & 9.55 & 2.58 & 8.77 & 2.43 & 2.93 \\
\hline 9.35 & 9.16 & 2.20 & 8.18 & 2.03 & 3.26 & 8.23 & 9.55 & 2.58 & 8.77 & 2.43 & 2.93 \\
\hline 12.34 & 9.55 & 2.58 & 8.77 & 2.43 & 2.93 & 9.97 & 9.55 & 2.58 & 8.77 & 2.43 & 2.93 \\
\hline 15.33 & 9.55 & 2.58 & 8.77 & 2.43 & 2.93 & 11.70 & 9.78 & 2.67 & 8.97 & 2.51 & 2.91 \\
\hline 18.32 & 9.55 & 2.58 & 8.77 & 2.43 & 2.93 & 13.44 & 9.74 & 2.62 & 8.93 & 2.52 & 2.95 \\
\hline 21.31 & 9.55 & 2.58 & 8.77 & 2.43 & 2.93 & 15.17 & 9.74 & 2.62 & 8.93 & 2.52 & 2.95 \\
\hline 24.30 & 9.55 & 2.58 & 8.77 & 2.43 & 2.93 & & & & & & \\
\hline 27.29 & 9.78 & 2.67 & 8.97 & 2.51 & 2.91 & & & & & & \\
\hline 30.28 & 9.79 & 4.21 & 7.97 & 3.69 & 1.85 & & & & & & \\
\hline \multicolumn{6}{|c|}{$\hat{\rho}_{1}$ Measure of Liquidity, Constrained Portfolios } & \multicolumn{6}{|c|}{ Q-Statistic Measure of Liquidity, Constrained Portfolios } \\
\hline-2.61 & 9.18 & 2.13 & 8.23 & 1.98 & 3.37 & 1.30 & 9.18 & 2.13 & 8.23 & 1.98 & 3.37 \\
\hline 0.38 & 9.18 & 2.13 & 8.23 & 1.98 & 3.37 & 3.03 & 9.18 & 2.13 & 8.23 & 1.98 & 3.37 \\
\hline 3.37 & 9.18 & 2.13 & 8.23 & 1.98 & 3.37 & 4.77 & 9.18 & 2.13 & 8.23 & 1.98 & 3.37 \\
\hline 6.36 & 9.18 & 2.13 & 8.23 & 1.98 & 3.37 & 6.50 & 9.18 & 2.13 & 8.23 & 1.98 & 3.37 \\
\hline 9.35 & 9.18 & 2.13 & 8.23 & 1.98 & 3.37 & 8.23 & 9.18 & 2.13 & 8.23 & 1.98 & 3.37 \\
\hline 12.34 & 9.18 & 2.13 & 8.23 & 1.98 & 3.37 & 9.97 & 9.16 & 2.13 & 8.25 & 1.98 & 3.36 \\
\hline 15.33 & 9.18 & 2.13 & 8.23 & 1.98 & 3.37 & 11.70 & 9.18 & 2.13 & 8.26 & 1.98 & 3.37 \\
\hline 18.32 & 9.18 & 2.13 & 8.26 & 1.98 & 3.37 & 13.44 & 9.17 & 2.13 & 8.25 & 1.98 & 3.36 \\
\hline 21.31 & 9.17 & 2.13 & 8.25 & 1.98 & 3.37 & 15.17 & 9.29 & 2.17 & 8.30 & 2.01 & 3.35 \\
\hline 24.30 & 9.19 & 2.14 & 8.27 & 1.98 & 3.36 & 16.91 & 9.30 & 2.19 & 8.32 & 2.04 & 3.33 \\
\hline 27.29 & 9.18 & 2.16 & 8.23 & 1.99 & 3.33 & 18.64 & 9.35 & 2.23 & 8.38 & 2.08 & 3.29 \\
\hline 30.28 & 9.27 & 2.23 & 8.16 & 2.03 & 3.26 & 20.38 & 9.44 & 2.29 & 8.48 & 2.12 & 3.25 \\
\hline 33.27 & 9.35 & 2.33 & 8.31 & 2.14 & 3.15 & 22.11 & 9.48 & 2.34 & 8.55 & 2.17 & 3.20 \\
\hline 36.26 & 9.57 & 2.53 & 8.50 & 2.33 & 3.00 & 23.85 & 9.52 & 2.39 & 8.61 & 2.23 & 3.15 \\
\hline 39.25 & 9.74 & 2.76 & 8.73 & 2.58 & 2.81 & 25.58 & 9.56 & 2.45 & 8.70 & 2.30 & 3.09 \\
\hline 42.24 & 9.86 & 3.03 & 8.91 & 2.89 & 2.60 & 27.31 & 9.65 & 2.52 & 8.78 & 2.37 & 3.03 \\
\hline 45.23 & 9.99 & 3.38 & 9.11 & 3.25 & 2.36 & 29.05 & 9.66 & 2.58 & 8.87 & 2.45 & 2.97 \\
\hline 48.22 & - & - & - & - & - & 30.78 & 9.74 & 2.66 & 8.95 & 2.53 & 2.91 \\
\hline 51.21 & - & - & - & - & - & 32.52 & 9.77 & 2.74 & 9.05 & 2.62 & 2.84 \\
\hline 54.20 & - & - & - & - & - & 34.25 & 9.80 & 2.82 & 9.15 & 2.71 & 2.77 \\
\hline
\end{tabular}

Note: The two liquidity metrics are the first-order serial correlation coefficient, $\hat{\rho}_{1}$, and the Ljung-Box (1978) $Q$-statistic using the first three autocorrelation coefficients. 


\section{Figure 6.5. Portfolio Weights of Liquidity-Constrained Mean-Variance-Liquidity Tangency Portfolios of} 13 CSFB/Tremont Hedge Fund Indexes, January 1994 to February 2004

\section{A. $\hat{\rho}_{1}$ Metric}

A1. Liquidity Level $=-2.61, E(R)=9.18, S D=2.13$ Portfolio Weight

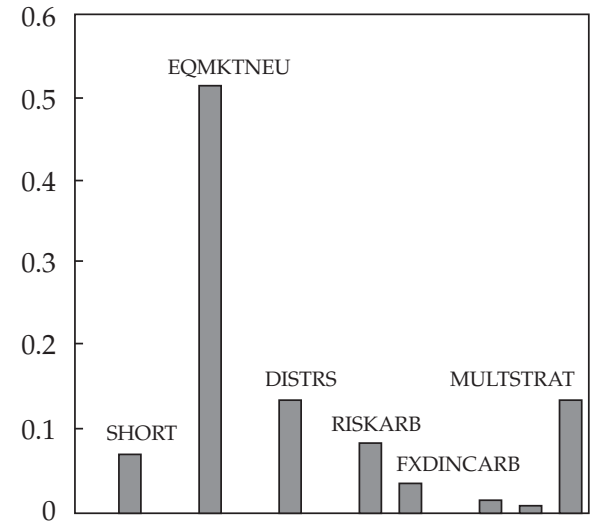

$\begin{array}{llllllllllllll}1 & 2 & 3 & 4 & 5 & 6 & 7 & 8 & 9 & 10 & 11 & 12 & 13\end{array}$

A3. Liquidity Level $=27.29, E(R)=9.18, S D=2.16$

Portfolio Weight

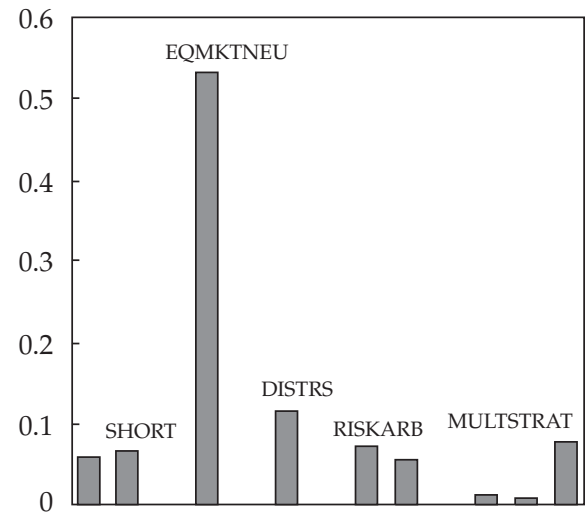

$\begin{array}{lllllllllllll}1 & 2 & 3 & 4 & 5 & 6 & 7 & 8 & 9 & 10 & 11 & 12 & 13\end{array}$
A2. Liquidity Level $=12.34, E(R)=9.18, S D=2.13$

Portfolio Weight

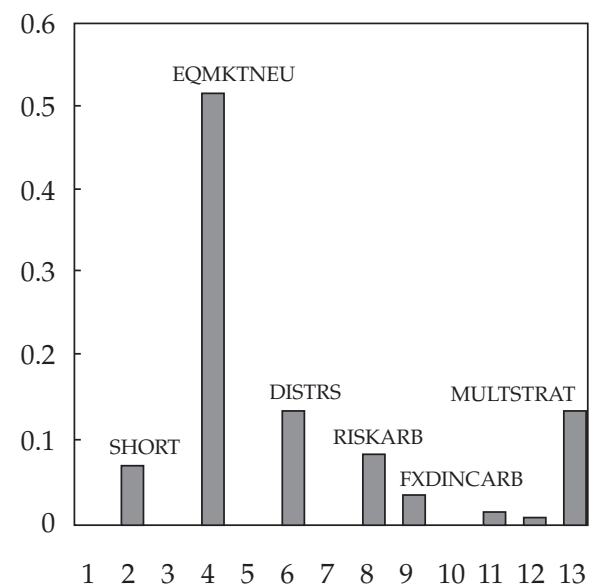

A4. Liquidity Level $=42.24, E(R)=9.86, S D=3.03$ Portfolio Weight

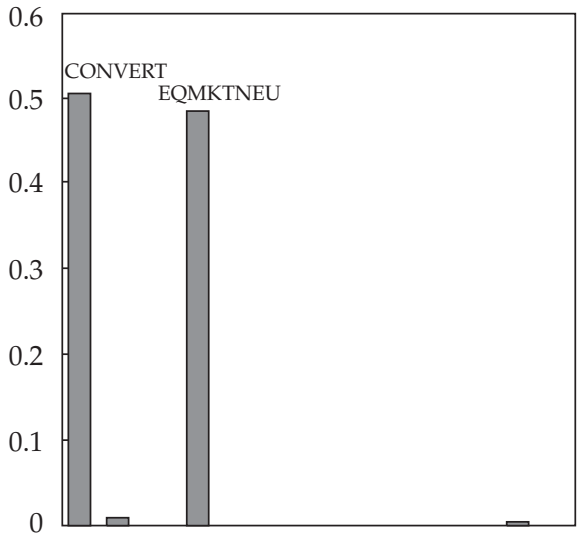

$\begin{array}{lllllllllllll}1 & 2 & 3 & 4 & 5 & 6 & 7 & 8 & 9 & 10 & 11 & 12 & 13\end{array}$ 
Figure 6.5. Portfolio Weights of Liquidity-Constrained Mean-Variance-Liquidity Tangency Portfolios of 13 CSFB/Tremont Hedge Fund Indexes, January 1994 to February 2004 (continued)

\section{B. $Q$ Metric}

B1. Liquidity Level $=1.30, E(R)=9.18, S D=2.13$

Portfolio Weight

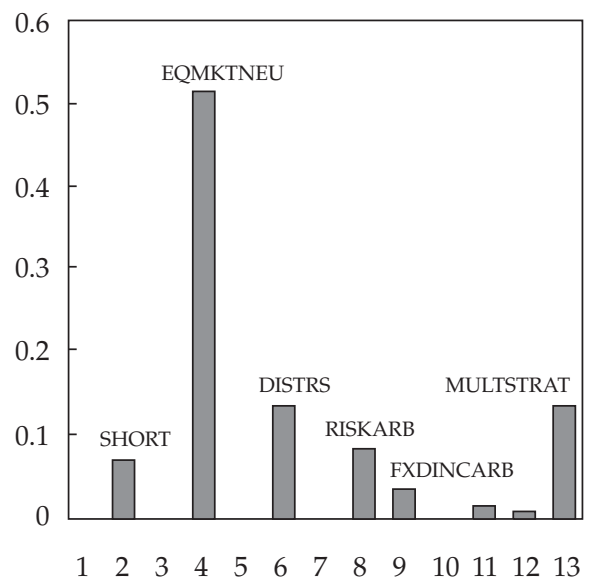

B3. Liquidity Level $=18.64, E(R)=9.35, S D=2.23$

Portfolio Weight

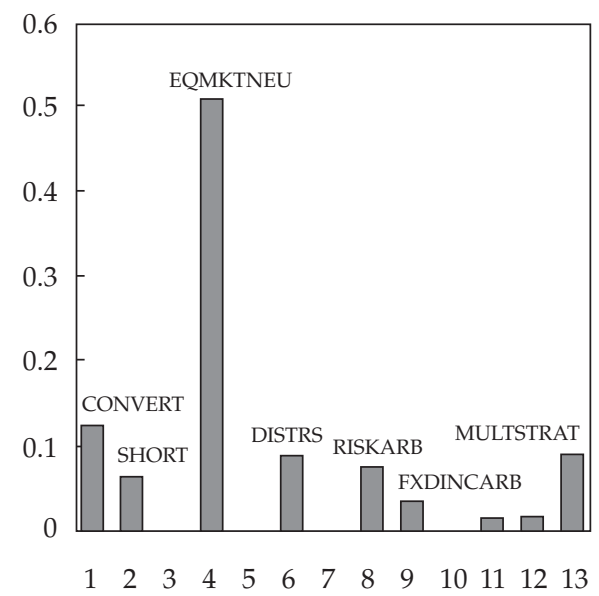

B2. Liquidity Level $=9.97, E(R)=9.16, S D=2.13$

Portfolio Weight

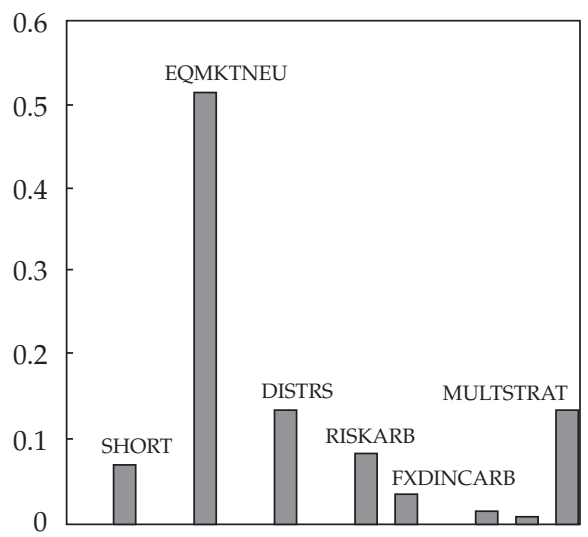

$\begin{array}{llllllllllllll}1 & 2 & 3 & 4 & 5 & 6 & 7 & 8 & 9 & 10 & 11 & 12 & 13\end{array}$

B4. Liquidity Level $=27.31, E(R)=9.65, S D=2.52$

Portfolio Weight

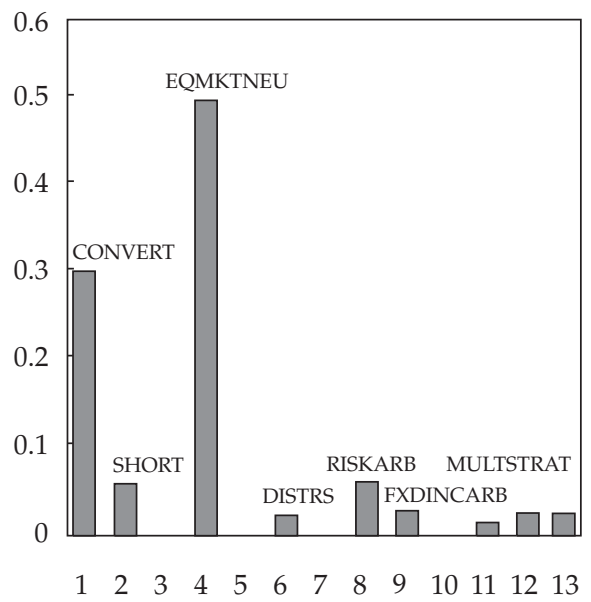

Notes: The four levels of liquidity constraints use two liquidity metrics: the first-order serial correlation coefficient, $\hat{\rho}_{1}$ and the Ljung-Box $Q$-statistic using the first three autocorrelation coefficients. SHORT = Dedicated Shortseller; EQMKTNEU = Equity Market Neutral; DISTRS = Distressed; RISKARB = Risk Arbitrage; FXDINCARB = Fixed-Income Arbitrage; MULTSTRAT = Multi-Strategy; CONVERT $=$ Convertible Arbitrage. 
Figure 6.6. Filtered and Constrained Mean-Variance-Liquidity Efficient Frontiers for 13 CSFB/Tremont Hedge Fund Indexes, January 1994 to February 2004

A. Liquidity-Filtered Frontier: $\hat{\rho}_{1}$ Metric

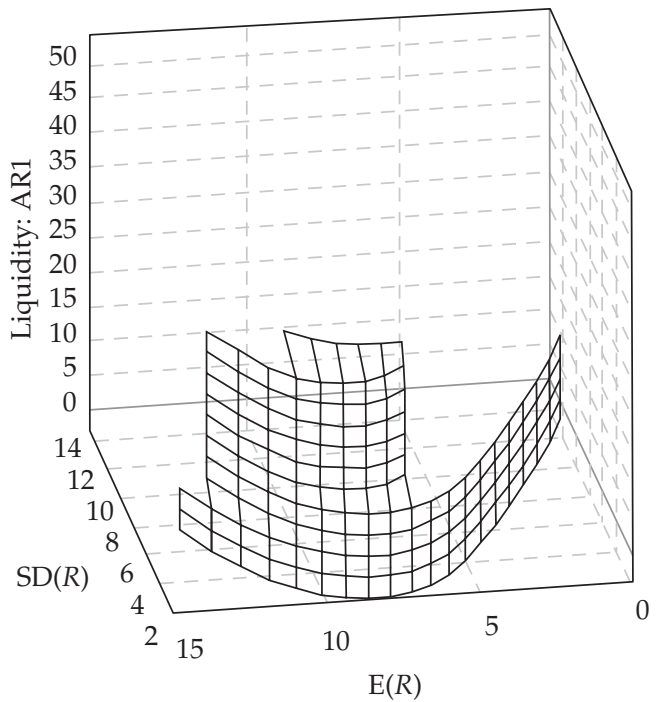

C. Liquidity-Filtered Frontier: Q Metric

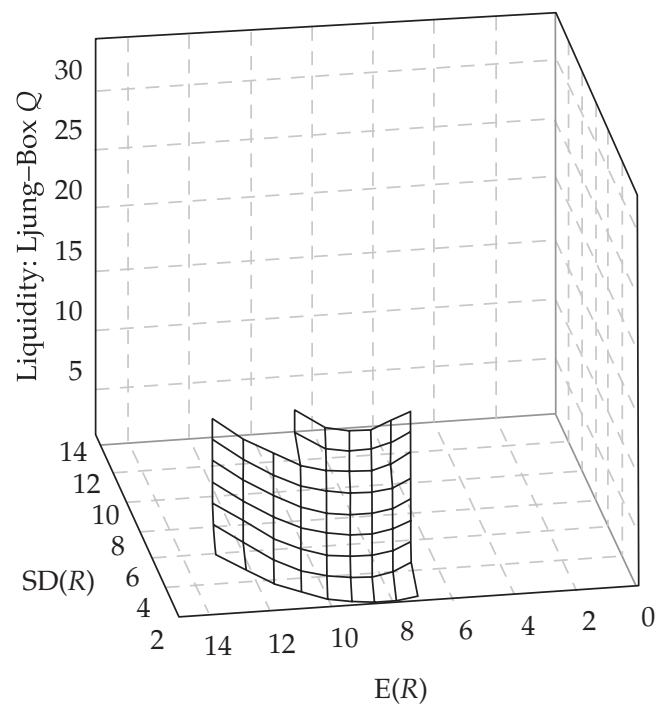

B. Liquidity-Constrained Frontier: $\hat{\rho}_{1}$ Metric

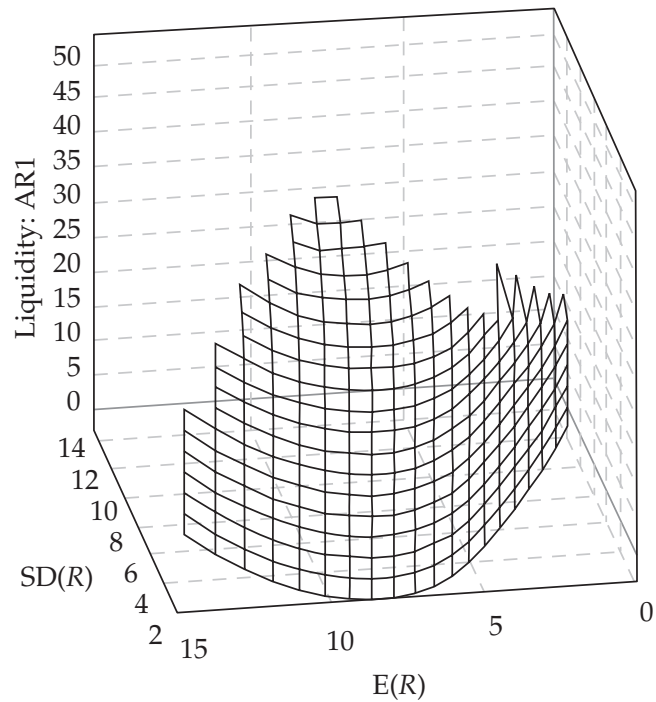

D. Liquidity-Constrained Frontier: $Q$ Metric

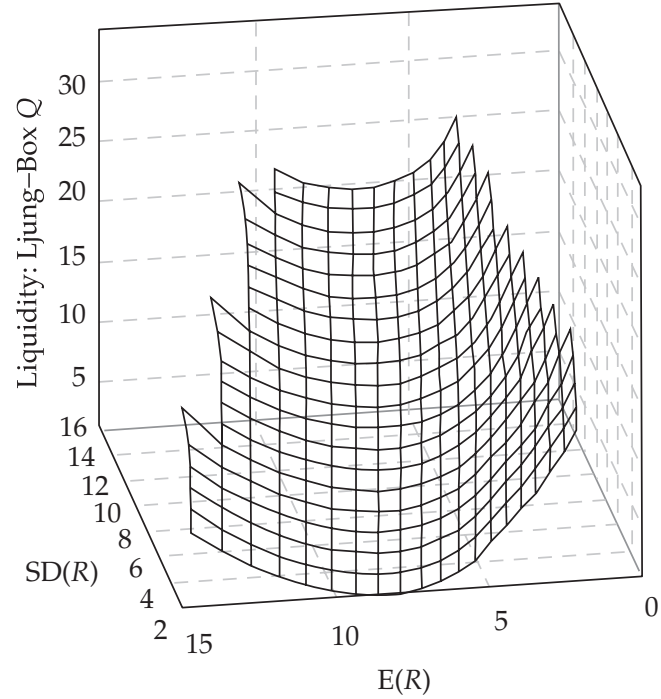

Note: The two liquidity metrics are the first-order serial correlation coefficient, $\hat{\rho}_{1}$, and the Ljung-Box $Q$-statistic using the first three autocorrelation coefficients. 
Figure 6.7. Trajectories of the Tangency Portfolios of Filtered and Constrained Mean-Variance-Liquidity Efficient Frontiers of 13 CSFB/Tremont Hedge Fund Indexes, January 1994 to February 2004

A. Tangency Portfolio, Liquidity: $\hat{\rho}_{1}$ Filtered Optimization, February 2005

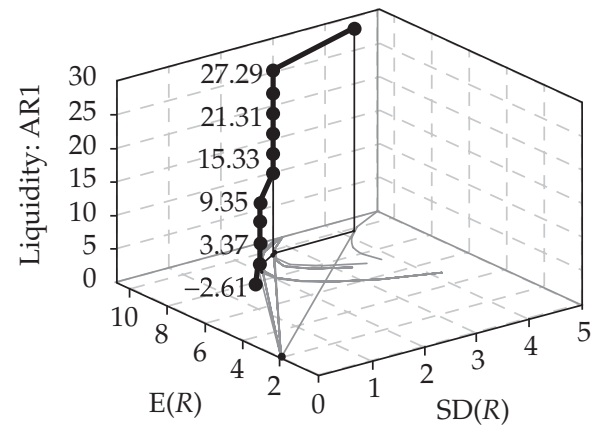

C. Tangency Portfolio, Liquidity: Ljung-Box Q, Filtered Optimization, February 2005

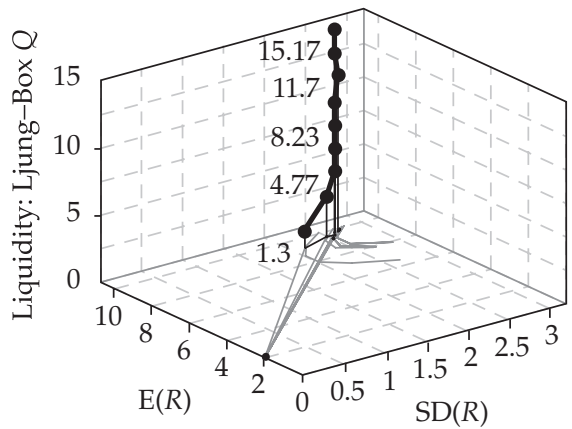

B. Tangency Portfolio, Liquidity: $\hat{\rho}_{1}$ Constrained Optimization, February 2005

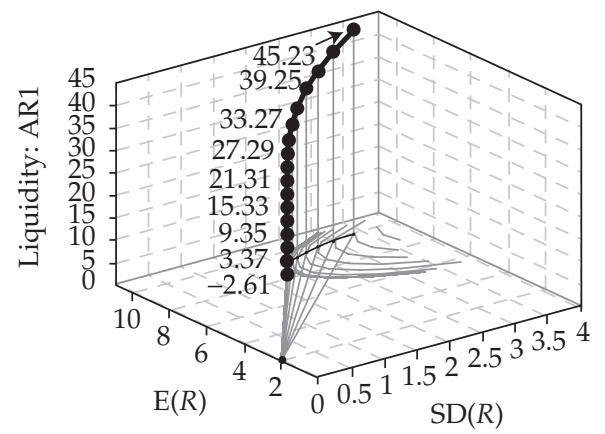

D. Tangency Portfolio, Liquidity: Ljung-Box $Q$, Constrained Optimization, February 2005

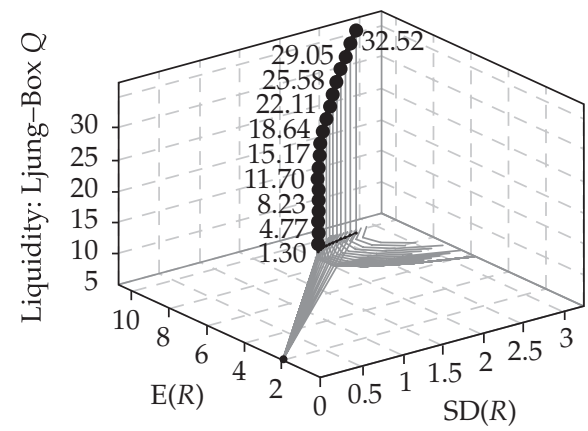

Note: The two liquidity metrics are the first-order serial correlation coefficient, $\hat{\rho}_{1}$, and the Ljung-Box $Q$-statistic using the first three autocorrelation coefficients. 
Figure 6.8. Mean-Variance-Efficient Frontiers for 13 CSFB/Tremont Hedge Fund Indexes, January 1994 to February 2004

\section{A. Filtered, $\hat{\rho}_{1}$ Metric}

Annualized E(R) (\%)

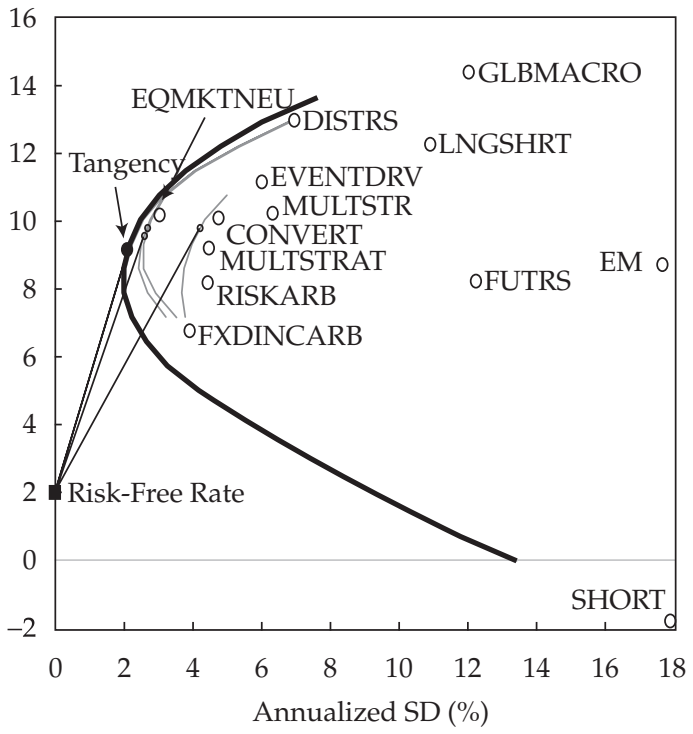

C. Filtered, $Q$ Metric

Annualized E(R) $(\%)$

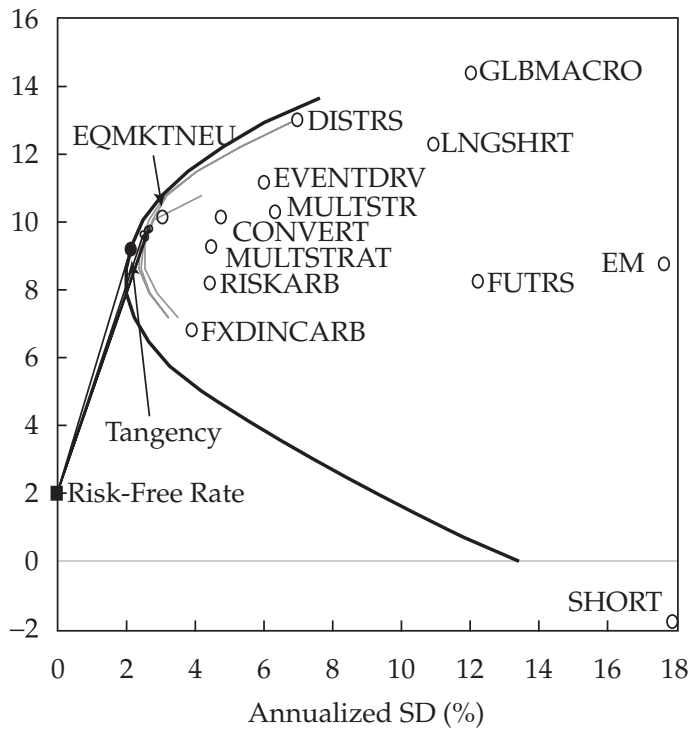

B. Constrained, $\hat{\rho}_{1}$ Metric

Annualized E(R) (\%)

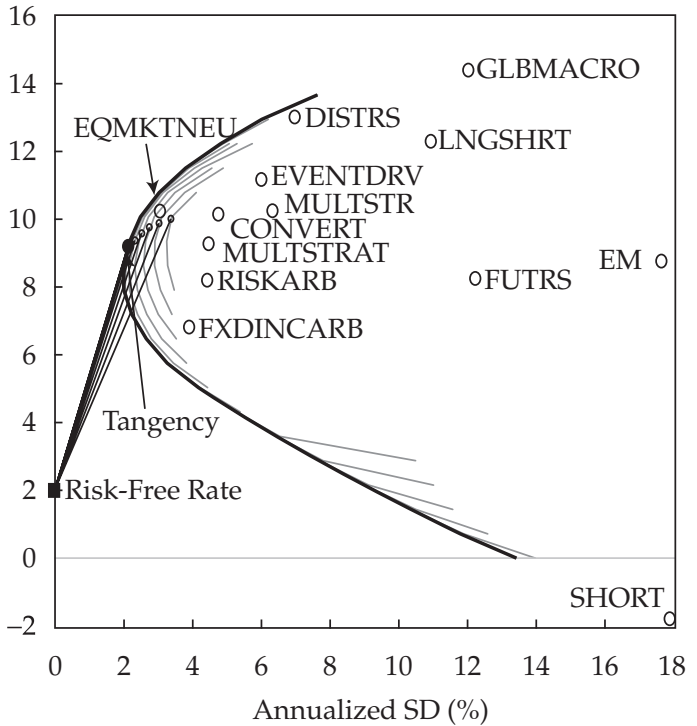

D. Constrained, Q Metric

Annualized E $(R)(\%)$

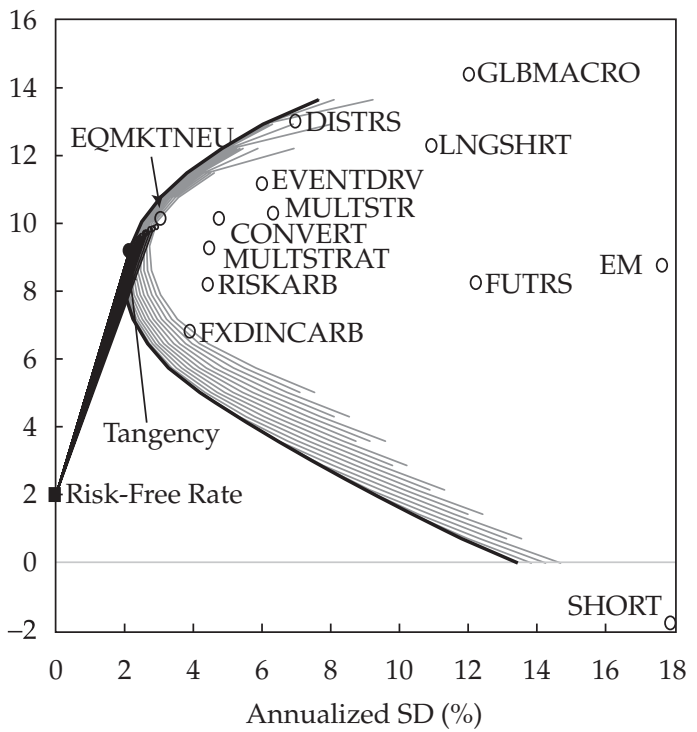

Note: Data for various levels of liquidity constraints and filters using two liquidity metrics: the first-order serial correlation coefficient, $\hat{\rho}_{1}$, and the Ljung-Box $Q$-statistic using the first three autocorrelation coefficients. 
Figure 6.9. Filtered and Constrained Sharpe Ratio Trajectories of Tangency Portfolios for Filtered and Constrained Mean-Variance-Liquidity Efficient Frontiers for 13 CSFB/Tremont Hedge Fund Indexes, January 1994 to February 2004

\section{A. Filtered, $\hat{\rho}_{1}$ Metric}

Sharpe Ratio $=\mathrm{F}($ Liquidity $)$

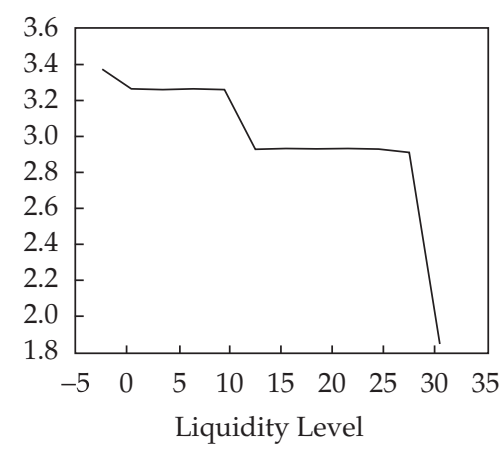

C. Filtered, $Q$ Metric

Sharpe Ratio $=\mathrm{F}($ Liquidity $)$

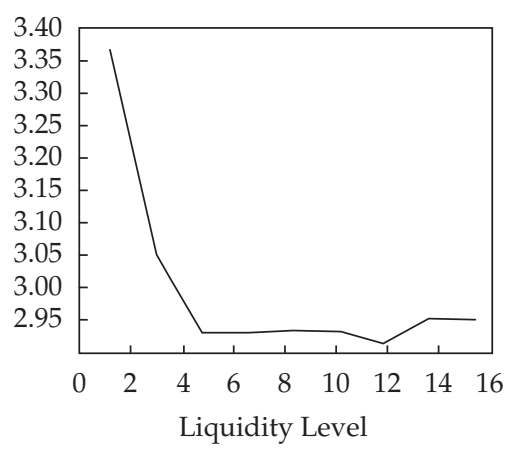

B. Constrained, $\hat{\rho}_{1}$ Metric

Sharpe Ratio $=\mathrm{F}($ Liquidity $)$

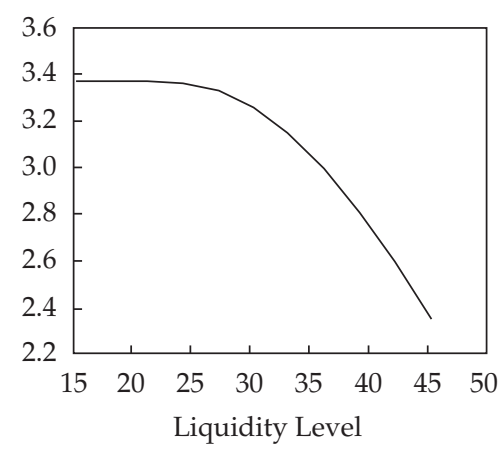

D. Constrained, Q Metric Sharpe Ratio $=$ F(Liquidity)

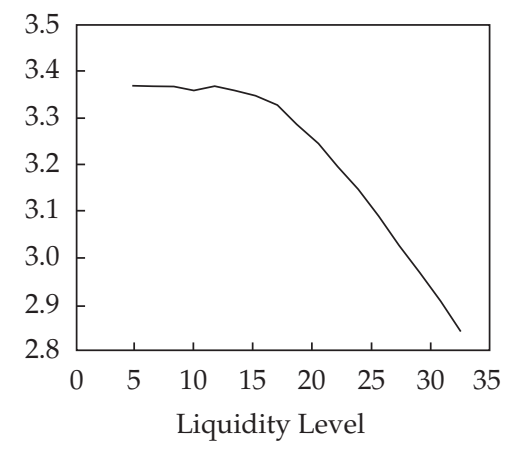

Note: The two liquidity metrics are the first-order serial correlation coefficient, $\hat{\rho}_{1}$, and the Ljung-Box $Q$-statistic using the first three autocorrelation coefficients. 


\section{An Integrated Hedge Fund Investment Process}

Despite the growing number of studies proposing quantitative approaches to alternative investments, 70 hedge fund investors have yet to embrace any single analytic framework for formulating their investment policies. There are several reasons for this state of affairs. One reason may lie in the cultural history of the hedge fund investor community, which was forged by high-net-worth individuals, family offices, foundations, and endowments. These early patrons of hedge funds, commodity trading advisors (CTAs), and private equity placed more emphasis on the specific characteristics of individual managers and entrepreneurs than on detailed portfolio construction algorithms. It was in this milieu that the financial "gunslinger" was born, an iconoclast with often cryptic and occasionally brilliant market insights, a healthy appetite for risk, and little regard for convention and constraints. As a result, the legal, tax, and operational aspects of individual managers became the centerpiece of the typical investment process. Having gone through generations of refinements and trial-and-error improvements, the "due diligence process," as this process is now known, has come to be an indispensable part of any serious hedge fund investor's deliberations. Because of the complexity and multifaceted nature of this process, ${ }^{71}$ many seasoned professionals have concluded that investing in hedge funds is best done through qualitative judgment and is simply not amenable to quantitative analysis.

A second reason for the current state of hedge fund investment processes is the acknowledged limitations of traditional portfolio management tools for most alternative investments. ${ }^{72}$ Experienced investors no doubt understand that diversification is important-indeed, this was the primary motivation for the creation of the very first hedge fund - but apart from acknowledging this simple truth, it is unclear how best to proceed. The capital allocation problem for a multi-manager fund or fund of funds differs in several respects from a standard portfolio construction problem. Issues such as lockup periods, incentive fees and high-water marks, clawback agreements, illiquidity and mark-to-market policies, leverage and credit exposure, dynamic shifts in trading strategies and objectives, enormous heterogeneity among managers, and an overall lack of transparency render the usual mean-variance portfolio optimization techniques less than compelling for alternative investments.

A third reason is simply the lack of data and research that are directly relevant for hedge funds. Until recently, there were no commercially available hedge fund databases; hence, the barriers to entry for investors were quite high. Large family offices and endowments were among the few organizations with a long history of investing in hedge funds and enjoyed a significant competitive advantage because of the private collection of manager track records they possessed. The lack of data naturally also placed a constraint on the quantity and quality of published research in alternative investments.

However, the hedge fund industry has progressed dramatically in the last decade. There are now many vendors of hedge fund data, resulting in a thriving academic and practitioner literature on alternative investments, 73 and a number of trade publications and professional organizations for hedge fund managers and investors. ${ }^{74}$ Therefore, this is an opportune time to revisit the application of quantitative methods to the hedge fund investment process.

\footnotetext{
70 See, for example, Amenc and Martinelli (2002); Amin and Kat (2003c); Terhaar, Staub, and Singer (2003); and Cremers, Kritzman, and Page (2004).

71To develop a deeper appreciation for the intricacies of the hedge fund due diligence process, review any hedge fund due diligence questionnaire from an experienced investor. The document is typically 20 pages or longer and covers a remarkably broad spectrum of issues ranging from back-office systems to investment strategies to personnel employment contracts to the manager's personal history. 72 See, in particular, Cremers, Kritzman, and Page (2004).

${ }^{73} \mathrm{See}$, for example, the Journal of Alternative Investments and the related website of the Center for International Securities and Derivatives Markets at the University of Massachusetts at Amherst (http://cisdm.som.umass.edu/), one of the pioneers in sponsored research on hedge funds.

${ }^{74}$ In addition to CFA Institute, which has a considerably broader focus than just alternative investments, the nonprofit Alternative Investment Management Association was founded in 1990 and now boasts members in 42 countries. In 2002, AIMA and CISDM (see Note 73) established the Chartered Alternative Investment Analyst Association, with its own certification process for training analysts in the area of alternative investments.
} 
In this chapter, I propose an analytical framework for constructing a portfolio of hedge funds (i.e., a riskbased approach to making capital allocations among multiple strategies or managers in an alternative investments context). However, contrary to the common belief that an investment process is either qualitative or quantitative but not both, I argue that it is possible — and essential— to combine the two approaches in a consistent fashion and within a single investment paradigm.

To achieve this integration, I propose a two-stage investment process in which capital allocations are made quantitatively across broad "asset classes," and then, within each asset class, capital is allocated to each manager according to a well-defined heuristic that integrates qualitative judgments into a quantitative framework. 75 The following is a summary of the design principles that underlie the approach described below:

- The target expected return for each strategy should be commensurate with the risks of that strategyhigher-risk strategies should have higher target expected returns.

- The uses of funds, not the sources of funds, should determine the target expected return.

- In evaluating the risk/reward ratio for each strategy, serial correlation and illiquidity exposure should be taken into account explicitly. In particular, the Sharpe ratios of strategies with large positively serially correlated returns should be deflated (see Lo 2002; Getmansky, Lo, and Makarov 2004; and Chapter 5 for details).

- Qualitative judgments about managers, strategies, and market conditions are valuable inputs into the capital allocation process that no quantitative models can replace, but those judgments should be integrated in a systematic and consistent fashion with traditional quantitative methods.

- Risk and performance attribution should be performed on a regular basis for and by each manager, as well as for the entire portfolio.

- $\quad$ Risk limits and related guidelines for each manager should be consistent across time and across managers and should be communicated clearly to all managers on a regular basis.

These design principles, coupled with insights from traditional portfolio management theory and practice, suggest a mean-variance-optimization problem in which required or "target" expected returns and variances are determined in advance by investor mandates and market conditions, covariances are estimated via econometric methods, and then asset-class allocations are determined by minimizing variance subject to an expected return constraint. Within each asset class, allocations are determined by incorporating qualitative information into the investment process through a scoring process. The seven components of such a capital allocation algorithm are as follows:

1. Define asset classes by strategy.

2. Set target portfolio expected return $\mu_{\mathrm{o}}$ and desired volatility $\sigma_{0}$.

3. Set target expected returns and risks for asset classes.

4. Determine correlations via econometric analysis.

5. Compute minimum-variance asset-class allocations subject to the $\mu_{\circ}$ constraint.

6. Allocate capital to managers within each asset class.

7. Monitor performance and risk budgets, and re-optimize as needed.

Each of these components is described in more detail in subsequent sections, and the general design of the two-stage process is outlined in Figure 7.1 and Figure 7.2. All mathematical details are relegated to the Appendix (see the section titled "Constrained Optimization"). The final specifications for the entire framework are summarized later in this chapter, and finally, I describe a method for communicating risk limits to individual managers based on the overall portfolio's risk capital.

Before proceeding with the exposition of this capital allocation algorithm, it is important to emphasize the disclaimer that the following discussion is not meant to be a detailed recipe for a specific hedge fund investment process. It is, instead, meant to serve as a prototype and framework for developing such a process within the context of each investor's particular objectives, constraints, and organizational infrastructure. Certain components will be appropriate for some investors but not for others, and all components require some degree of customization to render them applicable to a given investor and a given set of funds.

$75 \mathrm{~A}$ two-stage investment process is generally suboptimal relative to a single-stage optimization, but there are compelling reasons for adopting the former approach for alternative investments. See the section titled "Qualifications and Extensions," later in this chapter, for further discussion. 
Figure 7.1. Phase 1: Capital Allocation over Asset Classes

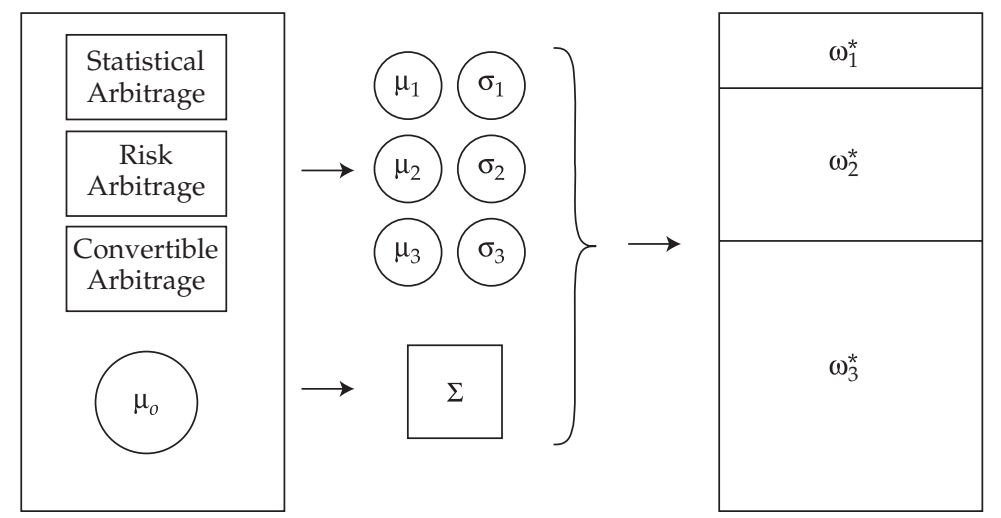

Note: First stage of a quantitative capital allocation algorithm for alternative investments, in which asset classes are defined and optimal asset-class weights are determined as a function of target expected returns and risk levels and an estimated covariance matrix.

Source: AlphaSimplex Group.

\section{Define Asset Classes by Strategy}

The first step involves subdividing the universe of strategies into a small number $n$ of relatively homogeneous managers or asset classes. Within each asset class, the strategies should have similar characteristics-expected returns, risks, legal and operational infrastructure, etc.- - and should be highly correlated. Examples of asset classes include

- $\quad$ equity market neutral,

- risk arbitrage,

- convertible arbitrage,

- fixed-income relative value,

Figure 7.2. Phase 2: Capital Allocation within Asset Classes

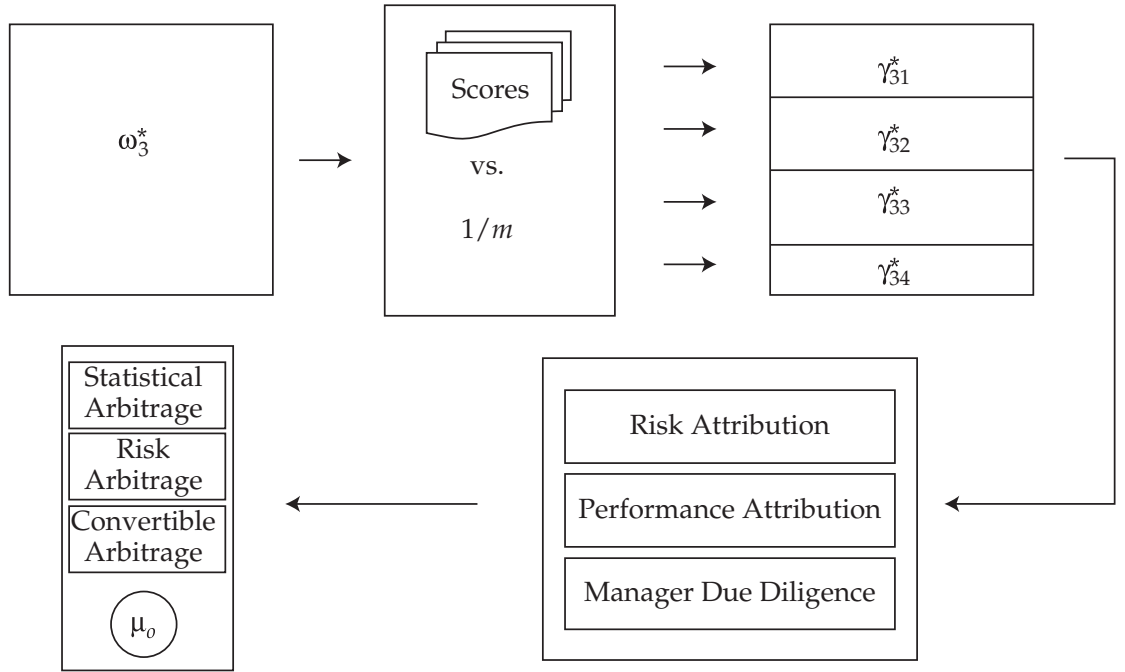

Note: Second stage of a quantitative capital allocation algorithm for alternative investments, in which capital is allocated to managers within an asset class according to a scoring procedure that incorporates qualitative as well as quantitative information.

Source: AlphaSimplex Group. 
- global macro,

- emerging market debt, and

- shortsellers, and Appendix A contains a more complete list of categories in the TASS hedge fund database.

\section{Set Portfolio Target Expected Returns}

Given client mandates and market conditions, a target expected return $\mu_{o}$ for the entire portfolio must be determined. For example, in the current economic environment, a portfolio of U.S. equity market-neutral strategies may call for an expected return of 8 percent. In 1997, such a portfolio might have had a target of 15 percent. This parameter is typically set by the investment committee or chief investment officer of a fund of funds.

A desired level of risk $\sigma_{o}$ should also be specified. Note that $\sigma_{o}$ is not called a "target" risk level because it is not generally possible to specify both the expected return and risk of a portfolio when the set of asset classes and managers is fixed. For a given set of assets, I can always construct a portfolio with expected return $\mu_{0}$ that is minimum variance, or a portfolio with risk $\sigma_{0}$ that has maximum expected return (as long as $\sigma_{0}$ is greater than the risk of the global minimum-variance portfolio), but not both (see "Constrained Optimization" in Appendix A). Therefore, the portfolio construction process is necessarily an iterative one that requires some qualitative judgment as well as quantitative analysis.

\section{Set Asset-Class Target Expected Returns and Risks}

For each asset class $i$ defined above, a target expected return $\mu_{i}$ and risk $\sigma_{i}$ must be specified. This is a critical step in the capital allocation process because it is here that the trade-off between risk and expected return is incorporated into the investment process. Managers undertaking more risky strategies should have a higher required rate of return, regardless of the financing costs associated with the capital - the uses of capital, not the sources of capital, should determine the target expected return.

A useful starting point for making this risk/reward trade-off is a linear factor model such as the Capital Asset Pricing Model or Arbitrage Pricing Theory, which typically implies a linear relation between an investment's expected return and its risk exposures. A modified version of such a relation for hedge fund applications is given by

$$
\mu_{i}=R_{f}+\beta_{i 1} \pi_{1}+\beta_{i 2} \pi_{2}+\cdots+\beta_{i p} \pi_{p}+\alpha_{i},
$$

where $\beta_{i j}$ is the risk exposure of asset class $i$ to factor $j, \pi_{j}$ is the risk premium associated with factor $j$, and $\alpha_{i}$ is the combined alpha of the managers in asset class $i$. The interpretation of Equation 7.1 is that the expected return of asset class $i$ above the cash return $R_{f}$ is proportional to the risk exposures of the asset class plus the value-added that active management provides. Factors that are most relevant for hedge fund strategies include the following:

- Price factors

- Sectors

- Investment style

- Volatilities

- Credit

- Liquidity

- Macroeconomic factors

- Sentiment

- Nonlinear interactions

However, the examples of Chapter 3 provide compelling motivation for developing nonlinear extensions of these linear factor models so as to account for some of the more complex dynamics of hedge fund strategies.

Once a factor model is specified, risk exposures can be readily estimated from historical data, but in some cases it may be necessary to adjust these estimates to reflect changes in current market conditions, the specific managers or strategies in each asset class, and other factors. For example, the 10-year historical average return and volatility of fixed-income arbitrage strategies are likely to be quite different from their post-1998 expected 
return and risk. Therefore, the target expected returns and risk levels should be set by the risk committee of the fund of funds, perhaps using historical estimates as initial values that are modified periodically through qualitative evaluation as well as quantitative analysis.

\section{Estimate Asset-Class Covariance Matrix}

Using both backtest and historical performance data, the correlations of the returns of the $n$ asset classes must be estimated. Ideally, the estimation method should incorporate nonlinearities that often characterize hedged strategies, as well as changes in regime, as in the pre- versus post-1998 periods (see the examples in Chapter 3 ). Once the correlations $\rho_{i j}$ have been estimated, the covariance matrix of the $n$ asset classes can be constructed using the definition of a covariance $\sigma_{i j}$ :

$$
\sigma_{i j}=\rho_{i j} \times \sigma_{i} \times \sigma_{j}
$$

where $\sigma_{i}$ and $\sigma_{j}$ have been specified in the preceding section.

Note that I propose to estimate the correlation matrix, not the covariance matrix. There are at least three reasons for such an approach. First, there is some empirical evidence to suggest that correlations are more stable over time than covariances. This is not altogether surprising, given the substantial literature documenting timevarying volatilities in financial asset returns (see, for example, Andersen, Bollerslev, and Diebold 2004). If second moments vary through time in a similar manner, ratios of those moments, such as correlation coefficients, are likely to be more stable. Second, time-varying correlation matrices can be modeled more parsimoniously than time-varying covariance matrices, as Engle (2002) illustrates, a fact which is particularly relevant for portfolios with a large number of funds. Third, recall that the variances of the asset classes are prespecified (see the preceding section) and not necessarily estimated from historical data. If such prespecified values are inserted into an estimated covariance matrix, the result need not be positive definite, a situation which can yield anomalous results such as spurious arbitrage opportunities and unstable portfolio weights. By reconstructing the covariance matrix from the estimated correlation matrix using Equation 7.2, I am guaranteed a well-behaved covariance matrix estimator.

\section{Compute Minimum-Variance Asset Allocations}

From the preceding sections, I now have the following parameters:

$\mu_{0}=$ target expected return

$\boldsymbol{\mu}=\left[\mu_{1} \ldots \mu_{n}\right]^{\prime}=$ target asset-class expected returns

$\boldsymbol{\Sigma}=$ asset-class covariance matrix

Given these parameters, I can now construct a portfolio of $n$ managers to minimize the variance of the portfolio subject to a constraint that the expected return is at least $\mu_{\circ}: 76$

$$
\operatorname{Min}_{\boldsymbol{\omega}} \frac{1}{2} \boldsymbol{\omega}^{\prime} \boldsymbol{\Sigma} \boldsymbol{\omega} \text { subject to } \boldsymbol{\omega}^{\prime} \boldsymbol{\mu} \geq \mu_{o} \text { and } \boldsymbol{\omega}^{\prime} \mathbf{\imath}=1 .
$$

The solution to Equation 7.3 is given by (see "Constrained Optimization" in Appendix A)

$$
\boldsymbol{\omega}^{*}=\lambda \boldsymbol{\Sigma}^{-1} \boldsymbol{\mu}+\xi \boldsymbol{\Sigma}^{-1} \mathbf{t}
$$

\footnotetext{
76 For most fund-of-fund and multi-manager applications, it is also necessary to impose non-negativity constraints on the portfolio weights, since it is typically impossible to establish a "short" position in a manager. However, as long as the target expected returns are realistic and the covariance matrix is well behaved, Equation 7.4 should yield non-negative portfolio weights. If not, this may be a sign of model misspecification that can serve as a useful diagnostic for identifying potential problems with the portfolio construction process. Alternatively, recent innovations in structured products do allow the synthetic shorting of certain hedge fund strategies, in which case, more efficient fund-of-funds portfolios may be possible. However, given the complexities of OTC derivatives on hedge funds and the significant risks they can generate, the shorting of hedge funds should be contemplated only by the most sophisticated and wellcapitalized of investors.
} 
where $\lambda$ and $\xi$ are defined in Appendix A. As a consistency check, it is useful to compute the volatility $\sigma$ of the entire portfolio implied by $\boldsymbol{\omega}^{*}$ :

$$
\sigma=\sqrt{\omega^{* \prime} \Sigma \omega^{*}}
$$

If $\sigma$ is higher than $\sigma_{o}$, this implies an inconsistency with the following set of objectives:

- target expected return $\mu_{0}$

- desired risk level $\sigma_{0}$

- target expected returns and risks of asset classes $\left(\mu_{i}, \sigma_{i}\right)$

and at least one of these three objectives must be modified to restore consistency.

If the total investment capital is $K$, the optimal dollar allocation to each asset class is simply $K_{i}^{*}$, where

$$
K_{i}^{*}=\omega_{i}^{*} K
$$

\section{Determine Manager Allocations within Each Asset Class}

For each asset class $i$, the optimal dollar allocation $K_{i}^{*}$ must be distributed among $m_{i}$ managers. Although these suballocations may also be determined quantitatively along the same lines as in the preceding section, this is likely to be less than ideal because of the qualitative nature of manager selection and development, particularly for new managers that do not possess extensive track records from which parameter estimates can be readily obtained. Therefore, consider the following heuristic method. Let $\gamma_{i k}$ denote the fraction of $K_{i}^{*}$ allocated to manager $k$ in asset class $i$; hence, $\Sigma_{k} \gamma_{i k}=1$. The starting point for the allocations is $\gamma_{i k}=1 / m_{i}$ (i.e., identical allocations across all $m_{i}$ managers). Now, for each manager, construct a score $S_{i k}$ by evaluating the manager against the following criteria, perhaps using a numerical score from 1 to 5 for each criterion:

- $\quad$ anticipated alpha

- $\quad$ anticipated risk

- $\quad$ anticipated capacity

- $\quad$ anticipated correlation with other managers and asset classes

- trading experience and past performance

- backtest performance attribution

- tracking error

- risk controls

- $\quad$ risk transparency

- alpha transparency

- operational risks

- other qualitative due diligence issues

For example, a manager with a high anticipated alpha (as determined through the largely qualitative manager selection and due diligence processes) would receive a score of 5, and a manager with a low anticipated alpha would receive a score of 1 . Similarly, a high-risk manager (relative to the asset-class volatility $\sigma_{i}$ ) would receive a score of 1 , and a moderate-risk manager would receive a score of 3 . The sum of each of these ratings yields the manager's score $S_{i k}$. Then define the relative score $s_{i k}$ as

$$
s_{i k}=\frac{S_{i k}}{S_{i 1}+\cdots+S_{i m_{i}}} .
$$

Then the manager's allocation can be defined as

$$
\gamma_{i k}=(1-\delta) \times \frac{1}{m_{i}}+\delta \times s_{i k},
$$

where $\delta$ is a parameter that determines the weight placed on the relative scores versus equality. 

For a given set of manager allocations $\gamma_{i} \equiv\left[\gamma_{i 1} \ldots \gamma_{i m_{i}}\right]^{\prime}$ in asset class $i$, the implied expected return and
volatility of the asset class are given by

$$
\tilde{\mu}_{i}=\boldsymbol{\gamma}_{i}^{\prime} \boldsymbol{\nu}_{i}, \quad \tilde{\sigma}_{i}=\sqrt{\gamma_{i}^{\prime} \bar{\Sigma}_{i} \gamma_{i}},
$$

where $\boldsymbol{v}_{i}$ is the vector of expected returns of each manager in asset class $i$ (as determined either by backtests or by historical performance) and $\boldsymbol{\Sigma}_{i}$ is the covariance matrix of the managers in asset class $i$. Before implementing the allocation $\boldsymbol{\gamma}_{i}$, it is important to check whether the implied expected return and risk of $\boldsymbol{\gamma}_{i}$ given in Equation 7.9 are consistent with the target expected return and risk, $\mu_{i}$ and $\sigma_{i}$, for sector $i$. If not, then the allocations in $\boldsymbol{\gamma}_{i}$ may need to be adjusted, or the target expected return and risk must be adjusted to reduce the discrepancy.

Given an allocation $\boldsymbol{\gamma}_{i}$, each manager's dollar allocation is then

$$
K_{i k}^{*}=K_{i}^{*} \times \gamma_{i k} .
$$

These scores should be recomputed at least quarterly and possibly more frequently as changes in market conditions dictate. Each manager should be given his or her score so that the manager is aware of the link between performance (as determined by the many dimensions of the score) and capital allocation. Moreover, such scores can be used as a hurdle for evaluating new managers so that the process of manager selection is less arbitrary over time and across individual fund analysts.

\section{Monitor Performance and Risk Budgets}

The performance of each manager should be monitored regularly to ensure that risk budgets and investment mandates are not being violated. In particular, if the target risk of asset class $i$ is $\sigma_{i}$, then the realized volatility $\hat{\sigma}_{i}$ of the asset class can be compared to $\sigma_{i}$ to determine any discrepancies that require further investigation, where

$$
\hat{\sigma}_{i} \equiv \sqrt{\gamma_{i}^{\prime} \Sigma_{i} \gamma_{i}}
$$

and $\boldsymbol{\Sigma}_{i}$ is the estimated covariance matrix of the $m_{i}$ managers in asset class $i$. Those managers who contribute more than proportionally to the asset-class volatility $\hat{\sigma}_{i}$ may be required to accept lower capital allocations, and those managers who contribute less than proportionally to the asset-class volatility may receive higher capital allocations, other things being equal.

As performance varies and as parameters change, the allocations across asset classes and across managers will require periodic updating. Allocations should be recomputed monthly, although no action is needed unless the updated allocations are significantly different from the current allocations.

\section{The Final Specification}

The final specification of the proposed optimal capital allocation algorithm is given by the input parameters and the outputs, listed below. A sample screenshot of a Microsoft Excel-based implementation is given in Table 7.1.

Inputs. The following are input parameters:

$\mu_{o}=$ target expected return of the portfolio

$\boldsymbol{\mu}=\left[\mu_{1} \ldots \mu_{n}\right]^{\prime}=$ target asset-class expected returns

$\Sigma=$ asset-class covariance matrix

$\boldsymbol{\Sigma}_{i}=$ covariance matrix of managers in asset class $i$

$S_{i k}=$ manager scores

$\delta=$ weighting parameter for manager scores

$K=$ total capital of the fund 
Table 7.1. Sample Screenshot of the AlphaSimplex Multi-Manager Capital Allocation Calculator

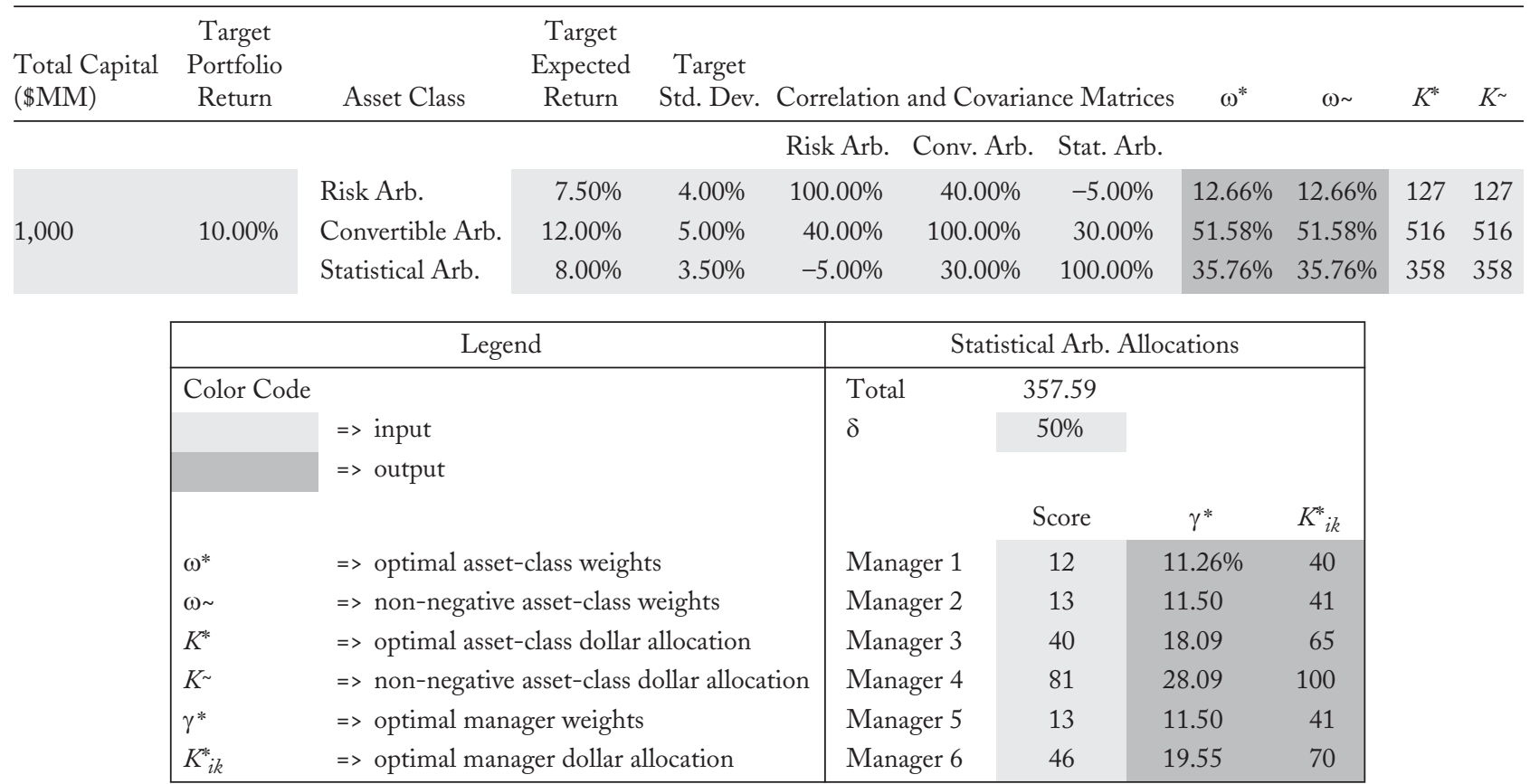

Outputs. The following are the three outputs of the optimal capital allocation process:

$K_{i}^{*}=$ optimal capital allocation for asset class $i$

$K_{i k}^{*}=$ optimal capital allocation for manager $k$

$V_{i k}^{*}=K_{i k}^{*} \times \mu_{i}=$ expected dollar revenue for manager $k$

\section{Risk Limits and Risk Capital}

Given a target expected return $\mu_{i}$ and a target risk level $\sigma_{i}$ for the managers in asset class $i$, I have the following expression for manager $k$ 's $100 \times(1-\theta)$ percent unconditional Value-at-Risk $(U V a R)$ :

$$
\begin{aligned}
& \theta=\operatorname{Prob}\left(R_{i k} K_{i k}^{*} \leq \mathrm{UVaR}\right) \\
& =\operatorname{Prob}\left(\frac{R_{i k}-\mu_{i}}{\sigma_{i}} \leq \frac{\left(\mathrm{UVaR} / K_{i k}^{*}\right)-\mu_{i}}{\sigma_{i}}\right) \\
& =\operatorname{Prob}\left(Z \leq \frac{\left(\mathrm{UVaR} / K_{i k}^{*}\right)-\mu_{i}}{\sigma_{i}}\right), \\
& F_{z}^{-1}(\theta)=\frac{\left(\mathrm{UVaR} / K_{i k}^{*}\right)-\mu_{i}}{\sigma_{i}}, \\
& \mathrm{UVaR}=K_{i k}^{*} \times\left(\mu_{i}+\sigma_{i} F_{z}^{-1}(\theta)\right),
\end{aligned}
$$

where $R_{i k}$ is the manager's annual return and $F_{z}(\cdot)$ is the cumulative distribution function of the standardized return $Z$. If $Z$ is assumed to be normally distributed and I set $\theta=0.01$, or 1 percent, then $F_{z}^{-1}(0.01)=-2.326$. 
For a manager with $\$ 100$ million of capital, a target expected return of 15 percent, and an annual standard deviation of 7.5 percent, the annual 1 percent $U V$ aR is

$\$ 100$ million $\times(0.15-0.075 \times 2.326)=-\$ 2.445$ million.

A more realistic distribution for statistical arbitrage returns is the $t$ distribution with four degrees of freedom or less; in the case of four degrees of freedom, $F_{z}^{-1}(0.01)=3.747$, yielding a 1 percent UVaR of

$\$ 100$ million $\times(0.15-0.075 \times 3.747)=-\$ 13.103$ million.

Of course, the proper aggregation UVaR across managers is a complex issue that involves correlated and highly nonlinear risk/reward functions. Moreover, the dynamic risk exposures of one manager can be very different from those of another- a statistical arbitrage manager has a very different dynamic risk profile than an equity derivatives manager-hence, UVaR may not be the ideal quantity on which to base a risk limit for a heterogeneous group of managers and strategies (see Lo 2001 for further discussion).

Now denote by $\mathrm{UVaR}_{p}$ the monthly Value-at-Risk of the entire portfolio, which is defined as

$$
\mathrm{UVaR}_{p} \equiv K r_{p}(\theta)
$$

where $K$ is the total investment capital of the portfolio and $r_{p}(\theta)$ is the $\theta$ percentile of the return distribution of the portfolio. For example, if the portfolio return is normally distributed with mean $\mu_{p}$ and standard deviation $\sigma_{p}$, then

$$
r_{p}(\theta)=\mu_{p}+\sigma_{p} \Phi^{-1}(\theta),
$$

where $\Phi^{-1}(\cdot)$ is the inverse of the normal cumulative distribution function. Now define the risk capital of the portfolio as the minimum level of funds $X_{p}$ for which a loss of $\mathrm{UVaR}_{p}$ is no more than a fraction $\xi_{p}$ of $X_{p}$, that is,

$$
X_{p} \equiv-\frac{\mathrm{UVaR}_{p}}{\xi_{p}}=-\frac{K r_{p}(\theta)}{\xi_{p}} .
$$

In other words, a minimum of $X_{p}$ must be set aside to ensure that in the event of a loss of $\mathrm{UVaR}_{p}$, the return on risk capital will be $-\xi_{p}$. The quantity $\xi_{p}$ is called the "loss limit" of the portfolio.

To see how $X_{p}$ is related to the required risk capital for each manager in the portfolio, I define the following quantities for each manager $k$ :

$$
\begin{array}{ll}
K_{k} & \equiv \text { manager } k \text { 's total investment capital } \\
\omega_{k} & \equiv K_{k} / K=\text { fraction of portfolio invested with manager } k \\
\mathrm{UVaR}_{k} & \equiv K_{k} r_{k}(\theta)=\text { manager } k \text { 's UVaR } \\
\mu_{k} & \equiv \text { manager } k \text { 's expected return } \\
\sigma_{k} & \equiv \text { manager } k \text { 's return standard deviation } \\
\xi_{k} & \equiv \text { manager } k \text { 's monthly loss limit } \\
X_{k} & \equiv-\mathrm{UVaR}_{k} / \xi_{k}=\text { manager } k \text { 's risk capital }
\end{array}
$$

Now from the definition of $X_{p}$, I have

$$
X_{p}=\sum_{i=1}^{m} X_{k}=-\sum_{i=1}^{m} \frac{K_{k} r_{k}(\theta)}{\xi_{k}},
$$

and substituting Equation 7.17 into Equation 7.19 yields the following equality:

$$
\sum_{i=1}^{m} K_{k} \frac{r_{p}(\theta)}{\xi_{p}}=\sum_{i=1}^{m} K_{k} \frac{r_{k}(\theta)}{\xi_{k}}
$$


For Equation 7.20 to be satisfied for all capital allocations $\left\{K_{k}\right\}$, it must be the case that

$$
\xi_{k}=\frac{r_{k}(\theta)}{r_{p}(\theta)} \xi_{p} .
$$

This is the fundamental relationship between the portfolio loss limit $\xi_{p}$ and the corresponding loss limits for each of the individual managers; Equation 7.21 shows that the loss limit required for each manager need not be equal to the loss limit of the portfolio, and that loss limits can and should differ from one manager to the next. In particular, the degree to which $\xi_{k}$ differs from $\xi_{p}$ is related to how much diversification the portfolio exhibits - the more diversification, the smaller is $r_{p}(\theta)$ relative to the typical $r_{k}(\theta)$ and the greater is the loss limit for manager $k$. A more readily interpretable version of Equation 7.21 can be obtained by converting return percentiles to UVaR quantities:

$$
\xi_{k}=\frac{r_{k}(\theta)}{r_{p}(\theta)} \xi_{p}=\frac{K_{k} r_{k}(\theta)}{K r_{p}(\theta)} \frac{K}{K_{k}} \xi_{p}=\frac{1}{\omega_{k}} \frac{\mathrm{UVaR}_{k}}{\mathrm{UVaR}_{p}} \xi_{p} ;
$$

hence, the loss limit for manager $k$ is simply the loss limit of the portfolio multiplied by the reciprocal of his weight in the portfolio times the ratio of his UVaR to the portfolio UVaR.

Recall that $X_{k}$ is defined as the risk capital of manager $k$, which is the ratio of his $\mathrm{UVaR}_{k}$ to $\xi_{k}$. Using the setting of $\xi_{k}$ in Equation 7.22 yields the following:

$$
\begin{aligned}
& X_{k}=\frac{\mathrm{UVaR}_{k}}{\xi_{k}}=\frac{\omega_{k} \mathrm{UVaR}_{k}}{\mathrm{UVaR}_{k}} \frac{\mathrm{UVaR}_{p}}{\xi_{p}}=\omega_{k} X_{p} \\
& \Rightarrow \frac{X_{k}}{X_{p}}=\omega_{k},
\end{aligned}
$$

which shows that the fraction of risk capital allocated to manager $k$ under the loss limit rule (Equation 7.22) is identical to the portfolio weight $\omega_{k}$ defined by the fraction of total investment capital, $K_{k} / K$, allocated to manager $k$.

These formulas for risk capital and loss limits can be made more explicit for more specific Value-at-Risk measures. For example, if I am willing to make parametric assumptions for the return distributions of individual managers and the portfolio as above, then $\mathrm{UVaR}_{k}$ may be written as

$$
\mathrm{UVaR}_{k}=K_{k}\left(\mu_{k}+\sigma_{k} F_{z}^{-1}(\theta)\right),
$$

where $F^{-1}(\cdot)$ is the inverse of the cumulative distribution function for the standardized return of manager $k$ (standardized to zero mean and unit variance). In many cases, risk management applications set $\mu_{k}=0$, which yields a particularly convenient expression for an individual manager's loss limit: 77

$$
\xi_{k}=\frac{\sigma_{k}}{\sigma_{p}} \xi_{p}
$$

where $\sigma_{p}$ is the return standard deviation of the portfolio.

For concreteness, observe that

$$
\sigma_{p}=\sqrt{\omega^{\prime} \Sigma \omega},
$$

where $\mathbf{\Sigma}$ is the covariance matrix of the $m$ managers' returns, and consider the following three special cases.

77 Setting the expected return of a portfolio equal to zero for purposes of risk management is often motivated by a desire to be conservative. Most portfolios will tend to have positive expected return; hence, setting $\mu$ equal to zero will generally yield larger values for $\mathrm{VaR}$. However, for actively managed portfolios that contain both long and short positions, the practice of setting expected returns equal to zero need not be conservative but, in some cases, can yield severely downward-biased estimates of VaR. This is particularly relevant for strategies designed to exploit mean reversion, such as fixed-income relative and equity market-neutral strategies. For such strategies, which involve buying "losers" and selling "winners," the unconditional mean is typically negative (since, by definition, "losers" will include securities with lower expected returns than the "winners"); hence, a zero expected return is, in fact, a more aggressive assumption from the risk management perspective. 
Perfect Correlation. Suppose the returns of all $m$ managers are perfectly correlated. In that case,

$$
\sigma_{p}=\sqrt{\boldsymbol{\omega}^{\prime} \boldsymbol{\sigma} \boldsymbol{\sigma}^{\prime} \boldsymbol{\omega}}=\sum_{i=1} \omega_{k} \sigma_{k}=\bar{\sigma},
$$

where $\boldsymbol{\sigma} \equiv\left[\begin{array}{lll}\sigma_{1} & \ldots & \sigma_{m}\end{array}\right]^{\prime}$. This is simply the weighted average of the standard deviations of the $m$ managers, and it implies that

$$
\xi_{k}=\frac{\sigma_{k}}{\bar{\sigma}} \xi_{p}
$$

so that managers with higher-than-average standard deviations should be allowed larger loss limits (of course, they should also be required to yield higher expected returns because of their higher risks). Only in the special case where all managers have identical standard deviations does $\xi_{k}=\xi_{p}$.

No Correlation. If the returns of the $m$ managers are all mutually uncorrelated, then

$$
\sigma_{p}=\sqrt{\sum_{i=1}^{m} \omega_{k}^{2} \sigma_{k}^{2}},
$$

and in the special case where all managers have identical return standard deviation $\sigma$ and the portfolio is divided equally among them,

$$
\xi_{k}=\sqrt{m} \xi_{p} .
$$

For a group of $m=25$ managers, the loss limit $\xi_{k}$ for an individual manager is a factor of 5.00 times the portfolio loss limit $\xi_{p}$.

Equal Correlation. For a collection of managers with identical return standard deviation $\sigma$, identical portfolio weights $\omega_{k}=1 / m$, and equally correlated returns with correlation coefficient $\rho$,

$$
\begin{aligned}
& \Sigma=\sigma^{2}\left[\rho \mathbf{\iota}^{\prime}+(1-\rho) \mathbf{I}\right] \\
& \sigma_{p}=\sqrt{\boldsymbol{\omega}^{\prime} \Sigma \boldsymbol{\omega}}=\sigma \sqrt{\rho+(1-\rho) / m},
\end{aligned}
$$

which implies

$$
\xi_{k}=\frac{\sigma}{\sigma_{p}} \xi_{p}=\frac{1}{\sqrt{\rho+(1-\rho) / m}} \xi_{p}
$$

Values for the factor $\sigma / \sigma_{p}$ in Equation 7.34 are reported in Table 7.2, which shows that for $m=25$ and $\rho=30$ percent, the loss limit for an individual manager is 1.75 times the portfolio loss limit $\xi_{p}$. Specifically, given a portfolio loss limit of 3 percent per month, each manager can be allowed a loss limit of 5.25 percent per month if the managers' returns are equally correlated with 30 percent correlation.

\section{Qualifications and Extensions}

The framework outlined in this chapter is by no means a complete specification of the investment process of a fund of funds, but merely one possible blueprint for developing such a process. Unlike traditional investments that have well-circumscribed risk and performance parameters, hedge fund investments are heterogeneous, highly dynamic and adaptive, and risky in many different dimensions. Therefore, a purely quantitative approach to managing a portfolio of hedge funds is neither possible nor desirable at this stage of the industry's life cycle. Instead, I propose an integrated approach that blends qualitative judgments with quantitative rigor in a consistent manner.

But there are costs to such integration, one of which is the two-stage optimization process that, by definition, is suboptimal when compared to a single-stage optimization of all managers; hence, this issue deserves further discussion. First, because of the time variation in correlations among individual hedge funds-due to estimation 
Table 7.2. Factors That, When Multiplied by the Monthly Portfolio Loss Limit, Yield the Allowable Monthly Loss Limits for Individual Managers with Identical Return Standard Deviations and Mutual Correlation Coefficients of $\rho$

\begin{tabular}{|c|c|c|c|c|c|c|c|}
\hline \multirow[b]{2}{*}{$\sigma / \sigma_{\rho}$} & \multicolumn{7}{|c|}{$m$} \\
\hline & 5 & 10 & 15 & 20 & 23 & 25 & 30 \\
\hline \multicolumn{8}{|l|}{$\rho(\%)$} \\
\hline 0 & 2.24 & 3.16 & 3.87 & 4.47 & 4.80 & 5.00 & 5.48 \\
\hline 5 & 2.04 & 2.63 & 2.97 & 3.20 & 3.31 & 3.37 & 3.50 \\
\hline 10 & 1.89 & 2.29 & 2.50 & 2.63 & 2.68 & 2.71 & 2.77 \\
\hline 15 & 1.77 & 2.06 & 2.20 & 2.28 & 2.31 & 2.33 & 2.37 \\
\hline 20 & 1.67 & 1.89 & 1.99 & 2.04 & 2.06 & 2.08 & 2.10 \\
\hline 25 & 1.58 & 1.75 & 1.83 & 1.87 & 1.88 & 1.89 & 1.91 \\
\hline 30 & 1.51 & 1.64 & 1.70 & 1.73 & 1.74 & 1.75 & 1.76 \\
\hline 35 & 1.44 & 1.55 & 1.59 & 1.62 & 1.63 & 1.63 & 1.64 \\
\hline 40 & 1.39 & 1.47 & 1.51 & 1.52 & 1.53 & 1.54 & 1.54 \\
\hline 45 & 1.34 & 1.41 & 1.43 & 1.45 & 1.45 & 1.46 & 1.46 \\
\hline 50 & 1.29 & 1.35 & 1.37 & 1.38 & 1.38 & 1.39 & 1.39 \\
\hline 55 & 1.25 & 1.30 & 1.31 & 1.32 & 1.33 & 1.33 & 1.33 \\
\hline 60 & 1.21 & 1.25 & 1.26 & 1.27 & 1.27 & 1.27 & 1.28 \\
\hline 65 & 1.18 & 1.21 & 1.22 & 1.22 & 1.23 & 1.23 & 1.23 \\
\hline 70 & 1.15 & 1.17 & 1.18 & 1.18 & 1.18 & 1.19 & 1.19 \\
\hline 75 & 1.12 & 1.14 & 1.14 & 1.15 & 1.15 & 1.15 & 1.15 \\
\hline 80 & 1.09 & 1.10 & 1.11 & 1.11 & 1.11 & 1.11 & 1.11 \\
\hline 85 & 1.07 & 1.08 & 1.08 & 1.08 & 1.08 & 1.08 & 1.08 \\
\hline 90 & 1.04 & 1.05 & 1.05 & 1.05 & 1.05 & 1.05 & 1.05 \\
\hline 95 & 1.02 & 1.02 & 1.02 & 1.02 & 1.02 & 1.02 & 1.03 \\
\hline 100 & 1.00 & 1.00 & 1.00 & 1.00 & 1.00 & 1.00 & 1.00 \\
\hline
\end{tabular}

errors, data errors, and outliers, as well as shifts in the true correlations-mean-variance optimization of individual hedge funds will yield highly unstable weights, fluctuating wildly from month to month and across managers. Mean-variance optimization of asset-class weights, however, is likely to be more stable. Second, quantitative information regarding aggregate trends, correlations, and volatilities of hedge fund investment styles is generally more reliable than similar information about individual funds, and it is easier to incorporate and track the value-added of such aggregate quantitative information in a two-stage process. And finally, the key differences between managers within a single hedge fund style category are easier to identify through qualitative judgment than quantitative analysis, especially given the lack of position transparency for most hedge funds. Therefore, a two-stage process in which quantitative analysis is applied to the asset allocation decision-where quantitative methods yield the highest value-added — and qualitative judgments are applied to manager selection-where quantitative methods are at a disadvantage - exploits the best of both processes.

However, the two-stage process is clearly a compromise between the theoretical tenets of mean-variance portfolio optimization and the practical exigencies of hedge fund investing. As hedge funds provide more transparency and as the qualitative due diligence process for identifying operational risks becomes more quantitative, investors can move closer to a single-stage optimization process and its corresponding performance benefits.

There are a number of additional directions for continuing research. Perhaps the most pressing is the need for further data, analysis, and quantification of operational risks such as potential conflicts of interest, weak corporate governance structures, improper accounting procedures, insufficient operational resources, and fraud. In a study of over 100 liquidated hedge funds during the past two decades, Feffer and Kundro (2003) conclude that "half of all failures could be attributed to operational risk alone," of which fraud is just one example. In fact, they observe that "The most common operational issues related to hedge fund losses have been misrepresentation of fund investments, misappropriation of investor funds, unauthorized trading, and inadequate resources" (p. 5). The last of these issues is, of course, not related to fraud, but Feffer and Kundro (2003, 
Figure 2) report that only 6 percent of their sample involved inadequate resources, whereas 41 percent involved misrepresentation of investments, 30 percent misappropriation of funds, and 14 percent unauthorized trading. These results suggest that operational issues are a significant risk factor and deserve considerable attention from investors and managers alike.

Modeling correlations and nonlinear statistical relations among hedge fund categories and managers also requires further study. For example, Chan, Getmansky, Haas, and Lo (2005) propose several methods for constructing risk models for hedge funds, including statistical regime-switching models that seem especially promising for capturing sudden shifts in correlations among hedge funds. To capture optionlike risk exposures of certain hedge fund strategies, the synthetic option replication approach of Haugh and Lo (2001) may be useful.

The asset allocation decision among hedge fund categories is another area in which considerable progress can be made. Unlike traditional asset-class returns, which have minimal levels of predictability, certain hedge fund returns are quite persistent, as the empirical analysis in Chapters 4 and 5 confirms. Such levels of predictability imply that significant benefits may accrue to a truly dynamic portfolio optimization process, along the lines of Samuelson (1969).

Finally, perhaps the most pressing issue facing fund-of-funds managers, beyond the basic investment process, is how to avoid hedge fund failures. While operational due diligence reviews can spot certain warning signs, these reviews occur too infrequently to be of significant value in managing a fund-of-funds portfolio on a monthly and quarterly basis. Chan et al. (2005) tackle this issue explicitly by modeling hedge fund liquidations in the TASS Graveyard database using a logit regression model in which the probability of liquidation is parametrized as a function of a variety of explanatory variables, including age, past performance, volatility, investment style, and assets under management. Although still at an early stage of research and development, this approach seems quite promising, as Chan et al. (2005) have shown that liquidation probabilities vary considerably across hedge fund styles and characteristics in intuitively sensible ways. 


\section{Practical Considerations}

In addition to the new analytics proposed in this monograph, there are several practical considerations that should be kept in mind when evaluating alternative investments. The first is that despite the emphasis on alpha among hedge fund managers and investors, risk management can be a significant source of alpha in and of itself, as I illustrate through a simple example in the next section. Of course, the ultimate determination of how much risk is appropriate for a hedge fund involves risk preferences - of both investors and managers - and this is discussed in the subsequent section. And finally, one of the most controversial issues surrounding alternative investments is the implications of the Efficient Markets Hypothesis for the industry. If markets are efficient, then alternative investments do not offer any advantages over traditional investments because any excess expected returns must be the result of additional risk exposures. Later in this chapter, this debate is reviewed and a resolution is offered based on an alternative to market efficiency-the "Adaptive Markets Hypothesis"and some preliminary empirical evidence is provided to support this new theory.

\section{Risk Management as a Source of Alpha}

In contrast to traditional investment vehicles such as stocks, bonds, and mutual funds, hedge funds have rather different risk-return objectives. Most hedge fund investors expect high returns in exchange for the corresponding risks that they are expected to bear. Perhaps because it is taken for granted that hedge funds are riskier, few hedge fund investors and even fewer hedge fund managers seem to devote much attention to active risk management. Hedge fund investors and managers often dismiss risk management as a secondary objective, with "alpha" or performance as the main objective.

However, if modern finance has produced one lasting insight, it is the inexorable trade-off between risk and expected return; hence, one cannot be considered without reference to the other. Moreover, it is often overlooked that proper risk management can, by itself, be a source of alpha. This concept is summarized neatly in the old Street wisdom that "one of the best ways to make money is not to lose it." More formally, consider the case of a manager with a fund that has an annual expected return $\mathrm{E}(R)$ of 10 percent and an annual volatility $\mathrm{SD}(R)$ of 75 percent, a rather mediocre fund that few hedge fund investors would consider seriously. Now suppose that such a manager layers a risk management process on top of his investment strategy that eliminates the possibility of returns lower than -20 percent; that is, his return after implementing this risk management protocol is $R^{*}$, where

$$
R^{*}=\operatorname{Max}[R,-20 \text { percent }] \text {. }
$$

Under the assumption of lognormally distributed returns, it can be shown that the expected value $\mathrm{E}\left[R^{*}\right]$ of $R^{*}$ is 20.9 percent - by truncating the left tail of the distribution of $R$ below -20 percent, the expected value of the strategy is doubled! In this case, risk management has become a significant source of alpha, indeed. Moreover, the volatility $\mathrm{SD}\left[R^{*}\right]$ of $R^{*}$ is 66.8 percent, lower than the volatility of $R$; hence, risk management can simultaneously increase alpha and decrease risk. Table 8.1 reports $\mathrm{E}\left[R^{*}\right]$ and $\mathrm{SD}\left[R^{*}\right]$ for various values of $\mathrm{E}[R]$ and $\mathrm{SD}[R]$ and various truncation levels, and it illustrates the potent and direct impact that risk management can have on performance.

Of course, risk management rarely takes the simple form of a guaranteed floor for returns. Indeed, such "portfolio insurance" is often quite costly - if it can be obtained at all—and is equivalent to the premium of a put option on the value of the portfolio. For example, the Black-Scholes premium for the put option implicit in Equation 8.1 is equal to 15.4 percent of the value of the portfolio to be insured. 78 But this example only highlights the relevance and economic value of risk management-according to the Black-Scholes formula, the ability to manage risks in such a way as to create a floor of -20 percent for annual performance is worth 15.4 percent of assets under management! The more effective a manager's risk management process is, the more it will contribute to alpha.

${ }^{78}$ This example assumes a one-year term for the put, with a strike that is 20 percent out of the money, and an annual volatility and riskfree rate of 75 percent and 5 percent, respectively. 
Table 8.1. The Value of Risk Management

Expected values $\mathrm{E}\left[R^{*}\right]$ (first rows) and standard deviations $\mathrm{SD}\left[R^{*}\right]$ (second rows) of $R^{*} \equiv$ Max $[R, \mathrm{~K}]$ for lognormally distributed return $R$ with expectation $\mathrm{E}[R]$, standard deviation $\mathrm{SD}[R]$, and truncation point $\mathrm{k}$

\begin{tabular}{|c|c|c|c|c|c|c|c|c|c|c|c|c|}
\hline \multirow[b]{2}{*}{$\mathrm{SD}[R]$} & \multicolumn{6}{|c|}{$\mathrm{E}[R]$} & \multicolumn{6}{|c|}{$\mathrm{E}[R]$} \\
\hline & $-5 \%$ & $0 \%$ & $5 \%$ & $10 \%$ & $15 \%$ & $20 \%$ & $-5 \%$ & $0 \%$ & $5 \%$ & $10 \%$ & $15 \%$ & $20 \%$ \\
\hline & \multicolumn{6}{|c|}{$\kappa=-50 \%$} & \multicolumn{6}{|c|}{$\kappa=-20 \%$} \\
\hline \multirow[t]{2}{*}{$5 \%$} & -5.0 & 0.0 & 5.0 & 10.0 & 15.0 & 20.0 & -5.0 & 0.0 & 5.0 & 10.0 & 15.0 & 20.0 \\
\hline & 5.0 & 5.0 & 5.0 & 5.0 & 5.0 & 5.0 & 5.0 & 5.0 & 5.0 & 5.0 & 5.0 & 5.0 \\
\hline \multirow[t]{2}{*}{$10 \%$} & -5.0 & 0.0 & 5.0 & 10.0 & 15.0 & 20.0 & -4.8 & 0.0 & 5.0 & 10.0 & 15.0 & 20.0 \\
\hline & 10.0 & 10.0 & 10.0 & 10.0 & 10.0 & 10.0 & 9.6 & 9.9 & 10.0 & 10.0 & 10.0 & 10.0 \\
\hline \multirow[t]{2}{*}{$25 \%$} & -5.0 & 0.0 & 5.0 & 10.0 & 15.0 & 20.0 & -1.6 & 2.2 & 6.3 & 10.7 & 15.4 & 20.2 \\
\hline & 24.9 & 25.0 & 25.0 & 25.0 & 25.0 & 25.0 & 21.2 & 22.3 & 23.2 & 23.9 & 24.4 & 24.7 \\
\hline \multirow[t]{2}{*}{$50 \%$} & -3.5 & 1.0 & 5.7 & 10.4 & 15.3 & 20.2 & 5.6 & 8.6 & 11.9 & 15.4 & 19.2 & 23.1 \\
\hline & 48.3 & 48.8 & 49.2 & 49.4 & 49.6 & 49.8 & 41.6 & 42.7 & 43.8 & 44.8 & 45.7 & 46.5 \\
\hline \multirow[t]{2}{*}{$75 \%$} & -0.5 & 3.5 & 7.8 & 12.1 & 16.6 & 21.2 & 12.0 & 14.8 & 17.8 & 20.9 & 24.3 & 27.8 \\
\hline & 71.4 & 72.0 & 72.5 & 73.0 & 73.4 & 73.7 & 64.2 & 65.0 & 65.9 & 66.8 & 67.6 & 68.5 \\
\hline \multirow[t]{3}{*}{$100 \%$} & 2.5 & 6.3 & 10.3 & 14.4 & 18.7 & 23.0 & 17.3 & 20.0 & 22.9 & 25.9 & 29.1 & 32.4 \\
\hline & 95.2 & 95.7 & 96.2 & 96.7 & 97.1 & 97.5 & 88.2 & 88.8 & 89.4 & 90.0 & 90.7 & 91.4 \\
\hline & \multicolumn{6}{|c|}{$\kappa=-40 \%$} & \multicolumn{6}{|c|}{$\kappa=-10 \%$} \\
\hline \multirow[t]{2}{*}{$5 \%$} & -5.0 & 0.0 & 5.0 & 10.0 & 15.0 & 20.0 & -4.6 & 0.0 & 5.0 & 10.0 & 15.0 & 20.0 \\
\hline & 5.0 & 5.0 & 5.0 & 5.0 & 5.0 & 5.0 & 4.4 & 4.9 & 5.0 & 5.0 & 5.0 & 5.0 \\
\hline \multirow[t]{2}{*}{$10 \%$} & -5.0 & 0.0 & 5.0 & 10.0 & 15.0 & 20.0 & -3.1 & 0.7 & 5.2 & 10.0 & 15.0 & 20.0 \\
\hline & 10.0 & 10.0 & 10.0 & 10.0 & 10.0 & 10.0 & 7.8 & 8.9 & 9.6 & 9.9 & 10.0 & 10.0 \\
\hline \multirow[t]{2}{*}{$25 \%$} & -4.7 & 0.1 & 5.1 & 10.0 & 15.0 & 20.0 & 2.2 & 5.1 & 8.5 & 12.3 & 16.4 & 20.8 \\
\hline & 24.5 & 24.8 & 24.9 & 25.0 & 25.0 & 25.0 & 18.3 & 19.8 & 21.1 & 22.2 & 23.1 & 23.8 \\
\hline \multirow[t]{2}{*}{$50 \%$} & -1.5 & 2.6 & 6.8 & 11.3 & 15.9 & 20.6 & 10.7 & 13.2 & 15.9 & 18.9 & 22.2 & 25.7 \\
\hline & 46.6 & 47.3 & 47.9 & 48.5 & 48.9 & 49.2 & 38.7 & 39.9 & 41.0 & 42.2 & 43.3 & 44.4 \\
\hline \multirow[t]{2}{*}{$75 \%$} & 2.8 & 6.4 & 10.2 & 14.2 & 18.3 & 22.6 & 17.7 & 20.2 & 22.7 & 25.5 & 28.4 & 31.5 \\
\hline & 69.3 & 70.0 & 70.7 & 71.3 & 71.9 & 72.4 & 61.5 & 62.3 & 63.2 & 64.1 & 65.0 & 66.0 \\
\hline \multirow[t]{3}{*}{$100 \%$} & 6.7 & 10.2 & 13.8 & 17.5 & 21.4 & 25.4 & 23.5 & 25.9 & 28.5 & 31.2 & 34.0 & 37.0 \\
\hline & 93.0 & 93.6 & 94.2 & 94.7 & 95.3 & 95.8 & 85.7 & 86.2 & 86.8 & 87.5 & 88.2 & 88.9 \\
\hline & \multicolumn{6}{|c|}{$\kappa=-30 \%$} & \multicolumn{6}{|c|}{$\kappa=-5 \%$} \\
\hline \multirow[t]{2}{*}{$5 \%$} & -5.0 & 0.0 & 5.0 & 10.0 & 15.0 & 20.0 & -3.0 & 0.4 & 5.0 & 10.0 & 15.0 & 20.0 \\
\hline & 5.0 & 5.0 & 5.0 & 5.0 & 5.0 & 5.0 & 3.0 & 4.4 & 4.9 & 5.0 & 5.0 & 5.0 \\
\hline $10 \%$ & -5.0 & 0.0 & 5.0 & 10.0 & 15.0 & 20.0 & -1.0 & 1.9 & 5.7 & 10.2 & 15.0 & 20.0 \\
\hline & 10.0 & 10.0 & 10.0 & 10.0 & 10.0 & 10.0 & 6.2 & 7.8 & 8.9 & 9.6 & 9.9 & 10.0 \\
\hline $25 \%$ & -3.8 & 0.7 & 5.3 & 10.2 & 15.1 & 20.0 & 4.8 & 7.3 & 10.2 & 13.5 & 17.3 & 21.4 \\
\hline & 23.4 & 24.0 & 24.4 & 24.7 & 24.9 & 24.9 & 16.8 & 18.3 & 19.7 & 21.0 & 22.1 & 23.0 \\
\hline $50 \%$ & 1.5 & 5.1 & 8.9 & 12.9 & 17.1 & 21.5 & 13.6 & 15.8 & 18.3 & 21.1 & 24.1 & 27.3 \\
\hline & 44.3 & 45.2 & 46.1 & 46.9 & 47.6 & 48.2 & 37.2 & 38.4 & 39.6 & 40.8 & 41.9 & 43.1 \\
\hline $75 \%$ & 7.0 & 10.2 & 13.6 & 17.1 & 20.9 & 24.8 & 20.9 & 23.1 & 25.5 & 28.0 & 30.8 & 33.7 \\
\hline & 66.8 & 67.6 & 68.4 & 69.2 & 69.9 & 70.7 & 60.1 & 60.9 & 61.8 & 62.7 & 63.7 & 64.6 \\
\hline $100 \%$ & 11.7 & 14.7 & 18.0 & 21.4 & 24.9 & 28.5 & 26.7 & 29.0 & 31.4 & 34.0 & 36.7 & 39.5 \\
\hline & 90.7 & 91.2 & 91.9 & 92.5 & 93.1 & 93.8 & 84.4 & 84.9 & 85.5 & 86.2 & 86.9 & 87.6 \\
\hline
\end{tabular}




\section{Risk Preferences}

Risk preferences play a major role in any investment process involving hedge funds, from both manager and investor perspectives. Hedge fund managers are typically compensated with both fixed and incentive fees, and this nonlinear payoff scheme can induce excess risk-taking behavior if it is not properly managed. Imposing hurdle rates, high-water marks, and other nonlinearities on the manager's compensation creates additional complexities that may have a material impact on the manager's investment decisions, particularly in extreme circumstances, such as after large losses. Moreover, given the large swings that often characterize hedge fund performance, the financial and psychological pressures faced by managers each day are not trivial and do take their toll.

At the same time, the risk preferences of investors are equally relevant for risk management for hedge funds, since the behavior of investors greatly influences the behavior of managers. If the stereotype that hedge fund investors are "hot money" is true, this will affect the types of risks that hedge fund managers can bear. Imposing "lockup" periods and redemption fees are typical methods of dealing with skittish investors, but these can sometimes exacerbate the all-too-human tendency to panic in the face of crisis. Ironically, despite all of the many tools offered to individual investors - risk-tolerance surveys, "what if" scenario simulators, and lifetime financial planning software - there is virtually nothing comparable for helping institutional investors determine their collective risk preferences. Perhaps the magnitude of this challenge is too daunting for any single manager or consultant, but without a clear understanding of an investor's risk preferences, it is impossible to manage risks properly or to formulate an appropriate investment policy.

The fact that institutional investors are almost always represented by a small group of individuals makes "risk preferences" even more difficult to quantify, which is all the more reason to take up this challenge. Consider the case of a pension fund that enjoyed a surplus of 5 percent just a few years ago but finds itself underfunded by 3 percent today. When facing a surplus, the fund's investment committee was conservative, lowering its equity allocation so as to preserve its gain; faced with a 3 percent deficit, the investment committee has become more aggressive, hoping to make up the shortfall by overweighting higher-yielding assets, including its first foray into alternative investments. This pension fund's risk preferences have changed significantly as a result of a change in its funding status, and while academics can debate the rationality of such preference reversals, they are a reality that must be addressed explicitly. By developing a better understanding of the dynamics of group decision-making processes and the risk preferences that they represent, institutional investors will be better prepared to deal with the inevitable swings in market conditions.

Any complete investment process involving alternative investments must take into account the risk preferences of both investors and managers in determining the appropriate risk exposures of a hedge fund. Given the magnitudes and many variations of risk that affect the typical hedge fund, it is even more important to integrate the "Three P's of Total Risk Management"-prices, probabilities, and preferences—in this context. 79 For example, in Lo, Repin, and Steenbarger (2004), a series of questionnaires designed to elicit risk preferences and personality traits was administered to a group of day traders over a period of several weeks, while the participants were actively trading, in an attempt to relate risk and personality profiles to trading performance. 80 Similar profiling methods may be developed for hedge fund managers and investors and, eventually, included in discussions between manager and investor so as to reduce the likelihood of misaligned expectations.

The importance of risk preferences underscores the human element in hedge funds, which is part of a broader set of issues often categorized as "operational risks." These include organizational aspects such as the reliability of back-office operations, legal infrastructure, accounting and trade reconciliation, personnel issues, and the day-to-day management of the business. Many of these aspects are not subject to quantitative analysis, but they are bona fide risks that cannot be ignored and, in some cases, can quickly overshadow market risks in determining fund performance. Organizations such as the Alternative Investment Management Association (AIMA, www.aima.org) provide sample due diligence questionnaires that provide excellent starting points for operational risk reviews.

${ }^{79}$ See Lo (1999) for further details.

${ }^{80} \mathrm{Lo}$ and Repin provide related risk surveys and personality profiling tools at www.riskpsychology.net. See also MacCrimmon and Wehrung (1986). 


\section{Hedge Funds and the Efficient Markets Hypothesis}

One of the most influential ideas in modern economics and finance is the Efficient Markets Hypothesis (EMH), the idea that market prices incorporate all information rationally and instantaneously. As with so many of the ideas of modern economics, the origins of the EMH can be traced back to Paul Samuelson (1965), whose contribution is neatly summarized by the title of his article: "Proof That Properly Anticipated Prices Fluctuate Randomly." In an informationally efficient market, price changes must be unforecastable if they are properly anticipated (i.e., if they fully incorporate the information and expectations of all market participants). Roberts (1967) and Fama (1970) operationalized this hypothesis - summarized in Fama's well-known statement that "prices fully reflect all available information"-by placing structure on various information sets available to market participants.

This concept of market efficiency has a wonderfully counterintuitive and seemingly contradictory flavor to it: The more efficient the market, the more random the sequence of price changes generated by such a market must be, and the most efficient market of all is one in which price changes are completely random and unpredictable. This, of course, is not an accident of nature but is the direct outcome of many active participants attempting to profit from their information. Legions of greedy investors aggressively pounce on even the smallest informational advantages at their disposal, and in doing so, they incorporate their information into market prices and quickly eliminate the profit opportunities that gave rise to their actions. If this occurs instantaneously, which it must in an idealized world of "frictionless" markets and costless trading, then prices must always fully reflect all available information and no profits can be garnered from information-based trading (because such profits have already been captured).

The EMH is particularly relevant for the hedge fund industry because the primary attraction of hedge funds is their higher expected returns and, in many cases, lower risk as measured by correlation to broad-based market indexes such as the S\&P 500. If the EMH is true, then it should not be possible to generate higher expected returns after adjusting for risk. For example, according to the Capital Asset Pricing Model (CAPM), the riskadjusted expected return of any investment $P$ is determined by the market beta of that investment; that is,

$$
\mathrm{E}\left[R_{p}\right]=R_{f}+\beta\left(\mathrm{E}\left[R_{m}\right]-R_{f}\right),
$$

where $R_{f}$ is the return on a riskless asset such as Treasury bills and $\mathrm{E}\left(R_{m}\right)$ is the expected return of the market portfolio, often approximated by the S\&P 500. But consider the example of Fund XYZ, a pseudonym for a live hedge fund drawn from the Altvest database with an annual mean return of 12.54 percent and annual return standard deviation of 5.50 percent over the period from January 1985 to December 2002 (see Figure 8.1). Assuming a riskless rate of 2.5 percent and a market risk premium of 8 percent during this period, the CAPM implies that XYZ should have a beta of

$$
\beta=\frac{\mathrm{E}\left[R_{x y z}\right]-R_{f}}{\mathrm{E}\left[R_{m}\right]-R_{f}}=\frac{12.54 \text { percent }-2.5 \text { percent }}{8 \text { percent }}=1.26 .
$$

However, a simple regression of XYZ's returns on the returns of the S\&P 500 yields an estimated beta of -0.028 with an $R^{2}$ of 0.66 percent. In other words, Fund $\mathrm{XYZ}$ is an asset with virtually no market risk exposure and yet has had returns comparable to those of the S\&P 500 over an 18-year period with considerably lower volatility. How can this case be consistent with the EMH?

Proponents of market efficiency would respond by arguing that the CAPM is not synonymous with the $\mathrm{EMH}$ and that the higher expected returns of hedge fund investments may be fair compensation for other "systematic" risk factors contained in their returns [e.g., liquidity, volatility, and tail risk (see, in particular, the examples in Chapter 3)]. However, even when such factors are taken into account, a number of funds still exhibit excess expected returns, implying that either the models are wrong or markets are inefficient.

Others have argued that funds like XYZ are simply statistical flukes, products of sample selection and survivorship bias. In other words, if a fair coin is flipped enough times, eventually a sequence of 20 heads in a row will be realized (see Lo and MacKinlay 1990b and Lo 1994). The difficulty with this argument is the existence of more than a few outliers in the hedge fund industry (e.g., Renaissance Technologies, D.E. Shaw, Soros Fund Management, Tudor Investments, Caxton Associates, Highbridge Capital Management, Moore Capital Management), implying either that they have been unusually lucky in this lifetime or that certain hedge fund managers do have genuine skill in producing excess risk-adjusted expected returns. 
Figure 8.1. Cumulative Total Return of Fund XYZ and the S\&P 500

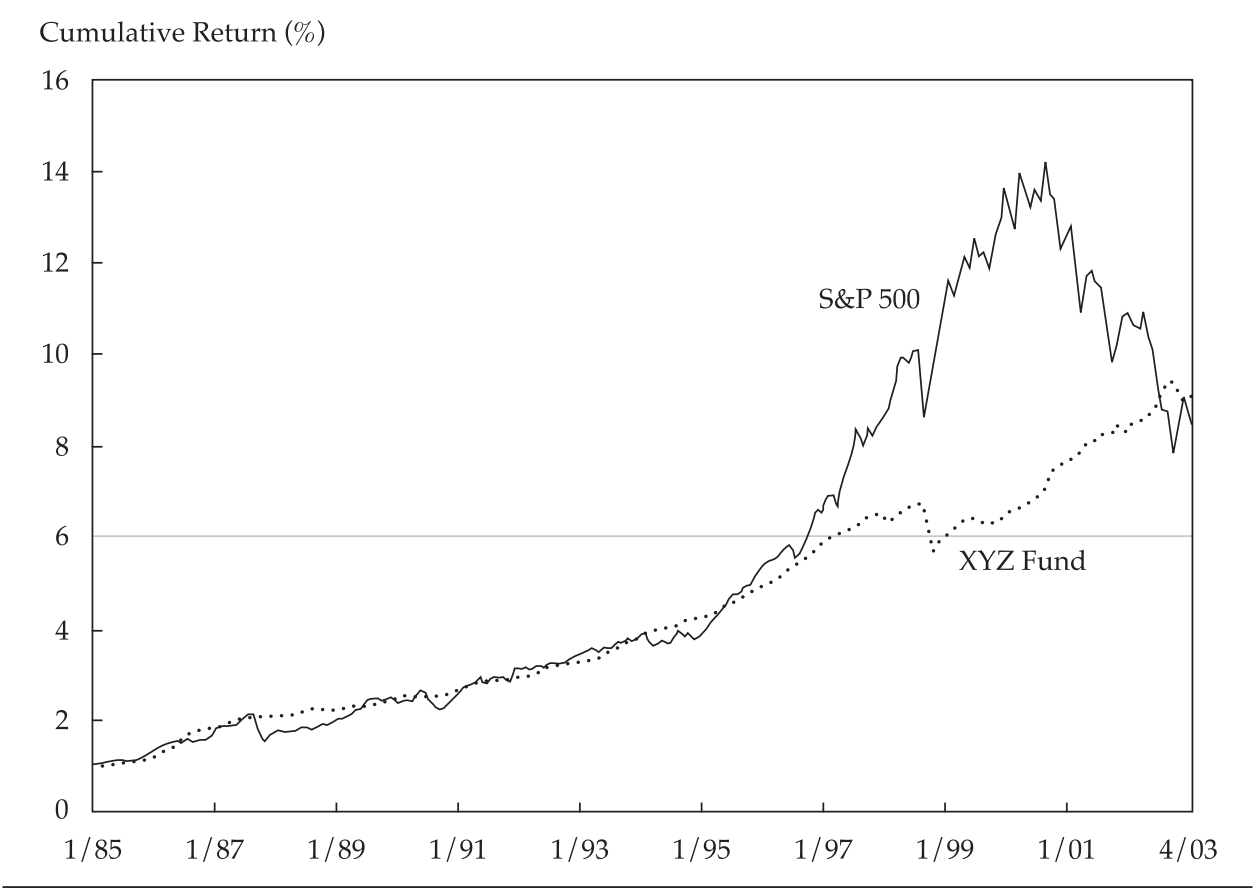

Source: Altvest.

A more satisfying resolution to this apparent contradiction may be found in the Adaptive Markets Hypothesis (AMH; Lo 2004), an alternative to the EMH in which evolutionary principles are applied to financial markets along the lines of Bernstein (1998), Farmer and Lo (1999), and Farmer (2002). Prices reflect as much information as is dictated by the combination of environmental conditions and the number and nature of "species" in the economy or, to use the appropriate biological term, the ecology. In this context, "species" means distinct groups of market participants, each behaving in a common manner. For example, pension funds may be considered one species; retail investors, another; market makers, a third; and hedge fund managers, a fourth. If multiple species (or the members of a single highly populous species) are competing for rather scarce resources within a single market, that market is likely to be highly efficient (e.g., the market for 10-year U.S. Treasury notes, which reflects most relevant information very quickly indeed). If, on the other hand, a small number of species are competing for rather abundant resources in a given market, that market will be less efficient (e.g., the market for oil paintings from the Italian Renaissance). Market efficiency cannot be evaluated in a vacuum but is highly context-dependent and dynamic, just as insect populations advance and decline as a function of the seasons, the number of predators and prey they face, and their ability to adapt to an ever-changing environment.

The profit opportunities in any given market are akin to the amount of food and water in a particular local ecology - the more resources present, the less fierce the competition. As competition increases, either because of dwindling food supplies or an increase in the animal population, resources are depleted, which, in turn, causes a population decline eventually, decreasing the level of competition and starting the cycle again. In some cases, cycles converge to corner solutions (i.e., certain species become extinct, food sources are permanently exhausted, or environmental conditions shift dramatically). By viewing economic profits as the ultimate food source on which market participants depend for their survival, the dynamics of market interactions and financial innovation can be readily derived.

Under the AMH, behavioral biases abound. The origins of such biases are heuristics that are adapted to nonfinancial contexts, and their impact is determined by the size of the population with such biases versus the size of competing populations with more effective heuristics. During the fall of 1998, the desire for liquidity and safety on the part of a certain population of investors overwhelmed the population of hedge funds attempting to arbitrage such preferences, causing those arbitrage relations to break down. However, in the years 
prior to August 1998, fixed-income relative-value traders profited handsomely from these activities, presumably at the expense of individuals with seemingly "irrational" preferences (in fact, such preferences were shaped by a certain set of evolutionary forces and might be quite rational in other contexts). Therefore, under the AMH, investment strategies undergo cycles of profitability and loss in response to changing business conditions, the number of competitors entering and exiting the industry, and the type and magnitude of profit opportunities available. As opportunities shift, so too will the affected populations. For example, after 1998, the number of fixed-income relative-value hedge funds declined dramatically—because of outright failures, investor redemptions, and fewer startups in this sector-but many have reappeared in recent years as performance for this type of investment strategy has improved.

A concrete example of these "population dynamics" can be found by considering the birth and death of funds in various style categories in the TASS database. Table 8.2 reports the number of entries and exits of funds in the TASS database within each of three style categories-Global Macro, Long/Short Equity, and Fixed-Income Arbitrage. As in Table 4.5, the entry-and-exit dynamics begin in 1994, when TASS began maintaining its Graveyard database. The last column of Table 8.2 reports the annual compound return of the $\mathrm{CSFB} /$ Tremont style index corresponding to each of the three categories. By comparing the index returns with yearly attrition rates, it is apparent that performance has implications for future entries and exits and vice versa. For example, 1995 to 1997 were exceptionally good years for Global Macro, with index returns of 30.7 percent, 25.6 percent, and 37.1 percent, respectively. Therefore, it is not surprising that the number of Global Macro funds increased from 64 at the end of 1994 to 100 at the end of 1998 with an attrition rate of 8.0 percent in 1998, which was considerably lower than the 20.0 percent attrition rate in 1996 . However, from 1998 to 2000, the Global Macro index yielded considerably lower returns of -3.6 percent, 5.8 percent, and 11.7 percent, respectively, and during this period the attrition rate for Global Macro funds increased from 8.0 percent in 1998 to 34.7 percent in 2000. As returns improved from 2000 to 2002, new funds entered, fewer funds exited, and attrition rates declined once again. The Long/Short Equity and Fixed-Income Arbitrage categories also exhibit the same kind of patterns.

This relation between attrition rates and performance is no accident but is the manifestation of the simple business dynamics of the hedge fund industry. Superior performance leads to greater demand for a particular style category, which spurs the launching of new funds in that category. The increased number funds in the category, or increased capital among existing funds in the category, implies that for a given set of profit opportunities in that sector, returns will eventually decline. Such a decline will inevitably lead to a withdrawal of capital, which in turn implies that the "weakest" funds-those with the poorest performance, the lowest profit margins, and the least-viable business entities - will be eliminated from the population.

The AMH has a number of concrete implications for the hedge fund industry in particular. The first implication is that contrary to the classical EMH, arbitrage opportunities do exist from time to time in the AMH. As Grossman and Stiglitz (1980) observe, without such opportunities, there will be no incentive to gather information and the price-discovery aspect of financial markets will collapse. From an evolutionary perspective, the existence of active, liquid financial markets implies that profit opportunities must be present. As they are exploited, they disappear. But new opportunities are also continually being created as certain species die out, as others are born, and as institutions and business conditions change. Rather than the inexorable trend toward higher efficiency predicted by the EMH, the AMH implies considerably more complex market dynamics, with cycles as well as trends, in addition to panics, manias, bubbles, crashes, and other phenomena that are routinely witnessed in natural market ecologies. These dynamics provide the motivation for active management, as Bernstein (1998) suggests, also giving rise to Niederhoffer's (1997) “carnivores" and "decomposers."

A second implication-highlighted by the entry-and-exit dynamics of Table 8.2-is that investment strategies will also wax and wane, performing well in certain environments and performing poorly in other environments. Contrary to the classical EMH, in which arbitrage opportunities are competed away, eventually eliminating the profitability of the strategy designed to exploit the arbitrage, the AMH implies that such strategies may decline for a time and then return to profitability when environmental conditions become more conducive to such trades. An obvious example is risk arbitrage, which has been unprofitable for several years because of the decline in investment banking activity since 2001. However, as merger and acquisition activity 
Table 8.2. Annual Entries and Exits within Three Style Categories in the TASS Hedge Fund Database, 1994 to 2003

\begin{tabular}{|c|c|c|c|c|c|c|c|}
\hline Year & $\begin{array}{l}\text { Existing } \\
\text { Funds }\end{array}$ & $\begin{array}{c}\text { New } \\
\text { Entries }\end{array}$ & $\begin{array}{l}\text { New } \\
\text { Exits }\end{array}$ & $\begin{array}{l}\text { Intra-Year } \\
\text { Entry/Exit }\end{array}$ & $\begin{array}{l}\text { Total } \\
\text { Funds }\end{array}$ & $\begin{array}{c}\text { Attrition } \\
\text { Rate } \\
(\%)\end{array}$ & $\begin{array}{c}\text { Index } \\
\text { Return } \\
(\%)\end{array}$ \\
\hline \multicolumn{8}{|c|}{ Global Macro } \\
\hline 1994 & 56 & 12 & 4 & 0 & 64 & 7.1 & -5.7 \\
\hline 1995 & 64 & 17 & 6 & 0 & 75 & 9.4 & 30.7 \\
\hline 1996 & 75 & 15 & 15 & 4 & 75 & 20.0 & 25.6 \\
\hline 1997 & 75 & 19 & 6 & 1 & 88 & 8.0 & 37.1 \\
\hline 1998 & 88 & 19 & 7 & 2 & 100 & 8.0 & -3.6 \\
\hline 1999 & 100 & 10 & 15 & 1 & 95 & 15.0 & 5.8 \\
\hline 2000 & 95 & 13 & 33 & 0 & 75 & 34.7 & 11.7 \\
\hline 2001 & 75 & 13 & 10 & 0 & 78 & 13.3 & 18.4 \\
\hline 2002 & 78 & 15 & 11 & 0 & 82 & 14.1 & 14.7 \\
\hline 2003 & 82 & 0 & 8 & 3 & 74 & 9.8 & 5.5 \\
\hline \multicolumn{8}{|c|}{ Long/Short Equity } \\
\hline 1994 & 164 & 54 & 3 & 0 & 215 & 1.8 & -8.1 \\
\hline 1995 & 215 & 76 & 7 & 0 & 284 & 3.3 & 23.0 \\
\hline 1996 & 284 & 110 & 20 & 2 & 374 & 7.0 & 17.1 \\
\hline 1997 & 374 & 123 & 15 & 3 & 482 & 4.0 & 21.5 \\
\hline 1998 & 482 & 114 & 33 & 2 & 563 & 6.8 & 17.2 \\
\hline 1999 & 563 & 155 & 45 & 3 & 673 & 8.0 & 47.2 \\
\hline 2000 & 673 & 164 & 58 & 5 & 779 & 8.6 & 2.1 \\
\hline 2001 & 779 & 142 & 120 & 3 & 801 & 15.4 & -3.7 \\
\hline 2002 & 801 & 74 & 122 & 5 & 753 & 15.2 & -1.6 \\
\hline 2003 & 753 & 0 & 101 & 9 & 652 & 13.4 & 2.6 \\
\hline \multicolumn{8}{|c|}{ Fixed-Income Arbitrage } \\
\hline 1994 & 22 & 16 & 3 & 0 & 35 & 13.6 & 0.3 \\
\hline 1995 & 35 & 12 & 2 & 0 & 45 & 5.7 & 12.5 \\
\hline 1996 & 45 & 14 & 4 & 0 & 55 & 8.9 & 15.9 \\
\hline 1997 & 55 & 14 & 4 & 1 & 65 & 7.3 & 9.4 \\
\hline 1998 & 65 & 16 & 14 & 0 & 67 & 21.5 & -8.2 \\
\hline 1999 & 67 & 12 & 8 & 0 & 71 & 11.9 & 12.1 \\
\hline 2000 & 71 & 10 & 10 & 0 & 71 & 14.1 & 6.3 \\
\hline 2001 & 71 & 17 & 8 & 0 & 80 & 11.3 & 8.0 \\
\hline 2002 & 80 & 14 & 5 & 1 & 89 & 6.3 & 5.7 \\
\hline 2003 & 89 & 0 & 8 & 0 & 81 & 9.0 & 4.0 \\
\hline
\end{tabular}

Note: Annual frequency counts of entries into and exits out of three style categories of funds in the TASS hedge fund database from 1994 to 2003.

begins to pick up again, risk arbitrage will start to regain its popularity among both investors and portfolio managers, as it has in 2005. A more striking example can be found by computing the rolling first-order autocorrelation $\hat{\rho}_{1}$ of monthly returns of the S\&P Composite Index from January 1871 to April 2003 (see Figure 8.2). As a measure of market efficiency (recall that the Random Walk Hypothesis implies that returns are serially uncorrelated; hence, $\rho_{1}$ should be zero in theory), $\hat{\rho}_{1}$ might be expected to take on larger values during the early part of the sample and become progressively smaller during recent years as the U.S. equity market becomes more efficient. However, it is apparent from Figure 8.2 that the degree of efficiency-as measured by the first-order autocorrelation - varies through time in a cyclical fashion, and there are periods in the 1950s when the market is more efficient than in the early 1990s! 


\section{Figure 8.2. First-Order Autocorrelation Coefficients for Monthly Returns of the S\&P Composite Index Using Five-Year Rolling Windows, January 1871-April 2003}

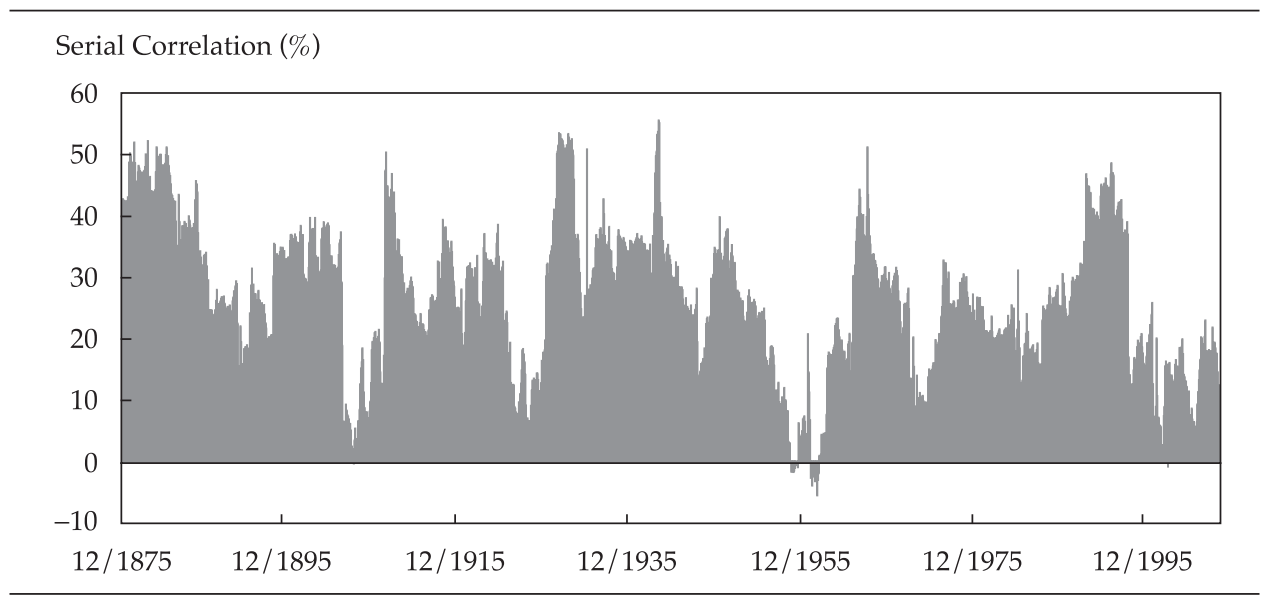

Such cycles are not ruled out by the EMH in theory, but in practice, none of its existing empirical implementations have incorporated these dynamics, assuming instead a stationary world in which markets are perpetually in equilibrium. This widening gulf between the stationary EMH and obvious shifts in market conditions no doubt contributed to Bernstein's (2003) recent critique of the policy portfolio in strategic asset allocation models and his controversial proposal to reconsider the case for tactical asset allocation.

A third implication is that innovation is the key to survival. The classical EMH suggests that certain levels of expected returns can be achieved simply by bearing a sufficient degree of risk. The AMH implies that the risk/reward relation varies through time and that a better way of achieving a consistent level of expected returns is to adapt to changing market conditions. By evolving a multiplicity of capabilities that are suited to a variety of environmental conditions, investment managers are less likely to become extinct as a result of rapid changes in business conditions. Consider the current theory of the demise of the dinosaurs (Alvarez 1997), and ask where the next financial asteroid might come from.

Finally, the AMH has a clear implication for all financial market participants: Survival is the only objective that matters. While profit maximization, utility maximization, and general equilibrium are certainly relevant aspects of market ecology, the organizing principle in determining the evolution of markets and financial technology is simply survival.

These evolutionary underpinnings are more than simple speculation in the context of the hedge fund industry. The extraordinary degree of competitiveness of global financial markets, the outsize rewards that accrue to the "fittest" managers, and the low barriers to entry and minimal fixed costs of setup suggest that Darwinian selection - "survival of the richest," to be precise-is at work in determining the typical profile of the successful hedge fund. After all, unsuccessful managers are eventually eliminated from the population after suffering a certain level of losses.

The new paradigm of the AMH is still under development and certainly requires a great deal more research to render it "operationally meaningful" in Samuelson's (1947) sense. However, even at this early stage, it is clear that an evolutionary framework is able to reconcile many of the apparent contradictions between efficient markets and the hedge fund industry. The former may be viewed as the steady state limit of a population with constant environmental conditions, and the latter involves specific adaptations of certain groups that may or may not persist, depending on the particular evolutionary paths that the economy experiences. More specific implications may be derived through a combination of deductive and inductive inference-for example, theoretical analysis of evolutionary dynamics, empirical analysis of evolutionary forces in financial markets, and experimental analysis of decision making at the individual and group level—and are currently under investigation (see Lo 2004 for further discussion). 


\section{Appendix A.}

This appendix contains the TASS category definitions, MATLAB source code for the Loeb price-impact function, and some of the more technical aspects of the integrated hedge fund investment process.

\section{TASS Category Definitions}

The following is a list of category descriptions, taken directly from TASS documentation, that define the criteria used by TASS in assigning funds in its database to one of 17 possible categories:

Equity Hedge: This directional strategy involves equity-oriented investing on both the long and short sides of the market. The objective is not to be market neutral. Managers have the ability to shift from value to growth, from small to medium to large capitalization stocks, and from a net long position to a net short position. Managers may use futures and options to hedge. The focus may be regional, such as long/short U.S. or European equity, or sector specific, such as long and short technology or healthcare stocks. Long/ short equity funds tend to build and hold portfolios that are substantially more concentrated than those of traditional stock funds. U.S. equity hedge, European equity hedge, Asian equity hedge, and global equity hedge are the regional focuses.

Dedicated Shortseller: Short biased managers take short positions in mostly equities and derivatives. The short bias of a manager's portfolio must be constantly greater than zero to be classified in this category.

Fixed-Income Directional: This directional strategy involves investing in Fixed-Income markets only on a directional basis.

Convertible Arbitrage: This strategy is identified by hedge investing in the convertible securities of a company. A typical investment is to be long the convertible bond and short the common stock of the same company. Positions are designed to generate profits from the fixed-income security, as well as the short sale of stock, while protecting principal from market moves.

Event Driven: This strategy is defined as "special situations" investing designed to capture price movement generated by a significant pending corporate event, such as a merger, corporate restructuring, liquidation, bankruptcy, or reorganization. There are three popular subcategories in event-driven strategies-risk (merger) arbitrage, distressed/high yield securities, and Regulation D.

Nondirectional/Relative Value: This investment strategy is designed to exploit equity and/or fixedincome market inefficiencies and usually involves being simultaneously long and short matched market portfolios of the same size within a country. Market-neutral portfolios are designed to be either beta or currency neutral, or both.

Global Macro: Global macro managers carry long and short positions in any of the world's major capital or derivative markets. These positions reflect their views on overall market direction as influenced by major economic trends and/or events. The portfolios of these funds can include stocks, bonds, currencies, and commodities in the form of cash or derivatives instruments. Most funds invest globally in both developed and emerging markets.

Natural Resources: This trading strategy has a focus on the natural resources around the world.

Leveraged Currency: This strategy invests in currency markets around the world.

Managed Futures: This strategy invests in listed financial and commodity futures markets and currency markets around the world. The managers are usually referred to as Commodity Trading Advisors, or CTAs. Trading disciplines are generally systematic or discretionary. Systematic traders tend to use price and market specific information (often technical) to make trading decisions, while discretionary managers use a judgmental approach. 
Emerging Markets: This strategy involves equity or fixed-income investing in emerging markets around the world.

Property: The main focus of the investments is property.

Fund of Funds: A "Multi Manager" fund will employ the services of two or more trading advisors or Hedge Funds who will be allocated cash by the Trading Manager to trade on behalf of the fund.

\section{MATLAB Loeb Function tloeb}

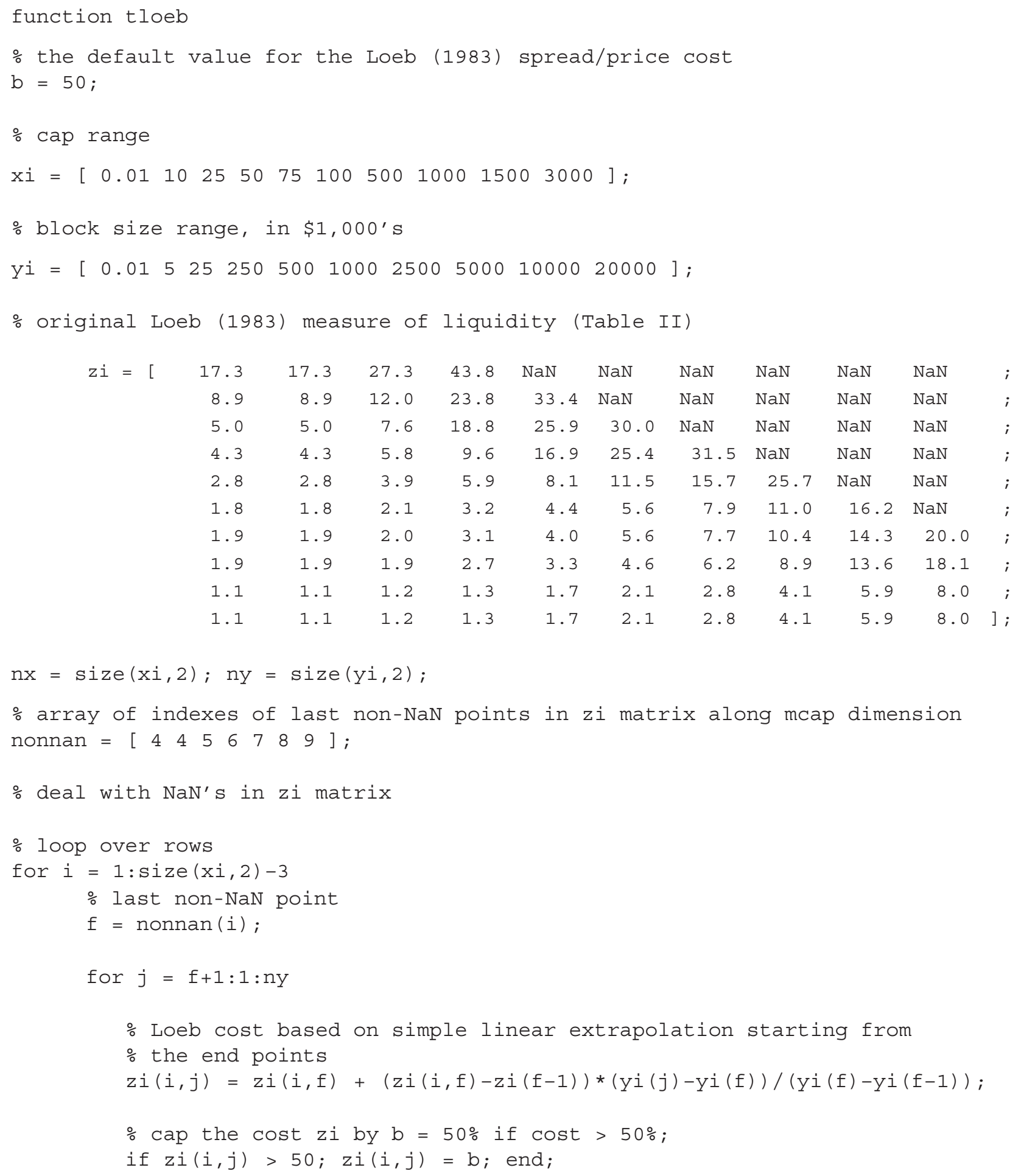


\% If trade size > 20\% of market cap (not T. Loeb's original 5\%),

o $\mathrm{zi}$ is still $\mathrm{NaN}$

if $(y i(j) / 1000)>0.2 * x i(i) ; z i(i, j)=N a N ;$ end;

end

end

$\mathrm{zi}$

\% produce arrays acceptable by MATLAB for 3D graphics

for $i=1: n y$

for $j=1: n x$

$x(i, j)=$

$(x i(j)) ;$

$y(i, j)=$

(yi (i)) ;

$z(i, j)=$

$z i(j, i)$;

end

end

\% determine max-min for interpolation

$\operatorname{maxx}=\max (x i) ; \min x=\min (x i) ; \operatorname{maxy}=\max (y i) ; \operatorname{miny}=\min (y i)$;

\% the number of nodes in each direction

$\mathrm{N}=40 ; \mathrm{dx}=(\operatorname{maxx}-\operatorname{minx}) / \mathrm{N} ; \mathrm{dy}=(\operatorname{maxy}-\operatorname{miny}) / \mathrm{N}$;

\% interpolated arrays

for $i=1: N$

for $j=1: N$

$x 1(i, j)=x i(1)+d x * j$;

$y 1(i, j)=y i(1)+d y * i$

end

end

\% plot extended Loeb function

mesh ( $(\mathrm{x} 1),(\mathrm{y} 1)$, interp2 (x, y, $\mathrm{z}, \mathrm{x} 1, \mathrm{y} 1$, 'linear') ) view $(30,50)$;

colormap (jet); grid on; xlabel('Cap $[\$ 1,000,000]$ ', 'FontSize', 8);

ylabel ('Block [\$1000] ', 'FontSize', 8)

zlabel ('Spread/Price Cost [\%] ') ;

otitle(' Loeb (1983) Total Spread/Price Cost');

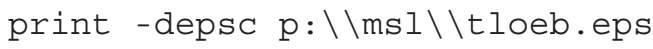

\section{Constrained Optimization}

To solve the following optimization problem,

$$
\operatorname{Min}_{\{\boldsymbol{\omega}\}} \frac{1}{2} \boldsymbol{\omega}^{\prime} \boldsymbol{\Sigma} \boldsymbol{\omega},
$$

subject to

$$
\begin{aligned}
& \boldsymbol{\omega}^{\prime} \boldsymbol{\mu} \geq \mu_{o}, \\
& \boldsymbol{\omega}^{\prime} \mathbf{\imath}=1,
\end{aligned}
$$


define the Lagrangian,

$$
\mathcal{L}=\frac{1}{2} \boldsymbol{\omega}^{\prime} \boldsymbol{\Sigma} \boldsymbol{\omega}+\lambda\left(\mu_{o}-\boldsymbol{\omega}^{\prime} \boldsymbol{\mu}\right)+\xi\left(1-\boldsymbol{\omega}^{\prime} \mathbf{\imath}\right),
$$

which yields the following first-order conditions:

$$
\begin{aligned}
& \frac{\partial \mathcal{L}}{\partial \boldsymbol{\omega}}=0=\boldsymbol{\Sigma} \boldsymbol{\omega}-\lambda \boldsymbol{\mu}-\xi_{\mathbf{\iota}} \\
& \frac{\partial \mathcal{L}}{\partial \gamma}=0=\mu_{o}-\boldsymbol{\omega}^{\prime} \boldsymbol{\mu} \\
& \frac{\partial \mathcal{L}}{\partial \lambda}=0=1-\boldsymbol{\omega}^{\prime} \mathbf{t} .
\end{aligned}
$$

Solving Equation A.5 for $\boldsymbol{\omega}$ yields the minimum-variance portfolio as a function of the two Lagrange multipliers:

$$
\boldsymbol{\omega}^{*}=\lambda \boldsymbol{\Sigma}^{-1} \boldsymbol{\mu}+\xi \boldsymbol{\Sigma}^{-1} \mathbf{t},
$$

and applying Equations A.6 and A.7 to Equation A.8 allows the Lagrange multipliers to be solved for explicitly as

$$
\lambda=\frac{\mu_{o} A-B}{D}, \xi=-\frac{\mu_{o} B-C}{D},
$$

where

$$
\begin{aligned}
& A \equiv \mathbf{\iota}^{\prime} \mathbf{\Sigma}^{-1} \mathbf{\imath}>0 \\
& B \equiv \mathbf{\iota}^{\prime} \mathbf{\Sigma}^{-1} \boldsymbol{\mu} \\
& C \equiv \boldsymbol{\mu}^{\prime} \boldsymbol{\Sigma}^{-1} \boldsymbol{\mu}>0 \\
& D \equiv A C-B^{2}>0 .
\end{aligned}
$$




\section{References}

Acharya, V., and L. Pedersen. 2002. “Asset Pricing with Liquidity Risk.” Working paper, London Business School.

Ackermann, C., R. McEnally, and D. Ravenscraft. 1999. "The Performance of Hedge Funds: Risk, Return, and Incentives." Journal of Finance, vol. 54, no. 3 (June):833-874.

Agarwal, V., and N. Naik. 2000a. "Performance Evaluation of Hedge Funds with Buy and Hold and OptionBased Strategies.” Hedge Fund Centre Working Paper HF-003, London Business School.

- 2000b. "On Taking the 'Alternative' Route: The Risks, Rewards, and Performance Persistence of Hedge Funds.” Journal of Alternative Investments, vol. 2, no. 4 (Spring):6-23.

- 2000c. "Multi-Period Performance Persistence Analysis of Hedge Funds." Journal of Financial and Quantitative Analysis, vol. 35, no. 3 (September):327-342.

- 2000d. "Generalised Style Analysis of Hedge Funds." Journal of Asset Management, vol. 1, no. 1 (July):93-109.

- 2004. "Risks and Portfolio Decisions Involving Hedge Funds." Review of Financial Studies, vol. 17, no. 1:63-98.

Agarwal, A., N. Daniel, and N. Naik. 2004. "Flows, Performance and Managerial Incentives in Hedge Funds.” Working paper, Georgia State University.

Aiyagari, R., and M. Gertler. 1991. “Asset Returns with Transaction Costs and Uninsured Individual Risk.” Journal of Monetary Economics, vol. 27, no. 3 (June):311-331.

Alvarez, W. 1997. T. Rex and the Crater of Doom. Princeton, NJ: Princeton University Press.

Amenc, N., and L. Martinelli. 2002. "Portfolio Optimization and Hedge Fund Style Allocation Decisions." Journal of Alternative Investments, vol. 5, no. 2 (Fall):7-20.

Amenc, N., S. E1 Bied, and L. Martinelli. 2003. "Predictability in Hedge Fund Returns." Financial Analysts Journal, vol. 59, no. 5 (September/October):32-46.

Amihud, Y., and H. Mendelson. 1986a. "Asset Pricing and the Bid-Ask Spread.” Journal of Financial Economics, vol. 17, no. 2 (December):223-249.

—. 1986b. "Liquidity and Stock Returns." Financial Analysts Journal, vol. 42, no. 3 (May/June):43-48.

Amin, G., and H. Kat. 2003a. "Hedge Fund Performance 1990-2000: Do the 'Money Machines' Really Add Value?” Journal of Financial and Quantitative Analysis, vol. 38, no. 2 (June):251-274.

- 2003b. "Welcome to the Dark Side: Hedge Fund Attrition and Survivorship Bias over the Period 1994-2001.” Journal of Alternative Investments, vol. 6, no. 1 (Summer):57-73.

- 2003c. "Stocks, Bonds, and Hedge Funds." Journal of Portfolio Management, vol. 29, no. 4 (Summer):113-120.

Andersen, T., T. Bollerslev, and F. Diebold. 2004. "Parametric and Nonparametric Volatility Measurement." In Handbook of Financial Econometrics. Edited by L. Hansen and Y. Ait-Sahalia. Amsterdam: North-Holland. 
Arnott, R., and W. Wagner. 1990. “The Measurement and Control of Trading Costs.” Financial Analysts Journal, vol. 46, no. 6 (November/December):73-80.

Asness, C., R. Krail, and J. Liew. 2001. “Do Hedge Funds Hedge?” Journal of Portfolio Management, vol. 28, no. 1 (Fall):6-19.

Atchison, M., K. Butler, and R. Simonds. 1987. "Nonsynchronous Security Trading and Market Index Autocorrelation." Journal of Finance, vol. 42, no. 1 (March):111-118.

Atkinson, C., and P. Wilmott. 1995. "Portfolio Management with Transaction Costs: An Asymptotic Analysis of the Morton and Pliska Model.” Mathematical Finance, vol. 5, no. 4 (October):357-367.

Bagehot, W. [Jack Treynor]. 1971. “The Only Game in Town.” Financial Analysts Journal, vol. 27, no. 2 (March/April):12-14, 22.

Baquero, G., J. ter Horst, and M. Verbeek. Forthcoming. "Survival, Look-Ahead Bias and the Performance of Hedge Funds." Journal of Financial and Quantitative Analysis.

Bares, P., R. Gibson, and S. Gyger. 2003. "Style Consistency and Survival Probability in the Hedge Funds Industry.” Working paper, University of Zurich.

Beneish, M. 2001. “Earnings Management: A Perspective." Managerial Finance, vol. 27, no. 12 (December):3-17.

Berk, J., and R. Green. 2004. "Mutual Fund Flows and Performance in Rational Markets." Journal of Political Economy, vol. 112, no. 6 (December):1269-95.

Bernstein, P. 1998. "Why the Efficient Market Offers Hope to Active Management." In Economics and Portfolio Strategy. New York: Peter Bernstein, Inc.

—. 2003. "Are Policy Portfolios Obsolete?” Economics and Portfolio Strategy (March 1).

Bertsimas, D., and A. Lo. 1998. "Optimal Control of Execution Costs.” Journal of Financial Markets, vol. 1, no. 1:1-50.

Bertsimas, D., P. Hummel, and A. Lo. 1999. "Optimal Control of Execution Costs for Portfolios." Computing in Science E' Engineering, vol. 1, no. 6 (November/December):40-53.

Bhargava, R., A. Bose, and D. Dubofsky. 1998. "Exploiting International Stock Market Correlations with Open-End International Mutual Funds." Journal of Business, Finance, and Accounting, vol. 25, nos. 5-6 (June):765-773.

Bhattacharya, S., and P. Pfleiderer. 1985. "Delegated Portfolio Management.” Journal of Economic Theory, vol. 36 , no. 1 (June):1-25.

Bickel, P., and K. Doksum. 1977. Mathematical Statistics: Basic Ideas and Selected Topics. San Francisco, CA: Holden-Day, Inc.

Billingsley, P. 1968. Convergence of Probability Measures. New York: John Wiley \& Sons.

Black, F. 1986. "Noise.” Journal of Finance, vol. 41, no. 3 (July):529-544.

Bodurtha, S., and T. Quinn. 1990. "Does Patient Program Trading Really Pay?” Financial Analysts Journal, vol. 46, no. 3 (May/June):35-42.

Bookstaber, R. 1999. “A Framework for Understanding Market Crisis.” In Risk Management: Principles and Practices. Charlottesville, VA: Association for Investment Management and Research. 
2000. "Understanding and Monitoring the Liquidity Crisis Cycle." Financial Analysts Journal, vol. 56, no. 5 (September/October):17-22.

Boudoukh, J., M. Richardson, M. Subrahmanyam, and R. Whitelaw. 2002. "Stale Prices and Strategies for Trading Mutual Funds.” Financial Analysts Journal, vol. 58, no. 4 (July/August):53-71.

Boyle, P., and T. Vorst. 1992. "Option Replication in Discrete Time with Transaction Costs." Journal of Finance, vol. 47, no. 1 (March):271-293.

Boyson, N. 2002. "How Are Hedge Fund Manager Characteristics Related to Performance, Volatility and Survival?” Working paper, Ohio State University.

Brinson, G., R. Hood, and G. Beebower. 1986. "Determinants of Portfolio Performance.” Financial Analysts Journal, vol. 42, no. 4 (July/August):39-44.

Brinson, G., B. Singer, and G. Beebower. 1991. "Determinants of Portfolio Performance II: An Update.” Financial Analysts Journal, vol. 47, no. 3 (May/June):40-48.

Brockwell, P., and R. Davis. 1991. Time Series: Theory and Methods. 2nd ed. New York: Springer-Verlag.

Brooks, C., and H. Kat. 2002. "The Statistical Properties of Hedge Fund Index Returns and Their Implications for Investors." Journal of Alternative Investments, vol. 5, no. 2 (Fall):25-44.

Brown, S., and W. Goetzmann. 2003. "Hedge Funds with Style." Journal of Portfolio Management, vol. 29, no. 2 (Winter):101-112.

Brown, S., W. Goetzmann, and R. Ibbotson. 1999. "Offshore Hedge Funds: Survival and Performance 19891995.” Journal of Business, vol. 72, no. 1 (January):91-117.

Brown, S., W. Goetzmann, R. Ibbotson, and S. Ross. 1992. "Survivorship Bias in Performance Studies." Review of Financial Studies, vol. 5, no. 4 (Winter):553-580.

Brown, S., W. Goetzmann, and B. Liang. 2004. "Fees on Fees in Funds of Funds." Journal of Investment Management, vol. 2, no. 4 (Fourth Quarter):39-46.

Brown, S., W. Goetzmann, and J. Park. 1997. "Conditions for Survival: Changing Risk and the Performance of Hedge Fund Managers and CTAs.” Working Paper F-59, Yale School of Management.

2000. "Hedge Funds and the Asian Currency Crisis." Journal of Portfolio Management, vol. 26, no. 4 (Summer):95-101.

- 2001. "Careers and Survival: Competition and Risk in the Hedge Fund and CTA Industry." Journal of Finance, vol. 56, no. 5 (October):1869-86.

Campbell, J., A. Lo, and C. MacKinlay. 1997. The Econometrics of Financial Markets. Princeton, NJ: Princeton University Press.

Carpenter, J. 2000. “Does Option Compensation Increase Managerial Risk Appetite?” Journal of Finance, vol. 55, no. 5 (October):2311-31.

Carpenter, J., and A. Lynch. 1999. "Survivorship Bias and Attrition Effects in Measures of Performance Persistence.” Journal of Financial Economics, vol. 54, no. 3 (December):337-374.

Carpenter, J., P. Dybvig, and H. Farnsworth. 2001. "Portfolio Performance and Agency." Working paper, Stern School of Business, New York University. 
Cecchetti, S., and N. Mark. 1990. "Evaluating Empirical Tests of Asset Pricing Models: Alternative Interpretations." American Economic Review, vol. 80, no. 2 (May):48-51.

Chalmers, J., R. Edelen, and G. Kadlec. 2001. "On the Perils of Financial Intermediaries Setting Security Prices: The Mutual Fund Wild Card Option.” Journal of Finance, vol. 56, no. 6 (December):2209-36.

Chan, L., and J. Lakonishok. 1993. "Institutional Trades and Intraday Stock Price Behavior." Journal of Financial Economics, vol. 33, no. 2 (April):173-199.

- 1995. “The Behavior of Stock Prices around Institutional Trades.” Journal of Finance, vol. 50, no. 4 (September):1147-74.

Chan, N., M. Getmansky, S. Haas, and A. Lo. 2005. "Systemic Risk and Hedge Funds." In The Risks of Financial Institutions and the Financial Sector. Edited by M. Carey and R. Stulz. Chicago, IL: University of Chicago Press.

Chandar, N., and R. Bricker. 2002. "Incentives, Discretion, and Asset Valuation in Closed-End Mutual Funds.” Journal of Accounting Research, vol. 40, no. 4 (September):1037-70.

Chevalier, J., and G. Ellison. 1997. "Risk Taking by Mutual Funds as a Response to Incentives.” Journal of Political Economy, vol. 105, no. 6 (December):1167-1200.

Chordia, T., R. Roll, and A. Subrahmanyam. 2000. "Commonality in Liquidity.” Journal of Financial Economics, vol. 56, no. 1 (April):3-28.

\section{—. 2001. "Market Liquidity and Trading Activity." Journal of Finance, vol. 56, no. 2 (April):501-530.}

- 2002. “Order Imbalance, Liquidity, and Market Returns.” Journal of Financial Economics, vol. 65, no. 1 (July):111-130.

Chordia, T., A. Subrahmanyam, and V. Anshuman. 2001. "Trading Activity and Expected Stock Returns." Journal of Financial Economics, vol. 59, no. 1 (January):3-32.

Cohen, K., G. Hawawini, S. Maier, R. Schwartz, and D. Whitcomb. 1983a. "Estimating and Adjusting for the Intervalling-Effect Bias in Beta.” Management Science, vol. 29, no. 1 (January):135-148.

- 1983b. "Friction in the Trading Process and the Estimation of Systematic Risk." Journal of Financial Economics, vol. 12, no. 2 (August):263-278.

Cohen, K., S. Maier, R. Schwartz, and D. Whitcomb. 1978. "The Returns Generation Process, Returns Variance, and the Effect of Thinness in Securities Markets." Journal of Finance, vol. 33, no. 1 (March):149-167.

—. 1979. "On the Existence of Serial Correlation in an Efficient Securities Market." Portfolio Theory, 25 Years After: Essays in Honor of Harry Markowitz, edited by E. J. Elton and M. J. Gruber. TIMS Studies in the Management Sciences, vol. 11. Amsterdam: North-Holland Publishing.

- 1981. "Transaction Costs, Order Placement Strategy and the Existence of the Bid-Ask Spread." Journal of Political Economy, vol. 89, no. 2 (April):287-305.

—. 1986. The Microstructure of Securities Markets. Englewood Cliffs, NJ: Prentice-Hall.

Collins, B., and F. Fabozzi. 1991. “A Methodology for Measuring Transaction Costs.” Financial Analysts Journal, vol. 47, no. 2 (March/April):27-36.

Constantinides, G. 1986. "Capital Market Equilibrium with Transaction Costs.” Journal of Political Economy, vol. 94, no. 4 (August):842-862. 
Cremers, J., M. Kritzman, and S. Page. 2004. "Optimal Hedge Fund Allocations: Do Higher Moments Matter?” Revere Street Working Paper Series, Financial Economics 272-13.

Cuneo, L., and W. Wagner. 1975. "Reducing the Cost of Stock Trading." Financial Analysts Journal, vol. 31, no. 6 (November/December):35-44.

Davis, M., and A. Norman. 1990. "Portfolio Selection with Transaction Costs." Mathematics of Operations Research, vol. 15, no. 4 (November):676-713.

Demsetz, H. 1968. “The Cost of Transacting.” Quarterly Journal of Economics, vol. 82, no. 1 (February):33-53.

Dimson, E. 1979. "Risk Measurement When Shares Are Subject to Infrequent Trading." Journal of Financial Economics, vol. 7, no. 2 (June):197-226.

Dumas, B., and E. Luciano. 1991. "An Exact Solution to a Dynamic Portfolio Choice Problem under Transactions Costs.” Journal of Finance, vol. 46, no. 2 (June):577-595.

Edwards, F., and M. Caglayan. 2001. "Hedge Fund and Commodity Fund Investments in Bull and Bear Markets.” Journal of Portfolio Management, vol. 27, no. 4 (Summer):97-108.

Engle, R. 2002. "Dynamic Conditional Correlation: A Simple Class of Multivariate Generalized Autoregressive Conditional Heteroskedasticity Models." Journal of Business and Economic Statistics, vol. 20, no. 3 (July):339-350.

Epps, T. 1976. "The Demand for Brokers' Services: The Relation between Security Trading Volume and Transaction Cost." Bell Journal of Economics, vol. 7, no. 1 (Spring):163-194.

Fama, E. 1970. "Efficient Capital Markets: A Review of Theory and Empirical Work." Journal of Finance, vol. 25, no. 2 (May):383-417.

Farmer, D. 2002. "Market Force, Ecology and Evolution." Industrial and Corporate Change, vol. 11, no. 5 (November):895-953.

Farmer, D., and A. Lo. 1999. "Frontiers of Finance: Evolution and Efficient Markets." Proceedings of the National Academy of Sciences, vol. 96, no. 18 (31 August):9991-92.

Feffer, S., and C. Kundro. 2003. "Understanding and Mitigating Operational Risk in Hedge Fund Investments." Capco White Paper (March).

Fisher, J., D. Geltner, and R. Webb. 1994. "Value Indices of Commercial Real Estate: A Comparison of Index Construction Methods." Journal of Real Estate Finance and Economics, vol. 9, no. 2:137-164.

Fisher, J., D. Gatzlaff, D. Geltner, and D. Haurin. 2003. "Controlling for the Impact of Variable Liquidity in Commercial Real Estate Price Indices.” Real Estate Economics, vol. 31, no. 2 (Summer):269-303.

Fisher, L. 1966. “Some New Stock Market Indexes.” Journal of Business, vol. 39, no. 1, part II (Supplement, January):191-225.

Fung, W., and D. Hsieh. 1997a. "Empirical Characteristics of Dynamic Trading Strategies: The Case of Hedge Funds.” Review of Financial Studies, vol. 10, no. 2 (Summer):275-302.

- 1997b. "Survivorship Bias and Investment Style in the Returns of CTAs: The Information Content of Track Records.” Journal of Portfolio Management, vol. 24, no. 1 (Fall):30-41.

—. 1999. “A Primer on Hedge Funds.” Journal of Empirical Finance, vol. 6, no. 3 (September):309-331. 
- 2000. "Performance Characteristics of Hedge Funds and Commodity Funds: Natural vs. Spurious Biases." Journal of Financial and Quantitative Analysis, vol. 35, no. 3 (September):291-307.

— 2001. "The Risk in Hedge Fund Strategies: Theory and Evidence from Trend Followers." Review of Financial Studies, vol. 14, no. 2 (Summer):313-341.

—. 2002a. "Asset-Based Style Factors for Hedge Funds.” Financial Analysts Journal, vol. 58, no. 5 (September/October):16-27.

- 2002b. "Hedge-Fund Benchmarks: Information Content and Biases." Financial Analysts Journal, vol. 58, no. 1 (January/February):22-34.

Gammill, J., and A. Pérold. 1989. “The Changing Character of Stock Market Liquidity.” Journal of Portfolio Management, vol. 15, no. 3 (Spring):13-18.

Garman, M., and J. Ohlson. 1981. "Valuation of Risky Assets in Arbitrage-Free Economies with Transactions Costs.” Journal of Financial Economics, vol. 9, no. 3 (September):271-280.

Getmansky, M. 2004. “The Life Cycle of Hedge Funds: Fund Flows, Size and Performance.” Working paper, MIT Laboratory for Financial Engineering.

Getmansky, M., and A. Lo. 2003. “A System Dynamics Model of the Hedge Fund Industry.” Working paper, MIT Laboratory for Financial Engineering.

Getmansky, M., A. Lo, and I. Makarov. 2004. "An Econometric Model of Serial Correlation and Illiquidity in Hedge Fund Returns.” Journal of Financial Economics, vol. 74, no. 3 (December):529-609.

Getmansky, M., A. Lo, and S. Mei. 2004. "Sifting through the Wreckage: Lessons from Recent Hedge-Fund Liquidations.” Journal of Investment Management, vol. 2, no. 4 (Fourth Quarter):6-38.

Glosten, L., and L. Harris. 1988. "Estimating the Components of the Bid/Ask Spread." Journal of Financial Economics, vol. 21, no. 1 (May):123-142.

Glosten, L., and P. Milgrom. 1985. "Bid, Ask and Transaction Prices in a Specialist Market with Heterogeneously Informed Traders.” Journal of Financial Economics, vol. 14, no. 1 (March):71-100.

Goetzmann, W., and N. Peles. 1997. “Cognitive Dissonance and Mutual Fund Investors.” Journal of Financial Research, vol. 20, no. 2 (Summer):145-158.

Goetzmann, W., J. Ingersoll, and S. Ross. 2003. "High-Water Marks and Hedge Fund Management Contracts.” Journal of Finance, vol. 58, no. 4 (August):1685-1718.

Goetzmann, W., Z. Ivkovic, and G. Rouwenhorst. 1999. "Day Trading International Mutual Funds: Evidence and Policy Solutions.” Journal of Financial and Quantitative Analysis, vol. 36, no. 3 (September):287-309.

Goetzmann, W., J. Ingersoll, M. Spiegel, and I. Welch. 2002. “Sharpening Sharpe Ratios.” NBER Working Paper W9116.

Goodwin, T. 1993. "Business-Cycle Analysis with a Markov-Switching Model." Journal of Business and Economic Statistics, vol. 11, no. 3 (July):331-339.

Granger, C. 1980. "Long Memory Relationships and the Aggregation of Dynamic Models." Journal of Econometrics, vol. 14, no. 2 (October):227-238.

— 1988. "Aggregation of Time Series Variables: A Survey.” Discussion Paper 1, Federal Reserve Bank of Minneapolis Institute for Empirical Macroeconomics. 
Greene, J., and C. Hodges. 2002. "The Dilution Impact of Daily Fund Flows on Open-End Mutual Funds.” Journal of Financial Economics, vol. 65, no. 1 (July):131-158.

Greenspan, A. 1998. "Statements to the Congress: Alan Greenspan-October 1, 1998." Federal Reserve Bulletin, vol. 84, no. 12 (December):1046-50.

Gregoriou, G. 2002. "Hedge Fund Survival Lifetimes." Journal of Asset Management, vol. 3, no. 3 (December):237-252.

Gromb, D., and D. Vayanos. 2002. "Equilibrium and Welfare in Markets with Financially Constrained Arbitrageurs." Journal of Financial Economics, vol. 66, nos. 2-3 (November/December):361-407.

Grossman, S. 1976. "On the Efficiency of Competitive Stock Markets Where Traders Have Diverse Information.” Journal of Finance, vol. 31, no. 2 (May):573-585.

Grossman, S., and G. Laroque. 1990. "Asset Pricing and Optimal Portfolio Choice in the Presence of Illiquid Durable Consumption Goods.” Econometrica, vol. 58, no. 1 (January):25-52.

Grossman, S., and J. Stiglitz. 1980. "On the Impossibility of Informationally Efficient Markets." American Economic Review, vol. 70, no. 3 (June):393-408.

Grossman, S., and J. Vila. 1992. "Optimal Dynamic Trading with Leverage Constraints.” Journal of Financial and Quantitative Analysis, vol. 27, no. 2 (June):151-168.

Gruber M. 1996. “Another Puzzle: The Growth in Actively Managed Mutual Funds.” Journal of Finance, vol. 51, no. 3 (July):783-810.

Gyourko, J., and D. Keim. 1992. "What Does the Stock Market Tell Us about Real Estate Returns?” AREUEA Journal, vol. 20, no. 3 (Fall):457-485.

Hamilton, J. 1989. "A New Approach to the Economic Analysis of Nonstationary Time Series and the Business Cycle.” Econometrica, vol. 57, no. 2 (March):357-384.

—_. 1990. "Analysis of Time Series Subject to Changes in Regime.” Journal of Econometrics, vol. 45, nos. 1-2 (July/August):39-70.

- 1996. "Specification Testing in Markov-Switching Time-Series Models." Journal of Econometrics, vol. 70, no. 1 (January):127-157.

Hansen, L. 1982. "Large Sample Properties of Generalized Method of Moments Estimators." Econometrica, vol. 50, no. 4 (July):1029-54.

Hasbrouck, J., and R. Schwartz. 1988. "Liquidity and Execution Costs in Equity Markets." Journal of Portfolio Management, vol. 14, no. 3 (Spring):10-16.

Haugh, M., and A. Lo. 2001. “Asset Allocation and Derivatives.” Quantitative Finance, vol. 1, no. 1 (January):45-72.

Hausman, J., A. Lo, and C. MacKinlay. 1992. “An Ordered Probit Analysis of Transaction Stock Prices.” Journal of Financial Economics, vol. 31, no. 3 (June):319-379.

Healy, P., and J. Wahlen. 1999. "A Review of the Earnings Management Literature and Its Implications for Standard Setting.” Accounting Horizons, vol. 14, no. 4 (December):365-383.

Heaton, J., and D. Lucas. 1996. "Evaluating the Effects of Incomplete Markets on Risk Sharing and Asset Pricing." Journal of Political Economy, vol. 104, no. 3 (June):443-487. 
- 1997. "The Importance of Investor Heterogeneity and Financial Market Imperfections for the Behavior of Asset Prices." Carnegie-Rochester Conference Series on Public Policy, vol. 42 (June):1-32.

Hendricks, D., J. Patel, and R. Zeckhauser. 1997. "The J-Shape of Performance Persistence Given Survivorship Bias." Review of Economics and Statistics, vol. 79, no. 2 (May):161-166.

Herrndorf, N. 1984. “A Functional Central Limit Theorem for Weakly Dependent Sequences of Random Variables.” Annals of Probability, vol. 12, no. 1 (February):141-153.

Hodges, S., and A. Neuberger. 1989. “Optimal Replication of Contingent Claims under Transactions Costs.” Working paper, Financial Options Research Center, University of Warwick.

Holmström, B., and J. Tirole. 2001. “LAPM: A Liquidity-Based Asset Pricing Model.” Journal of Finance, vol. 56, no. 5 (October):1837-67.

Howell, M.J. 2001. "Fund Age and Performance." Journal of Alternative Investments, vol. 4, no. 2 (Fall):57-60.

Huang, M. 2003. "Liquidity Shocks and Equilibrium Liquidity Premia." Journal of Economic Theory, vol. 109, no. 1 (March):104-129.

Ineichen, A. 2001. "The Myth of Hedge Funds: Are Hedge Funds the Fireflies ahead of the Storm?” Journal of Global Financial Markets, vol. 2, no. 4 (Winter):34-46.

Ingersoll, J. 1987. Theory of Financial Decision Making. Totowa, NJ: Rowman \& Littlefield.

Ippolito, R. 1992. "Consumer Reaction to Measures of Poor Quality: Evidence from the Mutual Fund Industry." Journal of Law and Economics, vol. 35, no. 1:45-70.

Jen, P., C. Heasman, and K. Boyatt. 2001. "Alternative Asset Strategies: Early Performance in Hedge Fund Managers.” Internal document, Lazard Asset Management.

Jobson, J., and R. Korkie. 1980. "Estimation for Markowitz Efficient Portfolios." Journal of the American Statistical Association, vol. 75, no. 371 (September):544-554.

- 1981. "Performance Hypothesis Testing with the Sharpe and Treynor Measures." Journal of Finance, vol. 36, no. 4 (September):889-908.

Kadlec, G., and D. Patterson. 1999. “A Transactions Data Analysis of Nonsynchronous Trading." Review of Financial Studies, vol. 12, no. 3 (Fall):609-630.

Kandel, S., and R. Stambaugh. 1991. "Asset Returns and Intertemporal Preferences." Journal of Monetary Economics, vol. 27, no. 1 (February):39-71.

Kao, D. 2000. "Estimating and Pricing Credit Risk: An Overview.” Financial Analysts Journal, vol. 56, no. 4 (July/August):50-66.

- 2002. "Battle for Alphas: Hedge Funds versus Long-Only Portfolios." Financial Analysts Journal, vol. 58, no. 2 (March/April):16-36.

Kaplan, S., and A. Schoar. Forthcoming 2005. "Private Equity Performance: Returns, Persistence, and Capital Flows." Journal of Finance.

Keim, D., and A. Madhavan. 1997. "Transactions Costs and Investment Style: An Inter-Exchange Analysis of Institutional Equity Trades." Journal of Financial Economics, vol. 46, no. 3 (December):265-292.

Kendall, M., A. Stuart, and K. Ord. 1983. The Advanced Theory of Statistics, 4th ed., vol. 3. New York: Macmillan. 
Klein, R., and V. Bawa. 1976. “The Effect of Estimation Risk on Optimal Portfolio Choice.” Journal of Financial Economics, vol. 3, no. 3 (June):215-231.

. 1977. "The Effect of Limited Information and Estimation Risk on Optimal Portfolio Diversification." Journal of Financial Economics, vol. 5, no. 1 (August):89-111.

Kramer, D. 2001. "Hedge Fund Disasters: Avoiding the Next Catastrophe." Alternative Investment Quarterly, no. 1 (October):5.

Kraus, A., and H. Stoll. 1972. "Price Impacts of Block Trading on the New York Stock Exchange." Journal of Finance, vol. 27, no. 3 (June):569-588.

Kroll, Y., H. Levy, and H. Markowitz. 1984. "Mean-Variance versus Direct Utility Maximization.” Journal of Finance, vol. 39, no. 1 (March):47-61.

Leinweber, D. 1993. “Using Information from Trading in Trading and Portfolio Management.” In Execution Techniques, True Trading Costs, and the Microstructure of Markets. Edited by K. Sherrerd. Charlottesville, VA: AIMR.

. 1994. "Careful Structuring Reins In Transaction Costs." Pensions and Investments (25 July):19.

Leland, H. 1985. "Option Pricing and Replication with Transactions Costs.” Journal of Finance, vol. 40, no. 5 (December):1283-1301.

Leroy, S. 1973. "Risk Aversion and the Martingale Property of Stock Returns." International Economic Review, vol. 14, no. 2 (June):436-446.

Liang, B. 1999. "On the Performance of Hedge Funds." Financial Analysts Journal, vol. 55, no. 4 (July/ August):72-85.

- 2000. "Hedge Funds: The Living and the Dead." Journal of Financial and Quantitative Analysis, vol. 35, no. 3 (September):309-326.

—. 2001. "Hedge Fund Performance: 1990-1999." Financial Analysts Journal, vol. 57, no. 1 (January/ February):11-18.

- 2003. "The Accuracy of Hedge Fund Returns." Journal of Portfolio Management, vol. 29, no. 3 (Spring):111-122.

Lillo, F., D. Farmer, and R. Mantegna. 2003. "Master Curve for Price-Impact Function.” Nature, vol. 421 (9 January):129-130.

Litzenberger, R., and J. Rolfo. 1984. "Arbitrage Pricing, Transaction Costs and Taxation of Capital Gains: A Study of Government Bonds with the Same Maturity Date.” Journal of Financial Economics, vol. 13, no. 3 (September):337-351.

Liu, J., and F. Longstaff. 2000. "Losing Money on Arbitrages: Optimal Dynamic Portfolio Choice in Markets with Arbitrage Opportunities.” Working paper, Anderson Graduate School of Management, UCLA.

Ljung, G., and G. Box. 1978. "On a Measure of Lack of Fit in Time Series Models.” Biometrika, vol. 65, no. 1:297-303.

Lo, A. 1994. "Data-Snooping Biases in Financial Analysis." In Blending Quantitative and Traditional Equity Analysis. Edited by H. Russell Fogler. Charlottesville, VA: AIMR. 
Lo, A., ed. 1997. Market Efficiency: Stock Market Behaviour in Theory and Practice, 2 vols. Cheltenham, UK: Edward Elgar.

February):87-129.

- 2001. "Risk Management for Hedge Funds: Introduction and Overview." Financial Analysts Journal, vol. 57, no. 6 (November/December):16-33.

- 2002. "The Statistics of Sharpe Ratios.” Financial Analysts Journal, vol. 58, no. 4 (July/August):36-50.

- 2004. "The Adaptive Markets Hypothesis: Market Efficiency from an Evolutionary Perspective." Journal of Portfolio Management, 30th Anniversary Issue (September):15-29.

Lo, A., and C. MacKinlay. 1988. "Stock Market Prices Do Not Follow Random Walks: Evidence from a Simple Specification Test.” Review of Financial Studies, vol. 1, no. 1 (Spring):41-66.

_. 1990a. "An Econometric Analysis of Nonsynchronous Trading." Journal of Econometrics, vol. 45, nos. 1-2 (July/August):181-211.

- 1990b. "Data-Snooping Biases in Tests of Financial Asset Pricing Models." Review of Financial Studies, vol. 3, no. 3 (Fall):431-467.

—. 1999. A Non-Random Walk Down Wall Street. Princeton, NJ: Princeton University Press.

Lo, A., and J. Wang. 2000. "Trading Volume: Definitions, Data Analysis, and Implications of Portfolio Theory." Review of Financial Studies, vol. 13, no. 2 (Summer):257-300.

Lo, A., H. Mamaysky, and J. Wang. 2004. “Asset Prices and Trading Volume under Fixed Transactions Costs.” Journal of Political Economy, vol. 112, no. 5 (October):1054-90.

Lo, A., C. Petrov, and M. Wierzbicki. 2003. "It's 11PM-Do You Know Where Your Liquidity Is? The Mean-Variance-Liquidity Frontier." Journal of Investment Management, vol. 1, no. 1 (First Quarter):55-93.

Lo, A., D. Repin, and B. Steenbarger. 2005. "Fear and Greed in Financial Markets: A Clinical Study of DayTraders." American Economic Review, vol. 95, no. 2:352-359.

Lochoff, R. 2002. "Hedge Funds and Hope." Journal of Portfolio Management, vol. 28, no. 4 (Summer):92-99.

Loeb, T. 1983. "Trading Cost: The Critical Link between Investment Information and Results.” Financial Analysts Journal, vol. 39, no. 3 (May/June):39-44.

Lucas, R. 1978. “Asset Prices in an Exchange Economy.” Econometrica, vol. 46, no. 6 (November):1429-46.

MacCrimmon, K., and D. Wehrung. 1986. Taking Risks. New York: Free Press.

MacKenzie, D. 2003. “Long-Term Capital Management and the Sociology of Arbitrage." Economy and Society, vol. 32, no. 3 (August):349-380.

Magill, M., and G. Constantinides. 1976. "Portfolio Selection with Transactions Costs." Journal of Economic Theory, vol. 13, no. 2 (October):245-263.

McDonough, W. 1998. “Statements to the Congress: William J. McDonough-October 1, 1998." Federal Reserve Bulletin, vol. 84, no. 12 (December):1050-54.

Michaud, R. 1989. “The Markowitz Optimization Enigma: Is 'Optimized' Optimal?” Financial Analysts Journal, vol. 45, no. 1 (January/February):31-42. 
1998. Efficient Asset Management: A Practical Guide to Stock Portfolio Optimization and Asset Allocation. Boston, MA: Harvard Business School Press.

Morton, A.J., and S.R. Pliska. 1995. "Optimal Portfolio Management with Fixed Transaction Costs." Mathematical Finance, vol. 5, no. 4 (October):337-356.

Newey, W., and K. West. 1987. "A Simple, Positive Semi-Definite, Heteroskedasticity and Autocorrelation Consistent Covariance Matrix.” Econometrica, vol. 55, no. 3 (May):703-708.

Niederhoffer, V. 1997. The Education of a Speculator. New York: John Wiley \& Sons.

Pastor, L., and R. Stambaugh. 2003. "Liquidity Risk and Expected Stock Returns.” Journal of Political Economy, vol. 111, no. 3 (June):642-685.

Pérold, A. 1988. “The Implementation Shortfall: Paper versus Reality.” Journal of Portfolio Management, vol. 14, no. 3 (Spring):4-9.

- 1999. "Long-Term Capital Management, L.P. (A-D)." Harvard Business School Case Nos. 200007-10 (November).

Pérold, A., and R. Salomon. 1991. "The Right Amount of Assets under Management." Financial Analysts Journal, vol. 47, no. 3 (May/June):31-39.

President's Working Group on Financial Markets. 1999. Hedge Funds, Leverage, and the Lessons of Long-Term Capital Management. Report of the President's Working Group on Financial Markets (28 April).

Richardson, M., and J. Stock. 1989. "Drawing Inferences from Statistics Based on Multiyear Asset Returns.” Journal of Financial Economics, vol. 25, no. 2 (December):323-348.

Roberts, H. 1967. “Statistical versus Clinical Prediction of the Stock Market.” Unpublished manuscript, Center for Research in Security Prices, University of Chicago (May).

Ross, S., and R. Zisler. 1991. "Risk and Return in Real Estate." Journal of Real Estate Finance and Economics, vol. 4, no. 2:175-190.

Rubinstein, M. 1976. “The Valuation of Uncertain Income Streams and the Pricing of Options.” Bell Journal of Economics, vol. 7, no. 2 (Autumn):407-425.

Sadka, R. 2003. "Momentum, Liquidity Risk, and Limits to Arbitrage.” Working paper, Kellogg Graduate School of Management, Northwestern University.

Samuelson, P. 1941. "Conditions That the Roots of a Polynomial Be Less than Unity in Absolute Value." Annals of Mathematical Statistics, vol. 45:689-693.

- 1947. Foundations of Economic Analysis. Harvard Economic Studies, vol. 80. Cambridge, MA: Harvard University Press.

— 1965. "Proof That Properly Anticipated Prices Fluctuate Randomly." Industrial Management Review, vol. 6, no. 2 (Spring):41-49.

- 1969. "Lifetime Portfolio Selection by Dynamic Stochastic Programming." Review of Economics and Statistics, vol. 51, no. 3 (August):239-246.

Schneeweis, T., R. Spurgin, and D. McCarthy. 1996. "Survivor Bias in Commodity Trading Advisor Performance: Introduction.” Journal of Futures Markets, vol. 16, no. 7 (October):757-772. 
Scholes, M., and J. Williams. 1977. "Estimating Betas from Nonsynchronous Data." Journal of Financial Economics, vol. 5, no. 3 (December):309-327.

Schwartz, R., and D. Whitcomb. 1988. Transaction Costs and Institutional Investor Trading Strategies. Salomon Brothers Center Monograph Series. New York: Salomon Brothers Center for the Study of Financial Institutions, New York University.

Schwert, G. 1977. "Stock Exchange Seats as Capital Assets.” Journal of Financial Economics, vol. 4, no. 1 (January):51-78.

Shanken, J. 1987. “Nonsynchronous Data and the Covariance-Factor Structure of Returns.” Journal of Finance, vol. 42, no. 2 (June):221-231.

Sharpe, W. 1994. “The Sharpe Ratio.” Journal of Portfolio Management, vol. 21, no. 1 (Fall):49-58.

Sherrerd, K., ed. 1993. Execution Techniques, True Trading Costs, and the Microstructure of Markets. Charlottesville, VA: AIMR.

Shleifer, A., and R. Vishny. 1997. “The Limits of Arbitrage.” Journal of Finance, vol. 52, no. 1 (March):35-55.

Sirri, E., and P. Tufano. 1998. "Costly Search and Mutual Fund Flows." Journal of Finance, vol. 53, no. 5 (October):1589-1622.

Spurgin, R. 2001. "How to Game Your Sharpe Ratio." Journal of Alternative Investments, vol. 4, no. 3 (Winter):38-46.

Stoll, H. 1993. Equity Trading Costs. Charlottesville, VA: The Research Foundation of the Institute of Chartered Financial Analysts.

Strogatz, S. 1994. “Norbert Wiener's Brain Waves.” In Frontiers in Mathematical Biology: Lecture Notes in Biomathematics, vol. 100. Edited by S. Levin. Berlin: Springer-Verlag.

Terhaar, K., R. Staub, and B. Singer. 2003. “Appropriate Policy Allocation for Alternative Investments.” Journal of Portfolio Management, vol. 29, no. 3 (Spring):101-110.

Ter Horst, J., T. Nijman, and M. Verbeek. 2001. "Eliminating Look-Ahead Bias in Evaluating Persistence in Mutual Fund Performance.” Journal of Empirical Finance, vol. 8, no. 4 (September):345-373.

Tiniç, S. 1972. "The Economics of Liquidity Services." Quarterly Journal of Economics, vol. 86, no. 1 (February):79-93.

Treynor, J. 1981. "What Does It Take to Win the Trading Game?" Financial Analysts Journal, vol. 37, no. 1 (January/February):55-60.

Tuckman, B., and J. Vila. 1992. “Arbitrage with Holding Costs: A Utility-Based Approach.” Journal of Finance, vol. 47, no. 4 (September):1283-1302.

Turner, C., R. Startz, and C. Nelson. 1989. “A Markov Model of Heteroskedasticity, Risk, and Learning in the Stock Market.” Journal of Financial Economics, vol. 25, no. 1 (November):3-22.

Vayanos, D. 1998. “Transaction Costs and Asset Prices: A Dynamic Equilibrium Model." Review of Financial Studies, vol. 11, no. 1 (Spring):1-58.

Vayanos, D., and J.L. Vila. 1999. "Equilibrium Interest Rate and Liquidity Premium with Transaction Costs." Economic Theory, vol. 13, no. 3:509-539. 
Wagner, W. 1993. "Defining and Measuring Trading Costs.” In Execution Techniques, True Trading Costs, and the Microstructure of Markets. Edited by K. Sherrerd. Charlottesville, VA: AIMR.

Wagner, W., and M. Banks. 1992. "Increasing Portfolio Effectiveness via Transaction Cost Management." Journal of Portfolio Management, vol. 19, no. 1 (Fall):6-11.

Wagner, W., and M. Edwards. 1993. "Best Execution.” Financial Analysts Journal, vol. 49, no. 1 (January/ February):65-71.

Watts, D. 1999. Small Worlds: The Dynamics of Networks between Order and Randomness. Princeton, NJ: Princeton University Press.

Watts, D., and S. Strogatz. 1998. "Collective Dynamics of 'Small-World' Networks.” Nature, vol. 393 (4 June):440-442.

Weisman, A. 2002. "Informationless Investing and Hedge Fund Performance Measurement Bias." Journal of Portfolio Management, vol. 28, no. 4 (Summer):80-91.

Willard, G., and P. Dybvig. 1999. "Empty Promises and Arbitrage.” Review of Financial Studies, vol. 12, no. 4 (Special):807-834.

Working, H. 1960. "Note on the Correlation of First Differences of Averages in a Random Chain." Econometrica, vol. 28, no. 4 (October):916-918.

Zheng, L. 1999. "Is Money Smart? A Study of Mutual Fund Investors' Fund Selection Ability.” Journal of Finance, vol. 54, no. 3 (June):901-933. 
